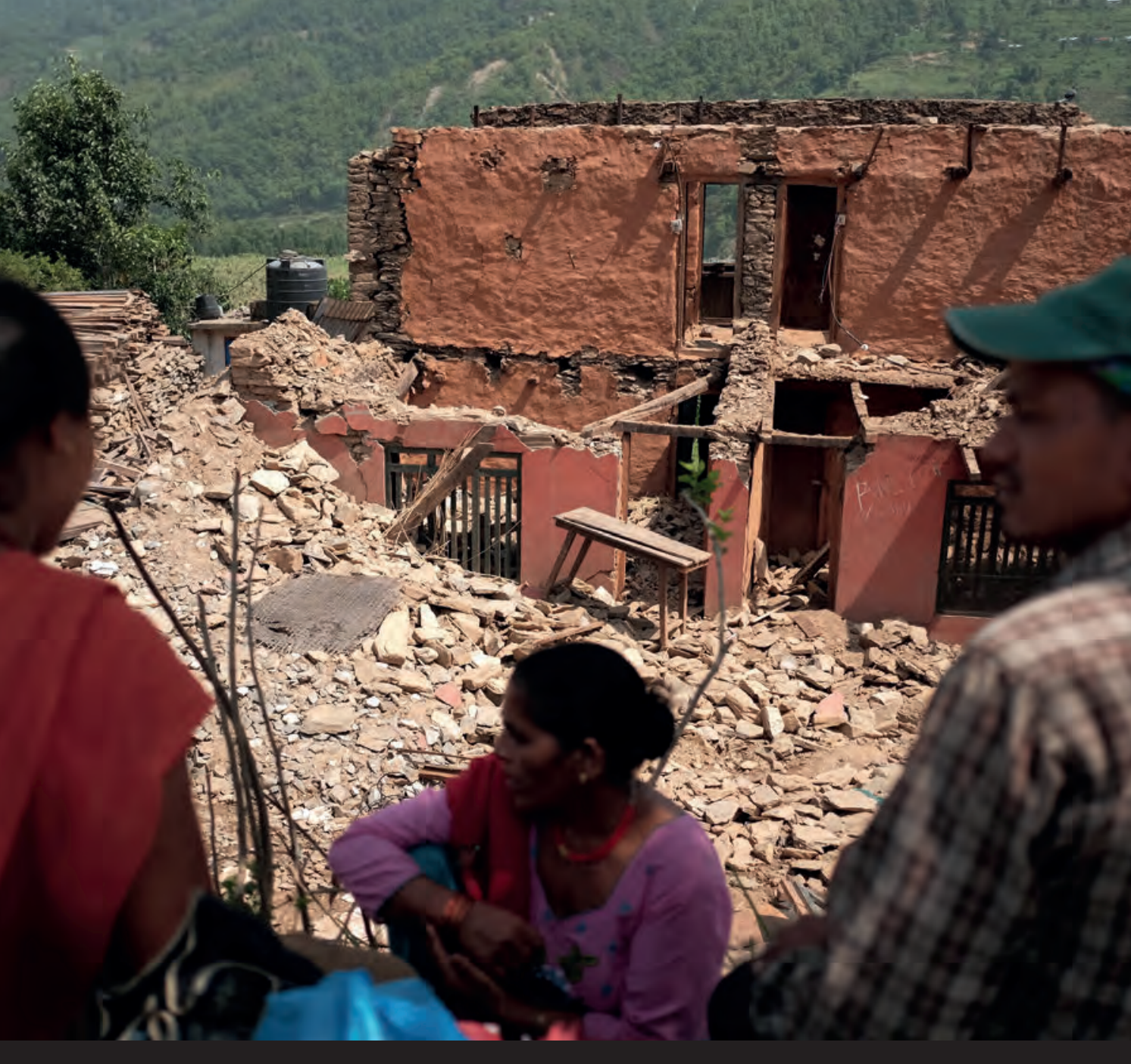

\title{
THE EFFECTIVENESS AND EFFICIENCY OF INTERVENTIONS SUPPORTING SHELTER SELF-RECOVERY FOLLOWING HUMANITARIAN CRISES
}




\begin{abstract}
About this evidence synthesis
This is an independent evidence synthesis commissioned by the Humanitarian Evidence Programme, a partnership between Oxfam GB and Feinstein International Center at the Friedman School of Nutrition Science and Policy, Tufts University, funded by aid from the United Kingdom (UK) government through the Humanitarian Innovation and Evidence Programme at the Department for International Development. The views and opinions expressed herein are those of the authors and do not necessarily represent those of Oxfam, Feinstein or the UK government.
\end{abstract}

\title{
About the research team
}

This evidence synthesis was led by Victoria Maynard, Elizabeth Parker and John Twigg. The research team at Habitat for Humanity and University College London also included:

Fatemeh Farnaz Arefian, Lizzie Babister, Laura Howlett, Anshu Sharma, Elizabeth Wagemann and Jake Zarins.

The initial database and website searches took place during January and February 2016.

\section{Citation}

Maynard, V., Parker, E. and Twigg, J. (2017). The effectiveness and efficiency of interventions supporting shelter self-recovery following humanitarian crises: An evidence synthesis. Humanitarian Evidence Programme. Oxford: Oxfam GB.

\section{Acknowledgments}

The authors would like to thank everyone who contributed their thoughts, reviewed drafts and shared documents as part of the development of this pioneering research in the shelter sector. We offer our thanks to all the interested parties who completed the survey and shaped the research questions - we hope the answers to some of the questions you put to us are in this report. We would also like to thank Eleanor Ott, Roxanne Krystalli and the team at Oxfam GB and Feinstein for their support throughout this process.

\section{Series editors}

The report forms part of a series of humanitarian evidence syntheses and systematic reviews covering child protection, market support, mental health, nutrition, pastoralist livelihoods, shelter, urban contexts, and water, sanitation and hygiene.

The reports and corresponding protocols (methodology) can be found at:

- https://www.gov.uk/dfid-research-outputs

- http://fic.tufts.edu/research-item/the-humanitarian-evidence-program/

- http://policy-practice.oxfam.org.uk/our-work/humanitarian/humanitarian-evidenceprogramme.

The series editors are: Roxanne Krystalli, Eleanor Ott and Lisa Walmsley.

\section{Photo credit}

Residents in front of a house destroyed by the earthquake in Tripureshwor VDC, Nepal. Jes Aznar/Oxfam. June 2015.

\section{(c) Copyright Oxfam GB 2017}

This publication is subject to copyright but the text may be used free of charge for the purposes of advocacy, campaigning, education and research, provided that the source is acknowledged in full. The copyright holder requests that all such use be registered with them for impact assessment purposes. For copying in any other circumstances, or for re-use in other publications, or for translation or adaptation, permission must be secured and a fee may be charged. Email: Iwalmsley1@ght.oxfam.org 


\section{CONTENTS}

0 EXECUTIVE SUMMARY

1 INTRODUCTION

2 BACKGROUND 2

2.1 Humanitarian shelter and settlements 2

2.2 Support for shelter self-recovery 5

2.3 How support for shelter self-recovery might work 8

2.4 The need for this research 9

3 METHODS 11

3.1 Report aims and research questions 11

$\begin{array}{lll}3.2 & \text { Overview of methods } & 11\end{array}$

3.3 Development of review protocol (Step 1) 12

3.4 Run OF search terms and initial screening of documents (Step 2) 12

3.5 Second screening of the documents (Step 3) 15

$\begin{array}{lll}\text { 3.6 Critical appraisal of 'included studies' (Step 4) } & 16\end{array}$

$\begin{array}{lll}\text { 3.7 } & \text { Data extraction and evidence synthesis (Step 5) } & 16\end{array}$

4 RESULTS: DOCUMENTS FOUND 18

4.1 Introduction to the documents found 18

\begin{tabular}{ll}
4.2 & Comparision of the 11 included studies \\
\hline
\end{tabular}

5 RESULTS: INTERVENTION 28

\begin{tabular}{ll}
5.1 & Introduction to the interventions \\
\hline & Comparson
\end{tabular}

5.2 Comparison of the 11 Interventions 32

6 RESULTS: EFFECTIVENESS

6.1 What household-level outcomes did the studies measure? 37

6.2 What effects did the interventions supporting shelter self-recovery have on household-level outcomes?

7 RESULTS: EFFICIENCY 45

7.1 What factors that helped or hindered programme implementation did the studies identify? 45

7.2 How did the factors help or hinder programme implementation? 47

8 DISCUSSION AND CONCLUSIONS 61

8.1 Humanitarian interventions supporting shelter self-recovery 61

8.2 Evidence synthesis regarding humanitarian shelter and settlements 63

$\begin{array}{lll}8.3 \text { Concluding remarks } & 65\end{array}$

9 REFERENCES $\quad 67$

$\begin{array}{ll}\text { APPENDICES } & 73\end{array}$

$\begin{array}{ll}\text { Appendix A: Search terms } & 73\end{array}$

Appendix B: Overview of search results $\quad 74$

Appendix C: Scoping assessment search results and screening guide 77

$\begin{array}{ll}\text { Appendix D: List of excluded documents } & 78\end{array}$

Appendix E: Quality appraisal template $\quad 85$

Appendix F: Deviations from protocol $\quad 89$

Appendix G: Strengths and limitations of the review 91 


\title{
ABBREVIATIONS
}

\author{
CASP Critical Appraisal Skills Programme \\ CRS Catholic Relief Services \\ DAC Development Assistance Committee (OECD) \\ DFID Department for International Development (UK) \\ ECHO European Commission Humanitarian Aid and Civil Protection Department \\ ERRA Earthquake Reconstruction and Rehabilitation Authority (Pakistan) \\ HEP Humanitarian Evidence Programme \\ IDP Internally displaced person \\ IFRC International Federation of Red Cross and Red Crescent Societies \\ IOM International Organization for Migration \\ NGO Non-governmental organization \\ OECD Organisation for Economic Cooperation and Development \\ RCRC Red Cross Red Crescent \\ Sida Swedish International Development Cooperation \\ UK United Kingdom \\ UN OCHA United Nations Office for the Coordination of Humanitarian Affairs \\ UN-Habitat United Nations Human Settlement Programme \\ UNHCR United Nations High Commissioner for Refugees \\ USA United States of America
}

USAID/OFDA US Agency for International Development - Office of US Foreign Disaster Assistance 
This evidence synthesis, commissioned by the Humanitarian Evidence Programme (HEP) and carried out by a team from Habitat for Humanity and University College London, represents the first ever attempt to apply systematic review methodology to an assessment of the evidence surrounding humanitarian shelter and settlement interventions in low and middle-income countries. ${ }^{1}$ It investigates both the process of implementing humanitarian interventions supporting shelter self-recovery and the effects of the interventions.

\section{What does 'supporting shelter self-recovery' mean?}

'Supporting shelter self-recovery' has become a frequently used term in humanitarian practice. We use it to refer to material, financial and/or technical assistance provided during the relief and/or recovery phase to enable affected households to repair, build or rebuild their own shelters themselves - either alone or with the assistance of local industry.

Other types of shelter intervention, such as transitional shelter and rental support, are outside the scope of this study. See Section 2 of the full report for further information on definitions used.

The evidence synthesis focuses on both households that had not been displaced and those returning from displacement or resettling in new locations to repair, build or rebuild their shelters with material, financial and/or technical assistance in the immediate aftermath of, and/or recovery period following, humanitarian emergencies:

- predominantly in rural areas

- in natural disaster and complex emergency settings.

The research team developed and tested a theory of change model for humanitarian interventions supporting shelter self-recovery (see Figure 0.1) and:

- mapped and documented existing research

- identified gaps in existing research and knowledge

- synthesized the evidence in response to two key research questions (summarized in Figure 0.2).

Figure 0.1: Theory of change for humanitarian interventions supporting shelter selfrecovery. Source: The research team, based on Buchanan-Smith and Cosgrave (2013); DFID (2011); Proudlock et al. (2009); Yates et al. (2016)

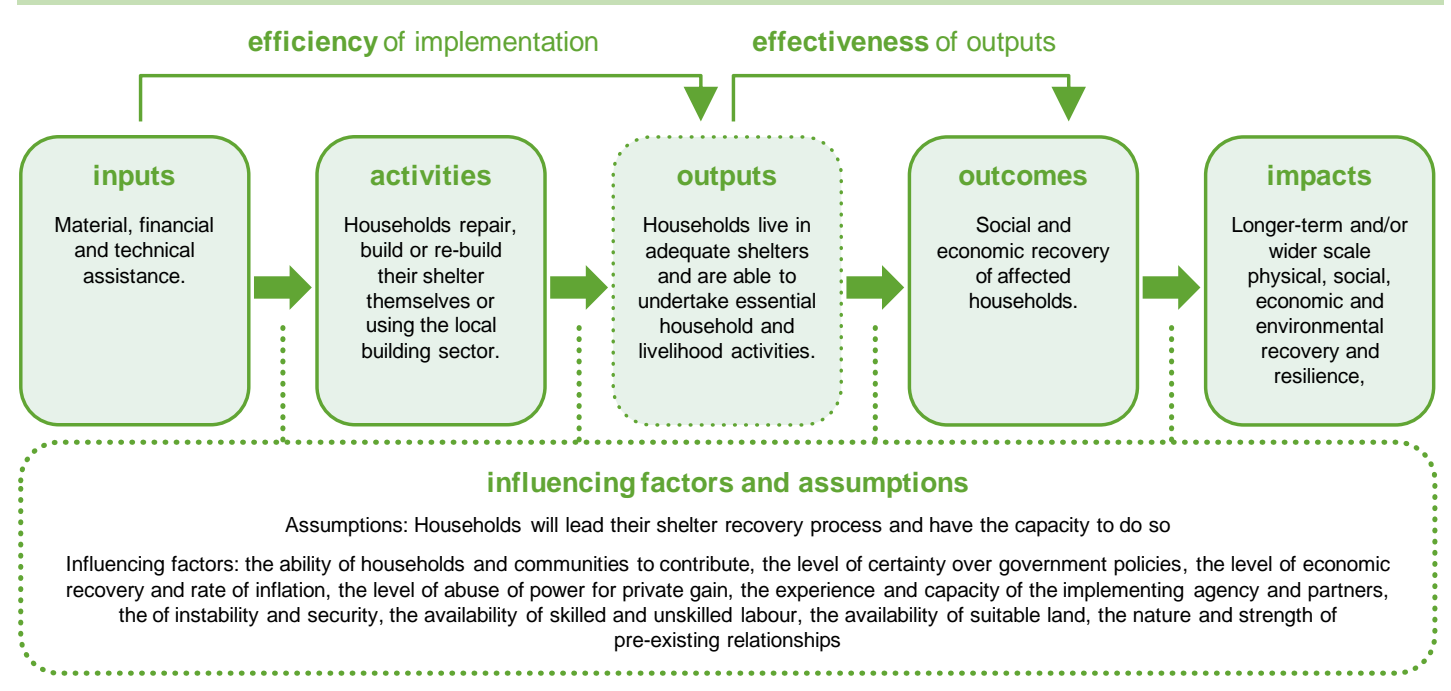

\footnotetext{
${ }^{1} \mathrm{HEP}$ is a partnership between Oxfam GB and the Feinstein International Center at the Friedman School of Nutrition Science and Policy, Tufts University. It is funded by the United Kingdom (UK) government's Department for International Development (DFID) through the Humanitarian Innovation and Evidence Programme.
} 
Figure 0.2: Summary of findings in response to the two research questions. Source: The research team

\begin{tabular}{|c|c|c|c|}
\hline $\begin{array}{l}\text { Q1: What effects do interventions that support affected } \\
\text { populations' own shelter self-recovery processes have on } \\
\text { household-level outcomes following humanitarian crises? }\end{array}$ & Consistency ${ }^{*}$ & $\begin{array}{l}\text { Number of } \\
\text { studies }^{\dagger}\end{array}$ & $\begin{array}{l}\text { Overall } \\
\text { strength of } \\
\text { evidence }^{\ddagger}\end{array}$ \\
\hline 1. Household dignity and self-reliance (positive) & Consistent & Medium (7) & Medium \\
\hline $\begin{array}{l}\text { 2. Household perception of safety from natural hazards and } \\
\text { security from crime and violence (positive) }\end{array}$ & Consistent & Medium (7) & Medium \\
\hline 3. Household incomes or livelihoods (unclear) & Inconsistent & Medium (4) & Limited \\
\hline 4. Household assets or debts (unclear) & Inconsistent & Small (2) & Limited \\
\hline 5. Household physical and mental health (unclear) & Inconsistent & Small (2) & Limited \\
\hline 6. Household knowledge of safer construction (unclear) & Inconsistent & Small (3) & Limited \\
\hline $\begin{array}{l}\text { Q2: What factors helped or hindered the implementation } \\
\text { of interventions supporting populations' own shelter self- } \\
\text { recovery processes following humanitarian crises? }\end{array}$ & Consistency ${ }^{*}$ & $\begin{array}{l}\text { Number of } \\
\text { studies }^{\dagger}\end{array}$ & $\begin{array}{l}\text { Overall } \\
\text { strength of } \\
\text { evidence }\end{array}$ \\
\hline \multicolumn{4}{|l|}{ Household factors (helping programme implementation) } \\
\hline $\begin{array}{l}\text { 1. The ability of households and communities to contribute } \\
\text { skills, labour, materials or finance }\end{array}$ & Consistent & Large (9) & Strong \\
\hline \multicolumn{4}{|l|}{ Programme factors (helping programme implementation) } \\
\hline $\begin{array}{l}\text { 2. Undertaking adequate initial assessments and regular } \\
\text { monitoring }\end{array}$ & Consistent & Medium (8) & Strong \\
\hline $\begin{array}{l}\text { 3. Developing a clear and simple plan that is understood by all } \\
\text { stakeholders }\end{array}$ & Consistent & Medium (4) & Medium \\
\hline $\begin{array}{l}\text { 4. Designing a programme that meets the changing needs of } \\
\text { households and responds to the context }\end{array}$ & Consistent & Medium (7) & Medium \\
\hline $\begin{array}{l}\text { 5. Developing clear and simple beneficiary selection criteria } \\
\text { and a transparent selection process }\end{array}$ & Consistent & Medium (7) & Medium \\
\hline $\begin{array}{l}\text { 6. Supporting coordinated community involvement and } \\
\text { adequate two-way communication }\end{array}$ & Consistent & Medium (7) & Medium \\
\hline $\begin{array}{l}\text { 7. Delivering adequate financial, technical and material } \\
\text { assistance }\end{array}$ & Consistent & Large (9) & Strong \\
\hline \multicolumn{4}{|l|}{$\begin{array}{l}\text { Contextual factors (helping or hindering programme } \\
\text { implementation) }\end{array}$} \\
\hline 8. The level of economic recovery and rate of inflation & Consistent & Medium (5) & Medium \\
\hline 9. The level of instability and armed conflict & Consistent & Medium (4) & Medium \\
\hline 10. The level of certainty over government policies & Consistent & Small (1) & Limited \\
\hline $\begin{array}{l}\text { 11. The adequate number of programme staff with appropriate } \\
\text { skills and experience }\end{array}$ & Consistent & Medium (4) & Medium \\
\hline 12. The nature and strength of pre-existing relationships & Consistent & Medium (4) & Medium \\
\hline 13. The level of abuse of power for private gain (corruption) & Consistent & Medium (5) & Medium \\
\hline 14. The availability of skilled and unskilled labour & Consistent & Small (3) & Limited \\
\hline $\begin{array}{l}\text { 15. The accuracy of land ownership records and the } \\
\text { availability of suitable land }\end{array}$ & Consistent & Medium (5) & Medium \\
\hline 16. The accessibility or remoteness of households & Consistent & Small (3) & Limited \\
\hline
\end{tabular}

Notes: * Evidence is classified as 'consistent' if all of the findings of the included studies suggest similar conclusions and 'inconsistent' if a range of conclusions is identified. $\dagger$ The number of documents is referred to as 'small' if there are three or fewer studies, 'medium' if there are between four and seven studies, and 'large' if there are more than eight studies. $¥$ Overall strength of evidence: A combined assessment, based on the size and consistency of each grouping. 


\section{What effects do interventions that support affected populations' own shelter self-recovery processes have on household-level outcomes following humanitarian crises?}

The research team identified six main potential impacts of shelter self-recovery interventions at household level:

- dignity and self-reliance

- perception of safety and security

- income or livelihoods

- assets or debts

- physical and mental health

- knowledge about safer construction.

The majority of studies included in the synthesis note positive effects on 1) dignity and self-reliance, which increased as a result of households living in their own homes and taking ownership of the construction process and 2) perceptions of safety and security, which increased as a result of reduced overcrowding; integration or reintegration into host communities; household awareness of the material and construction quality of their homes; and the incorporation of safer construction techniques.

The evidence on the positive effects on household incomes, livelihoods, assets, debts, physical health, mental health and knowledge of safer construction techniques is either inconsistent or unclear.

\section{What factors helped or hindered the implementation of interventions supporting populations' own shelter self-recovery processes following humanitarian crises?}

The research team identified 16 factors that either helped or hindered the implementation of interventions supporting shelter self-recovery:

- at household level

the ability of households and communities to contribute skills, labour, materials or finance

- at programme level

- undertaking adequate assessments and regular monitoring

- developing a clear and simple plan

- designing a programme that meets the changing needs of households in different contexts

- developing clear and simple beneficiary selection criteria and transparent selection processes

- supporting coordinated community involvement and adequate two-way communication

- delivering adequate financial, technical and/or material assistance

- at contextual level

the level of certainty over government policies

the level of economic recovery and rate of inflation

the level of abuse of power for private gain (corruption)

the experience and capacity of the implementing agency and partners

the level of instability and security

the availability of skilled and unskilled labour

the availability of suitable land

the nature and strength of pre-existing relationships

the accessibility or remoteness of the household.

Five of the eleven studies eligible for inclusion in the synthesis identify that vulnerable households are at a greater disadvantage than non-vulnerable households when involved in shelter-self recovery programmes because the standard package of assistance may not meet their needs. 
Examples of disadvantages for vulnerable households such as those comprising single elderly people, those with family members with disabilities, female-headed households and those on low incomes include:

- less access to skilled and unskilled labour

- greater vulnerability to inflation

- challenges managing funds.

Specific disadvantages reported for female-headed households include:

- access to tools based on prior ownership

- increased costs associated with paying for additional labour

- poor quality materials and construction

- training is not inclusive of women.

The evidence suggests that household capacity should be assessed (early on in the case of vulnerable households) and should inform programme design in order to avoid the shelter intervention placing an undue burden on the household; where programmes are unable to meet specific and changing household needs, the household has to make up the shortfall itself.

The majority of studies note that these programme factors helped implementation when they were completed adequately and hindered where not.

Each of the above contextual factors is identified in around one third of the studies synthesized; however, as they are context-specific, it is not possible to extrapolate or infer generalized trends.

\section{What evidence was eligible for synthesis?}

Of the 4,613 English language documents initially identified through searching academic databases, humanitarian websites and stakeholder engagement activities, 11 studies were eligible for inclusion following screening and quality appraisal (see Sections 3 and 4 plus appendices of full report for details):

- the research team searched for documents published since 1990; the studies included in the evidence synthesis were all published between 2005 and $2015^{2}$

- the synthesis includes primary research only - it does not include opinion pieces, commentaries, literature reviews, guidelines and marketing material

- eight of the included studies were identified as mixed methods (triangulation design); the other three were qualitative studies (qualitative descriptive)

- eight of the studies were evaluations, one was an 'impact assessment' and the other two were academic peer-reviewed journal articles

- the 11 interventions were located in: Asia (Indonesia, Pakistan, Philippines and Sri Lanka); the Middle East (Afghanistan, Lebanon); Central and South America (Belize, Colombia); and Europe (Bosnia and Herzegovina) none of the studies eligible for inclusion detail interventions in Africa only one intervention took place in a country classified as 'low income' (Afghanistan) ${ }^{3}$ just three comment on adaptation to urban or peri-urban contexts

- the majority of interventions assisted between 5,000 and 50,000 households, with a range of between 70 and 600,000 households; overall, they met less than 10 percent of stated needs

two notable exceptions are the interventions in Afghanistan and Pakistan, where approximately 220,000 and 600,000 households were assisted respectively and where a significant proportion of shelter assistance needs were met.

- interventions ranged in length from three months to more than 10 years; only two of the studies include the exact start and end date of the intervention (month and year)

${ }^{2}$ Initial database and website searches took place during January and February 2016.

${ }^{3}$ World Bank classifications. See: http://data.worldbank.org/about/country-and-lending-groups 
- intervention costs varied from US\$80,000 to US\$21 million; however, we were not able to compare or analyse costs as 1) the value of materials, services and labour varies significantly between countries and 2) only three studies record the cost of the shelter self-recovery programme.

A number of documents were identified that would be suitable for inclusion in a broader 'lessons learned' or literature review focused more on the process of implementing humanitarian interventions supporting shelter self-recovery. This fell outside the scope of the current research but could be useful information for practitioners delivering programmes supporting shelter-self recovery.

\section{What's the state of the evidence on humanitarian shelter self- recovery?}

Despite increasing demand for evidence, and a substantial volume of documentation, shelter and settlement interventions remain an under-researched aspect of humanitarian response (Peacock, Dash and Zhang, 2007; Twigg, 2002):

- at the end of April 2016, the Shelter Projects database contained 167 case studies $^{4}$ and ALNAP's resource library contained 136 'shelter and housing' evaluation reports ${ }^{5}$

- 'evidence' within the shelter sector remains largely based on experience and expert opinion, project or programme evaluations, case studies and academic papers on specific topics - with little evidence on the outcomes or impact of programmes undertaken

- future research should focus on both the effects of humanitarian interventions supporting shelter self-recovery and factors that help or hinder interventions to generate positive effects.

\section{Further considerations}

Implementing agencies and donors commissioning or producing evaluation reports are key contributors to knowledge about the effects of humanitarian shelter and settlement interventions. This creates a significant risk of bias but also an opportunity for collaboration to improve the quantity and quality of evidence available within the sector. Further consideration might be given to:

- investigating factors that help or hinder the process of commissioning and learning from humanitarian evaluation

- providing guidance and/or training on applying appropriate study designs, research methods, evaluation frameworks and indicators as well as basic minimum criteria and standards (such as including programme start and end dates, programme costs and methodologies).

${ }^{4}$ www.sheltercasestudies.org, retrieved 12 April 2016

${ }^{5} \mathrm{http}: / /$ www.alnap.org/resources/results.aspx?tag=511\&type=22, retrieved 12 April 2016 


\section{INTRODUCTION}

This evidence synthesis on the effectiveness and efficiency of interventions supporting shelter self-recovery following humanitarian crises represents one of eight areas being explored as part of the Humanitarian Evidence Programme (HEP) - a United Kingdom (UK) Department for International Development (DFID)-funded partnership between Oxfam and Feinstein. ${ }^{6}$ The research was carried out by Habitat for Humanity and University College London between July 2015 and September 2016.

The research team undertook a scoping assessment in order to:

- map the breadth, depth and nature of documentation available in the shelter and settlements sector

- engage with and collect feedback from stakeholders to understand the demand for evidence synthesis (or primary research).

The scoping assessment identified that:

- there is evidence available, and stakeholder interest in, humanitarian interventions that enable affected households to repair, build or rebuild their own shelters themselves or through using the local building sector (support for shelter self-recovery)

- the quantity and quality of evidence regarding humanitarian shelter and settlement is limited.

It was subsequently decided to focus on humanitarian interventions supporting shelter selfrecovery in the form of an evidence synthesis.

The purpose of this document is to communicate the findings of this research. Thus it describes:

- the background, justification, aims and research questions (Section 2)

- the methodology (Section 3)

- the documents found (Section 4)

- the interventions included (Section 5)

- the results of the evidence synthesis (Sections 6 and 7)

- discussion and conclusions (Section 8)

- the references used in this document (Section 9)

- appendices containing further details on the scoping assessment and the proposed search strategy, quality appraisal checklist for this review and supporting analysis.

Further details on the background and methodology are described in the research protocol (Maynard, Parker and Twigg, 2016).

\footnotetext{
${ }^{6}$ The eight areas under review in the current phase of HEP are urban contexts, market support, shelter, pastoralist livelihoods, water, sanitation and hygiene, mental health, nutrition and shelter. See: http://policy-practice.oxfam.org.uk/our-

work/humanitarian/humanitarian-evidence-programme and http://fic.tufts.edu/research-item/the-humanitarian-evidence-program for further details.
} 


\section{$2.1 \quad$ HUMANITARIAN SHELTER AND SETTLEMENTS}

Humanitarian emergencies (or crises) can be defined as 'an event or series of events that represents a critical threat to the health, safety, security or wellbeing of a community or other large group of people, usually over a wide area' (Humanitarian Coalition, 2015). They are often categorized as either:

- 'natural disasters', ${ }^{7}$ which can be geophysical (e.g. earthquakes, tsunamis, volcanic eruptions), hydrological (e.g. floods, avalanches), climatological (e.g. droughts), meteorological (e.g. storms, cyclones), or biological (e.g. epidemics, plagues)

- complex emergencies, which often have a combination of natural and man-made elements, and different causes of vulnerability and a combination of factors leads to a humanitarian crisis. Examples include food insecurity, armed conflicts, and displaced populations' (Humanitarian Coalition, 2015).

Shelter is critical to the survival of populations affected by humanitarian crises as it provides safety and security, protection from the climate and resistance to ill health and disease (The Sphere Project, 2011; Zetter, 2012), see Figure 2.1. Populations affected by natural disasters or complex emergencies may continue to live in their own homes and communities (even if they have been damaged or destroyed), or they may be forced to seek shelter elsewhere. Shelter and settlement interventions are therefore often described as targeting displaced or non-displaced populations (Shelter Centre, United Nations Office for the Coordination of Humanitarian Affairs (UN OCHA) and DFID, 2010). Having somewhere safe, secure and healthy to live, with access to livelihood opportunities, healthcare and education is also fundamental to sustaining family and community life during post-crisis recovery and reconstruction or displacement, return and resettlement.

Figure 2.1: Shelter provides... Source: Ashmore and Treherne (2010)

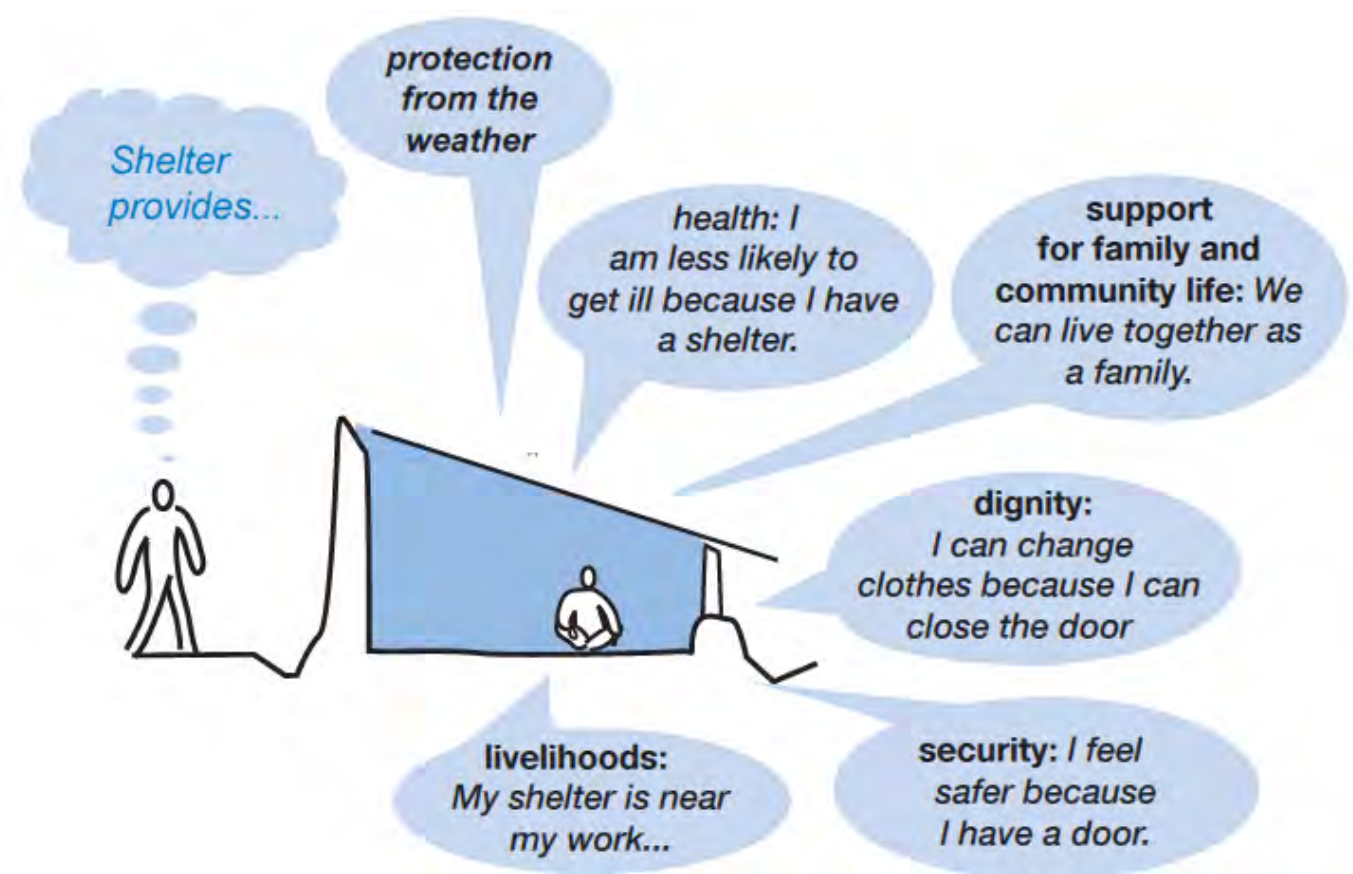

\footnotetext{
${ }^{7}$ The phrase 'natural disaster' is commonly used by humanitarian policymakers and practitioners and is therefore used throughout this review. The research team note, however, that there is no such thing as a 'natural' disaster. Disasters occur when the impact of a natural hazard overwhelms the capacity of a community or society to cope and is heavily influenced by the underlying vulnerabilities of the affected population. See Twigg (2015) for further details.
} 
Within developmental housing theory and practice it has long been understood that housing is both a noun and a verb (Turner and Fichter, 1972; Turner, 1976) and that assisting organizations should adopt 'supporting' rather than 'providing' approaches (Hamdi, 1995, p. 26). This involves identifying critical interventions in access to and management of resources such as land, services, finance and technical assistance to enable households to improve their own housing conditions, rather than providing completed houses themselves (Hamdi, 1995). However, 30 years after Davis (1978) highlighted that shelter after humanitarian crises 'must be considered as a process, not as an object' Kennedy et al. found that 'supporting' approaches were still 'rarely implemented in the field' (2007, p. 28).

\section{Figure 2.2: The difference between three-phase reconstruction and an incremental process. Source: Shelter Centre (2012)}
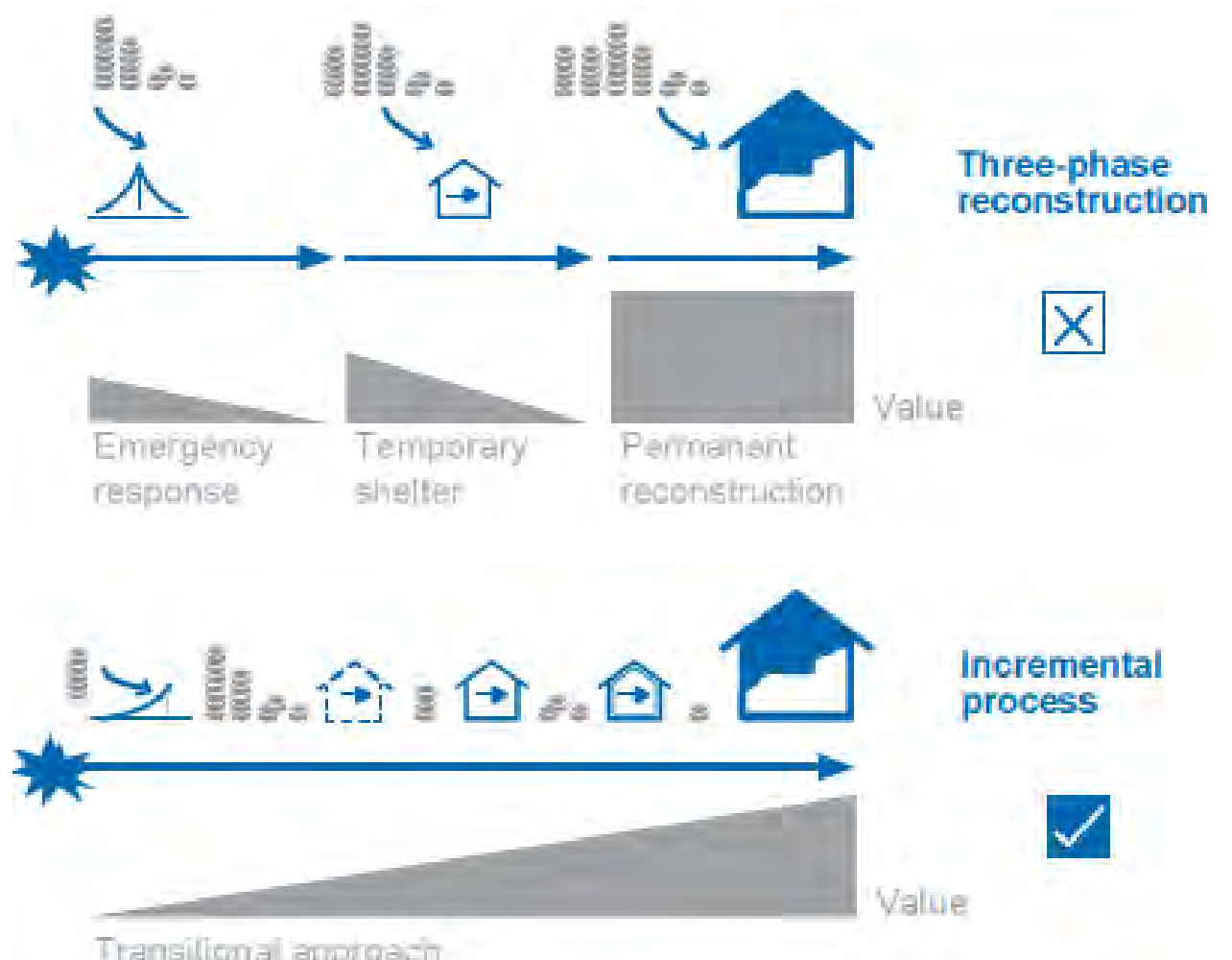

Humanitarian shelter policy and practice has recently begun to acknowledge the owner-driven, incremental nature of the housing process (see Figure 2.2). Authors have highlighted the multiplicity of shelter pathways followed by disaster-affected families (Corsellis and Vitale, 2005), the importance of owner-driven approaches (Jha and Duyne Barenstein, 2010; Lyons, Schilderman and Boano, 2010) and the importance of 'supporting' rather than 'providing' approaches to shelter assistance in urban humanitarian response (Sanderson, Knox Clarke, and Campbell, 2012). The International Federation of Red Cross and Red Crescent Societies (IFRC) has also begun to describe shelter after disaster as 'a process of sheltering' (Satterthwaite, 2010, p. 25), see Figure 2.3. While Habitat for Humanity has adopted a 'Pathways to Permanence' approach, see Figure 2.4, 'that focuses on both the process of sheltering as well as the products that support it' (Flores and Meaney, 2013, p. 11). 
Figure 2.3: Overlapping definitions of shelter terminology. Source: IFRC (2013)

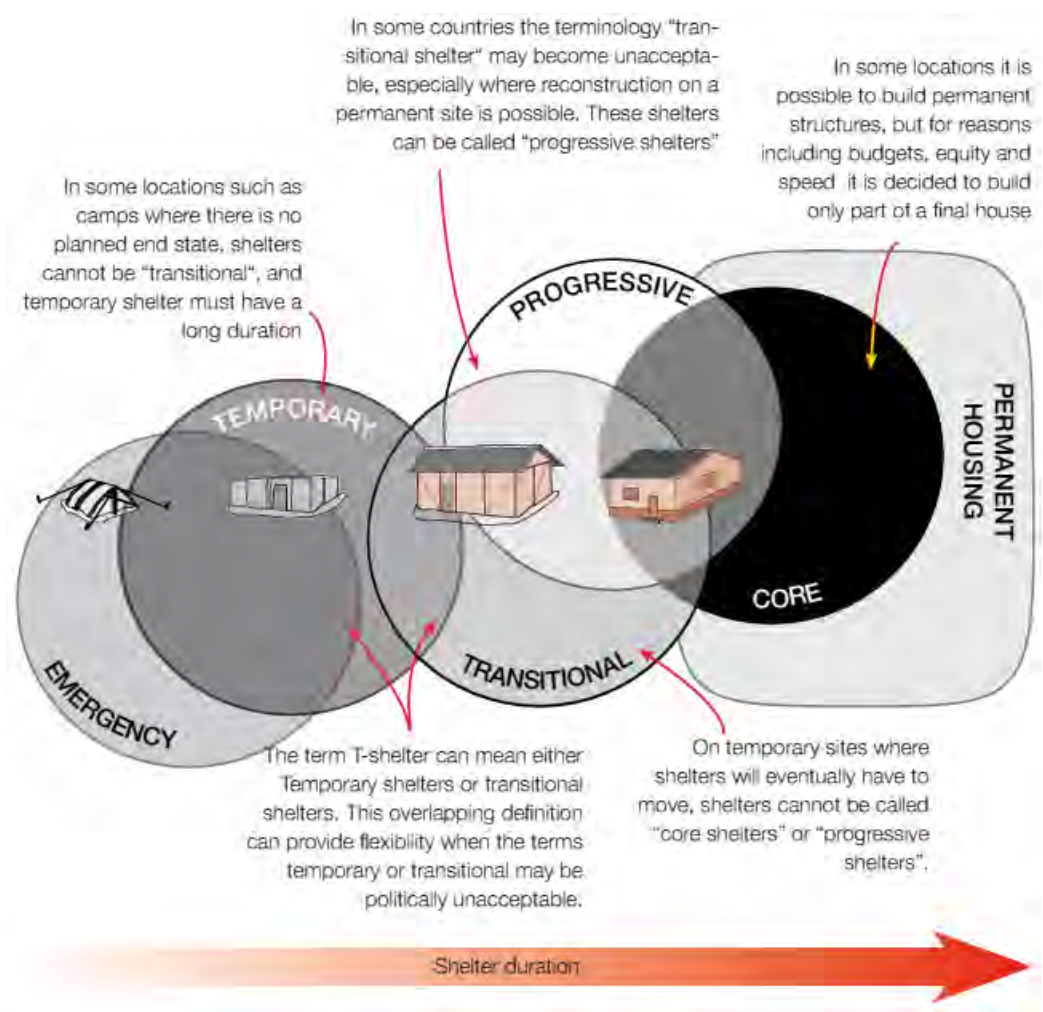

Figure 2.4: "Families A and B will walk different "pathways" toward a permanent housing solution. Shelter-support interventions can enable incremental improvements to their shelter conditions along the way.' Source: Flores and Meany (2013)

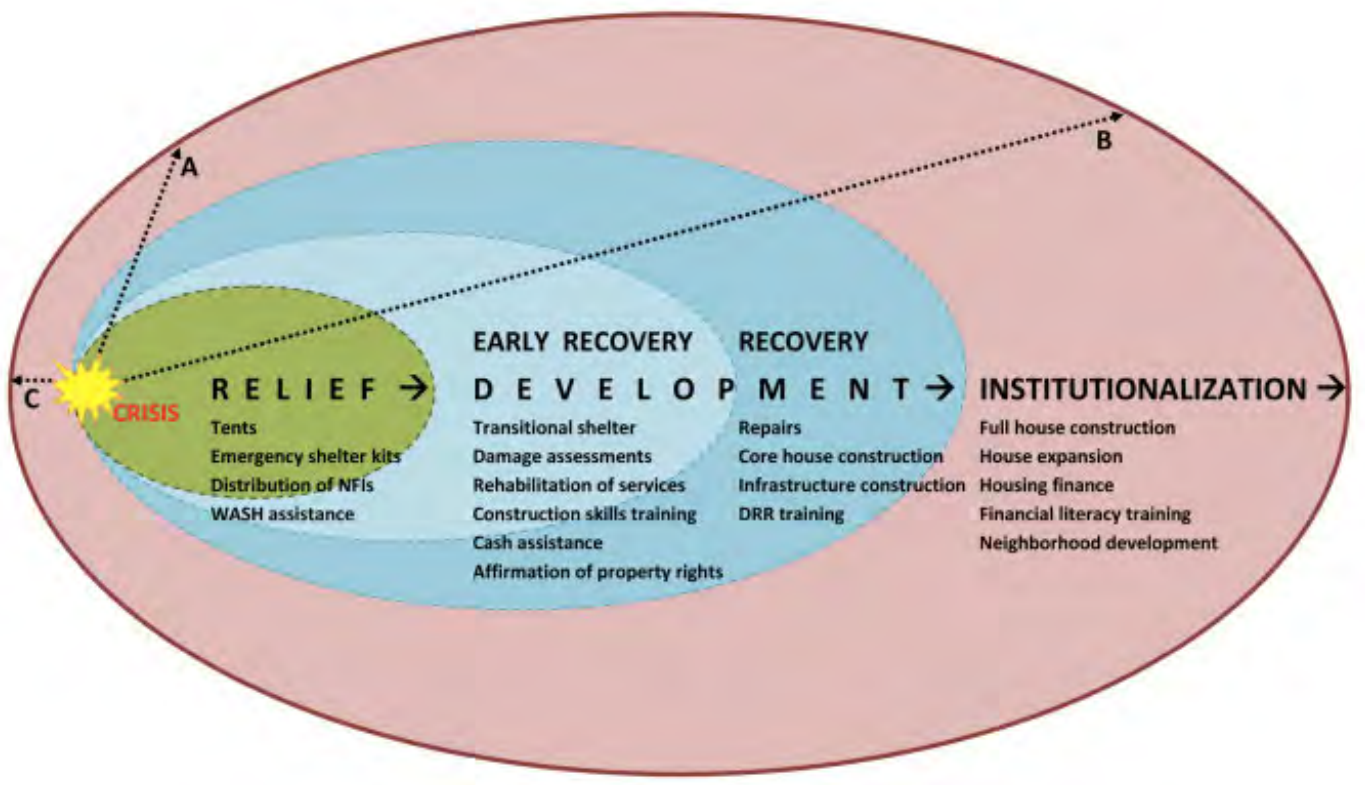




\title{
2.2 SUPPORT FOR SHELTER SELF-RECOVERY
}

\author{
What is support for shelter self-recovery?
}

To the knowledge of the research team Getting the message across for safer self-recovery in post-disaster shelter (Parrack et al., 2014) is the only academic paper using the phrase 'self-recovery' with regard to humanitarian shelter and settlements. Parrack et al. (2014, p. 47) define shelter 'self-recovery' as when populations affected by natural disasters 'rebuild or repair damaged or destroyed homes using their own assets' through self-building or using the local informal building sector. ${ }^{8}$ Given that the majority of shelter needs after disasters are met by affected families and communities themselves (Davis, 1978) they argue that this process is in fact 'not the exception but the norm' (Parrack et al., 2014, p. 47).

Searches of the Shelter Cluster website and the Shelter Case Studies database ${ }^{9}$ indicate that shelter practitioners may have begun using the term 'self-recovery' following Cyclone Sidr in Bangladesh in 2007 (Kabir, 2009). It was also used during humanitarian shelter responses to: Cyclone Nargis in Myanmar in 2008 (Emergency Shelter Cluster, 2008); earthquakes in Indonesia in 2009 (Rantanen, 2011); armed conflict in Sri Lanka in 2011 (United Nations High Commissioner for Refugees (UNHCR), 2011) and flooding in Pakistan in 2011 (IFRC et al., 2013, p. 71). The phrase 'self-recovery' became widely used following Typhoon Haiyan in the Philippines in 2013 where providing 'support for household selfrecovery' was one of three strategic objectives of the Shelter Cluster (Global Shelter Cluster, 2013). The approach was subsequently identified as a strategic objective of the humanitarian shelter response to the armed conflict in South Sudan in 2013 (Shelter Cluster South Sudan, 2014) and to the earthquake in Nepal in 2015 (Nepal Shelter Cluster, 2015). ${ }^{10}$

\section{Is support for shelter self-recovery called anything else?}

With just two exceptions, these examples are all responses to 'natural' disasters in the AsiaPacific region within the last 10 years. Given the lack of standardized terminology in the shelter sector, ${ }^{11}$ it is important to consider if interventions supporting shelter self-recovery have been called something else in different contexts or at different periods of time. The terms 'self-help,' 'self-build' and 'incremental' have long been used in developmental approaches to housing (Wakely and Riley, 2011) while self-help approaches to permanent housing after disasters have been described as 'rapid' or 'owner-driven' reconstruction (Davis, 1978; Jha and Duyne Barenstein, 2010).

Searches of the Shelter Cluster website and the Shelter Case studies database for these alternative terms identified a number of additional responses where humanitarian shelter interventions aimed to support affected households' self-recovery processes. These included humanitarian shelter interventions supporting populations affected by complex emergencies in Afghanistan (United Nations Human Settlements Programme (UN-Habitat) et al., 2008), Cote d'Ivoire (IFRC et al., 2013), Mali (IFRC et al., 2013), Kenya (Kenya Shelter Cluster, 2012), Gaza (Norwegian Refugee Council, 2013) and Somalia (Shelter Cluster Somalia, 2013). The term 'progressive sheltering' was also found to describe a similar approach following Typhoon Pam in Vanuatu in 2015 (Government of Vanuatu, 2015).

\footnotetext{
${ }^{8}$ The term 'self-recovery' has been introduced by humanitarian shelter practitioners to describe shelter self-recovery; therefore the term 'shelter self-recovery' rather than 'self-recovery' more generally is used in this research.

${ }^{9}$ www.sheltercluster.org and www.sheltercasestudies.org, retrieved 26 November 2015.

${ }^{10}$ See Figure 2.5 for further details of these examples.

${ }^{11}$ For further details see Box 3 in Maynard et al. (2016).
} 


\section{What interventions support shelter self-recovery?}

Based on these initial searches, the research team concluded that potential programmes for inclusion in this synthesis should not be defined by whether or not they were described as supporting shelter 'self-recovery'. Instead a more precise definition was developed based on the specific interventions provided. To identify which interventions are commonly described as 'supporting shelter self-recovery' the interventions mentioned in the documents referenced earlier in this section were mapped against the 17 'response options' identified in Shelter Projects 2013-2014 (IFRC et al., 2014). This analysis (see Figure 2.5) indicated that humanitarian programmes described as providing support for shelter self-recovery typically include the provision of a combination of:

- material assistance, including construction materials, tools, salvaging and reuse of debris

- financial assistance (cash or vouchers) for the purchase of construction materials, tools or labour

- technical assistance, including training, on-site monitoring and the provision of guidance through guidelines/mass communications.

\section{When is support for shelter self-recovery provided?}

From these initial searches it seemed that the term 'self-recovery' has been used to describe interventions supporting affected households to repair, build or rebuild emergency, temporary or transitional shelter while the terms 'self-help' and 'self-build' have also been applied to reconstruction. There is no standard timescale for humanitarian shelter programmes as these 'vary according to the local conditions and type of disaster' (IFRC and UN OCHA, 2015). However, in practical terms, humanitarian funding for relief and early recovery activities is often limited to the first 12 months following the onset of the crisis (DFID, 2015; USAID/OFDA, 2012). Given the existing literature on owner-driven reconstruction (IFRC, 2010; Jha and Duyne Barenstein, 2010), the focus of humanitarian funding on the first 12 months following the onset of a crisis, and the need to identify comparable interventions for inclusion in the evidence synthesis, the research focused on shelter programmes that began implementation within 18 months after a natural disaster or during any time period for displaced or non-displaced populations affected by complex emergencies (including armed conflict).

\section{Definition of support for shelter self-recovery}

Based on the definition introduced by Parrack et al. (2014) and the initial searches presented above, the research team proposed that for the purposes of this synthesis:

Humanitarian interventions supporting shelter self-recovery following humanitarian crises can be defined as those: providing one or a combination of material, financial and technical assistance, during the relief and/or recovery phase, to enable affected households to repair, build or rebuild their own shelters themselves or through using the local building industry. Material assistance includes the provision of construction materials, tools and support for salvaging and reuse of debris. Financial assistance includes the provision of cash or vouchers. Technical assistance can include (but is not limited to) the provision of guidance on construction through training, guidelines or mass communications. 
Figure 2.5: Example humanitarian interventions described as supporting shelter self-recovery. Source: The research team

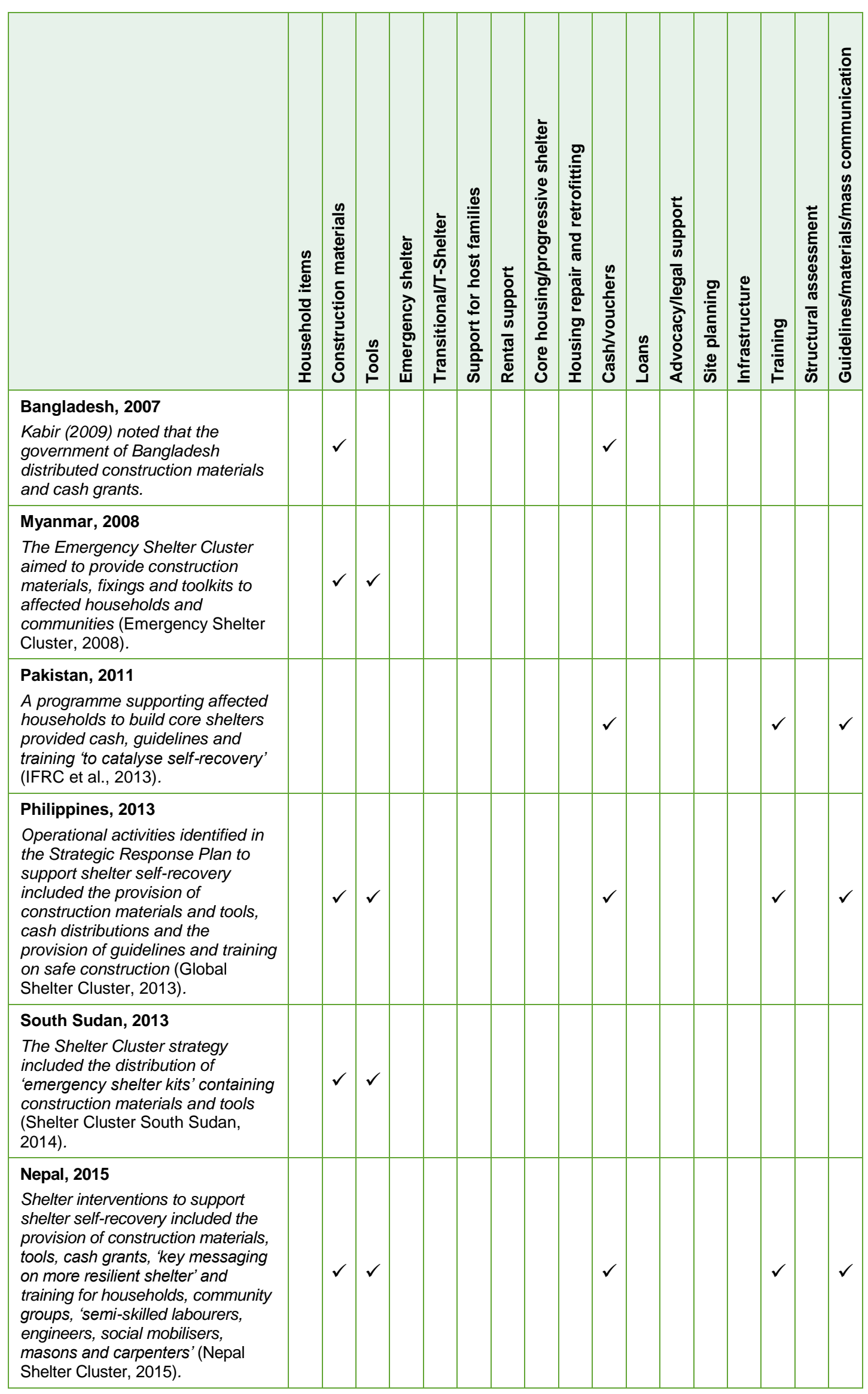

Note: $\checkmark$ indicates that the document specifically states the intervention was provided. 


\section{HOW SUPPORT FOR SHELTER SELF-RECOVERY MIGHT WORK}

Following the guidance of Popay et al. (2006) a theory of change model for humanitarian interventions supporting shelter self-recovery was developed as part of the protocol and revised during the evidence synthesis (See Figure 2.6). ${ }^{12} \mathrm{~A}$ comparison of the theory of change for interventions supporting shelter self-recovery with agency- or contractor-build interventions is provided in Box 'Comparison of 'support for shelter self-recovery' and agency- or contractor-build interventions' (p. 9).

\section{Figure 2.6: Theory of change for humanitarian interventions supporting shelter self- recovery. Source: The research team, based on Buchanan-Smith and Cosgrave, (2013); DFID (2011); Proudlock et al. (2009); Yates et al. (2016)}

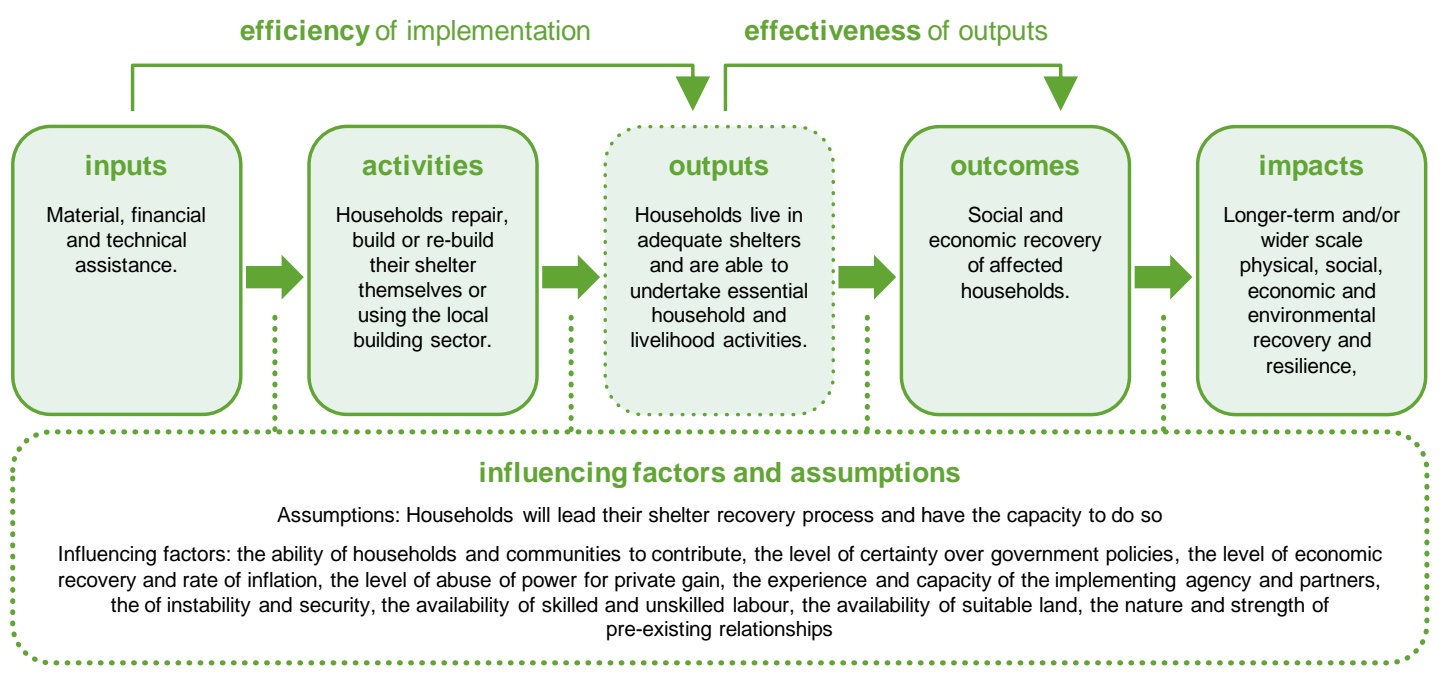

The inputs into a programme supporting shelter self-recovery are material, financial and/or technical assistance (see Section 2.2 for further details).

The primary activity is that affected households repair, build or rebuild their shelter themselves or using the local building industry.

The output of shelter self-recovery is that households have built (and live in) 'adequate' shelters. The Sphere Project noted that 'adequate' shelter provides 'sufficient covered living space providing thermal comfort, fresh air and protection from the climate ensuring their privacy, safety [from natural hazards] and health and enabling essential household and livelihood activities to be undertaken' $\left(2011\right.$, p. 258). ${ }^{13}$ However, these vary in relation to important variables such as the climate and context, the duration of time households intend to live in the shelter, and their social, cultural and livelihood practices. Each of these variables will affect what activities are required to take place within and adjacent to the shelter (or elsewhere in the settlement) and consequently the space, privacy, safety, security, thermal comfort and ventilation the shelter needs to provide (The Sphere Project, 2011).

The outcome of living in adequate shelter is the social and economic recovery of affected households. See Section 6 for the outcome measures identified in this synthesis.

The inputs, activities, outputs and outcomes of shelter self-recovery also support broader physical, social, economic and environmental recovery and long-term risk reduction and resilience (impacts).

\footnotetext{
${ }^{12}$ The review team recognises that humanitarian response is complex and the links between interventions, outcomes and impacts are 'messy, unpredictable and iterative... [However] used sensibly, this model is a useful starting point for mapping the causal assumptions underlying the specific objectives of an intervention, by providing a common framework to think about how the intervention will actually deliver the changes we wish to bring about' (Proudlock et al., 2009, p. 16)

${ }^{13}$ Security (from crime or violence) is not mentioned in this standard regarding 'covered living space' but this appears to be an oversight as it is part of an earlier standard on 'strategic planning' and the introductory text to the shelter and settlement standards.
} 
The current report intends to synthesize evidence on both the effects (outcomes) of humanitarian interventions supporting shelter self-recovery and the process of implementation. The relationship between the outputs and outcomes of humanitarian interventions is often described as effectiveness or 'how well an activity has achieved its purpose' (Buchanan-Smith and Cosgrave, 2013, p. 54). Efficiency, on the other hand, describes the relationship between inputs, activities and outputs and 'evaluating efficiency usually requires comparing alternative approaches to achieving an output' (Buchanan-Smith and Cosgrave, 2013, p. 54). Thus, the terms effectiveness and efficiency have been used to describe the dual aspects of this research.

\section{Comparison of 'support for shelter self-recovery' and agency- or contractor-build interventions}

The outputs of shelter interventions are generally reported as the number of products delivered or services completed by the implementing agency. For example, 'the number of persons/households/communities provided with training related to shelter assistance.${ }^{14}$ However, the research team notes that these are actually inputs into a shelter self-recovery programme and recommends that alternative measures are used to report the outputs of shelter programmes so that both the process and effects of humanitarian interventions supporting shelter selfrecovery can be compared with agency- or contractor-build interventions. See Section 6 for the indicators used in the studies included in this synthesis.

\section{Support for self-recovery interventions}

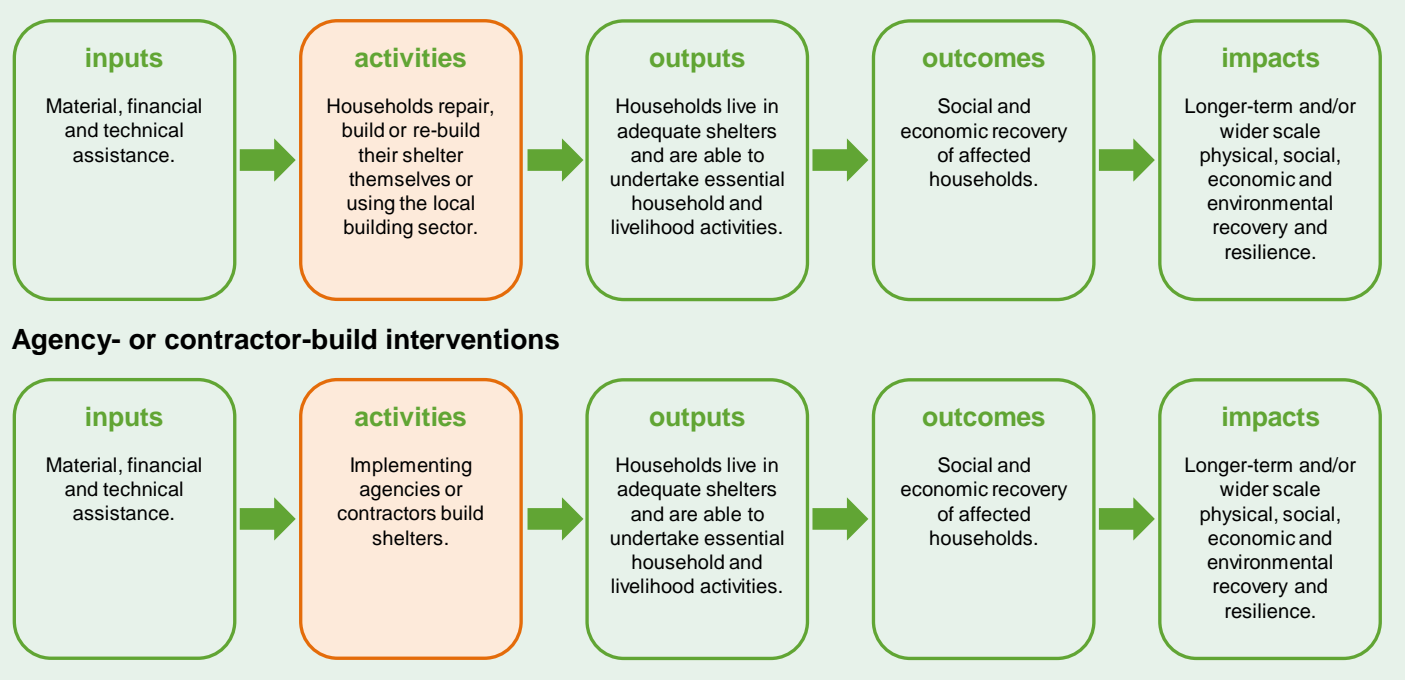

\subsection{THE NEED FOR THIS RESEARCH}

\section{The demand for evidence}

'The humanitarian system has never reached more people in so many places' (World Humanitarian Summit, 2015). Yet, while funding for humanitarian response is at its highest level ever, the average level of funding per person has dropped as need has outstripped supply (Stoddard et al., 2015). Historically there has been relatively little research into humanitarian interventions - with evaluation of interventions not common until the 1990s (Darcy et al., 2013; Dijkzeul et al., 2013). ${ }^{15}$ In the current context of limited resources there is 'an increasingly urgent need to generate knowledge about 'what works" (Proudlock et al., 2009 , p. 9) both to inform decision making and demonstrate the effectiveness of interventions (Darcy et al., 2013).

Despite increasing demand for evidence, shelter and settlement interventions remain an under-researched aspect of humanitarian response (Peacock et al., 2007; Twigg, 2002). This is a particular concern because without the security offered by somewhere to call

\footnotetext{
${ }^{14}$ Examples output indicators for the Global Shelter Cluster can be viewed at

www.humanitarianresponse.info/en/applications/ir/indicators/global-clusters/4/ind-type/output (retrieved 31 March 2016).

${ }^{15}$ Dijkzeul et al. cite a number of reasons for this including: 'it was not considered appropriate to pose questions about the efficiency and effectiveness of life-saving action' (2013, p. 52); an acceptance of 'quick and dirty' data gathering in order to inform immediate action; that humanitarian agencies 'derive their legitimacy and credibility by making reference to their principles rather than to their evidencebased approaches' (ibid.).
} 
'home' the ability of families to return to normality is limited, and delays in shelter recovery often delay all other aspects of recovery (Peacock et al., 2007). Furthermore 'if the international response continues with conventional product-based responses such as transitional and permanent shelter, it will not meet a significant proportion of the need with a solution that is long term, high quality and safe' (Parrack et al., 2014, p. 48).

The humanitarian shelter and settlements sector has recently begun to publish evaluations and case studies on a previously unprecedented scale. For example, in April 2016 the Shelter Projects database contains 167 case studies ${ }^{16}$ while ALNAP's resource library contains 136 evaluation reports focused on 'shelter and housing'. ${ }^{17}$ While the level of documentation is increasing, 'evidence' in the shelter sector remains largely based on experience and expert opinion, project or programme evaluations, case studies and academic papers on specific topics - with little evidence on the outcomes or impact of programmes undertaken.

\section{Stakeholder interest}

As part of the scoping assessment for this synthesis, the research team undertook a series of stakeholder engagement activities (presentations at conferences, webinars, flyers, website, emails, mail-outs through online communities of practice and an online survey). There was a high-level of engagement and interaction from a wide range of stakeholders and 49 respondents completed the online survey. Survey respondents were asked to suggest specific subject areas/topics of interest in order to narrow the initial research question posed by HEP: 'What is the evidence on the impacts of different shelter and settlement strategies in the immediate aftermath of and recovery period following humanitarian emergencies?'

The research team combined the findings from the stakeholder consultation with a mapping of the depth, breadth and nature of existing literature on humanitarian shelter and settlements in order to ensure that there was both interest and suitable documentation on a specific topic. Following this analysis, we concluded that while there was significant demand for further research across a number of areas, investigation of humanitarian interventions that 'support shelter self-recovery' was the most suitable topic for evidence synthesis.

Research questions suggested included:

- How do communities recover themselves without external support? Do they incorporate lessons learned? How can we strengthen the natural recovery process of communities?

- Is it possible to maximize efficiency/effectiveness in delivery with a progressive/iterative shelter approach, and how should cash and household participation fit into this?

- What type of shelter training achieves the best long-term impact in affected communities?

${ }^{16}$ www.sheltercasestudies.org, retrieved 12 April 2016.

${ }^{17} \mathrm{http}: / /$ www.alnap.org/resources/results.aspx?tag=511\&type=22 retrieved 12 April 2016. 
The aim of this report is to synthesize the existing evidence on the effectiveness and efficiency of interventions that support affected populations' own shelter self-recovery processes following humanitarian crises. In doing so we aim to address the following research questions:

- What effects do interventions that support affected populations' own shelter self-recovery processes have on household-level outcomes following humanitarian crises?

- What factors helped or hindered the implementation of interventions supporting populations' own shelter self-recovery processes following humanitarian crises?

\subsection{OVERVIEW OF METHODS}

Figure 3.1 summarises the research approach for the evidence synthesis. The process set out in Figure 3.1 and detailed in this section focuses on completing a narrative synthesis of qualitative, quantitative and mixed methods research. Please refer to the research protocol for additional information on the research method (Maynard et al., 2016).

Figure 3.1: Research approach. Source: The research team based on Higgins and Green (2011); Humanitarian Evidence Programme (2015), and lessons learned from undertaking the scoping assessment that preceded the research protocol (Maynard et al., 2016)

\begin{tabular}{|c|c|}
\hline Stage & Activities \\
\hline $\begin{array}{l}\text { Step 1: } \\
\text { Development of } \\
\text { review protocol }\end{array}$ & $\begin{array}{l}\text { Define the research question(s). } \\
\text { Develop the eligibility (inclusion/exclusion) criteria. } \\
\text { Define the databases, websites, search engines etc. that will be searched. } \\
\text { - Develop (and test) the search strings. } \\
\text { Define the screening, data extraction and appraisal process. } \\
\text { Define the type of evidence synthesis. }\end{array}$ \\
\hline $\begin{array}{l}\text { Step 2: } \\
\text { Run of search terms } \\
\text { and initial screening } \\
\text { of the documents }\end{array}$ & $\begin{array}{l}\text { Run the search terms, contact stakeholders. } \\
\text { - Remove duplicates for documents identified through academic databases. } \\
\text { - Conduct first round of screening. } \\
\text { - Remove documents from the review that do not meet the criteria. } \\
\text { - Enter all documents that meet the criteria into a Microsoft Excel database. } \\
\text { - Remove duplicates for all documents. }\end{array}$ \\
\hline $\begin{array}{l}\text { Step 3: } \\
\text { Second screening of } \\
\text { the documents }\end{array}$ & $\begin{array}{l}\text { Conduct second round of screening for full text of all studies that have been } \\
\text { classified as 'potentially eligible' or where there is a doubt about potential eligibility. } \\
\text { Classify all documents as either 'included' or 'excluded'; record reason for } \\
\text { exclusion. } \\
\text { Import all 'included' documents into Mendeley. } \\
\text { Review references/bibliographies/citations of imported documents in order to } \\
\text { identify additional documents ('snowballing'). Repeat screening detailed in steps } 2 \\
\text { and } 3 \text { with any new records. }\end{array}$ \\
\hline
\end{tabular}

\footnotetext{
${ }^{18}$ Typically the first stage of a systematic review is 'Run the search terms' and the second stage is 'Screen the titles and abstracts'. However, a key lesson from the scoping assessment is that due to the type of documentation available, and the interfaces of the repositories searched, it is not possible to adopt this approach for a large number of documents, primarily because they do not have abstracts (or contents pages/executive summaries/keywords). Consequently these two stages have been merged, so running the search terms and initial screening are undertaken at the same time to avoid the need to input documents that do not meet the eligibility criteria into the research team's document management database.
} 


\begin{tabular}{|l|l|}
\hline Stage & Activities \\
\hline $\begin{array}{l}\text { Step 4: } \\
\begin{array}{l}\text { Critical appraisal of } \\
\text { 'included' studies }\end{array}\end{array}$ & $\begin{array}{l}\text { - Assess study quality. } \\
\text { - Exclude documents assessed as low/very low quality, or with no external validity } \\
\text { from the study. }\end{array}$ \\
\hline $\begin{array}{l}\text { Step 5: } \\
\text { Data extraction and } \\
\text { evidence synthesis }\end{array}$ & $\begin{array}{l}\text { - Extract data and synthesize evidence. } \\
\text { - Contact authors of documents if any gaps in information, as required. }\end{array}$ \\
\hline
\end{tabular}

\subsection{DEVELOPMENT OF REVIEW PROTOCOL (STEP 1)}

The first step in the research was to develop the research protocol (Maynard et al., 2016). The purpose of the protocol was to clearly describe the proposed research methodology so as to reduce the impact of review authors' biases, promote transparency of methods and processes, and reduce the potential for duplication; and so that it could be peer-reviewed before undertaking the study (Light and Pillemer, 1984). Thus the protocol set out the theoretical background to the study; the research questions and the approach for undertaking the review, including the inclusion and exclusion criteria; the search strategy; and the procedure for data collection, analysis and synthesis. Please see Appendix F for details of the differences between the protocol and the actual methodology implemented.

\subsection{RUN OF SEARCH TERMS AND INITIAL SCREENING OF DOCUMENTS (STEP 2)}

The second step in the research consisted of implementing the search strategy to identify potentially relevant documents while undertaking an initial round of screening to identify documents that were suitable for inclusion.

\section{Search strategy}

The search strategy was developed iteratively throughout the scoping assessment and protocol development. Key papers were used to test the completeness of the search results. There were four input sources of documents for this evidence synthesis:

- scoping assessment documents ${ }^{19}$

- academic literature sources

- grey literature sources

- stakeholder engagement.

Figure 3.2 details the databases and websites searched for each of the four sources of documentation. Appendix A details the search terms used for the academic literature searches and Appendix B presents a complete overview of the sources and the exact search terms used (for example where the search terms were adapted for the grey literature sources).

References in documents that were selected for inclusion in the evidence synthesis were used for 'snowballing'. The reference/bibliography section of the documents was reviewed to identify any additional documents not yet found. As part of the 'snowballing' strategy all 'included' documents were also entered into Google Scholar to conduct forward citation tracking.

\footnotetext{
${ }^{19}$ The research already undertaken as part of the scoping assessment is included in the evidence synthesis. In total 2,187 documents were identified through the scoping assessment. Of these, 60 documents met the inclusion/exclusion criteria and were included in the scoping assessment analysis. See Appendix $\mathrm{C}$ for further details on the scoping assessment search strategy and screening guide.
} 


\begin{tabular}{l} 
Figure 3.2: Details of databases and websites searched. Source: The research \\
team ${ }^{20}$ \\
\begin{tabular}{|l|l|}
\hline Scoping assessment & Database/website \\
\hline & $\begin{array}{l}\text { Scopus, ALNAP Humanitarian Evaluation and Learning Portal, Humanitarian } \\
\text { Library, websites of the } 11 \text { Shelter Cluster Strategic Advisory Group members } \\
\text { (ACTED, Australian Red Cross, Care International, Habitat for Humanity, } \\
\text { IFRC, Interaction, International Organization for Migration, Norwegian Refugee } \\
\text { Council, UNHCR, UN-Habitat, World Vision International), stakeholder } \\
\text { engagement activities }\end{array}$ \\
\hline Academic literature sources & Scopus, Web of Science, PubMed, ProQuest Dissertations \& Theses Global \\
\hline Grey literature sources & $\begin{array}{l}\text { i-Rec, British Library e-theses online service (EThOS) Humanitarian Exchange } \\
\text { Magazine, Social Science Research Network (SSRN), DFID (R4D), Jolis: Joint } \\
\text { Bank-Fund Library of the World Bank and IMF, 3ie's database of impact } \\
\text { evaluations, British Library for Development Studies (BLDS), International } \\
\text { Recovery Platform, IRFC, National Society for Earthquake Technology - Nepal } \\
\text { (NSET), ProVention Consortium, Save the Children, Australian Aid (Australian } \\
\text { Agency for International Development), Build Change, the Overseas } \\
\text { Development Institute (ODI), Incremental Housing - MIT, Oxfam, Plan } \\
\text { International, Shelter Cluster, Practical Action, USAID/OFDA, ERRA } \\
\text { (Earthquake Reconstruction and Rehabilitation Authority), European } \\
\text { Commission Humanitarian Aid and Civil Protection Department (ECHO), } \\
\text { Eldis (Institute of Development Studies), Abdul Latif Jameel Poverty Action } \\
\text { Lab (J-PAL) }\end{array}$ \\
\hline Stakeholder engagement & Website, emails, personal correspondence \\
\hline
\end{tabular} \\
\hline
\end{tabular}

\section{First round of screening}

In order to be considered for inclusion in the synthesis, the document needed to meet the following inclusion criteria:

- populations affected by humanitarian crises (natural disaster and complex emergencies, including armed conflict)

- populations in low and middle-income countries ${ }^{21}$

- populations supported by shelter intervention(s) - types of participants could include those that were not displaced, those displaced within their home country, or refugees displaced in other low or middle-income countries

- interventions supporting shelter self-recovery as defined in Section 2.2

- interventions that began implementation: within 18 months after a natural disaster, within 18 months following return or resettlement as a result of complex emergencies (including armed conflict), during any time period for displaced populations while they are displaced as a result of natural disasters or complex emergencies (including armed conflict), during any time period for non-displaced populations affected by complex emergencies (including armed conflict)

- interventions that supported populations affected by humanitarian crises to repair, build or rebuild shelters themselves or by using the local building industry

- all outcome measures were included, including physical, social, economic and environmental outcomes

- all study designs were considered (qualitative, quantitative and mixed methods) - to be eligible documents needed to be based on data collected from project or programme beneficiaries, implementing agencies or other stakeholders; clearly identify and describe the activities, outputs and outcomes of the shelter intervention; and report on procedures for data collection, and analysis methods

\footnotetext{
${ }^{20}$ This list was compiled from a) recommendations from the research team; b) review of systematic reviews in the international development sector to identify the websites they reviewed; and c) suggestions received from the online stakeholder survey undertaken during the scoping stage. See Appendix B for additional information on the search terms used for each database.

${ }^{21}$ The World Bank classifications for low and middle-income countries were used to determine eligibility for inclusion. Please note, these classifications are revised annually on July $1^{\text {st }}$; therefore this review used the classifications for the financial year 2015/2016. Further details on the World Bank classifications for low and middle-income countries can be seen here:

http://data.worldbank.org/about/country-and-lending-groups
} 
- documents published after 1990

- documents available in English.

Documents not meeting the inclusion criteria and therefore excluded from the study included those that detailed:

- interventions that addressed disaster risk reduction, climate change adaptation or development interventions such as retrofitting of existing houses

- interventions that did not result in the construction or repair of a shelter, for example support for host families, rental support or distribution of household items

- interventions that did not directly support affected populations' own shelter self-recovery, such as: contractor-built shelter and pre-fabricated temporary shelter; advocacy and legal support; site/settlement planning or infrastructure rehabilitation.

All non-primary research sources were excluded, therefore publication types that were ineligible included:

- opinion pieces

- commentaries

- literature reviews

- debates

- guidelines

- marketing material, such as case studies of individual beneficiaries or households

- systematic reviews.

In order to assess the documents identified through the search strategy against the inclusion/exclusion criteria, the research team used the screening guide (see Figure 3.3).

In the first round of screening, the researchers adopted a multi-pronged approach (in order of preference):

- document contains abstract - all titles and abstracts were screened

- document does not contain abstract - all titles and executive summaries were screened

- document does not contain abstract or executive summary - full text screening.

For both stages of the screening process we applied a team-based approach to the review, ${ }^{22}$ which enabled quality control of the screening process at several stages. The researchers reviewed a selection of 10 abstracts and then discussed their application of the inclusion/exclusion criteria with one another to identify any differences of opinion and reach consensus. Through this initial collaborative process, a common approach was agreed and each researcher went on to review a small selection of different abstracts, again followed by review and discussion with the rest of the research team. No significant differences were identified between the approaches of the researchers and they went on to review the remainder of the abstracts/documents.

Following this first round of screening, studies were classified as either 'exclude' or 'potentially eligible'.

\footnotetext{
${ }^{22}$ Please note: The same approach was undertaken for the scoping assessment
} 
Figure 3.3: Screening guide. Source: The research team

\begin{tabular}{|c|c|c|}
\hline \multicolumn{2}{|c|}{ First round of screening } & \multirow{2}{*}{$\begin{array}{l}\text { Notes to researcher } \\
\text { If the answer is no, exclude. }\end{array}$} \\
\hline 1 & $\begin{array}{l}\text { Does the document describe intervention(s) responding to } \\
\text { humanitarian crisis/crises? }\end{array}$ & \\
\hline 2 & Is the type of document likely to contain primary data? & If the answer is no, exclude. \\
\hline 3 & $\begin{array}{l}\text { Is the document about interventions that support shelter self- } \\
\text { recovery by providing a combination of material, financial and/or } \\
\text { technical assistance? }\end{array}$ & If the answer is no, exclude. \\
\hline 4 & Is the document in English? & If the answer is no, exclude. \\
\hline 5 & Was the document published after $1990 ?$ & If the answer is no, exclude. \\
\hline 6 & $\begin{array}{l}\text { Does the document describe intervention(s) in low and middle- } \\
\text { income countries? }\end{array}$ & If the answer is no, exclude. \\
\hline 7 & Does the document potentially include information about outcomes? & $\begin{array}{l}\text { If the answer is clearly no, } \\
\text { exclude. }\end{array}$ \\
\hline
\end{tabular}

\begin{tabular}{|l|l|l|}
\hline \multicolumn{2}{|c|}{ Documents identified as: 'Potentially eligible' or 'Exclude' } \\
\hline 8 & $\begin{array}{l}\text { Is the document based on data collected from project or programme } \\
\text { beneficiaries, implementing agencies or other stakeholders? }\end{array}$ & If the answer is no, exclude. \\
\hline 9 & $\begin{array}{l}\text { Does the document report on procedures for data collection } \\
\text { methods? }\end{array}$ & If the answer is no, exclude. \\
\hline 10 & $\begin{array}{l}\text { Does the document report on interventions that were implemented: } \\
\text { within } 18 \text { months after a natural disaster } \\
\text { within } 18 \text { months following return or resettlement as a result of } \\
\text { complex emergencies (including armed conflict) } \\
\text { during any time period for displaced populations while they are } \\
\text { displaced as a result of 'natural' disasters or complex } \\
\text { emergencies (including armed conflict) } \\
\text { during any time period for non-displaced populations affected by } \\
\text { complex emergencies (including armed conflict)? }\end{array}$ & If the answer is no, exclude. \\
\hline 11 & $\begin{array}{l}\text { Does the document clearly identify and describe the activities and } \\
\text { outputs of the intervention supporting shelter self-recovery? }\end{array}$ & If the answer is no, exclude. \\
\hline 12 & $\begin{array}{l}\text { Does the document clearly identify and describe the outcomes of the } \\
\text { intervention supporting shelter self-recovery? }\end{array}$ & If the answer is no, exclude. \\
\hline
\end{tabular}

Documents identified as: 'include or 'exclude' (pending quality appraisal)

\subsection{SECOND SCREENING OF THE DOCUMENTS (STEP 3)}

In the second round of screening, full texts of all studies that had been classified as 'potentially eligible' or where there was doubt about potential eligibility, were assessed by the researchers using the second part of the screening guide (see Figure 3.3). Studies were classified as either 'included' (pending quality appraisal) or 'excluded'; where clarification was required, consensus was reached through discussion between the researchers.

\footnotetext{
${ }^{23}$ Note: For transparency and accountability it is important to understand where the information reported in a document comes from. If the source of the information is not clear this undermines the credibility of the findings as it is not possible to assess the risk of bias in the research. Quality documents from both academia and practice (such as evaluations and impact studies) include information on their data collection methods as standard practice. This question did not unfairly bias the review towards 'academic' research and a broad range of documents were included in the evidence synthesis. See Section 4 for additional information.
} 
For the purposes of this synthesis, a 'quality appraisal template' was developed to assess the quality of the documents included, recognizing that these would primarily be qualitative and mixed methods studies (see Appendix E for the quality appraisal template). Two researchers independently completed the quality appraisal template for each document. The researchers then shared, discussed and agreed the assessment of each document against each of the criteria in order to determine an overall quality score. Following this stage, documents identified as very low quality, and findings assessed as having no or limited external validity, were excluded from the synthesis. This resulted in the complete and final list of documents included in the evidence synthesis.

\section{Data extraction}

Two researchers extracted data from different documents using a structured data extraction form: this included a description of the study (author, title, date, study design) and information on the activities, outputs and outcomes of the intervention as well as the population and context. Data was manually entered into a form in Microsoft Excel to allow ease of comparison and analysis. One researcher then undertook a second round of data extraction using the qualitative data analysis software NVivo to systematically check each of the included studies for any data that may have been missed in the first round. If when following this two-step process there were any data points that were unclear in the documents or the researchers were unsure of, these were discussed with the Principal Investigator, who made the final decision. See the research protocol for additional information (Maynard et al., 2016).

Thus, a 'bottom-up' (or inductive) approach was applied to the extraction and analysis of data on the effects of interventions and the factors that helped or hindered implementation. In the first round of data extraction, all effects or factors noted in the documents were captured in the data extraction form as quotes or a very close paraphrase. These were then grouped - both thematically and through mapping - against the stages of the project cycle identified in the theory of change (see Section 2.3). This led to revision and refinement of the proposed theory of change model for interventions supporting shelter self-recovery and identification of the categories of effects and factors noted in the documents. The second round of data extraction then systematically checked each of the included studies for any data that may have been missed in the first round.

\section{Evidence synthesis}

The analysis followed the guidance provided by the Economic and Social Research Council Methods Programme for narrative synthesis in systematic reviews (Popay et al., 2006). This consists of four, iterative elements:

- developing a theory of how the intervention(s) work, why and for whom

- developing a preliminary synthesis of findings of included studies

- exploring relationships within and between studies

- assessing the robustness of the synthesis.

The types of interventions evaluated in this synthesis are diverse in context, populations and methods of measuring outcomes. This resulted in significant heterogeneity and thus findings were summarized narratively, using text, diagrams and tables (See Figure 3.4 for further details on the tools and techniques used for each element). 
Figure 3.4: The different tools and techniques used for each research question. Source: The research team, based on Popay et al. (2006)

\begin{tabular}{|l|l|l|}
\hline Main elements of synthesis & Question 1 (effectiveness) & Question 2 (implementation) \\
\hline $\begin{array}{l}\text { 1. Developing a theory of how the } \\
\text { intervention(s) work, why and for } \\
\text { whom }\end{array}$ & See Section 2 & See Section 2 \\
\hline $\begin{array}{l}\text { 2. Developing a preliminary } \\
\text { synthesis of findings of included } \\
\text { studies }\end{array}$ & $\begin{array}{l}\text { Textual descriptions } \\
\text { Tabulation } \\
\text { Transforming the data (common } \\
\text { rubric) } \\
\text { Groupings and clustering } \\
\text { Thematic analysis }\end{array}$ & $\begin{array}{l}\text { Transforming the data (common } \\
\text { rubric) } \\
\text { Groupings and clustering }\end{array}$ \\
\hline $\begin{array}{l}\text { 3. Exploring relationships within } \\
\text { and between studies }\end{array}$ & $\begin{array}{l}\text { Translation } \\
\text { Idea webbing and conceptual } \\
\text { mapping }\end{array}$ & $\begin{array}{l}\text { Thematic analysis } \\
\text { Idea webbing and conceptual } \\
\text { mapping }\end{array}$ \\
\hline $\begin{array}{l}\text { 4. Assessing the robustness of the } \\
\text { synthesis }\end{array}$ & $\begin{array}{l}\text { Critical reflection on the synthesis } \\
\text { process }\end{array}$ & $\begin{array}{l}\text { Critical reflection on the synthesis } \\
\text { process }\end{array}$ \\
\hline
\end{tabular}

This report was reviewed by: the research team at Habitat for Humanity and University College London and the HEP team at Oxfam and the Feinstein International Center at the Friedman School of Nutrition Science and Policy, Tufts University. It was subsequently blind peer-reviewed. Following each of these review stages, the report was updated to reflect comments and recommendations of reviewers. 
This section of the report introduces the documents found and compares the key characteristics of the included studies.

\section{$4.1 \quad$ INTRODUCTION TO THE DOCUMENTS FOUND}

Figure 4.1 summarises the findings from the process of identification, screening and quality appraisal. In total 4,613 documents were identified. Of these, 2,187 documents were identified through the scoping assessment and 2,455 documents were identified during searches for the evidence synthesis (see Appendix $C$ and Appendix $B$ respectively for the two search results). At the scoping assessment stage 2,127 documents were excluded as they did not meet the scoping assessment eligibility criteria (detailed in Appendix C) and 60 were carried forwards to the evidence synthesis screening. A further 258 academic documents were removed as they were duplicates, thus 2,228 documents underwent round one screening for eligibility. Appendix D provides further detail on excluded documents.

\section{Figure 4.1: Flow chart illustrating the process from identification through to selection of included documents}

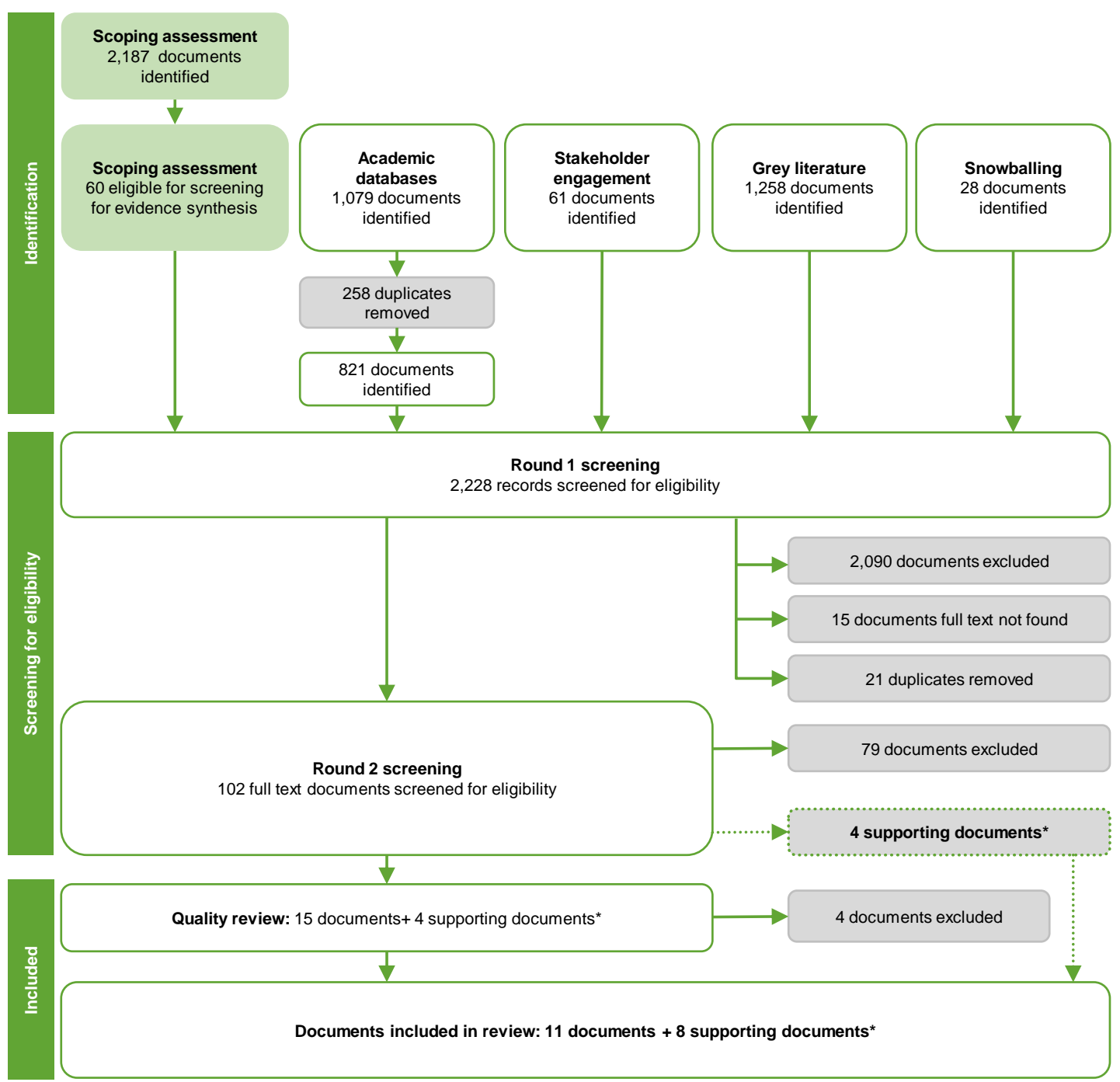

Note: Please see Figure 4.2 for additional detail on supporting documents. 
In total, 2,090 documents were excluded following round one screening as they did not meet the eligibility criteria. ${ }^{24}$ At this stage 21 duplicates were also removed, as well as 15 documents that were not available as full texts; 102 documents underwent a second round of screening, and a further 79 were excluded. Documents were excluded at this stage because they:

- did not detail findings that were clearly based on primary data (screening question 8): For example Tariq (2012) and Minervini (2002) were excluded because they did not indicate primary data was collected. Equally Kuittinen and Winter (2015) was excluded because it was an impact evaluation of the carbon footprint of transitional shelters and was based solely on secondary data

- did not adequately report on details of data collection (screening question 9): For example Rhyner (2014) and Flinn (2010) did not provide sufficient information to understand the source of the data (e.g. who were interviews undertaken with? how many interviews were undertaken?)

- did not sit within the required timeframes (screening question 10): Only one study was excluded on this basis (Tafti and Tomlinson, 2015), as it clearly states that 'The reconstruction of residential units started two years after the earthquake' (Tafti and Tomlinson, 2015, p. 175), and is outside the required 18-month period following a natural disaster. This document was also assessed as having limited details on the intervention and outcomes (screening question 11 and 12)

- did not sufficiently detail the intervention (screening question 11): Documents were excluded on this screening question for two reasons:

a) the studies did not sufficiently describe the intervention (e.g. the description available indicated the intervention would be classified as supporting shelter self-recovery). For example Hanley et al. (2014) is a multi-sector, multi-agency assessment of the Typhoon Haiyan response in the Philippines, of which the shelter component was the provision of 'shelter self-recovery kits'; however, the document did not contain sufficient information on the shelter intervention for analysis

b) the studies did not describe interventions that provided material, financial and/or technical assistance directly to households (e.g. the description available indicated the intervention would not be classified as supporting shelter self-recovery). For example García (2015) was excluded because the intervention provided cash support to landlords to improve their properties in order to house displaced families rent free for 12 months; thus this was categorized as a form of rental support. Eri and Fogden was excluded because the implementing agency 'constructed the structure of the house... before passing it over to the recipient who is then responsible for completing the remainder, including the walls to roof height, and positioning of doors and windows' (2013, p. 25); thus this was categorized as a form of core housing support

- did not sufficiently detail the outcomes of an intervention (screening question 12). For example Ganapati and Mukherji (2014) described the context and the intervention clearly, but did not report on outcomes or impacts.

The most common reason for exclusion was because the document did not sufficiently detail the intervention (screening question 11) or the outcomes (screening question 12); often documents were excluded for both these reasons (see Appendix D).

Then 19 documents were critically appraised using the 'quality appraisal template' (see Appendix E). Three documents were excluded at this stage as they were classified as very low quality with no or limited external validity. One further document was excluded because a subsequent report identified on the same programme presented contradictory findings; thus the data was not considered reliable (Anonymous, 2011). Following this process 11 studies (and eight supporting documents) were included in the evidence synthesis (see Figure 4.2 for an overview).

\footnotetext{
${ }^{24}$ Documents excluded from academic databases at this stage included those: describing humanitarian shelter and settlement interventions in high-income countries such as the United States of America (USA) and Japan (notably few were identified on New Zealand); proposing post-disaster shelter designs or tools; describing pre-disaster interventions or disaster impacts; documenting support to refugees in countries such as the UK, USA, Canada and Australia. Documents excluded from the grey literature websites included promotional or advocacy materials, job advertisements, guidance documents and 'how-to' guides, opinion pieces, training documents and research based exclusively on secondary data (e.g. literature reviews).
} 
Appendix D provides further detail of each of the documents that were excluded in the second round of screening or following the quality appraisal, including the four supporting documents that did not meet the inclusion/exclusion criteria but have been useful in providing additional contextual data.

\section{Figure 4.2: Summary of included documents and relationships with supporting documents}

\begin{tabular}{|c|c|c|c|}
\hline & Document & Title & Details of supporting documents \\
\hline 1 & Aysan, 2008 & $\begin{array}{l}\text { External Evaluation of the Swiss } \\
\text { Consortium's Cash for Repair and } \\
\text { Reconstruction Project in Sri Lanka } \\
2005-08\end{array}$ & $\begin{array}{l}\text { Aysan el al (2007)* } \\
\text { Supporting document is a mid-term } \\
\text { evaluation of the same programme. }\end{array}$ \\
\hline 2 & $\begin{array}{l}\text { Barakat and Zyck, } \\
2011\end{array}$ & $\begin{array}{l}\text { Housing reconstruction as } \\
\text { socioeconomic recovery and state } \\
\text { building: Evidence from Southern } \\
\text { Lebanon }\end{array}$ & $\begin{array}{l}\text { Barakat et al (2008)* } \\
\text { Supporting document is a longer, more } \\
\text { detailed research paper providing } \\
\text { additional information on the 'included' } \\
\text { academic paper. }\end{array}$ \\
\hline 3 & $\begin{array}{l}\text { CARE } \\
\text { International UK, } \\
2015\end{array}$ & $\begin{array}{l}\text { CARE Philippines: Typhoon Haiyan } \\
\text { Shelter Recovery Project Evaluation }\end{array}$ & No supporting documents \\
\hline 4 & $\begin{array}{l}\text { Catholic Relief } \\
\text { Services (CRS), } \\
2010\end{array}$ & $\begin{array}{l}\text { CRS Indonesia West Sumatra } \\
\text { Transitional Shelter Evaluation Report }\end{array}$ & $\begin{array}{l}\text { Aspin }(2010)^{*} \\
\text { Supporting document is a study that } \\
\text { happened in parallel and whose findings } \\
\text { were included to draw conclusions. } \\
\text { Supporting data extracted for CRS } \\
\text { programme only. }\end{array}$ \\
\hline 5 & $\begin{array}{l}\text { Corsellis and } \\
\text { Sweetnam, } 2014\end{array}$ & $\begin{array}{l}\text { Evaluation of One Room Shelter } \\
\text { Programme for the } 2011 \text { floods } \\
\text { response in South Sindh, Pakistan }\end{array}$ & No supporting documents \\
\hline 6 & Cukur et al., 2005 & $\begin{array}{l}\text { Returning Home - An Evaluation of } \\
\text { Sida's Integrated Area Programmes in } \\
\text { Bosnia and Herzegovina }\end{array}$ & $\begin{array}{l}\text { Bagić and Dedic (2005) } \\
\text { Supporting document presents the } \\
\text { study findings in more detail. }\end{array}$ \\
\hline 7 & DiPretoro, 2010 & $\begin{array}{l}\text { Cash for Shelter Program: Hurricane } \\
\text { Richard } 2010\end{array}$ & No supporting documents \\
\hline 8 & $\begin{array}{l}\text { Samuel Hall, } \\
2012\end{array}$ & $\begin{array}{l}\text { Evaluation of the UNHCR Shelter } \\
\text { Assistance Programme }\end{array}$ & $\begin{array}{l}\text { Loschmann et al. (2014) } \\
\text { Supporting document uses the data } \\
\text { collected from the 'included' document } \\
\text { but undertakes different analysis. } \\
\text { Ferretti and Ashmore (2010); Foley } \\
\text { (2005) } \\
\text { Supporting documents are earlier } \\
\text { evaluations of the same/similar } \\
\text { programme that did not sufficiently meet } \\
\text { the inclusion/exclusion criteria to be } \\
\text { included independently. }\end{array}$ \\
\hline 9 & Skat, 2009 & $\begin{array}{l}\text { IFRC Community Recovery and } \\
\text { Reconstruction Partnership (CRRP): } \\
\text { Evaluation Report }\end{array}$ & No supporting documents \\
\hline 10 & van Dijk, 2012 & $\begin{array}{l}\text { Impact assessment of a Participatory } \\
\text { Community Development Program in } \\
\text { Cucuta, Colombia }\end{array}$ & No supporting documents \\
\hline 11 & $\begin{array}{l}\text { van Leersum and } \\
\text { Arora, } 2011\end{array}$ & $\begin{array}{l}\text { Implementing seismic-resistant } \\
\text { technologies in post-earthquake } \\
\text { Pakistan: A process analysis of owner } \\
\text { driven reconstruction }\end{array}$ & $\begin{array}{l}\text { van Leersum (2009)* } \\
\text { Supporting document is a longer, more } \\
\text { detailed research paper providing } \\
\text { additional information on the 'included' } \\
\text { academic paper. }\end{array}$ \\
\hline
\end{tabular}

Note: The four supporting documents identified as $\left({ }^{*}\right)$ met the inclusion/exclusion criteria and were eligible for inclusion as standalone documents, thus data has been extracted to address the research questions. The remaining four supporting documents did not meet the inclusion/exclusion criteria and have been used as supporting documents to supplement contextual data on the intervention, population and setting only. 


\section{$4.2 \quad$ COMPARISION OF THE 11 INCLUDED STUDIES}

\section{When were the documents published?}

The research team searched for documents published since 1990; those eligible for inclusion in the evidence synthesis were all published between 2005 and 2015. See Figure 4.3 for additional detail.

\section{How were the documents identified?}

Two documents were identified through academic searches, six through grey literature searches and three through stakeholder engagement. Both of the documents identified through academic searches were found in the academic database Scopus (Barakat and Zyck, 2011; van Leersum and Arora, 2011). Five of the six grey literature documents were identified through searching the ALNAP Humanitarian Evaluation and Learning Portal. ${ }^{25}$ Just one document identified via searching grey literature websites was not available on ALNAP (Corsellis and Sweetnam, 2014). Of the three documents identified through stakeholder engagement, one was not publicly available (van Dijk, 2012) while two were hosted on websites not included in the grey literature searches (CARE International UK, 2015; DiPretoro, 2010). ${ }^{26}$ See Figure 4.3 for additional detail.

\section{What was the study design?}

Eight studies were identified as mixed methods (triangulation design). ${ }^{27}$ The remaining three were qualitative studies (qualitative descriptive). ${ }^{28}$ No studies included in the evidence synthesis were purely quantitative. Only two of the authors explicitly stated their study design (Barakat and Zyck, 2011; van Dijk, 2012); thus study design was assessed largely through researcher interpretation. Finally, across all of the documents no or very limited justification was provided for selecting the study design that was applied. See Figure 4.3 for additional detail.

\section{How was data collected and analysed in the studies?}

The qualitative documents collected data primarily through interviews with affected households and key informants (implementing agency, government officials, partners etc.). All three qualitative studies reported augmenting the interview data through observations and focus groups/workshops (Aysan, 2008; Corsellis and Sweetnam, 2014; Skat, 2009). See Figure 4.3 for additional detail.

All eight of the mixed methods studies used a household survey to collect quantitative data. Three of these included control groups. This was triangulated with data collected through qualitative research tools: interviews, focus groups/workshops and field observations. One document also completed a survey with community leaders (Samuel Hall, 2012). See Box 'Sampling strategies in household surveys' (p. 22) for additional information on sampling strategies adopted by the authors of the included documents.

Within the mixed methods studies half employed statistical techniques such as 'difference in differences' or 'between group' analyses in order to establish a causal link between the intervention and its effects (Cukur, Magnusson, Molander and Skotte, 2005; Samuel Hall,

\footnotetext{
${ }^{25}$ www.alnap.org

${ }^{26}$ www.reliefweb.int and www.cashlearning.org

${ }^{27}$ As stated by the authors themselves or defined by the researchers using the definitions in Pluye et al. (2011, p.7). Triangulation design is defined as: 'The qualitative and quantitative components are concomitant. The purpose is to examine the same phenomenon by interpreting qualitative and quantitative results (bringing data analysis together at the interpretation stage), or by integrating qualitative and quantitative datasets (e.g. data on same cases), or by transforming data (e.g. quantization of qualitative data)'.

${ }^{28}$ As stated by the authors themselves or defined by the researchers using the definitions in Pluye et al. (2011, p.3). Qualitative descriptive is defined as: 'There is no specific methodology, but a qualitative data collection and analysis, e.g. in-depth interviews or focus groups, and hybrid thematic analysis (inductive and deductive).'
} 
2012; van Dijk, 2012; van Leersum and Arora, 2011). The remaining studies investigated trends in the quantitative data through beneficiary interviews or focus groups. For example, one study asked interviewees 'whether they thought the changes in their situation were fully, partially or not due to the shelter assistance they had received' (CARE International UK, 2015, pp. 26-27).

\section{Sampling strategies in household surveys}

The purpose of interviewing a sample of households is to draw conclusions about the total population without having to interview every household. There are two types of sample: probability and non-probability. Using a probability sample enables statistical generalizations to be made about the wider population. Analytical generalizations can be made from non-probability samples, often through triangulation with qualitative data, although quantitative data can also be used. It is therefore important to consider if the sampling strategies adopted did in fact enable the studies to draw conclusions about the total population, and if the sampling method was appropriate for the purpose of the research.

Six studies use a combination of probability and non-probability methods in multi-stage sampling strategies. They divided the total population into a variety of geographical areas and population groups (using stratified, clustered or judgemental sampling) before selecting households for interview (see Figure below). One study (DiPretoro, 2010) simply randomly selected 59 households for interview from a list of all the 69 households that had received assistance (simple random sampling). One study surveyed every one of the 178 households that had received assistance and compared the results with a control group (van Dijk, 2012).

Only one study (DiPretoro, 2010) explicitly describes how the survey findings can be viewed as statistically representative of the total population in terms of the confidence interval and margin of error. ${ }^{29}$ Cukur et al. (2005) does not state the confidence interval or margin of error of the survey data, and it does not accurately state the total population at the time of the survey. However, villages and households were selected at random, from within clearly defined groups of the larger population. The findings from the survey were also compared with a control group.

The majority of the studies do not discuss whether statistical or analytical generalizations can be made from the survey data, and may have introduced biases when using non-probabilistic sampling in the selection of households and villages (Barakat and Zyck, 2011; CARE International UK, 2015; CRS, 2010) or districts and provinces (Samuel Hall, 2012; van Leersum and Arora, 2011). The research team recommends that future programme evaluations make more explicit the purpose of the study (either statistical or analytical generalizations) and the sampling strategies adopted, in order to increase the quality of future primary research.

\begin{tabular}{|c|c|c|c|c|c|}
\hline & \multirow[t]{2}{*}{ Sample size } & \multirow{2}{*}{$\begin{array}{l}\text { Total } \\
\text { assisted } \\
\text { population }\end{array}$} & \multicolumn{3}{|c|}{ Multi-stage sampling strategy for household survey } \\
\hline & & & $\begin{array}{l}\text { Stage } 1 \\
\text { Selection of } \\
\text { larger unit e.g. } \\
\text { province }\end{array}$ & $\begin{array}{l}\text { Stage } 2 \\
\text { Selection of } \\
\text { villages }\end{array}$ & $\begin{array}{l}\text { Stage } 3 \\
\text { Selection of } \\
\text { households }\end{array}$ \\
\hline $\begin{array}{l}\text { Barakat and } \\
\text { Zyck, } 2011\end{array}$ & $\begin{array}{l}379 \text { (phase 1) } \\
120 \text { (phase 2) }\end{array}$ & 80,000 & $\begin{array}{l}\text { Selection of } \\
\text { districts - } \\
\text { unclear }\end{array}$ & $\begin{array}{l}\text { Judgemental } \\
\text { (phase 1) } \\
\text { Systematic } \\
\text { (phase 2) }\end{array}$ & Unclear \\
\hline $\begin{array}{l}\text { CARE } \\
\text { International } \\
\text { UK, } 2015\end{array}$ & 533 & 15,859 & $\mathrm{n} / \mathrm{a}$ & Judgemental & $\begin{array}{l}\text { Simple random } \\
\text { sampling }\end{array}$ \\
\hline $\begin{array}{l}\text { Catholic Relief } \\
\text { Services, } \\
2010\end{array}$ & $\begin{array}{l}208 \text { (mid-term) } \\
256 \text { (final) }\end{array}$ & $\begin{array}{l}11,324 \\
\text { (total) }\end{array}$ & $\mathrm{n} / \mathrm{a}$ & $\begin{array}{l}\text { n/a (mid-term) } \\
\text { Cluster (final) }{ }^{30}\end{array}$ & $\begin{array}{l}\text { Simple random } \\
\text { sampling (mid- } \\
\text { term) } \\
\text { Simple random } \\
\text { sampling (final) }\end{array}$ \\
\hline
\end{tabular}

Continued on next page

\footnotetext{
29 'The confidence level and margin of error can be interpreted in the following way: one can be confident with 95 percent certainty that the true value for the entire population of any indicator falls within the range of the sample estimate $+/-5$ percent. For example, if the survey would find that 80 percent of respondents understood how to use the voucher; one could be confident with 95 percent certainty that the true value for the entire population of this indicator would fall within 75 percent ( 80 percent -5 percent) and 85 percent ( 80 percent +5 percent).' (DiPretoro, 2010, p. 3).

${ }^{30}$ The study describes the methodology of the second survey as cluster sampling, although it does not describe the methodology, so it may have been judgemental.
} 


\begin{tabular}{|c|c|c|c|c|c|}
\hline & \multirow[t]{2}{*}{ Sample size } & \multirow{2}{*}{$\begin{array}{l}\text { Total } \\
\text { assisted } \\
\text { population }\end{array}$} & \multicolumn{3}{|c|}{ Multi-stage sampling strategy for household survey } \\
\hline & & & $\begin{array}{l}\text { Stage } 1 \\
\text { Selection of } \\
\text { larger unit e.g. } \\
\text { province }\end{array}$ & $\begin{array}{l}\text { Stage } 2 \\
\text { Selection of } \\
\text { villages }\end{array}$ & $\begin{array}{l}\text { Stage } 3 \\
\text { Selection of } \\
\text { households }\end{array}$ \\
\hline $\begin{array}{l}\text { Cukur et al. } \\
2005\end{array}$ & $\begin{array}{l}2,000 \\
\text { (intervention } \\
\text { group) } \\
1,000 \text { (control } \\
\text { group) }\end{array}$ & $\begin{array}{l}11,000 \\
\text { (approx.) }\end{array}$ & $\begin{array}{l}\text { Stratified - } \\
\text { implementing } \\
\text { organization } \\
\text { (intervention } \\
\text { group) }\end{array}$ & $\begin{array}{l}\text { Cluster } \\
\text { (intervention } \\
\text { group) } \\
\text { Cluster (control } \\
\text { group) }\end{array}$ & $\begin{array}{l}\text { Simple random } \\
\text { sampling } \\
\text { (intervention } \\
\text { group) } \\
\text { Random walk } \\
\text { sampling } \\
\text { (control group) }\end{array}$ \\
\hline $\begin{array}{l}\text { DiPretoro, } \\
2010\end{array}$ & 59 & 69 & $\mathrm{n} / \mathrm{a}$ & $\mathrm{n} / \mathrm{a}$ & $\begin{array}{l}\text { Simple random } \\
\text { sampling }\end{array}$ \\
\hline $\begin{array}{l}\text { Samuel Hall, } \\
2012\end{array}$ & 4,488 & $\begin{array}{l}+220,000 \\
\text { (approx.) }\end{array}$ & $\begin{array}{l}\text { Selection of } \\
\text { districts - } \\
\text { unclear } \\
\text { Selection of } \\
\text { provinces - had } \\
\text { received } \\
\text { assistance }\end{array}$ & Cluster & $\begin{array}{l}\text { Simple random } \\
\text { sampling } \\
\text { (includes } \\
\text { beneficiaries, } \\
\text { beneficiaries of } \\
\text { other } \\
\text { interventions, } \\
\text { and non- } \\
\text { beneficiaries) }\end{array}$ \\
\hline van Dijk, 2012 & $\begin{array}{l}178 \\
\text { (intervention } \\
\text { group) } \\
139 \text { (control } \\
\text { group) }\end{array}$ & 178 & $\mathrm{n} / \mathrm{a}$ & $\begin{array}{l}\mathrm{n} / \mathrm{a} \text { (intervention } \\
\text { group) } \\
\text { Comparable with } \\
\text { intervention } \\
\text { group (control } \\
\text { group) }\end{array}$ & $\begin{array}{l}\text { Complete } \\
\text { enumeration } \\
\text { (intervention } \\
\text { group) } \\
\text { Simple random } \\
\text { sampling } \\
\text { (control group) }\end{array}$ \\
\hline $\begin{array}{l}\text { van Leersum } \\
\text { and Arora } \\
2011\end{array}$ & 141 & $\begin{array}{l}400,000 \text { to } \\
600,000 \\
\text { (approx.) }\end{array}$ & Unclear & $\begin{array}{l}\text { Stratified - level } \\
\text { of damage and } \\
\text { accessibility }\end{array}$ & $\begin{array}{l}\text { Random walk } \\
\text { sampling }\end{array}$ \\
\hline
\end{tabular}

\section{What type of publication were the documents?}

Eight of the 11 studies were evaluations and one was an 'impact assessment' (van Dijk, 2012). The remaining two documents were academic peer-reviewed journal articles: Barakat and Zyck (2011) summarises the findings from a large research study commissioned by the Norwegian Refugee Council (Barakat et al., 2008), while van Leersum and Arora (2011) summarises findings from the lead author's Master's thesis (van Leersum, 2009).

\section{When was the research undertaken?}

In seven of the studies research was undertaken during programme implementation or directly following completion (Barakat and Zyck, 2011; CARE International UK, 2015; CRS, 2010; Cukur et al., 2005; DiPretoro, 2010; Samuel Hall, 2012; Skat, 2009). In two interventions, the evaluation/research was undertaken approximately one year (Aysan, 2008) and two years (van Dijk, 2012) following the completion of the intervention. Two of the studies had insufficient data to assess the relationship between the completion of the implementation and when the evaluation took place (Corsellis and Sweetnam, 2014; van Leersum and Arora, 2011). See Figure 5.5.

\section{What was the quality of the documents?}

The principles of the 'quality appraisal template' were based on the following key factors underpinning quality (Centre for Reviews and Dissemination, 2008; Posthumus et al., 2013):

- appropriateness of study design to the research objective (e.g. the relevance)

- risk of bias (e.g. the systematic deviations from the true underlying effect brought about by poor study design or conduct in the collection, analysis, interpretation or publication). 
Assessing the appropriateness of the study design to the research objective was challenging because only two of the documents stated the study design (Barakat and Zyck, 2011; van Dijk, 2012), a wide variety of data collection methods were used and limited description of data and methodology were typically given in the documents. Furthermore a number of the studies suffered from gaps in information and some were missing appendixes or annexes (DiPretoro, 2010; Skat, 2009) ${ }^{31}$ However, all the documents state their research aims, objectives and/or research questions and provide some contextual background. Most studies also include some details on the methods of data collection, but very few set out clearly and explicitly how data had been recorded or analysed. In terms of the risk of bias:

- staff employed by the implementing agency (or its umbrella organization) undertook four of the studies and four were funded directly by the implementing agency or donor organization only one of the 11 studies was assessed as an 'independent study' (i.e. it was not directly or indirectly funded by the donor or implementing agency) - in this instance the author was affiliated with a university (van Leersum 2011, Eindhoven University of Technology) none of the documents had explicit statements regarding conflict of interest

- very few studies clearly set out or detail any ethical considerations one noted that consent was gained from communities before undertaking fieldwork (CARE International UK, 2015); another developed consent forms for data collection (Corsellis and Sweetnam, 2014); and one noted that it "considered the "do no harm" approach' (Skat, 2009, p. 15)

- with the exceptions of CRS (2010) and Corsellis (2014), the documents do not clearly detail the limitations of the research

three documents provide information on limitations relating to the data collection (Samuel Hall, 2012; Skat, 2009; van Leersum, 2009)

- all documents containing household survey information detail the participant selection procedures (sampling) and provide information on sample characteristics such as sample size and location (see Box 'Requirements of robust impact evaluations' for further information)

three of the documents also include a control group only one document details the statistical accuracy of the household survey findings, and provides details on the confidence interval and margin of error (DiPretoro, 2010) overall the qualitative documents provide less detail on how participants were selected for interview.

- Thus, while there is some variation, many of the included studies can be criticized in terms of the robustness of the data collection, analysis or detailed reporting that introduce a significant risk of bias. In addition, the documents do not contain sufficient information on the methodology for the research team to confidently and accurately attribute a quality rating. ${ }^{32}$ Further information on the 'quality appraisal template' used to assess the quality of the documents can be found in Appendix E. See Figure 4.3 for the summary of the quality appraisal for each study and Box below for a brief description of the minimal requirements of a robust impact evaluation.

\section{Requirements of robust impact evaluations}

Robust impact evaluations in any sector require:

- a well-defined theory of change, supported by good formative research to understand the context and background of the initiative

- explicit or implicit counterfactuals that help measure what would have happened in the absence of the intervention

- qualitative and quantitative baseline and end line data

- a well-defined set of beneficiaries and outcome variables

- identification methods that use this data to quantifiably measure changes in outcomes that may have occurred due to the intervention; and the ability to use evidence in other situations and contexts.

Source: White, H, 2011. Conducting theory based impact evaluations; referenced in Puri et al. (2014).

\footnotetext{
${ }^{31}$ In both instances authors were contacted. In one case the author did not respond, while in the second the authors were not able to provide the missing documentation because it is not in the public domain.

${ }^{32}$ The researchers answered 'partially' or 'unclear' to a significant number of the questions asked by the 'quality appraisal template' (see Appendix E).
} 
Figure 4.3: Summary of included documents: documentation type (listed alphabetically by author)

\begin{tabular}{|c|c|c|c|c|c|}
\hline Document & $\begin{array}{l}\text { How } \\
\text { identified? }\end{array}$ & $\begin{array}{l}\text { Study } \\
\text { design? }\end{array}$ & $\begin{array}{l}\text { Quantitative } \\
\text { data } \\
\text { collection } \\
\text { methods? }\end{array}$ & $\begin{array}{l}\text { Qualitative } \\
\text { data } \\
\text { collection } \\
\text { methods? }\end{array}$ & Summary of quality appraisal \\
\hline Aysan, 2008 & $\begin{array}{l}\text { Grey } \\
\text { literature }\end{array}$ & $\begin{array}{l}\text { Qualitative: } \\
\text { Descriptive } \\
\text { (researcher } \\
\text { interpretation) }\end{array}$ & & $\begin{array}{l}\text { Interviews } \\
\text { (beneficiaries, } \\
\text { stakeholders, } \\
\text { non- } \\
\text { beneficiaries) } \\
\text { Focus groups } \\
\text { (beneficiaries) } \\
\text { Observation }\end{array}$ & $\begin{array}{l}\text { Donor-funded final evaluation completed by } \\
\text { independent researchers (incorporating findings from } \\
\text { mid-term evaluation - Aysan et al 2007). Research aims } \\
\text { and approach clearly stated but not justified (authors } \\
\text { noted they had limited time in the field). Data collection } \\
\text { methods are partly described. Data analysis methods, } \\
\text { limitations of the study, ethical issues and the role of the } \\
\text { researcher are not discussed. Detailed findings are } \\
\text { presented in context allowing wider applicability of } \\
\text { findings. }\end{array}$ \\
\hline $\begin{array}{l}\text { Barakat and } \\
\text { Zyck, } 2011\end{array}$ & Academic & $\begin{array}{l}\text { Mixed } \\
\text { methods: } \\
\text { Triangulation } \\
\text { (author stated } \\
\text { as 'composite } \\
\text { approach') }\end{array}$ & $\begin{array}{l}\text { Survey } \\
\text { (household) }\end{array}$ & $\begin{array}{l}\text { Interviews } \\
\text { (beneficiaries, } \\
\text { stakeholders) }\end{array}$ & $\begin{array}{l}\text { Peer-reviewed journal article based on a large } \\
\text { research study commissioned by the Norwegian } \\
\text { Refugee Council (Barakat et al., 2008). Research aims } \\
\text { and approach clearly described and justified. Data } \\
\text { collection methods are described and appropriate but } \\
\text { data collection tools (surveys etc.) not provided. } \\
\text { Findings clearly presented, within sufficient context, and } \\
\text { their wider applicability discussed. Very limited } \\
\text { discussion of data analysis methods, limitations of the } \\
\text { study, ethical implications or the role of the researcher. }\end{array}$ \\
\hline $\begin{array}{l}\text { CARE } \\
\text { International } \\
\text { UK, } 2015\end{array}$ & Stakeholder & $\begin{array}{l}\text { Mixed } \\
\text { methods: } \\
\text { Triangulation } \\
\text { (researcher } \\
\text { interpretation) }\end{array}$ & $\begin{array}{l}\text { Survey } \\
\text { (household) }\end{array}$ & $\begin{array}{l}\text { Interviews } \\
\text { (stakeholders) } \\
\text { Focus groups } \\
\text { (beneficiaries } \\
\text { and non- } \\
\text { beneficiaries) } \\
\text { Observation }\end{array}$ & $\begin{array}{l}\text { Agency-funded final evaluation completed by } \\
\text { agency staff. Research objectives, framework and } \\
\text { questions clearly described. Data collection methods } \\
\text { listed and appropriate. Data collection methods are } \\
\text { described and appropriate and data collection tools } \\
\text { (interview questions) are provided; however, lack of } \\
\text { clarity regarding exact numbers/locations of households } \\
\text { surveyed and limitations to survey questions noted. } \\
\text { Detail provided on selection of key informants but less } \\
\text { clarity on focus group participants. Limited discussion of } \\
\text { study limitations and the role of the researcher. No } \\
\text { discussion of ethics or data analysis method. Detailed } \\
\text { findings are clearly presented under each data source. } \\
\text { Authors make recommendations for applying lessons in } \\
\text { other contexts. }\end{array}$ \\
\hline $\begin{array}{l}\text { Catholic } \\
\text { Relief } \\
\text { Services, } \\
2010\end{array}$ & $\begin{array}{l}\text { Grey } \\
\text { literature }\end{array}$ & $\begin{array}{l}\text { Mixed } \\
\text { methods: } \\
\text { Triangulation } \\
\text { (researcher } \\
\text { interpretation) }\end{array}$ & $\begin{array}{l}\text { Survey } \\
\text { (household) }\end{array}$ & $\begin{array}{l}\text { Interviews / } \\
\text { Focus groups } \\
\text { (beneficiaries, } \\
\text { stakeholders, } \\
\text { non- } \\
\text { beneficiaries) } \\
\text { Shelter } \\
\text { completion } \\
\text { checklist } \\
\text { Observation }\end{array}$ & $\begin{array}{l}\text { Agency-funded final evaluation completed by } \\
\text { agency staff. Report combining findings from previous } \\
\text { mid-term evaluation. Research aims and evaluation } \\
\text { framework clearly stated and followed. Detailed } \\
\text { discussion of methodology and limitations although data } \\
\text { collection tools (surveys/checklists) not included. } \\
\text { Several qualitative and quantitative data collection } \\
\text { methods used and combined to provide rich findings. } \\
\text { Programme and context are described in sufficient detail } \\
\text { for meaningful applicability of the findings to other } \\
\text { contexts. Limited detail on the recruitment strategy or } \\
\text { the researchers influence. }\end{array}$ \\
\hline $\begin{array}{l}\text { Corsellis } \\
\text { and } \\
\text { Sweetnam, } \\
2014\end{array}$ & $\begin{array}{l}\text { Grey } \\
\text { literature }\end{array}$ & $\begin{array}{l}\text { Qualitative: } \\
\text { Qualitative } \\
\text { description } \\
\text { (researcher } \\
\text { interpretation) } \\
33\end{array}$ & & $\begin{array}{l}\text { Interviews } \\
\text { (stakeholders) } \\
\text { Focus groups } \\
\text { (community) } \\
\text { Observation }\end{array}$ & $\begin{array}{l}\text { Agency-funded final evaluation completed by } \\
\text { independent researchers. Research aims detailed, } \\
\text { and research methods outlined but data collection tools } \\
\text { not included (e.g. an interview template). Findings are } \\
\text { integrated with analysis/discussion. Insufficient detail on } \\
\text { the recruitment strategy or the researchers influence. } \\
\text { Limited detail on wider applicability of findings but } \\
\text { sufficient context provided that findings can be } \\
\text { transferred. }\end{array}$ \\
\hline
\end{tabular}

${ }^{33}$ Corsellis and Sweetnam (2014) state that the study includes 'case studies'. These are in-depth interviews with beneficiaries written up as 'case study' boxes, rather than 'case studies' in a research sense. Yin (2014) defines case study research as 'empirical inquiry that investigates a contemporary phenomenon (the 'case') in depth and within its real-world context, especially when the boundaries between phenomenon and context may not be clearly evident' (Yin, 2014, p. 16). This should include triangulation of findings using multiple sources of evidence, establishing a clear chain of evidence linking data, analysis and findings, and having the draft case study (or parts of it) reviewed by key informants (Yin, 2014, p. 47). 


\begin{tabular}{|c|c|c|c|c|c|}
\hline Document & $\begin{array}{l}\text { How } \\
\text { identified? }\end{array}$ & $\begin{array}{l}\text { Study } \\
\text { design? }\end{array}$ & $\begin{array}{l}\text { Quantitative } \\
\text { data } \\
\text { collection } \\
\text { methods? }\end{array}$ & $\begin{array}{l}\text { Qualitative } \\
\text { data } \\
\text { collection } \\
\text { methods? }\end{array}$ & Summary of quality appraisal \\
\hline $\begin{array}{l}\text { Cukur et al., } \\
2005\end{array}$ & $\begin{array}{l}\text { Grey } \\
\text { literature }\end{array}$ & $\begin{array}{l}\text { Mixed } \\
\text { methods: } \\
\text { Triangulation } \\
\text { (researcher } \\
\text { interpretation) }\end{array}$ & $\begin{array}{l}\text { Survey } \\
\text { (household) }\end{array}$ & $\begin{array}{l}\text { Interviews } \\
\text { (beneficiaries, } \\
\text { stakeholders) } \\
\text { Observation? }\end{array}$ & $\begin{array}{l}\text { Donor-funded final evaluation completed by } \\
\text { independent researchers comprising three different } \\
\text { study types (anthropological case studies, survey, case } \\
\text { study). Each study draws its own conclusions and } \\
\text { recommendations; final analysis compares and draws } \\
\text { on all three. Research aims, evaluation framework and } \\
\text { approach clearly described. Data collection } \\
\text { methodologies partially described and very limited } \\
\text { description of analysis. Detailed findings presented and } \\
\text { discussed in relation to the evaluation framework. } \\
\text { Significant context provided and lessons learned for } \\
\text { future programmes noted. Limited detail on limitations of } \\
\text { the studies and no discussion of ethical considerations } \\
\text { or the role of the researcher. The survey describes the } \\
\text { sampling strategy and questions asked; no detail is } \\
\text { given on non-respondents. Qualitative studies do not } \\
\text { detail how respondents were selected. }\end{array}$ \\
\hline $\begin{array}{l}\text { DiPretoro, } \\
2010\end{array}$ & Stakeholder & $\begin{array}{l}\text { Mixed } \\
\text { methods: } \\
\text { Triangulation } \\
\text { design } \\
\text { (researcher } \\
\text { interpretation) }\end{array}$ & $\begin{array}{l}\text { Survey } \\
\text { (household) }\end{array}$ & $\begin{array}{l}\text { Interviews } \\
\text { (stakeholders) } \\
\text { Focus groups } \\
\text { (community } \\
\text { members) } \\
\text { Observation }\end{array}$ & $\begin{array}{l}\text { Donor-funded final evaluation completed by } \\
\text { researcher within organizations. Research aims and } \\
\text { approach clearly stated, data collection methods } \\
\text { described in annexes, sampling methods and tools } \\
\text { provided as annexes; however, annexes not included in } \\
\text { report (authors contacted and annexes requested). No } \\
\text { discussion of limitations, ethical issues and the role of } \\
\text { the researcher. Data analysis methods not described. } \\
\text { Detailed findings described in context and explicit } \\
\text { discussion of lessons learned/transferability to other } \\
\text { contexts. }\end{array}$ \\
\hline $\begin{array}{l}\text { Samuel Hall, } \\
2012\end{array}$ & $\begin{array}{l}\text { Grey } \\
\text { literature }\end{array}$ & $\begin{array}{l}\text { Mixed } \\
\text { methods: } \\
\text { Triangulation } \\
\text { (researcher } \\
\text { interpretation) }\end{array}$ & $\begin{array}{l}\begin{array}{l}\text { Survey } \\
\text { (household) }\end{array} \\
\text { Survey } \\
\text { (community } \\
\text { leaders) }\end{array}$ & $\begin{array}{l}\text { Interviews } \\
\text { (stakeholders) } \\
\text { Focus group } \\
\text { discussions } \\
\text { (?) } \\
\text { Observation }\end{array}$ & $\begin{array}{l}\text { Agency-funded mid-term evaluation completed by } \\
\text { independent researchers. Research aims and } \\
\text { approach and data collection methods stated with a } \\
\text { good level of detail; however; list of survey questions } \\
\text { not noted. Data analysis methods are partially } \\
\text { discussed and limitations of the study noted. Ethical } \\
\text { issues and the role of the researcher not discussed. } \\
\text { Detailed findings are presented in context allowing wider } \\
\text { applicability of findings, furthermore the authors review } \\
\text { and expand the programmes 'guiding principles', } \\
\text { building on their conclusions. }\end{array}$ \\
\hline Skat, 2009 & $\begin{array}{l}\text { Grey } \\
\text { literature }\end{array}$ & $\begin{array}{l}\text { Qualitative: } \\
\text { Descriptive } \\
\text { (researcher } \\
\text { interpretation) }\end{array}$ & & $\begin{array}{l}\text { Interviews } \\
\text { (stakeholders, } \\
\text { beneficiaries } \\
\text { and non- } \\
\text { beneficiaries) } \\
\text { Workshops } \\
\text { (Community) } \\
\text { Observation }\end{array}$ & $\begin{array}{l}\text { Agency-funded final evaluation completed by } \\
\text { independent researchers. Research aims and } \\
\text { approach clearly stated. Data collection methods } \\
\text { described and tools provided as annexes; however, } \\
\text { annexes not included in report (authors contacted and } \\
\text { annexes requested). Partial discussion of limitations, } \\
\text { ethical issues and the role of the researcher. Data } \\
\text { analysis methods not described. Detailed findings } \\
\text { described in context and recommendations for future } \\
\text { programmes identified. }\end{array}$ \\
\hline $\begin{array}{l}\text { van Dijk, } \\
2012\end{array}$ & Stakeholder & $\begin{array}{l}\text { Mixed } \\
\text { methods: } \\
\text { Triangulation } \\
\text { design } \\
\text { (author } \\
\text { stated) }\end{array}$ & $\begin{array}{l}\text { Survey } \\
\text { (household) }\end{array}$ & $\begin{array}{l}\text { Interviews } \\
\text { (beneficiaries) }\end{array}$ & $\begin{array}{l}\text { Agency-funded impact assessment completed by } \\
\text { researcher within organization. Research aims and } \\
\text { questions clearly stated. Explicit details of research } \\
\text { approach, data collection and analysis. Limitations and } \\
\text { ethical considerations not discussed; also no analysis or } \\
\text { detail on how findings may be transferable to other } \\
\text { contexts. However, sufficient context provided to enable } \\
\text { wider applicability of findings. }\end{array}$ \\
\hline $\begin{array}{l}\text { van } \\
\text { Leersum } \\
\text { and Arora } \\
2011\end{array}$ & Academic & $\begin{array}{l}\text { Mixed } \\
\text { methods: } \\
\text { Triangulation } \\
\text { (researcher } \\
\text { interpretation) }\end{array}$ & $\begin{array}{l}\text { Survey } \\
\text { (household) }\end{array}$ & $\begin{array}{l}\text { Interviews } \\
\text { (beneficiaries, } \\
\text { stakeholders) } \\
\text { Focus groups } \\
\text { (community) }\end{array}$ & $\begin{array}{l}\text { Peer-reviewed journal article based on independent } \\
\text { research. Research questions and approach clearly } \\
\text { described. Data sources briefly described and } \\
\text { appropriate but tools not included. Data analysis } \\
\text { methods not described and unclear if all data is } \\
\text { reported. Sampling strategy described but no detail on } \\
\text { survey questions, power calculations or response rate. } \\
\text { Partial detail provided on selection of key informants. No } \\
\text { discussion of limitations of the study, ethical issues or } \\
\text { the role of the researcher. Detailed findings are } \\
\text { presented with sufficient context and discussion of their } \\
\text { wider implication to enable wider applicability of } \\
\text { findings. }\end{array}$ \\
\hline
\end{tabular}




\begin{tabular}{|c|c|c|c|c|c|}
\hline Document & $\begin{array}{l}\text { How } \\
\text { identified? }\end{array}$ & $\begin{array}{l}\text { Study } \\
\text { design? }\end{array}$ & $\begin{array}{l}\text { Quantitative } \\
\text { data } \\
\text { collection } \\
\text { methods? }\end{array}$ & $\begin{array}{l}\text { Qualitative } \\
\text { data } \\
\text { collection } \\
\text { methods? }\end{array}$ & Summary of quality appraisal \\
\hline \multicolumn{6}{|c|}{ Supporting documents } \\
\hline Aspin, 2010 & Snowball & $\begin{array}{l}\text { Qualitative: } \\
\text { Descriptive } \\
\text { (researcher } \\
\text { interpretation) } \\
\text { Author stated: } \\
\text { 'mixed } \\
\text { qualitative } \\
\text { method' }\end{array}$ & & $\begin{array}{l}\text { Interviews } \\
\text { (CRS } \\
\text { stakeholders), } \\
\text { Workshop } \\
\text { (stakeholders) }\end{array}$ & $\begin{array}{l}\text { Inter-agency funded impact assessment completed } \\
\text { by independent researcher. Research aims clearly } \\
\text { stated. Research approach not justified. Data collection } \\
\text { methods clearly described and details provided as } \\
\text { annexes. Detailed findings presented in context and } \\
\text { recommendations made for future responses. Methods } \\
\text { of data analysis, limitations, ethical issues and the role } \\
\text { of the researcher not discussed. }\end{array}$ \\
\hline $\begin{array}{l}\text { Aysan el al, } \\
2007\end{array}$ & $\begin{array}{l}\text { Grey } \\
\text { literature }\end{array}$ & $\begin{array}{l}\text { Qualitative: } \\
\text { Descriptive } \\
\text { (researcher } \\
\text { interpretation) }\end{array}$ & & $\begin{array}{l}\text { Interviews } \\
\text { (beneficiaries, } \\
\text { stakeholders, } \\
\text { non- } \\
\text { beneficiaries) } \\
\text { Focus groups } \\
\text { (beneficiaries), } \\
\text { Observation }\end{array}$ & $\begin{array}{l}\text { Donor-funded mid-term evaluation completed by } \\
\text { independent researchers. Research questions clearly } \\
\text { stated. Research approach not justified. Data collection } \\
\text { methods described and tools/lists of interviewees } \\
\text { included as annexes. Detailed findings presented in } \\
\text { context enabling wider applicability of findings. Data } \\
\text { analysis methods not described. Limitations, ethical } \\
\text { issues and the role of the researcher not discussed. }\end{array}$ \\
\hline $\begin{array}{l}\text { Barakat et } \\
\text { al., } 2008\end{array}$ & $\begin{array}{l}\text { Grey } \\
\text { literature }\end{array}$ & $\begin{array}{l}\text { Mixed } \\
\text { methods: } \\
\text { Triangulation } \\
\text { (author } \\
\text { stated) }\end{array}$ & $\begin{array}{l}\text { Survey } \\
\text { (household) }\end{array}$ & $\begin{array}{l}\text { Interviews } \\
\text { (beneficiaries) } \\
\text { Interviews } \\
\text { (stakeholders) }\end{array}$ & $\begin{array}{l}\text { Norwegian Refugee Council-funded study } \\
\text { completed by independent researchers. Research } \\
\text { aims and approach clearly stated and justified. Data } \\
\text { collection methods and tools clearly described. Partial } \\
\text { discussion of data analysis methods, limitations, ethical } \\
\text { issues and the role of the researcher. Detailed } \\
\text { description of both context and findings allowing wider } \\
\text { applicability of findings. }\end{array}$ \\
\hline $\begin{array}{l}\text { van } \\
\text { Leersum, } \\
2009\end{array}$ & Stakeholder & $\begin{array}{l}\text { Mixed } \\
\text { methods: } \\
\text { Triangulation } \\
\text { (researcher } \\
\text { interpretation) }\end{array}$ & $\begin{array}{l}\text { Survey } \\
\text { (household) }\end{array}$ & $\begin{array}{l}\text { Interviews } \\
\text { (beneficiaries, } \\
\text { stakeholders) } \\
\text { Focus groups } \\
\text { (community) }\end{array}$ & $\begin{array}{l}\text { Master's thesis based on independent research. } \\
\text { Research questions and data sources described and } \\
\text { tools included. Data analysis methods not described } \\
\text { and unclear if all data is reported because findings are } \\
\text { integrated into analysis. Sampling strategy described } \\
\text { but no detail on power calculations or response rate. } \\
\text { Detail provided on selection of key informants. Brief } \\
\text { discussion of limitations of the data collection but no } \\
\text { information on ethical issues or the role of the } \\
\text { researcher. Detailed findings are presented with } \\
\text { sufficient context and wider implication. }\end{array}$ \\
\hline
\end{tabular}


11 studies (and eight supporting documents) are included in the evidence synthesis; the interventions are as follows.

Aysan, 2008: Following the 2004 Indian Ocean earthquake and tsunami, the Swiss Consortium ${ }^{34}$ acted as both donor and implementing agency in providing conditional cash grants and technical assistance (limited site supervision) to 10,629 households in Sri Lanka to repair or rebuild their homes. Through a memorandum of understanding the consortium worked with the local government to deliver the project. Houses were assessed as 'partially damaged' or 'fully damaged' and a different amount of funding was given to each group: for the former, payment was made in two instalments and for the latter in four instalments directly to household bank accounts. Payment of the next instalment was linked to inspection of building quality and approval by the technical programme staff to build to a number of standard designs. A second phase of the programme provided additional 'top-up' grants. This intervention directly supported the delivery of government policy.

Barakat and Zyck, 2008: Following the 33-day 'July war' in Lebanon in 2006, a number of donors provided unconditional cash as compensation to approximately 80,000 homeowners whose properties had been destroyed or damaged. There was no overall coordination between donors with different organizations providing different levels of compensation through different processes. For example, some donors directly transferred funds to individual households in the form of grants (Qatar and Jihad al-Bina'a) while others issued cheques in the name of the intended recipient and these were distributed through the Government of Lebanon (Kuwait Fund for Arab Economic Development). However, most donors provided sector-specific budgetary support to the state to then distribute to affected households in instalments. ${ }^{35}$ Instalments seem to be based on the availability of the funds.

CARE International UK, 2015: Following the 2013 Typhoon Haiyan in the Philippines, CARE partnered with a number of local/national non-government organizations (NGOs), ${ }^{36}$ to provide 15,859 households with 'self-recovery kits' ${ }^{37}$ in line with the strategic objective of the Shelter Cluster to support 'household self-recovery' (Global Shelter Cluster, 2013). The kits included conditional cash grants and technical assistance (training and site supervision) to repair or rebuild. A second stage of the programme provided additional cash 'top-up' grants to a percentage of those who had received the initial support but were not able to complete their houses. For both stages the grants were made in single instalments. Communities were organized into 'distribution groups' of 10 households, each with a group leader. The group leader was responsible for gathering receipts for the expenditure and submitting them to CARE: 'the requirement to spend the cash on shelter was not strictly enforced, however, and households were able to spend cash on other urgent needs as a result' (2015, p. 37). In some locations these shelter programmes were delivered alongside gender, capacity building, and food and livelihood components.

\footnotetext{
${ }^{34}$ The Swiss Consortium was made up of the Swiss Agency of Development and Cooperation, the Swiss Red Cross, Hilfswerke der Evangelischen Kirchen Schweiz and Swiss Solidarity. Further funding was provided by Red Cross Red Crescent (RCRC) national societies and some smaller NGOs (not named).

${ }^{35}$ Donors including Saudi Arabia, Egypt, Syria, Yemen, Jordan, Bahrain, Iraq and Indonesia.

${ }^{36}$ Implementing Partners were: Assistance and Cooperation for Community Resilience and Development, Inc, (ACCORD); the Leyte Center for Development, Inc.; Metro Ormoc Community Cooperative; USWAG Development Foundation; Laua- an Multi-Purpose Cooperative; Pontevendra Vendors Development Cooperative; Sara Multi-Purpose Cooperative.

${ }^{37} 100$ percent of people received plain galvanized iron sheets $(x 1)$, corrugated galvanized iron sheets (x10). Between 74 percent and 80 percent of households report receiving: hand saw, tin snip, hammer, steep strap $(5 \mathrm{~kg})$, staple wire carton, galvanized iron wire 16 $(1.6 \mathrm{~kg})$, elastoseal $(500 \mathrm{ml})$, aluminium screen $3.8 \mathrm{~m}$, flat nails $1.5^{\prime \prime}(1 \mathrm{~kg})$, common wire nails $4 "(2 \mathrm{~kg})$, common wire nails $3^{\prime \prime}(2 \mathrm{~kg})$, umbrella nails $(3 \mathrm{~kg})$.
} 
Catholic Relief Services, 2010: Following the 2009 earthquake in Indonesia, CRS partnered with a local/national NGO, Wahana Lingkungan Hidup Indonesia, to provide support to 11,324 households through conditional cash grants and technical assistance (training, site supervision, posters) to build a temporary shelter. The cash was distributed in two instalments directly to affected households through a partnership with the Indonesian Post Office. Payment of the next instalment was linked to inspection of building quality and approval by the technical programme staff to meet certain design standards. This was a single-sector shelter programme.

Corsellis and Sweetnam, 2014: Following the 2011 floods in Pakistan, DFID funded the International Organization for Migration (IOM) to work through 26 local/national partners to support 22,900 households through conditional cash grants and technical assistance (training, site supervision, posters) to build new homes. The cash was distributed in three instalments, via a community-elected 'focal point'. Payment of the next instalment was linked to inspection of building quality and approval by the technical programme staff to build all shelters in a village to a standard design. The 'focal point' distributed the funds to individual households. This was a single-sector shelter programme that supported the Pakistan government's ‘Early Recovery Plan' of January 2012 (which identified shelter as a key response area).

Cukur et al., 2005: Following the 1992-1995 conflict in Bosnia and Herzegovina, the Sida (Swedish International Development Cooperation) funded programmes through a variety of implementing agencies ${ }^{38}$ that supported 14,806 households through the provision of material and technical assistance (technical advice, site supervision) to repair or rebuild their homes. Material assistance included construction materials, basic tools, machines to share and internal transportation. In some locations these shelter programmes were delivered alongside education, health, infrastructure, food security, water and sanitation, and livelihood components.

DiPretoro, 2010: Following Hurricane Richard in Belize in 2010, the Belize Red Cross, with funding from the American Red Cross, supported 70 households through the provision of financial assistance in the form of vouchers to repair or rebuild their homes. Damage to the houses was assessed as 'minor', 'major' or 'destroyed' and a different amount of funding was given to the owners of the houses in each of the three categories. Vouchers were redeemable within 30 days at a building supply store that organized bulk delivery of the purchases to the communities. Vouchers were provided in one instalment. Households selected their own materials/tools to suit their needs; however, they were required to purchase a minimum of 24 hurricane straps. This was a single-sector shelter programme.

Samuel Hall, 2012: Since the fall of the Taliban in Afghanistan in 2001, UNHCR and its implementing partners supported more than 220,000 returning or vulnerable households through material and technical assistance (training, site supervision) to build new homes. In addition, extremely vulnerable people were provided with additional cash grants in some locations. Material assistance included a shelter package containing essential construction materials such as tools, roofing beams, doors and windows. Households were supported through site supervision to build houses to a number of standard designs. In some locations this shelter programme was delivered alongside water and sanitation, education and infrastructure components.

Skat, 2009: Following the 2004 Indian Ocean earthquake and tsunami, UN-Habitat, the Sri Lankan Red Cross Society and the IFRC supported 5,354 households in Sri Lanka through the provision of conditional cash transfers and technical assistance (limited site supervision) to repair or rebuild their homes. The cash transfers were made in instalments, although the number of these was not specified. Payment of each instalment was linked to inspection of building quality and approval by the technical programme staff to build to the quality required to meet the national housing development authority building standards. In some locations this shelter programme was delivered alongside water and sanitation, community development and livelihoods components. This intervention directly supported the delivery of government policy.

\footnotetext{
${ }^{38}$ Implementing agencies included Lutheran World Federation (LWF), Swedish Rescue Services Agency, Caritas, PUM Interlife (known as Cross Roads International in BiH), PEP International and the British Salvation Army.
} 
van Dijk, 2012: Following displacement due to violence and natural disasters, the Colombian Red Cross supported 178 households with material (construction materials) and technical assistance (training, site supervision) from 2006 to 2010 to build new homes. This shelter programme was delivered alongside additional training (e.g. first aid), education and infrastructure components.

van Leersum and Arora, 2011: Following the 2005 earthquake in Pakistan, ERRA aimed to support between 400,000 and 600,000 households (exact figure not stated), through the delivery of conditional cash grants and technical assistance (site supervision, mass communication, training). Houses were assessed as 'damaged beyond economic repair' (category 1) or 'damaged within economic reparability' (category 2). All households received a grant to cover immediate shelter needs; then category 1 homeowners received further funds in three instalments. Payment of the next instalment was linked to inspection of building quality and approval by the technical programme staff that the house incorporated seismic-resistance principles. Category 2 homeowners also received further funds for restoration or retrofitting their property; the study indicates this was paid in one instalment. This shelter programme was delivered alongside a community development component. This intervention directly supported the delivery of government policy.

Figure 5.1: Summary of included documents: Intervention results (listed alphabetically)

\begin{tabular}{|c|c|c|c|c|c|c|c|c|c|c|c|}
\hline 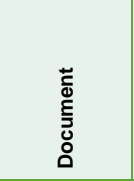 & 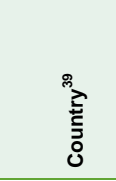 & 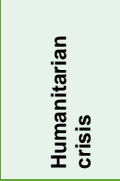 & 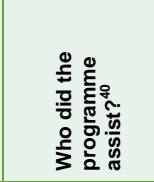 & 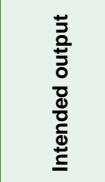 & 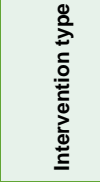 & 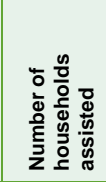 & 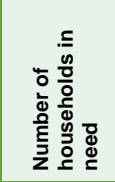 & 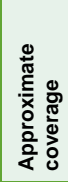 & 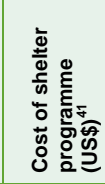 & 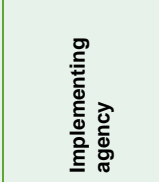 & 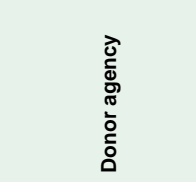 \\
\hline Aysan, 2008 & $\begin{array}{l}\text { Sri Lanka } \\
\left({ }^{\star \star}\right)\end{array}$ & $\begin{array}{l}\text { Tsunami } \\
(2004) \text { and } \\
\text { conflict }\end{array}$ & $\begin{array}{l}\text { Non-displaced } \\
\text { - land/ } \\
\text { homeowners }\end{array}$ & $\begin{array}{l}\text { Repair } \\
\text { and } \\
\text { rebuild }\end{array}$ & $\begin{array}{l}\text { Financial } \\
\text { and } \\
\text { technical }\end{array}$ & 10,629 & $114,069^{42}$ & $9 \%$ & $\begin{array}{l}21 \mathrm{~m} \\
\text { (approx.) }\end{array}$ & $\begin{array}{l}\text { Hilfswerke der } \\
\text { evangelischen } \\
\text { Kirchen } \\
\text { Schweiz, } \\
\text { Swiss Red } \\
\text { Cross, } \\
\text { Government of } \\
\text { Sri Lanka }\end{array}$ & $\begin{array}{l}\text { Swiss Consortium } \\
\text { (plus others for 'top } \\
\text { up' grant) }\end{array}$ \\
\hline $\begin{array}{l}\text { Barakat and } \\
\text { Zyck, } 2011\end{array}$ & $\begin{array}{l}\text { Lebanon } \\
\left(^{* * *}\right)\end{array}$ & Conflict & $\begin{array}{l}\text { Displaced and } \\
\text { non-displaced } \\
\text { - land/ } \\
\text { homeowners }\end{array}$ & $\begin{array}{l}\text { Repair, } \\
\text { build and } \\
\text { rebuild }\end{array}$ & Financial & 80,000 & 125,000 & $64 \%$ & $\begin{array}{l}\text { Not } \\
\text { stated }\end{array}$ & Various & $\begin{array}{l}\text { Various: Qatar, } \\
\text { Jihad al-Bina'a, } \\
\text { Kuwait Fund for } \\
\text { Arab Economic } \\
\text { Development, Saudi } \\
\text { Arabia, Qatar, } \\
\text { Egypt, Syria, } \\
\text { Yemen, Jordan, } \\
\text { Bahrain, Iraq and } \\
\text { Indonesia }\end{array}$ \\
\hline $\begin{array}{l}\text { CARE } \\
\text { International } \\
\text { UK, 2015 }\end{array}$ & $\begin{array}{l}\text { Philippines } \\
\left({ }^{* *}\right)\end{array}$ & $\begin{array}{l}\text { Typhoon } \\
\text { (2013) }\end{array}$ & $\begin{array}{l}\text { Displaced and } \\
\text { non-displaced } \\
\text { - most } \\
\text { vulnerable }\end{array}$ & $\begin{array}{l}\text { Repair, } \\
\text { build and } \\
\text { rebuild }\end{array}$ & $\begin{array}{l}\text { Material, } \\
\text { financial } \\
\text { and } \\
\text { technical }\end{array}$ & 15,859 & $1,084,762$ & $1 \%$ & $\begin{array}{l}\text { Not } \\
\text { stated }\end{array}$ & $\begin{array}{l}\text { CARE and } \\
\text { seven partners }\end{array}$ & $\begin{array}{l}\text { Various: Disasters } \\
\text { Emergency } \\
\text { Committee, } \\
\text { Humanitarian } \\
\text { Coalition, } \\
\text { Department of } \\
\text { Foreign Affairs, } \\
\text { Trade and } \\
\text { Development } \\
\text { (Canada), } \\
\text { Humanitarian } \\
\text { Partnership } \\
\text { Agreement, } \\
\text { Norway, Diageo, } \\
\text { Rational, French } \\
\text { private companies }\end{array}$ \\
\hline
\end{tabular}

\footnotetext{
${ }^{39}$ World Bank Classifications noted: $\left({ }^{*}\right)$ Low income; $\left({ }^{* *}\right)$ Lower-middle income; $\left({ }^{* * *}\right)$ Upper-middle income.

${ }^{40}$ Please note: in instances where no relocation, displacement or return is noted in the document, it is assumed the population is nondisplaced.

${ }^{41}$ Where costs were originally provided in alternative currencies these have been converted to US $\$$ using xe.com. These are indicated with (approx.), as are places where approximate costs were noted in the document.

${ }^{42}$ Data not available in document. Sourced from:

http://www.recoveryplatform.org/countries_and_disasters/disaster/15/indian_ocean_tsunami_2004
} 


\begin{tabular}{|c|c|c|c|c|c|c|c|c|c|c|c|}
\hline 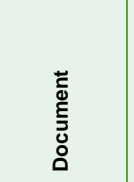 & 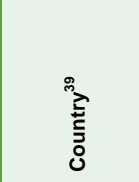 & 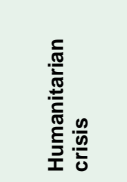 & 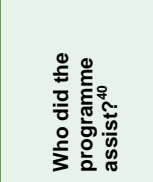 & 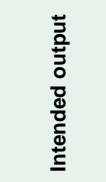 & 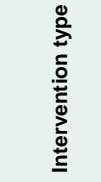 & 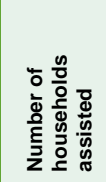 & 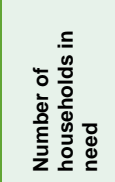 & 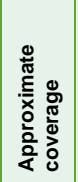 & 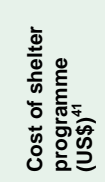 & 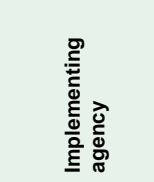 & $\begin{array}{l}\text { ̀े } \\
\bar{\Xi} \\
\frac{0}{\pi} \\
\vdots \\
\vdots \\
\vdots\end{array}$ \\
\hline $\begin{array}{l}\text { Catholic } \\
\text { Relief } \\
\text { Services, } \\
2010\end{array}$ & $\begin{array}{l}\text { Indonesia } \\
\left({ }^{\star \star}\right)\end{array}$ & $\begin{array}{l}\text { Earthquake } \\
\text { (2009) }\end{array}$ & $\begin{array}{l}\text { Non-displaced } \\
\text { - most } \\
\text { vulnerable }\end{array}$ & $\begin{array}{l}\text { Build } \\
\text { (transitio } \\
\text { nal } \\
\text { Shelter) }\end{array}$ & $\begin{array}{l}\text { Financial } \\
\text { and } \\
\text { technical }\end{array}$ & 11,324 & 249,833 & $5 \%$ & $4.6 \mathrm{~m}$ & $\begin{array}{l}\text { CRS and } \\
\text { partner } \\
\text { (Wahana } \\
\text { Lingkungan } \\
\text { Hidup } \\
\text { Indonesia) }\end{array}$ & $\begin{array}{l}\text { Various: Action } \\
\text { Contra le Faim (in- } \\
\text { kind contribution), } \\
\text { CRS Private funds, } \\
\text { USAID/OFDA, } \\
\text { Caritas Australia, } \\
\text { Caritas New } \\
\text { Zealand, } \\
\text { Trocaire/lrish Aid, } \\
\text { PLAN International } \\
\text { and private } \\
\text { foundations }\end{array}$ \\
\hline $\begin{array}{l}\text { Corsellis } \\
\text { and } \\
\text { Sweetnam, } \\
2014\end{array}$ & Pakistan $\left({ }^{* *}\right)$ & $\begin{array}{l}\text { Flood } \\
\text { (2011) }\end{array}$ & $\begin{array}{l}\text { Non-displaced } \\
\text { - most } \\
\text { vulnerable }\end{array}$ & $\begin{array}{l}\text { Build } \\
\text { (core } \\
\text { home) }\end{array}$ & $\begin{array}{l}\text { Financial } \\
\text { and } \\
\text { technical }\end{array}$ & 22,900 & $1,500,000$ & $2 \%$ & $\begin{array}{l}\text { Not } \\
\text { stated }\end{array}$ & $\begin{array}{l}1 \mathrm{OM} \text { and } 26 \\
\text { partners }\end{array}$ & DFID \\
\hline $\begin{array}{l}\text { Cukur et al., } \\
2005\end{array}$ & $\begin{array}{l}\text { Bosnia and } \\
\text { Herzegovina } \\
\left({ }^{* * *}\right)\end{array}$ & Conflict & $\begin{array}{l}\text { Returnees } \\
\text { (refugees and } \\
\text { internally } \\
\text { displaced } \\
\text { persons } \\
\text { (IDPs)) - } \\
\text { varied }\end{array}$ & $\begin{array}{l}\text { Repair } \\
\text { and } \\
\text { rebuild }\end{array}$ & $\begin{array}{l}\text { Material } \\
\text { and } \\
\text { technical }\end{array}$ & 14,806 & 400,000 & $4 \%$ & $\begin{array}{l}\text { Not } \\
\text { stated }\end{array}$ & Various & Sida \\
\hline $\begin{array}{l}\text { DiPretoro, } \\
2010\end{array}$ & Belize $\left.{ }^{\star \star *}\right)$ & $\begin{array}{l}\text { Hurricane } \\
\text { (2010) }\end{array}$ & $\begin{array}{l}\text { Non-displaced } \\
\text { - most } \\
\text { vulnerable }\end{array}$ & $\begin{array}{l}\text { Repair } \\
\text { and } \\
\text { rebuild }\end{array}$ & Financial & 70 & 800 & $9 \%$ & $\begin{array}{l}\text { 80k } \\
\text { (approx.) }\end{array}$ & $\begin{array}{l}\text { Belize Red } \\
\text { Cross }\end{array}$ & $\begin{array}{l}\text { American Red } \\
\text { Cross }\end{array}$ \\
\hline $\begin{array}{l}\text { Samuel Hall, } \\
2012\end{array}$ & $\begin{array}{l}\text { Afghanistan } \\
\left(^{*}\right)\end{array}$ & Conflict & $\begin{array}{l}\text { Returnees } \\
\text { (refugees and } \\
\text { IDPs) - land/ } \\
\text { homeowners } \\
\text { and 'possibility } \\
\text { of land } \\
\text { allocation' for } \\
\text { most } \\
\text { vulnerable }\end{array}$ & $\begin{array}{l}\text { Build } \\
\text { (core } \\
\text { home) }\end{array}$ & $\begin{array}{l}\text { Material, } \\
\text { financial } \\
\text { and } \\
\text { technical }\end{array}$ & $\begin{array}{l}+ \\
220,000 \\
\text { (approx.) }\end{array}$ & $500,000^{43}$ & $44 \%$ & $\begin{array}{l}\text { Not } \\
\text { stated }\end{array}$ & $\begin{array}{l}\text { UNHCR } \\
\text { (though } \\
\text { implementing } \\
\text { partners) }\end{array}$ & $\begin{array}{l}\text { Various: ECHO, } \\
\text { national } \\
\text { governments } \\
\text { (including Japan, } \\
\text { Denmark, Sweden), } \\
\text { European } \\
\text { Commission/Europe } \\
\text { an Union, private } \\
\text { donors }\end{array}$ \\
\hline Skat, 2009 & $\begin{array}{l}\text { Sri Lanka } \\
\left({ }^{\star *}\right)\end{array}$ & $\begin{array}{l}\text { Tsunami } \\
(2004) \text { and } \\
\text { conflict }\end{array}$ & $\begin{array}{l}\text { Displaced and } \\
\text { non-displaced } \\
\text { - land/ } \\
\text { homeowners }\end{array}$ & $\begin{array}{l}\text { Repair, } \\
\text { build and } \\
\text { rebuild }\end{array}$ & $\begin{array}{l}\text { Financial } \\
\text { and } \\
\text { technical }\end{array}$ & $5,354^{44}$ & $114,069^{45}$ & $5 \%$ & $\begin{array}{l}\text { Not } \\
\text { stated }\end{array}$ & $\begin{array}{l}\text { UN-Habitat, } \\
\text { SLRCS, IFRC } \\
\text { Government of } \\
\text { Sri Lanka }\end{array}$ & $\begin{array}{l}\text { Various: RCRC } \\
\text { national societies: } \\
\text { American Red } \\
\text { Cross, Irish Red } \\
\text { Cross, Canadian } \\
\text { Red Cross }\end{array}$ \\
\hline $\begin{array}{l}\text { van Dijk, } \\
2012\end{array}$ & $\begin{array}{l}\text { Colombia } \\
\left({ }^{* \star *}\right)\end{array}$ & $\begin{array}{l}\text { Complex } \\
\text { (conflict } \\
\text { and natural } \\
\text { disasters) }\end{array}$ & $\begin{array}{l}\text { Displaced } \\
\text { (IDPs) - } \\
\text { selection } \\
\text { criteria unclear }\end{array}$ & $\begin{array}{l}\text { Build } \\
\text { (core } \\
\text { home) }\end{array}$ & $\begin{array}{l}\text { Material } \\
\text { and } \\
\text { technical }\end{array}$ & 178 & $25,000^{46}$ & $1 \%$ & $\begin{array}{l}\text { Not } \\
\text { stated }\end{array}$ & $\begin{array}{l}\text { Colombian } \\
\text { Red Cross }\end{array}$ & $\begin{array}{l}\text { Not stated (probably } \\
\text { Netherlands Red } \\
\text { Cross Society) }\end{array}$ \\
\hline $\begin{array}{l}\text { van } \\
\text { Leersum } \\
\text { and Arora, } \\
2011\end{array}$ & Pakistan $\left({ }^{* *}\right)$ & $\begin{array}{l}\text { Earthquake } \\
(2005)\end{array}$ & $\begin{array}{l}\text { Non-displaced } \\
\text { (?) } \\
\text { - land/ } \\
\text { homeowners }\end{array}$ & $\begin{array}{l}\text { Repair } \\
\text { and } \\
\text { rebuild }\end{array}$ & $\begin{array}{l}\text { Financial } \\
\text { and } \\
\text { technical }\end{array}$ & $\begin{array}{l}400,000 \\
\text { to } \\
600,000 \\
\text { (approx.) }\end{array}$ & $600,000^{47}$ & $\begin{array}{l}100 \\
\%\end{array}$ & $\begin{array}{l}\text { Not } \\
\text { stated }\end{array}$ & $\begin{array}{l}\text { ERRA and } \\
\text { partners }\end{array}$ & Not stated \\
\hline
\end{tabular}

\footnotetext{
${ }^{43}$ According to Loschmann et al 'Data from a number of sources estimates that around 500,000 homes have been either partially or totally destroyed' (2014, p. 7).

${ }^{44}$ Unclear if number of houses/units or number of beneficiaries. On p. 29, referred to as 'beneficiaries' on p. 20 'the total number of houses implemented $\ldots$ is 5,434 units ' Assume number of houses.

${ }^{45} \mathrm{http} / / /$ www.recoveryplatform.org/countries_and_disasters/disaster/15/indian_ocean_tsunami_2004

${ }^{46}$ Calculated: According to van Dijk the 'number of displaced people that have arrived in Cucuta over the last 10 years is close to 100,000 ' (2012, p. 17) while the average family size is 4 (2012, p. 16).

${ }^{47}$ Data not available in document. Sourced from:

http://www.recoveryplatform.org/countries_and_disasters/disaster/9/south_asia_earthquake_2005
} 
5.2 COMPARISON OF THE 11 INTERVENTIONS

\section{Where were the interventions?}

- The majority of included interventions were located in Asia (Indonesia, Pakistan, Philippines and Sri Lanka), with others in the Middle East (Afghanistan, Lebanon), Central and South America (Belize, Colombia) and Europe (Bosnia and Herzegovina): no studies detailing interventions in Africa were eligible for inclusion.

- Only one of the interventions was located in a low-income country - Afghanistan (Samuel Hall, 2012): ${ }^{48}$

- seven interventions were located in lower middle-income countries, and the remaining five in upper middle-income countries.

- See Figure 5.1 for additional detail.

\section{What type of humanitarian crisis did the interventions respond to?}

- Five interventions followed rapid-onset natural disasters (earthquakes, hurricanes, floods, typhoons).

- Six interventions are classified as responses to complex crises:

- four of the interventions were in response to complex crises (conflict; displacement due to violence and natural disasters)

two interventions were located in Sri Lanka, where programmes were implemented in districts affected by natural disasters (tsunami) and by complex emergencies (conflict and tsunami) - both are treated as complex crises in this synthesis (Aysan, 2008; Skat, 2009).

- See Figure 5.1 for additional detail.

\section{Who did the intervention aim to support?}

- Of the six interventions responding to complex emergencies:

- one supported internally displaced persons (IDPs) (van Dijk, 2012)

- two supported returning IDPs and refugees (Cukur et al., 2005; Samuel Hall, 2012)

- three supported displaced and non-displaced households (Aysan, 2008; Barakat and Zyck, 2011; Skat, 2009).

- Of the five interventions that supported households following rapid onset natural disasters: four supported non-displaced households one supported both displaced and non-displaced households (CARE International UK, 2015).

- Four of the interventions supported homeowners or households with secure land tenure.

- Four of the interventions supported the 'most vulnerable', based on defined criteria ${ }^{49}$ and one required the beneficiary to have 'access to land on which to build a house... [or in]... the case of landless families in need of shelter, [for those] who meet the vulnerability criteria, there is the possibility of land allocation in order to allow them to benefit from the programme (Samuel Hall, 2012, p. 11).

\footnotetext{
${ }^{48}$ For this review World Bank classifications were used. Further details on the World Bank classifications for low and middle-income countries can be seen here: http://data.worldbank.org/about/country-and-lending-groups.

${ }^{49}$ Typical criteria for 'most vulnerable' included: households that were in remote, geographically isolated and/or disadvantages areas; were isolated from the community/lacking community support; included members with disabilities or a chronic illness; were single/women-headed households or included elderly, pregnant/lactating women; were families with malnourished children, families with many young children, indigenous people; or had a very low income (CARE International UK, 2015; Corsellis and Sweetnam, 2014; CRS, 2010; Samuel Hall, 2012).
} 
- Four of the documents contain insufficient detail on the interventions to assess the selection criteria.

- See Figure 7.3 for additional detail.

\section{What was the intervention type, activities and intended output?}

Intervention types varied:

- the majority of interventions (five) provided financial and technical assistance

- two interventions supported shelter self-recovery through material, technical and financial assistance

- two interventions provided material and technical assistance

- two interventions provided financial assistance only.

The studies described a range of activities (see Figure 2.6: Theory of change).

- Seven interventions supported affected households to repair or rebuild their homes: three of these also supported displaced households to build new homes

- four interventions required households to build to a standard design

- one of these was a transitional shelter programme

- three supported households to build core homes

- see Figure 5.1 and Figure 5.3 for additional detail.

Intended programme outputs included:

- permanent or core houses, built to a specified design or with a choice of two or three different designs (Aysan, 2008; Corsellis and Sweetnam, 2014; Samuel Hall, 2012)

- permanent or core houses, built to a set of minimum standards (Skat, 2009; van Leersum and Arora, 2011)

- transitional or temporary shelters, built to a set of minimum standards (CRS, 2010)

- no required output, for example when unconditional cash was the method of assistance (Barakat and Zyck, 2011; DiPretoro, 2010).

\section{Figure 5.2: Type of assistance and type of humanitarian crisis. Source: The} research team

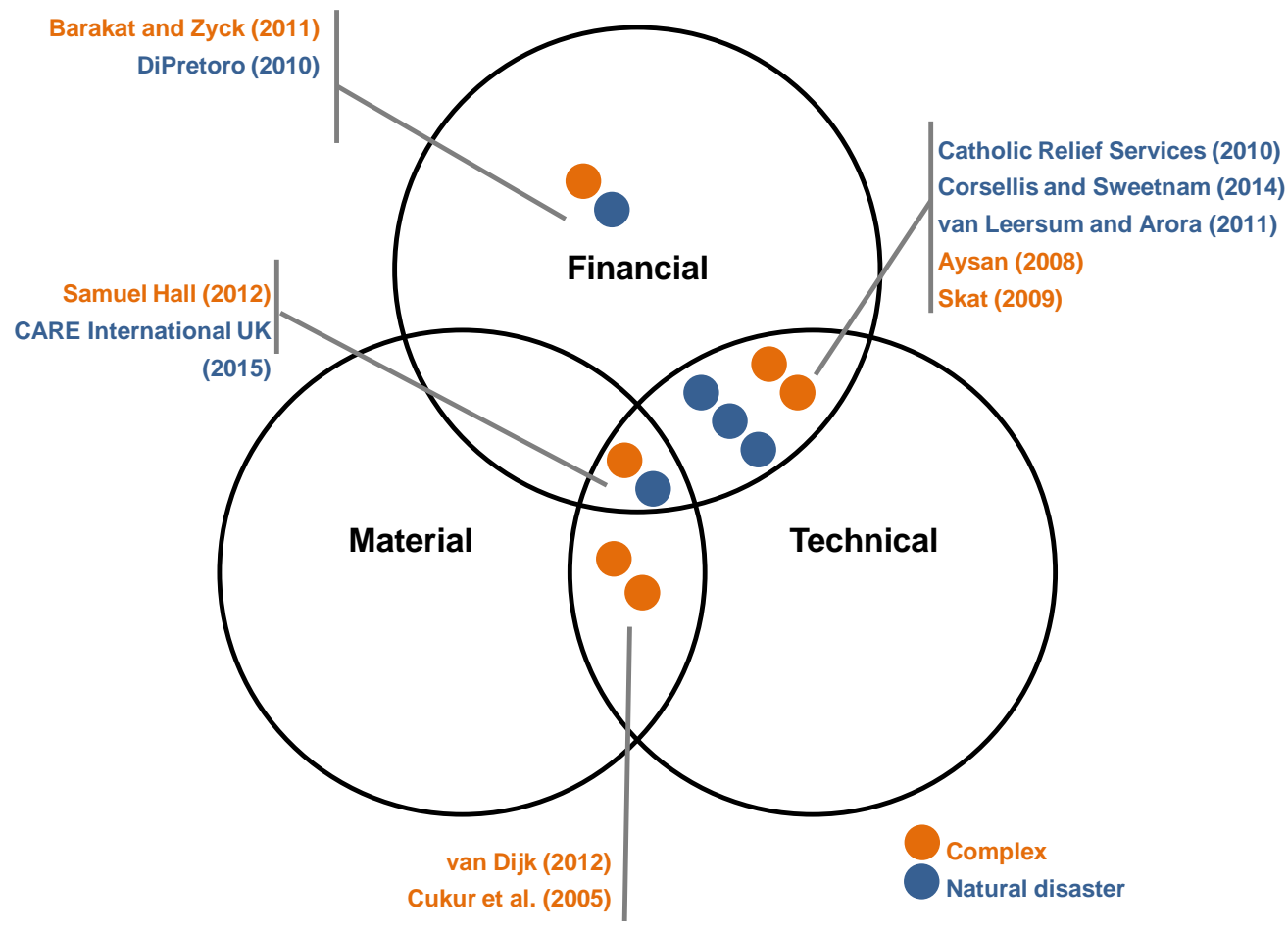


Figure 5.3: Type of assistance and activities. Source: The research team

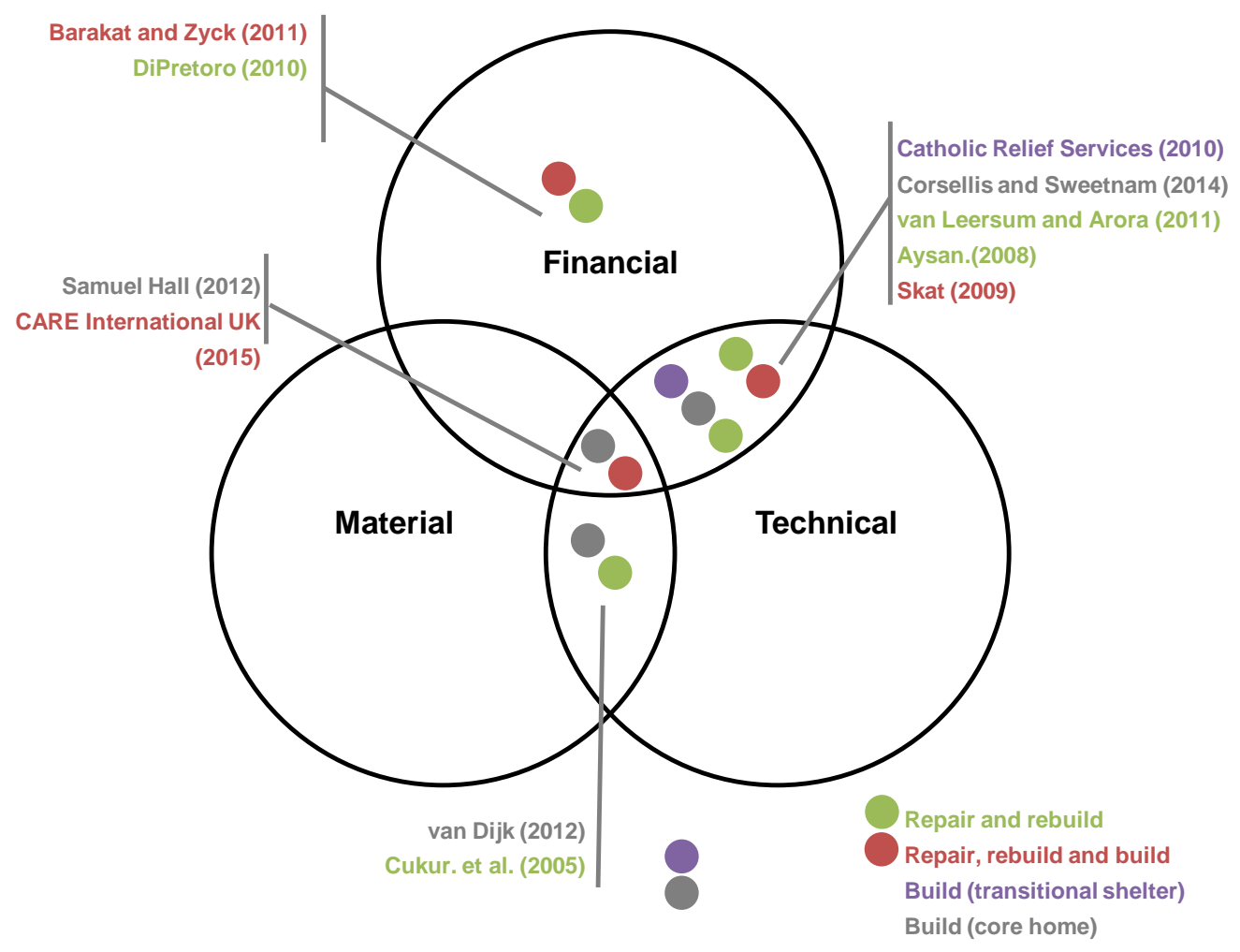

\section{What was the coverage of the intervention in relation to the need?}

The interventions ranged in scale from supporting just 70 households to approximately 600,000 . The majority of interventions assisted between 5,000 and 50,000 households and met less than 10 percent of the need for shelter assistance. Two notable exceptions are the interventions in Afghanistan and Pakistan. These interventions assisted approximately 220,000 and 600,000 households respectively and met a significant proportion of the need for shelter assistance. See Figures 5.1 and 5.4 for additional detail.

\section{Figure 5.4: Coverage of the interventions (listed by number of households} assisted). Source: The research team

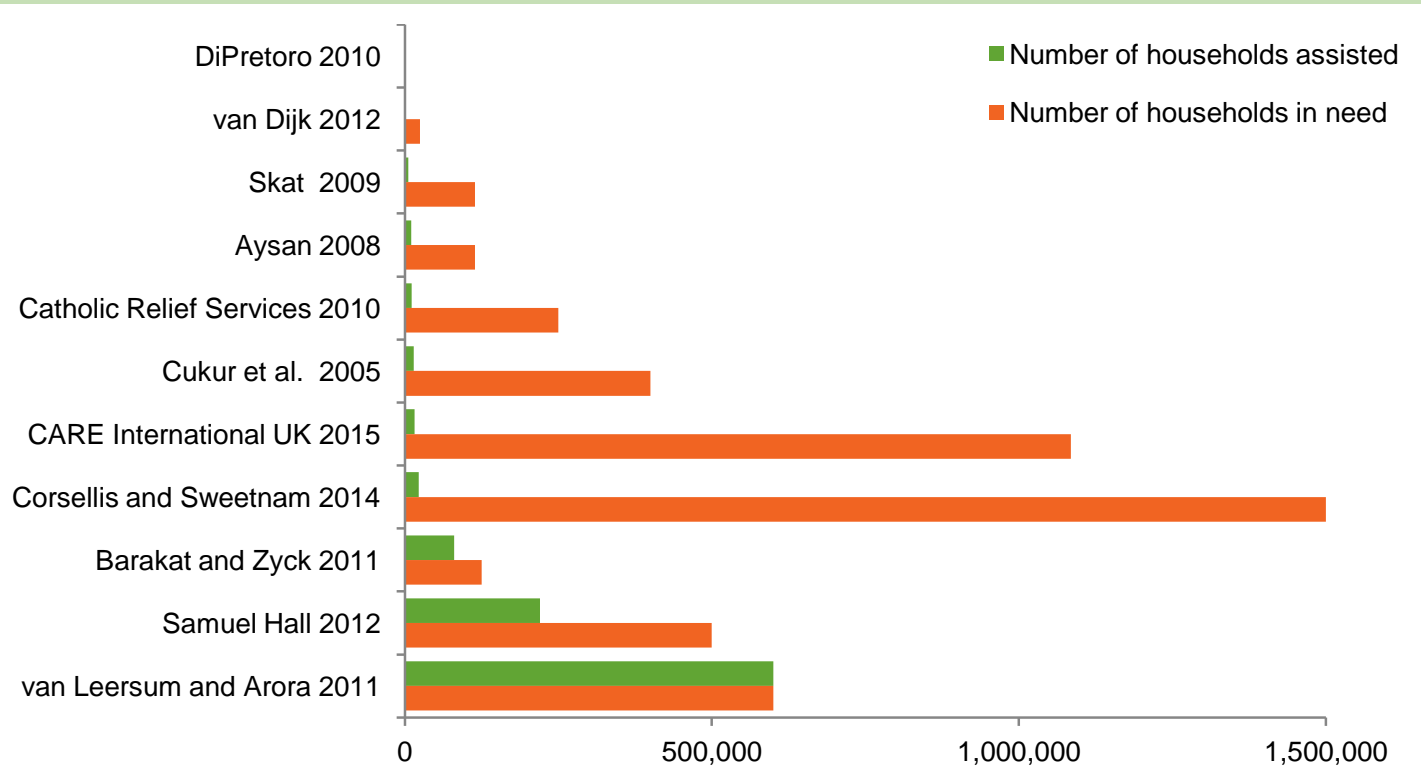




\section{How long did the programmes last?}

As Figure 5.5 indicates, only two of the documents note the exact start and end date of the intervention (month and year). Interventions ranged in length from three months (DiPretoro, 2010), to more than 10 years (Cukur et al., 2005; Samuel Hall, 2012).

The interventions with the longest duration were responding to complex emergencies (Aysan, 2008; Barakat and Zyck, 2011; Cukur et al., 2005; Samuel Hall, 2012; van Dijk, 2012). These programmes ranged from approximately 2.5 years to more than 10 years. The programmes with the shortest durations were responding to rapid-onset natural disasters. These programmes ranged from three to nine months (CARE International UK, 2015; CRS, 2010; DiPretoro, 2010).

The research team did not observe any pattern by comparing the timeline and the type of intervention (e.g. the support provided through financial, material and/or technical assistance).

\section{How much did the interventions cost?}

Only three of the documents recorded the cost of the shelter self-recovery programme e.g. only for the cost of the shelter component, and not concurrent livelihoods or health projects (Aysan, 2008; CRS, 2010; DiPretoro, 2010). The cost of the interventions varied from US $\$ 21 \mathrm{~m}$ (Aysan, 2008) to US $\$ 80,000$ (DiPretoro, 2010). See Figure 5.1 for additional detail.

Costs could not be compared and analysed across the programmes because the value of materials, services and labour varies significantly between countries and also because many of the documents did not explicitly state what was included/excluded in the programme/household costs provided 
Figure 5.5: Diagram illustrating the timing and duration of interventions (listed alphabetically). Source: The research team

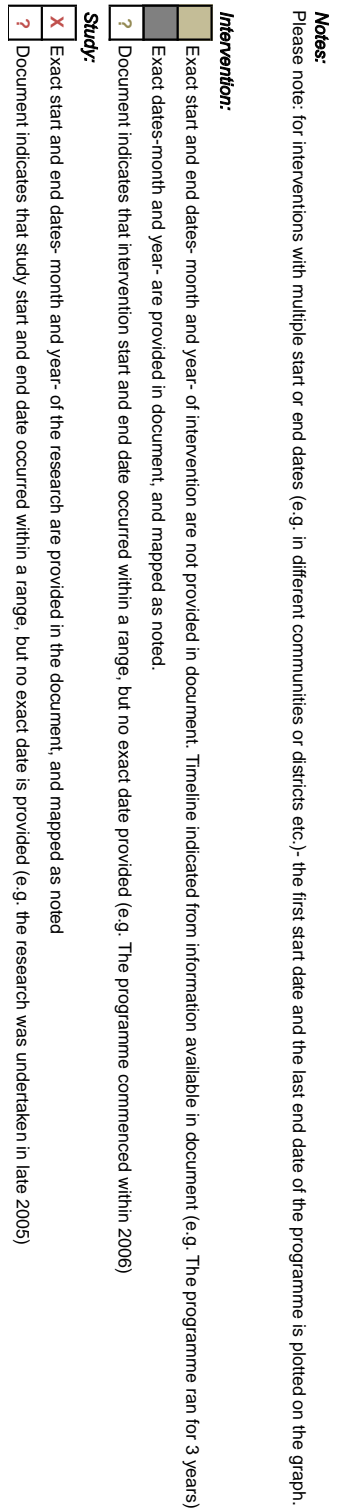
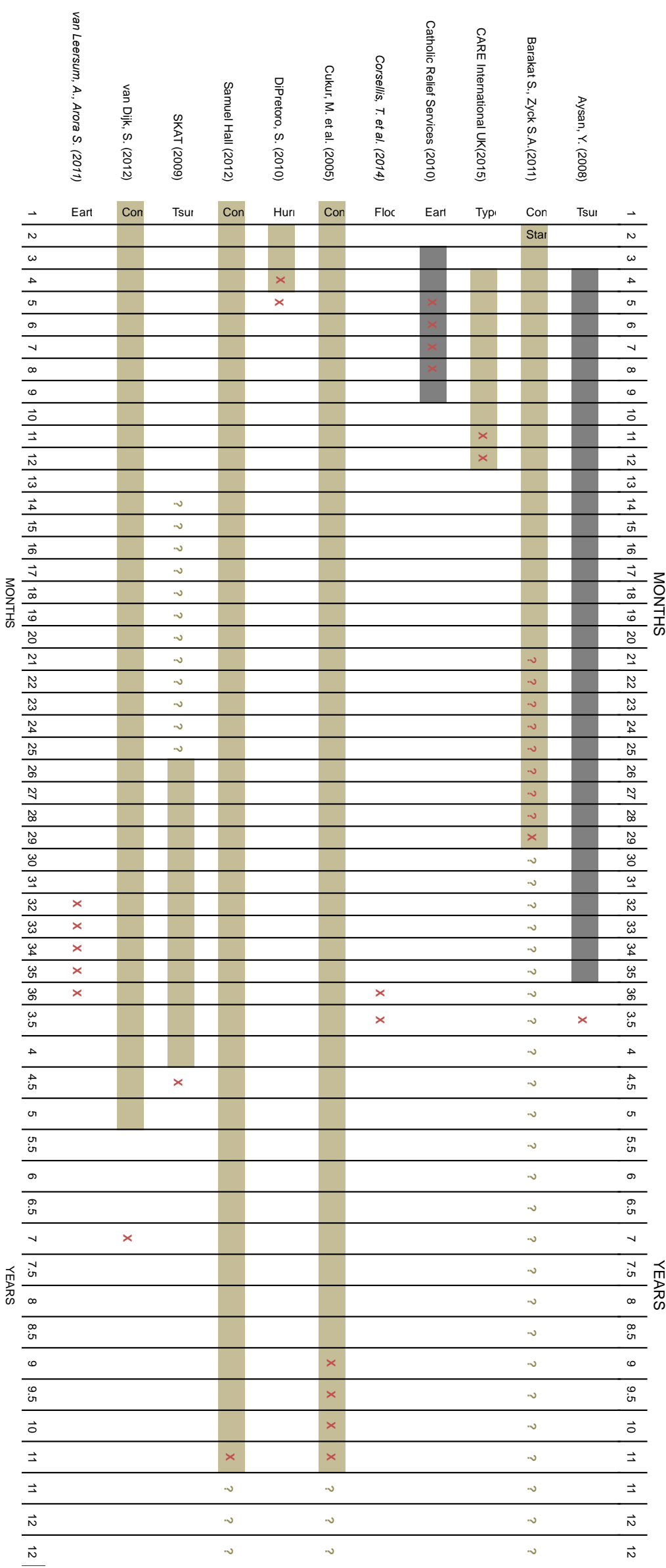
This section of the report addresses research question one: What effects do interventions that support affected populations' own shelter self-recovery processes have on household-level outcomes following humanitarian crises?

\section{1}

\section{WHAT HOUSEHOLD-LEVEL OUTCOMES DID THE STUDIES MEASURE?}

The studies described the effects of humanitarian interventions supporting shelter selfrecovery on six household-level outcomes. The effects identified are summarized in Figure 6.1, while further detail on the effects noted in each document is given in Figure 6.2, Section 6.2. Given the limitations of this evidence synthesis the results reported within this section should be interpreted with caution (see Appendix G) ${ }^{50}$ In particular, please note that this section of the report summarises the effects reported in the studies. Some of these are surprising given that, in addition to building shelters, implementing agencies and the academic literature often suggest that interventions supporting shelter self-recovery increase households' knowledge of safer construction techniques, improve their health, and contribute to an improvement in their economic situation. The evidence synthesis revealed little evidence to support these statements and this is a suggested topic for future research.

\section{Figure 6.1: Summary of key findings on effects of interventions supporting shelter- self-recovery}

\begin{tabular}{|c|c|}
\hline Outcome & Explanation of certainty in the evidence \\
\hline \multicolumn{2}{|l|}{ Consistent results } \\
\hline $\begin{array}{l}\text { 1. Interventions supporting shelter self-recovery had } \\
\text { positive effects on household dignity and self- } \\
\text { reliance. The positive effects resulted from } \\
\text { households both living in their own home and taking } \\
\text { ownership over the construction process. }\end{array}$ & $\begin{array}{l}\text { Seven studies noted positive effects on this } \\
\text { outcome. None reported neutral or negative } \\
\text { impacts. } \\
\text { The studies described interventions in several } \\
\text { countries and in response to both natural disasters } \\
\text { and complex emergencies. }\end{array}$ \\
\hline $\begin{array}{l}\text { 2. Interventions supporting shelter self-recovery had } \\
\text { positive effects on household perception of safety } \\
\text { from natural hazards and security from crime and } \\
\text { violence. The positive effects resulted from } \\
\text { households' perception of the 'strength' of their houses } \\
\text { and social factors such as reduced overcrowding and } \\
\text { the reintegration of returnees. }\end{array}$ & $\begin{array}{l}\text { Seven studies noted positive effects on this } \\
\text { outcome. None reported neutral or negative } \\
\text { impacts. } \\
\text { The studies described interventions in several } \\
\text { countries and in response to both natural disasters } \\
\text { and complex emergencies. }\end{array}$ \\
\hline
\end{tabular}

\footnotetext{
${ }^{50}$ The summary findings are presented in line with other reviews that included a range of study designs (mixed-methods, qualitative, quantitative), for example (Glenton et al., 2013; Oketch et al., 2014). The research team have not reported the summary findings in terms of the quality of the included studies because a) they vary significantly in their design and therefore it is not appropriate to directly compare them using a standard measure (such as number of participants in the study); b) the majority of the documents included in the review have significant gaps in their methodologies, restricting accurate disaggregation (e.g. into 'medium' or 'high' quality documents), and doing so would introduce an artificial distinction. Thus, while a preferred approach to evidence synthesis is to be able to weight findings of individual studies by strength of findings, in this review it was not feasible and 'vote counting', alongside a clear breakdown of findings (Sections 6 and 7) and a detailed narrative on quality (Figure 4.3), was applied.
} 


\begin{tabular}{|c|c|}
\hline Outcome & Explanation of certainty in the evidence \\
\hline \multicolumn{2}{|l|}{ Inconsistent results } \\
\hline $\begin{array}{l}\text { 3. The effects of interventions supporting shelter self- } \\
\text { recovery on household incomes or livelihoods are } \\
\text { unclear. }\end{array}$ & $\begin{array}{l}\text { Four studies noted positive effects on this outcome. } \\
\text { A further two studies specifically reported that the } \\
\text { intervention had not had an effect on household } \\
\text { incomes or livelihoods and one study reported } \\
\text { negative effects on the livelihoods of households } \\
\text { who were relocated. } \\
\text { The studies described interventions in a range of } \\
\text { countries in response to both natural disasters and } \\
\text { complex emergencies. }\end{array}$ \\
\hline $\begin{array}{l}\text { 4. The effects of interventions supporting shelter self- } \\
\text { recovery on household assets or debts are unclear. }\end{array}$ & $\begin{array}{l}\text { Two studies noted positive effects on ownership of } \\
\text { assets while three reported negative effects on } \\
\text { household debt. } \\
\text { The studies described interventions in Afghanistan, } \\
\text { Lebanon, Sri Lanka and Colombia in response to } \\
\text { complex emergencies. }\end{array}$ \\
\hline $\begin{array}{l}\text { 5. The effects of interventions supporting shelter self- } \\
\text { recovery on household physical and mental health are } \\
\text { unclear. }\end{array}$ & $\begin{array}{l}\text { Two studies noted positive effects on this outcome } \\
\text { while one reported no effects. } \\
\text { The studies described interventions in the } \\
\text { Philippines, Bosnia and Herzegovina and Colombia } \\
\text { in response to both natural disasters and complex } \\
\text { emergencies. }\end{array}$ \\
\hline $\begin{array}{l}\text { 6. The effects of interventions supporting shelter self- } \\
\text { recovery on household knowledge of safer } \\
\text { construction are unclear. }\end{array}$ & $\begin{array}{l}\text { Three studies noted positive effects on this } \\
\text { outcome while four specifically reported no effects. } \\
\text { - The studies described interventions in a range of } \\
\text { countries in response to both natural disasters and } \\
\text { complex emergencies. } \\
\text { The studies included interventions that provided } \\
\text { technical assistance alongside financial and/or } \\
\text { material assistance and those that provided } \\
\text { financial assistance without technical support. }\end{array}$ \\
\hline
\end{tabular}

\section{What did the studies report on activities or outputs?}

Six of the studies report on the completion rate of shelters (Aysan, 2008; Barakat and Zyck, 2011; CARE International UK, 2015; CRS, 2010; Samuel Hall, 2012; Skat, 2009). However, the studies note the challenges of measuring 'completed' shelters and the difference between completion as defined by households, and completion to agreed standards. Two of the studies report findings on the level of satisfaction (or dissatisfaction) of beneficiaries with the process and outputs of the intervention (Samuel Hall, 2012; Skat, 2009).

Six studies comment on the level of occupancy (Barakat and Zyck, 2011; CARE International UK, 2015; Corsellis and Sweetnam, 2014; CRS, 2010; Cukur et al., 2005; Samuel Hall, 2012).

The studies in Pakistan and Afghanistan highlight that low occupancy rates resulted from families using the shelters for storage, guest rooms, guesthouses or shops and were potentially the result of mis-targeting (Corsellis and Sweetnam, 2014; Samuel Hall, 2012). In the intervention in Indonesia households were assisted to build what were meant as temporary shelters adjacent to their permanent homes. However, the study notes that around one quarter of households preferred to live in their 'unsafe houses' because they did not understand the benefit of living in the 'safe shelter' or preferred to live in their homes 'out of a concern for keeping their assets secure' (CRS, 2010, p. 11).

The studies identify four measures relating to the quality of the shelters repaired, built or rebuilt as part of the supported self-recovery process. These were that the shelter had adequate:

- size or space for household activities (CARE International UK, 2015; Cukur et al., 2005; Samuel Hall, 2012; van Dijk, 2012);

- number and arrangement of rooms (Aysan, 2008; van Dijk, 2012);

- light and ventilation (CARE International UK, 2015; Samuel Hall, 2012);

- material, construction and structural quality (Aysan, 2008; Barakat and Zyck, 2011; CARE International UK, 2015; Corsellis and Sweetnam, 2014; DiPretoro, 2010; Skat, 2009; van Dijk, 2012; van Leersum and Arora, 2011).

The studies also measure whether or not households had adequate:

- security of tenure (Samuel Hall, 2012; Skat, 2009);

- access to basic services such as water, sanitation, electricity and fuel (CARE International UK, 2015; Cukur et al., 2005; Samuel Hall, 2012; Skat, 2009; van Dijk, 2012);

- access to social infrastructure such as schools, health facilities and religious buildings (Cukur et al., 2005; Samuel Hall, 2012; van Dijk, 2012). 


\subsection{WHAT EFFECTS DID THE INTERVENTIONS SUPPORTING SHELTER SELF-RECOVERY HAVE ON HOUSEHOLD-LEVEL OUTCOMES?}

\section{Consistent results}

\section{Interventions supporting shelter self-recovery had positive effects on household dignity and self-reliance.}

Certainty in the evidence: Seven studies note positive effects on this outcome (CARE International UK, 2015; Cukur et al., 2005; DiPretoro, 2010; Samuel Hall, 2012; Skat, 2009; van Dijk, 2012; van Leersum and Arora, 2011). The studies describe interventions in several countries in response to both natural disasters and complex emergencies.

\section{The positive effects resulted from households both living in their own home and} taking ownership over the construction process. For example:

- living in their own home was 'a way for beneficiary household[s] to re-establish an 'honourable' social position in their community. Sharing houses gave some beneficiaries the feeling of imposing an undue burden on their relatives. Living in tents or not owning one's own house was perceived as a loss of social status' (Samuel Hall, 2012, p. 93).

- taking responsibility for the construction process (van Leersum and Arora, 2011, p. 261) including 'managing a whole construction site, supervising masons and carpenters, organising building material and equipment, handling payments, coping with delays, technical problems and other 'normal' challenges of construction' (Skat, 2009, p. 43) increased their self-reliance (van Leersum and Arora, 2011, p. 261) and made households 'robust enough to tackle more challenges in life' (Skat, 2009, p. 43).

- being treated with dignity and respect, being empowered to make choices, and representing their own interests to local authorities also strengthened self-esteem and self-confidence (Cukur et al., 2005) and 'had a positive impact on [their] recovery process' (DiPretoro, 2010, p. 7).

\section{Interventions supporting shelter self-recovery had positive effects on household} perception of safety from natural hazards and security from crime and violence.

Certainty in the evidence: Seven studies report positive effects on this outcome (CARE International UK, 2015; Corsellis and Sweetnam, 2014; CRS, 2010; Cukur et al., 2005; Samuel Hall, 2012; van Dijk, 2012; van Leersum and Arora, 2011). The studies describe interventions in several countries in response to both natural disasters and complex emergencies.

Household perception of safety from natural hazards and security from crime and violence are separate and highly interrelated outcomes. They are also highly related to the context of the intervention - in terms of both social and environmental conditions - and whether the intervention was in response to a natural disaster or complex emergency. This is reflected in the way results on this topic are presented in the studies.

Within the studies describing responses to natural disasters (CARE International UK, 2015; Corsellis and Sweetnam, 2014; CRS, 2010; van Leersum and Arora, 2011), the positive effects on household perception of safety resulted from households' awareness of the 'strength' of their homes (both in terms of material and construction quality and their incorporation of safer construction techniques). For example:

- following Typhoon Haiyan in the Philippines, CARE International UK found that 'construction quality was felt to be high, and most thought the houses were stronger, largely because of the implementation of safer building measures and the high quality CGI [corrugated galvanised iron] roofing sheets' (2015, p. 44).

- following the 2005 earthquake in Pakistan, Van Leersum noted that 'while earthquakes are perceived as a serious threat, the combined effects of unemployment and disease are more direct concerns of the average household. These data collected during the time when new 'stronger' houses were being constructed may be viewed as indicators of homeowners' trust in the safety of their new seismic-resistant house' (2011, p. 257). 
- following the 2011 floods in Pakistan, Corsellis and Sweetnam found that beneficiary households 'thought they were safer in the... [new] housing, quoting, raised plinth, larger size of house, use of lime plaster, higher doors, strengthened and lighter roof as the qualities of the build that will keep them safer and allow their building to withstand future crisis' $\left(2014\right.$, p. 44)..$^{51}$

The studies describing responses to complex emergencies highlight the close relationship between safety and security ${ }^{52}$ (Samuel Hall, 2012; van Dijk, 2012). For example van Dijk notes that 'feeling safe has to do with several aspects of the house, one of them being the strength of the building/house, and another element is the possibility to protect yourself and your belongings' (2012, p. 28). Samuel Hall highlights that 'the impact of the programme in terms of protection is multifaceted' (2012, p. 92).

Within the studies describing responses to complex emergencies (Cukur et al., 2005; Samuel Hall, 2012; van Dijk, 2012), the positive effects on household perception of safety and security resulted from both the material and construction quality of their homes and social factors such as reduced overcrowding and the reintegration of returnees. For example:

- when describing an intervention supporting IDPs affected by conflict and natural disasters in Colombia, van Dijk notes that 'households in [the intervention group] feel significantly safer [sic] in their house compared to households in [the control group]... The difference in construction and materials used for the walls play an important role in this' (2012, p. 28).

- in the context of Afghanistan, Samuel Hall reports that in every focus group discussion beneficiaries highlighted that 'a durable shelter is [a] real improvement in terms of protection of returnee and IDP families in an environment where protection risks are numerous and reinforced by displacements' (2012, p. 92). These risks included vulnerability to harsh weather conditions and communicable diseases and an increased risk of violence against women and children resulting from overcrowded living conditions (ibid).

- Cukur et al. describe an intervention following armed conflict in Bosnia and Herzegovina - a country at low risk of natural hazards. The authors note that households felt 'secure and at home' (2005, p. xi) but this was attributed solely to social factors such as the disappearance of 'the fear associated with the first days of return... explained as a consequence of 'attempts to strike terror in village inhabitants' $(2005$, p. 56), whereas 'today people generally feel safe, and claim that those of other ethnic groups are either friendly or neutral' (2005, p. 125).

\section{Inconsistent results}

\section{The effects of interventions supporting shelter self-recovery on household incomes or livelihoods are unclear.}

Certainty in the evidence: Four studies note positive effects on this outcome (CARE International UK, 2015; CRS, 2010; Samuel Hall, 2012; van Dijk, 2012). A further two studies specifically report that the intervention had not had an effect on household incomes or livelihoods (Corsellis and Sweetnam, 2014; Cukur et al., 2005) and one study reports negative effects on the livelihoods of households who were relocated (Skat, 2009). The studies describe interventions in a range of countries in response to both natural disasters and complex emergencies.

\footnotetext{
${ }^{51}$ Although 'the benefits quoted to the evaluation teams were remarkably similar in most villages and the teams felt that they were being given the version learned as part of the [one room shelter] process' (Corsellis and Sweetnam, 2014, p. 44).

${ }^{52}$ Also described as 'protection'.
} 
Of the studies reporting positive effects on household incomes:

- Samuel Hall notes that UNHCR beneficiaries were '7 percent less likely to be below the poverty line (\$1.25/day)' (2012, p. 108) than households which did not receive assistance when comparing their situation when they first returned from abroad and after being surveyed.

- Van Dijk states that while there was no significant difference between the intervention group and the control group in terms of number of sources of income, there was a slight increase in the intervention group compared with the control group in terms of income level (2012, p. 35). Van Dijk also reports that there was a slight significant difference between the intervention and control groups in terms of household perception of their 'economic independence' but no significant difference in terms of their access to a bank account (2012, p. 36).

- CRS reports that 'once beneficiaries had a safe place to stay, they could turn their attention to their livelihoods' (2010, p. 25).

- CARE International UK notes that beneficiaries rated their household livelihood/income as slightly worse than their pre-crisis situation and significantly better than immediately after the typhoon. The majority of respondents felt that these changes were fully $(+40$ percent) or partially (+30 percent) due to the intervention (2015, pp. 26-28).

Of the studies reporting no effects on household incomes:

- Corsellis and Sweetnam report finding 'no widespread additionality that can be reasonable attributed to the programme inputs, in terms of growth of livelihoods, potential etc.' (2014, p. 38).

- Cukur et al. state that 'many of the [supported] returnees have not been able to re-establish appropriate livelihoods - to do so would have needed additional support' (2005:128). However, households who received assistance 'are neither better nor worse off than others. For the inhabitants of Bosnian villages life is hard' $(2005$, p. 107).

In the study reporting negative effects on the livelihoods of households who were relocated these were attributed to households: losing social networks and finding it difficult to find employment in a new community, spending more money on transport, and experiencing difficulties continuing their existing livelihoods (such as fishing) because of being further from the sea (Skat, 2009, p. 45)

\section{The effects of interventions supporting shelter self-recovery on household ownership of assets or debts are unclear.}

Certainty in the evidence: One study notes positive effects on household ownership of assets (van Dijk, 2012), while two studies note negative effects on household debts (Aysan, 2008; Barakat et al., 2008). One study reports both positive effects on household ownership of assets and negative effects on household debt (Samuel Hall, 2012). The studies describe interventions in Afghanistan, Lebanon, Sri Lanka and Colombia in response to complex emergencies:

With regard to household assets:

- Samuel Hall reports a significant difference in terms of access to a mobile phone between beneficiaries and households which did not receive assistance when comparing their situation when they first returned from abroad and after being surveyed (2012, p. 108).

- Van Dijk created a wealth index in order to compare households in the intervention and control groups. This revealed a significant difference between the two groups and 'means that... [in terms of] ownership of several indicators such as a bicycle, a refrigerator etc. the households in [the intervention group] score an higher average in wealth' (2012, p. 40). 
With regard to household debts:

- Samuel Hall notes that 47 percent of beneficiary households felt that household debt had increased as a result of the intervention (2012, p. 52). Factors noted as influencing the level of household debt included differences in the types of materials used to build shelters in different locations, higher prices of materials and labour in remote areas, and the requirement to pay bribes or purchase fake documentation in order to qualify for assistance (2012, pp. 95-96). However, the authors noted that both taking and giving informal credit between households is common practice for households in Afghanistan in the absence of a formal banking system or welfare state. Thus, while 'indebtedness did increase in absolute terms [as a result of the intervention]... in an environment where every household incurs debts, beneficiary households are actually benefiting from a very unusual access to in-kind support for the construction of their shelter... The fact that a large majority of beneficiary respondents said that they did not regret participating in the programme despite the extra debt that they had to incur tends to suggest that the issue of indebtedness was not a major challenge for beneficiaries' (2012, p. 96).

- Barakat et al. report that the intervention had contributed to 'the entrenchment of a "cycle of indebtedness"... thus [poverty], was solidified, in many cases, through the slow pace of the housing compensation process and the loans necessitated by delays' $(2008, p .32)$.

- Aysan states that households that got into debt due to price increases had previously expressed 'a preference for a 'donor-driven' house' (2008, pp. 15-16).

\section{The effects of interventions supporting shelter self-recovery on household physical and mental health are unclear.}

Certainty in the evidence: Two studies report positive effects on this outcome (CARE International UK, 2015; Cukur et al., 2005), while one reports unclear effects (van Dijk, 2012). The studies describe interventions in the Philippines, Bosnia and Herzegovina and Colombia in response to both natural disasters and complex emergencies:

- According to CARE International, UK beneficiaries rated their physical and mental health as similar to their pre-crisis situation and significantly better than immediately after the typhoon. The majority of respondents felt that this was fully (+40 percent) or partially (+30 percent) due to the intervention (2015, pp. 26-28).

- Cukur et al. note that use of medicines among the returnee population had reduced, and 'it may therefore be inferred that the housing program — and the way it has been implemented - has positively impacted the physical and psychological wellbeing of the population' $(2005$, p. 37).

- Van Dijk (2012) report that households felt their health was the same or improved as a result of the intervention. However, there was no significant difference statistically in terms of health and access to healthcare between the control and intervention groups.

\section{The effects of interventions supporting shelter self-recovery on household knowledge of safer construction are unclear.}

Certainty in the evidence: Three studies note positive effects on this outcome (CARE International UK, 2015; DiPretoro, 2010; van Leersum and Arora, 2011) while four highlight the lack of effects (Barakat and Zyck, 2011; Corsellis and Sweetnam, 2014; Samuel Hall, 2012, Skat, 2009). The studies describe interventions in a range of countries in response to both natural disasters and complex emergencies. The studies include interventions that provided technical assistance alongside financial and/or material assistance (CARE International UK, 2015; Corsellis and Sweetnam, 2014; Samuel Hall, 2012; van Leersum and Arora, 2011; Skat 2009) and ones that provided financial assistance without technical support (Barakat and Zyck, 2011; DiPretoro, 2010).

Of the studies describing interventions including the provision of technical assistance, two report positive effects, while three report the lack of positive effects: 
- CARE International UK notes that 'knowledge of the four main safer construction messages (roof connections, steel strapping, bracing and anchored foundations) was high' (2015, p. 44). However, while 'build back safer knowledge has been learnt, retained and practiced in communities. It has generally not been "understood" and there is evidence of misapplication (2015, p. 66).

- Van Leersum reports that 60 percent of respondents felt confident using seismic-resistant technologies in future construction activities. However, 35 percent remained neutral and five percent were unsure (2011, p. 257).

- Corsellis and Sweetnam state that 'there have been no widespread changes in building techniques' (2014, p. 44) and 'no change in attitudes to construction practice can be claimed, so far as can be seen from the lack of the use of lime in repairs $(2014$, p. 54).

- Samuel Hall reports that while more than 70 percent of beneficiaries had received 'some form of training in conjunction with shelter assistance ${ }^{, 53}(2012, p .55)$ beneficiaries in earthquake-prone areas removed wood bracing from their shelters 'due to a lack of awareness of their use. This emphasizes the need for proper awareness training about the importance of wood bracing and other risk mitigation measures' (2012, p. 154).

- Skat notes that 'the majority of the rebuilt houses are constructed according to NHDA [Sri Lanka National Housing Development Authority] guidelines or of higher standard' yet 'a challenge remains as beneficiaries are not sure of how to undertake repairs and how to finance them in the future' $(2009$, p. 7$)$.

Of the studies describing interventions that did not include the provision of technical assistance:

- Barakat and Zyck note that even though 'relatively substantial amounts of assistance were provided in a timely manner, the lack of technical assistance meant that homes were built without regard to technical standards and without due caution to threats posed by earthquakes and renewed conflict' (2011, p. 150).

- DiPretoro reports that 'beneficiaries were required to purchase a minimum of 24 hurricane straps at the merchant' $(2010$, p. 5). At the time of the assessment, 60 percent of respondents had used the hurricane straps, while 'those who have not yet used them... have them on-site, recognize their usefulness and indicated plans to install them prior to the start of the next hurricane season' (ibid). Thus while technical assistance was not provided, the use of hurricane strapping was encouraged through conditions of the financial assistance provided.

\section{What non-household-level outcomes did the studies measure?}

Because the research question focused on household-level outcomes, the research team did not systematically collect data on community- or larger-scale outcomes of interventions supporting shelter self-recovery. However, a number of community-level outcomes were identified in the documents. For example:

- Several studies report effects on the strength of relationships between community members (social capital). These typically resulted from the processes of beneficiary selection and community engagement. Positive effects were described as strengthening 'social trust', 'collective confidence' and 'solidarity' (Cukur et al., 2005) or improving 'community relations' (van Dijk, 2012). Other authors note some increased 'internal tensions and divisions in the community' (Samuel Hall, 2012) or 'disputes, tensions and sometimes abuses of power' (Aysan et al., 2007).

- Two studies specifically comment on the integration of returnees into the local community. Samuel Hall noted that 'there is little evidence of difficulties in integrating into the local community' (2012, p. 82). Cukur et al. reported that while the intervention had physically brought communities back together 'people are not living together, but rather side by side' (2005, pp. $x$-xi).

- A number of studies note effects on the local building industry. For example, van Leersum (2011) reports households' level of confidence in the ability of artisans to apply safer construction techniques in reconstruction. Barakat et al. highlighted that delays in the disbursement of financial assistance to households had wider implications for construction workers or material suppliers $(2008$, p. 88).

- Some studies comment on behavioural changes at community level. For example, Samuel Hall notes that 'the programme had a sort of 'domino effect' on the living condition of the rest of the community by raising the standards in housing or in hygiene' (2012, pp. 111-112).

${ }^{53}$ This included training on construction (54 percent), maintenance (33 percent), procurement (26 percent) and hygiene promotion

(20 percent) (Samuel Hall, 2012); numbers rounded up or down to nearest percent. 
Figure 6.2: Summary of effects reported in the studies (listed alphabetically)

\begin{tabular}{|c|c|c|c|c|c|c|}
\hline & 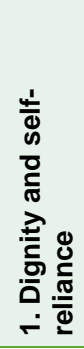 & 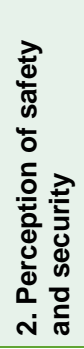 & 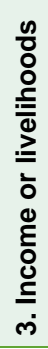 & $\begin{array}{l}0 \\
0 \\
0 \\
0 \\
\vdots \\
0 \\
0 \\
0 \\
0 \\
0 \\
\frac{0}{4} \\
\dot{+0}\end{array}$ & 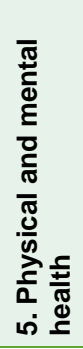 & 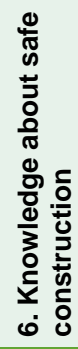 \\
\hline Aysan, 2008 & - & - & - & $\mathbf{N}$ & - & - \\
\hline Barakat and Zyck, 2011 & - & - & - & $\mathbf{N}$ & - & 0 \\
\hline CARE International UK, 2015 & $\mathbf{P}$ & $\mathbf{P}$ & $\mathbf{P}$ & - & $\mathbf{P}$ & $\mathbf{P}$ \\
\hline Catholic Relief Services, 2010 & - & $\mathbf{P}$ & $\mathbf{P}$ & - & - & - \\
\hline Corsellis and Sweetnam, 2014 & - & $\mathbf{P}$ & 0 & - & - & 0 \\
\hline Cukur et al., 2005 & $\mathbf{P}$ & $\mathbf{P}$ & 0 & - & $\mathbf{P}$ & - \\
\hline DiPretoro, 2010 & $\mathbf{P}$ & - & - & - & - & $\mathbf{P}$ \\
\hline Samuel Hall, 2012 & $\mathbf{P}$ & $\mathbf{P}$ & $\mathbf{P}$ & $\mathbf{P} / \mathbf{N}$ & - & 0 \\
\hline Skat, 2009 & $\mathbf{P}$ & - & $\mathbf{N}$ & - & - & 0 \\
\hline van Dijk, 2012 & $\mathbf{P}$ & $\mathbf{P}$ & $\mathbf{P}$ & $\mathbf{P}$ & 0 & - \\
\hline van Leersum and Arora, 2011 & $\mathbf{P}$ & $\mathbf{P}$ & - & - & - & $\mathbf{P}$ \\
\hline
\end{tabular}

Note: $\mathbf{P}$ indicates the study notes the intervention had a positive effect on this outcome;

$\mathbf{N}$ indicates a negative effect; and $\mathbf{O}$ that the study specifically notes no effect.

\section{What indicators did the studies use to measure effects?}

Nine of the included studies explicitly aim to report on the effects of humanitarian interventions supporting shelter self-recovery. One is an 'impact assessment' (van Dijk, 2012), five structure findings around the Organisation for Economic Cooperation and Development (OECD) Development Assistance Committee (DAC) criteria and thus include sections on 'impact' (Aysan, 2008; CARE International UK, 2015; CRS, 2010; Cukur et al., 2005; Skat, 2009) while three have bespoke structures with 'impact' sections (Barakat and Zyck, 2011; Corsellis and Sweetnam, 2014; DiPretoro, 2010). However, there is little commonality within the studies in terms of the research methods or indicators used to identify effects, or even how effects were separated from activities and outputs. Based on analysis of the included studies, the research team suggests that the following indicators may be useful in future studies researching the effects of humanitarian interventions supporting shelter self-recovery.

The number or percentage of households indicating their dignity and self-confidence has increased as a result of the intervention. For example, van Dijk asked beneficiaries 'How did the [intervention] influence your life [in terms of independence]?' (2012, p. 24) and then compared their answers with a control group.

The number or percentage of households indicating their perception of safety and security has increased as a result of the intervention. For example, CARE International UK asked beneficiaries to rate their safety and security on a scale of 1 (very poor) to 5 (very good) before and immediately after the crisis and at the time of the survey. Interviewees were also 'asked whether they thought the changes in their situation were fully, partially or not due to the shelter assistance they had received' (2015, pp. 26-27).

The number or percentage of households indicating their incomes or livelihoods have improved as a result of the intervention. For example, van Dijk asked beneficiaries 'How many sources of income does this household have?' 'From all the sources of income together how much does this household earn per month?', 'Is the income sufficient for the basic needs of this family?', 'How do you value your household's economic independence?' and 'Does anyone in the family have a bank account?' (2012, pp. 36-37). The answers of beneficiaries were then compared with those in a control group.

The number or percentage of households indicating their assets have increased as a result of the intervention. For example, van Dijk created a wealth index that compared household ownership of assets between the intervention and control group. Assets identified as suitable for comparison included bicycles, refrigerators, mobile phones, televisions, sound systems, DVD players, living room furniture, sofas and 'ventilators' (2012, pp. 39-40).

The number or percentage of households indicating their debts have increased as a result of the intervention. For example, Barakat et al. asked interviewees 'Were you required to take out a loan to pay for house repairs?' (2008, p. 96).

The number or percentage of households indicating that their physical and mental health has improved as a result of the intervention. For example, van Dijk asked beneficiaries whether, within the last year, they had experienced sickness, needed a doctor or needed hospital care. The answers of beneficiaries were then compared with those in a control group (2012, p. 41).

The number or percentage of households indicating that their knowledge of safer construction techniques has improved as a result of the intervention. For example, van Leersum asked interviewees 'Do you feel confident about using [seismic-resistant techniques] again in the future?' (2009, p. 113). 
This section of the report addresses research question two: What factors helped or hindered the implementation of interventions supporting populations' own shelter self-recovery processes following humanitarian crises?

\subsection{WHAT FACTORS THAT HELPED OR HINDERED PROGRAMME IMPLEMENTATION DID THE STUDIES IDENTIFY?}

The studies identify 16 main factors that helped or hindered the implementation of interventions supporting populations' own shelter self-recovery processes following humanitarian crises. These have been categorized as household factors, programme factors or contextual factors and are summarized in Figure 7.1. Further detail on the relationship between individual documents and each factor can be seen in Figure 7.5. Given the limitations of this evidence synthesis the results reported in this section should be interpreted with caution (see Appendix $G$ for further details).$^{54}$ In particular, please note:

- The researchers only extracted data where authors explicitly note that a factor helped or hindered programme implementation. For example, if a study notes that there was inflation, but does not indicate that this helped/hindered programme implementation, or describe the effect the inflation had on the programme implementation, this has not been counted as this would have been assumptive (i.e. the researchers would have been assuming causal links).

- 'Supporting shelter self-recovery' is defined as one intervention type, as the provision of one or a combination of material, financial and technical assistance. This was partly because one of the first decisions to be made when designing a 'support for shelter selfrecovery' programme is whether to support households through the provision of material and/or financial and/or technical assistance. Thus, it is considered that there are lessons to be learned through comparing the different approaches. However, it can be argued that these are in fact four different intervention types, ${ }^{55}$ and the comparison of heterogeneous programmes is a limitation.

- The factors that helped or hindered are summaries of broad, descriptive texts. In many cases the documents reporting the factors that helped or hindered were not clearly operationalized or contained limited detail. For example, for factor 2: 'Undertaking adequate initial assessments and regular monitoring', none of the documents detail how frequently 'regular monitoring' should take place, but five documents do note that monitoring at various stages in the programme helps project delivery, for example by: 'identify[ing] strengths and weaknesses in the implementation of the programme', allowing the programme to be adapted to ensure its ongoing relevance and appropriateness (Aysan, 2008; Samuel Hall, 2012, p. 63). Thus this factor is summarized by the research team as 'regular' monitoring. Further detail or definition is not possible to conclude from this synthesis (e.g. if monitoring should take place every week, every month, every two months).

\footnotetext{
${ }^{54}$ The summary findings are presented in line with other reviews that included a range of study designs (mixed-methods, qualitative, quantitative), for example (Glenton et al., 2013; Oketch et al., 2014). The research team have not reported the summary findings in terms of the quality of the included studies because a) they vary significantly in their design and therefore it is not appropriate to directly compare them using a standard measure (such as number of participants in the study); b) the majority of the documents included in the review have significant gaps in their methodologies, restricting accurate disaggregation (e.g. into 'medium' or 'high' quality documents), and doing so would introduce an artificial distinction. Thus, while a preferred approach to evidence synthesis is to be able to weight findings of individual studies by strength of findings, in this review it was not feasible and 'vote counting', alongside a clear breakdown of findings (sections 6 and 7) and a detailed narrative on quality (Figure 4.3) was applied.

${ }^{55}$ These are: 1) Material, financial and technical assistance; 2) Financial assistance; 3) Technical and financial assistance; 4) Material and technical assistance. See Section 5.2 and Figures 5.2 and 5.3 for additional information.
} 


\section{Figure 7.1: Summary of key findings on factors that helped or hindered the implementation of interventions supporting shelter-self-recovery following humanitarian crises}

\begin{tabular}{|c|c|}
\hline Factor & Level of certainty in the evidence \\
\hline \multicolumn{2}{|c|}{ Household factors: helps programme implementation } \\
\hline $\begin{array}{l}\text { 1. The ability of } \\
\text { households and } \\
\text { communities to } \\
\text { contribute skills, labour, } \\
\text { materials or finance }\end{array}$ & $\begin{array}{l}\text { Nine studies identify this as a factor that either helped or hindered programme } \\
\text { implementation. } \\
\text { - The documents describe interventions in several countries and in response to } \\
\text { both natural disasters and complex emergencies. }\end{array}$ \\
\hline
\end{tabular}

Programme factors: helps programme implementation

2. Undertaking adequate initial assessments and regular monitoring
- Eight documents identify this as a factor that helped programme implementation when adequate, or hindered implementation when not adequate.

- The documents describe interventions in several countries and in response to both natural disasters and complex emergencies.

\section{Developing a clear and simple plan that is understood by all stakeholders}

\section{Designing a} programme that meets the changing needs of households and responds to the context

5. Developing clear and simple beneficiary selection criteria and a transparent selection process

\section{Supporting} coordinated community involvement and adequate two-way communication

7. Delivering adequate financial, technical and material assistance
- Four documents identify this as a factor that helped programme implementation when in place, or hindered implementation when not in place.

- The documents describe interventions in Sri Lanka, Indonesia and the Philippines and in response to natural disasters and complex emergencies.

- Seven documents identify this as a factor that helped programme implementation when adequate, or hindered implementation when not adequate.

- The documents describe interventions in several countries and in response to both natural disasters and complex emergencies.

- Seven documents identify this as a factor that helped programme implementation when adequate, or hindered implementation when not adequate.

- The documents describe interventions in several countries and in response to both natural disasters and complex emergencies.

- Seven documents identify this as a factor that helped programme implementation when adequate, or hindered implementation when not adequate.

- The documents describe interventions in several countries and in response to both natural disasters and complex emergencies.

- Nine documents identify this as a factor that helped programme implementation when adequate, or hindered implementation when not adequate.

- The documents describe interventions in several countries and in response to both natural disasters and complex emergencies.

Contextual factors: helps or hinders programme implementation

8. The level of economic recovery and rate of inflation

\section{The level of instability} and armed conflict

10. The level of certainty over government policies

11. The adequate number of programme staff with appropriate skills and experience

12. The nature and strength of pre-existing relationships
- Five documents identify this as a factor that either helped or hindered programme implementation.

- The documents describe interventions in four countries and in response to both natural disasters and complex emergencies.

- Four documents identify this as a factor that either helped or hindered programme implementation.

- The documents describe interventions in Bosnia and Herzegovina, Afghanistan and Sri Lanka in response to complex emergencies.

- One document identifies this as a factor that hindered programme implementation.

- This document describes interventions in Sri Lanka, in response to a complex emergency.

- Five studies identify this as a factor that either helped or hindered programme implementation.

- The studies describe interventions in Bosnia and Herzegovina, the Philippines, Pakistan and Sri Lanka and in response to both natural disasters and complex emergencies.

- Four documents identify this as a factor that either helped or hindered programme implementation.

- The studies describe interventions in Indonesia, Belize, the Philippines and Sri Lanka and in response to both natural disasters and complex emergencies. 


\begin{tabular}{|l|l|}
\hline Factor & Level of certainty in the evidence \\
\hline $\begin{array}{l}\text { 13. The level of abuse of } \begin{array}{l}\text { power for private gain } \\
\text { (corruption) }\end{array} \\
\begin{array}{l}\text { 14. The availability of } \\
\text { skilled and unskilled } \\
\text { labour }\end{array}\end{array}$ & $\begin{array}{l}\text { Five documents identify this as a factor that hindered programme } \\
\text { implementation. }\end{array}$ \\
\hline $\begin{array}{l}\text { The documents describe interventions in several countries and in response to } \\
\text { both natural disasters and complex emergencies. }\end{array}$ \\
\hline $\begin{array}{l}\text { 15. The accuracy of land } \\
\text { ownership records and } \\
\text { the availability of } \\
\text { suitable land }\end{array}$ & $\begin{array}{l}\text { Three documents identify this as a factor that either helped or hindered } \\
\text { The documents describe interventions in Indonesia in response to natural } \\
\text { disasters and in Sri Lanka in response to a complex emergency. }\end{array}$ \\
\hline $\begin{array}{l}\text { 16. The accessibility or } \\
\text { remoteness of } \\
\text { households }\end{array}$ & $\begin{array}{l}\text { Five documents identify this as a factor that either helped or hindered } \\
\text { The documents describe interventions in several countries and in response to } \\
\text { complex emergencies. }\end{array}$ \\
\hline
\end{tabular}

\subsection{HOW DID THE FACTORS HELP OR HINDER PROGRAMME IMPLEMENTATION?}

\section{Household factors}

\section{The household's ability to contribute skills, labour, materials or finance helps programme implementation.}

Certainty in the evidence: Nine documents identify this as a factor that helped or hindered programme implementation. The documents describe interventions in several countries and in response to both natural disasters and complex emergencies (see Figure 7.5 for further detail).

Of the 11 studies, 10 report contribution in the form of skills/labour, materials or finance from the households in order to 'complete' their shelter (Figure 7.2) ${ }^{56}$ For example Cukur et al. observe: 'there is substantial evidence that the capacities, the capabilities, knowledge and skills of the people of the communities were recognized and that the programme drew benefit from them' (2005, p. 125). Aysan and Cukur et al. both note that 'people were traditionally involved in organising the building of their own dwellings' (Aysan, 2008, p. 7) and that 'most house owners have experience of construction activities' (Cukur et al., 2005, p. 8). Equally, Skat reports that the 'quality depended first mainly on the beneficiaries' skills and experience in the building sector. If beneficiaries were masons or carpenters by profession, it was much easier for them to pay attention to adequate quality levels' (2009, p. 30).

Financial contributions included accessing bank credits, loans, selling or pawning assets (such as jewellery or livestock) (Aysan et al., 2007; Corsellis and Sweetnam, 2014; Cukur et al., 2005; Samuel Hall, 2012). These additional funds were used for paying for additional costs that were not planned for at the outset at the programme ${ }^{57}$ (Corsellis and Sweetnam, 2014; Samuel Hall, 2012).

\section{Inability of households to contribute financially hindered programme implementation because it:}

- slowed the construction progress as 'the cash grant amount was not enough to cover the full construction cost, and that... time [was] needed for saving more money or pooling family resources' (CRS, 2010, p. 24)

\footnotetext{
${ }^{56}$ While 10 studies reported household contributions, only 9 explicitly stated that this helped or hindered programme implementation.

57 'For example: one village was paying Pakistani Rupee (PKR)1,500 for mud to be delivered from $30 \mathrm{~km}$ away, as they had local issues with salinity' (Corsellis and Sweetnam, 2014, p. 38); households reported lack of sufficient access to water and a reliance on 'costly' alternative solutions (Samuel Hall, 2012, p. 27).
} 
- meant that households 'with fewer resources frequently lacked access to technical expertise and skilled builders', thus impacting on the quality of construction (Barakat and Zyck, 2011, p. 150).

Finally, use of salvaged material is also reported across four interventions, and is understood to help programme implementation by reducing costs (Corsellis and Sweetnam, 2014; CRS, 2010; DiPretoro, 2010; van Leersum, 2009).

Figure 7.2: Summary of included documents: household's contribution of skills/labour, finance and/or materials (listed alphabetically)

\begin{tabular}{|c|c|c|c|c|}
\hline Document & Skills/labour & Finance & Materials & Details \\
\hline Aysan, 2008 & $\checkmark$ & $\star$ & $?$ & $\begin{array}{l}\text { 'Beneficiaries invested another US } \$ 1,000 \text { to US } \$ 1,500 \\
\text { from their own savings but mostly by pawning their } \\
\text { jewellery with the Peoples Bank - a common practice } \\
\text { of collateral in Sri Lanka - to complete and improve the } \\
\text { house to a good level of finishing' (2008, p. 19) }\end{array}$ \\
\hline $\begin{array}{l}\text { Barakat and } \\
\text { Zyck, } 2011\end{array}$ & $?$ & $\star$ & $?$ & $\begin{array}{l}\text { 'The 'socioeconomically better off were able to dedicate } \\
\text { savings and other resources to the process of housing } \\
\text { reconstruction and frequently were able to contract } \\
\text { skilled labourers and engineers' (2011, p. 150) }\end{array}$ \\
\hline $\begin{array}{l}\text { CARE } \\
\text { International } \\
\text { UK, } 2015\end{array}$ & $\star$ & $?$ & $?$ & $\begin{array}{l}\text { 'In almost all cases the assistance was supplemented } \\
\text { by recipients' own resources so they could build a } \\
\text { house appropriate to their needs' }(2015, \text { p. } 60)\end{array}$ \\
\hline $\begin{array}{l}\text { Catholic } \\
\text { Relief } \\
\text { Services, } \\
2010\end{array}$ & $\checkmark$ & $\checkmark$ & $\checkmark$ & $\begin{array}{l}\text { ' } 75 \% \text { of respondents used salvaged materials from } \\
\text { their damaged home'... ' } 87 \% \text { of respondents in the final } \\
\text { evaluation spent the full cash grant or more on } \\
\text { construction }[74 \% \text { spent more] }(2010, \text { p. } 21)\end{array}$ \\
\hline $\begin{array}{l}\text { Corsellis } \\
\text { and } \\
\text { Sweetnam, } \\
2014\end{array}$ & $\checkmark$ & $\checkmark$ & $\checkmark$ & $\begin{array}{l}\text { Salvaged doors and roof beams... ' } 43 \% \text { said [the funds] } \\
\text { were insufficient and said that they had... used savings, } \\
\text { (often selling livestock) or took loans from their landlord } \\
\text { to complete... construction, or to add doors and } \\
\text { windows' }(2014, \text { p. } 38)\end{array}$ \\
\hline $\begin{array}{l}\text { Cukur et al., } \\
2005\end{array}$ & $\checkmark$ & $\checkmark$ & $X$ & $\begin{array}{l}\text { 'Only small amounts of building materials were } \\
\text { recycled. The damage was almost total and most of } \\
\text { what could be recycled had been recycled already'... } \\
\text { 'In order to complete reconstruction work on time } \\
\text { (formally three months) many informants able to do so, } \\
\text { obtained a bank credit, while a few took loans' (2005, } \\
\text { p. 74) }\end{array}$ \\
\hline $\begin{array}{l}\text { DiPretoro, } \\
2010\end{array}$ & $?$ & $?$ & $\star$ & $\begin{array}{l}\text { 'In some cases the funds provided were sufficient, } \\
\text { when combined with the use of salvaged materials, to } \\
\text { purchase enough materials to completely reconstruct a } \\
\text { home' }(2010, \text { p. } 3)\end{array}$ \\
\hline $\begin{array}{l}\text { Samuel Hall, } \\
2012\end{array}$ & $?$ & $\star$ & $?$ & $\begin{array}{l}\text { 'Almost all beneficiaries mentioned that they had to } \\
\text { take up loans to cover labour costs and wall } \\
\text { components. Additional costs were also necessary for } \\
\text { buying stones for foundations and, depending on the } \\
\text { availability of material in a given area, bricks, cement or } \\
\text { clay' (2012, p. 44) }\end{array}$ \\
\hline Skat, 2009 & $?$ & $\star$ & $?$ & $\begin{array}{l}\text { 'In some cases to contribute with own private savings } \\
\text { or additional loans' }(2009, \text { p. } 20)\end{array}$ \\
\hline $\begin{array}{l}\text { van Dijk, } \\
2012\end{array}$ & $?$ & $?$ & $?$ & Not stated \\
\hline $\begin{array}{l}\text { van } \\
\text { Leersum } \\
\text { and Arora, } \\
2011\end{array}$ & $?$ & $\star$ & $\star$ & $\begin{array}{l}\text { With 'available resources, homeowners have been able } \\
\text { to express their economic wealth by opting for a bigger } \\
\text { house or a more sophisticated finish ' (van Leersum, } \\
2009 \text {, p. 55) }\end{array}$ \\
\hline
\end{tabular}

Note: $\star$ indicates that the document mentions households contributed in the category indicated; $X$ indicates the households are reported not to have contributed in the category indicated; and ? indicates the document does not mention whether or not households contributed in the category indicated. 


\section{Programme factors}

\section{Undertaking adequate initial assessment to inform the programme design, as well as effective learning through regular monitoring of project activities, outputs and outcomes can help programme implementation.}

Certainty in the evidence: Eight documents identify this as a factor that helped or hindered programme implementation. The documents describe interventions in several countries and in response to both natural disasters and complex emergencies (see Figure 7.5 for further detail).

Five studies identify that damage assessments were undertaken to determine eligibility of households and level of need (Aysan, 2008; Barakat and Zyck, 2011; CRS, 2010; DiPretoro, 2010; Skat, 2009) ${ }^{58}$ CRS notes that programme staff undertook the initial surveys and this helped implementation because of the technical value and for the personal relationships built as a result of the direct interaction' (2010, p. 14). Two further studies identify a number of assessments that were helpful at the outset of the programme: 'local needs' (CARE International UK, 2015, p. 5), market assessments (CARE International UK, 2015; DiPretoro, 2010) and 'assessments [to] determine that there [is] the technical capacity to conduct basic repairs and construction at the household and community level' (CARE International UK, 2015; DiPretoro, 2010, p. 5). These assessments helped validate the relevance and appropriateness of the programme and avoid further harm to the affected population (CARE International UK, 2015; DiPretoro, 2010). In addition, as part of their lessons learned the studies highlight the value of undertaking 'environmental impact assessments when undertaking construction programmes at scale' (CARE International UK, 2015, p. 70), 'risk assessment for all construction activities' (CARE International UK, 2015, p. 71) and 'natural disaster risks assessments [to inform shelter design]' (Samuel Hall, 2012, p. 54). Also see Box 'What health and safety construction risks were identified?' (p. 50).

Five studies identify one of the following monitoring activities as helpful: 'official field and/or technical reports, evaluations and reviews' (van Leersum and Arora, 2011, p. 260), 'yearly reviews' (Samuel Hall, 2012, p. 63) and 'monitor[ing] the availability and prices of key goods and services' (Aysan, 2008, p. 16; DiPretoro, 2010; Skat, 2009). As part of their lessons learned two studies also identify as helpful the value of 'qualitative and analytical monitoring and reporting on impact and the process of implementation' (Aysan et al., 2007, p. 24) and 'an appropriate outcome monitoring system' (Skat, 2009, p. 50). This ongoing monitoring was helpful in 'identify[ing] strengths and weaknesses in the implementation of the programme', allowing the programme to be adapted to ensure its ongoing relevance and appropriateness (Aysan, 2008; Samuel Hall, 2012, p. 63) - also see factor 4.

3. Developing a clear and simple plan that is understood by all stakeholders, that sets out roles and responsibilities and incorporates learning from previous programmes, helps programme implementation.

Certainty in the evidence: Four documents identify this as a factor that helped or hindered programme implementation. The documents describe interventions in three countries and in response to both natural disasters and complex emergencies (see Figure 7.5 for further detail).

Three studies identify that having a 'clear strategy in place from the beginning [was] a very positive influence (CARE International UK, 2015, p. 52; Corsellis and Sweetnam, 2014; CRS, 2010) - this included vision/goals, methodology - as it helped:

- make 'expectations clear, both for CRS to implement and community members to support the program' (CRS, 2010, p. 4)

- give 'clarity and direction to the response' (CARE International UK, 2015, p. 52)

- by 'having a clear vision across senior actors such as DFID and IOM, the Cluster enabled the process and technology to be effective within the... programme' (Corsellis and Sweetnam, 2014, p. 51).

\footnotetext{
${ }^{58}$ See factor 5 (beneficiary selection) and factor 13 (corruption) for further discussion of damage assessments.
} 
Learning from previous interventions, their successes and their challenges, is also reported to have 'improved the efficacy of the programme' (Corsellis and Sweetnam, 2014, p. 52); with Aysan noting that 'limited learning' from earlier programmes was a 'weakness' (Aysan et al., 2007, p. 37).

In particular, when partnerships were formed to implement programmes, the studies report the importance of precisely defining respective roles and responsibilities for each partner from the beginning (Aysan et al., 2007; CRS, 2010; Skat, 2009). Aysan et al. report that the lack of adequately defined roles hindered programme implementation because 'staff in the field offices [were] in the difficult position of having to determine and negotiate their responsibilities... with limited guidance or authority to successfully influence policy or practice' (Aysan et al., 2007, p. 32).

What health and safety construction risks were identified?

Implementing agencies have a responsibility to ensure that adequate assessments of health and safety risks and appropriate mitigation measures are in place. This is not identified as a factor because the studies do not explicitly state how this helped or hindered programme implementation. However, there are clear links with factors 2 and 15.

Two of the studies identify occasions when homeowners were injured as a result of their involvement in the construction process. Corsellis and Sweetnam note that there were 'three instances reported to us of children and women going sick or injured when using lime....none of the injuries were long term' (2014, p. 44). In addition, 'there was... one report of a fall [from the roof] and one woman was reported to have injured herself badly when digging mud' (ibid). CARE International UK also identifies that the 'accident rate appears to be reasonably high... [with] reports of cuts, stepping on nails and trips and slips. In the 15 barangays [(small districts)] visited, there were four accidents mentioned which were potentially life-or livelihood-threatening (falls from height or serious cuts), two of which had serious outcomes requiring hospitalization or affecting the victim's ability to work' (2015, p. 48).

In one of the supporting documents - Ferretti and Ashmore - there is also an account of a beneficiary building a wall on foundations that were 'not yet dried-up', which led to the collapse of a wall provoking the death of two children in a neighbouring house (2010, p. 17)

These accounts of injury or even death as a result of households' involvement in the construction process is directly in contrast to the Sphere standards Protection Principle 1: 'Avoid exposing people to further harm as a result of your actions' (The Sphere Project, 2011). In all three studies mentioned in this box there were some measures in place to manage some of the risks:

- personal protective equipment was supplied to reduce the risk of working with lime (Corsellis and Sweetnam, 2014)

- distribution of leaflets with advice on staying safe while doing construction work (CARE International UK, 2015)

- the owner of the home where the wall collapsed had been advised of the risks by the implementing agency (Ferretti and Ashmore, 2010).

However, given the accounts of injuries or death detailed in the studies there is room for significant improvement. Improved assessments and ongoing monitoring of health and safety risks should inform the provision of the technical assistance required to best manage the risks associated with construction by homeowners.

\section{Insufficient flexibility in programme design hinders programme implementation because the programme does not meet the changing needs of targeted households or respond to changes in the contextual factors.}

Certainty in the evidence: Seven documents identify this as a factor that helped or hindered programme implementation. The documents describe interventions in several countries in response to both natural disasters and complex emergencies (see Figure 7.5 for further detail).

A 'one-size-fits all' approach is noted as hindering programme implementation because households with additional requirements (greater transport costs, larger families, local hazards requiring more complex technical design solutions, such as slopes or flooding) do not receive adequate financial, material or technical support, and need to find funds through alternative means (such as selling assets) to 'complete' their shelters (Aysan et al., 2007; CARE International UK, 2015; Corsellis and Sweetnam, 2014). Also see Box 'How did the programmes adapt to urban contexts?' (p. 51).

Five of the studies provide examples of flexibility in programming to better support local need:

- diverting funds to support vulnerable households without land tenure (Aysan, 2008)

- initiating additional financial assistance paid to each household ('top ups') (Aysan, 2008; CARE International UK, 2015) 
- continually readjusting training and awareness raising activities (van Leersum and Arora, 2011)

- 'not specifying a single desired construction standard in the strategy document... [and promoting a] a range of "locally-known" technologies' (van Leersum and Arora, 2011, p. 258)

- supplementing housing recovery policies and programmes with longer-term livelihood recovery strategies (CARE International UK, 2015; Cukur et al., 2005; Skat, 2009).

\section{How did the programmes adapt to urban contexts?}

Three studies provide useful insights into the adaptation of interventions supporting shelter self-recovery to urban contexts.

Cukur et al. describe the application of a 'modified self-help' approach in a suburb of Sarajevo where the majority of housing was apartment buildings (2005, pp. 72-73). The implementing organization renovated the building exterior and installed services. Households were then provided with construction materials and kitchen and bathroom fittings and were responsible for renovation of apartment interiors themselves. Apartments not being renovated were sealed with timber shutters, while in buildings to which more than 75 percent of occupiers returned, the implementing organization also reconstructed stairways and facades.

In the Philippines, CARE International UK found that households were less satisfied with the quality of reconstructed houses in peri-urban areas because 'previously houses had been largely built of concrete blocks, and the new timber houses were not seen to be as strong, or as durable' (2015, p. 45). The organization's 'roving teams' of carpenters providing technical assistance also 'found it more difficult to commit the time [in periurban areas] as it meant giving up on time spent earning money' (2015, p. 47).

Samuel Hall reports that households in urban areas in Afghanistan 'often had to adapt the design of their shelters to the size and shape of the land plot they occupy' (2012, p. 38). The implementing organization developed several different packages of shelter assistance to suit different conditions. The 'one-room shelter' model was more popular in urban areas as it 'allows upgrading or expanding of shelters that already house displaced family members, who opt for living with host families. It also fits more realistically with the more limited space available in urban areas compared to returnee townships or rural areas' (2012, p. 29).

Urban households in Afghanistan were also significantly less satisfied with the assistance they received than were households in peri-urban or rural areas as there was a 'clear expectations gap between what the shelter programme offers and urban household needs' (Samuel Hall, 2012, p. 35). Urban households were more critical of the quantity and quality of the materials and technical assistance provided. This was because the materials provided 'often do not match the quality available on the local market' (2012, p. 43). Additionally, 'unskilled and skilled labour is easier to come by in urban areas' (ibid) and households living in urban areas were more likely to receive training (2012, p. 56). Yet, urban households felt they lacked the technical knowledge to build or supervise the construction of their shelters 'due to the different landscape and requirements of urban shelter construction' (2012, p. 43).

\section{Developing clear and simple beneficiary selection criteria that is supported by a transparent process to compile and verify the beneficiary list can help programme implementation}

Certainty in the evidence: Seven documents identify this as a factor that helped or hindered programme implementation. The documents describe interventions in several countries and in response to both natural disasters and complex emergencies (see Figure 7.5 for further detail).

Across all 11 documents beneficiary selection criteria is underpinned by one or more of the following (also see Figure 7.3 for further details):

- level of vulnerability (households were eligible for support if they met the selection criteria that defined vulnerability)

- damage or loss of previous house (households were eligible for support if their homes had been damaged or destroyed)

- ownership or secure tenure of land on which to build (households were eligible for support if they had proof of land ownership or tenure).

In most instances the beneficiary selection criteria were developed by the implementing agency to align with broader government policy (such as Aysan, 2008; Barakat and Zyck, 2011) or with the organization's mandate to support the most vulnerable (such as CARE International UK, 2015). In one instance, the selection criteria was developed by the 'Village Committee', who were then responsible for 'select[ing] beneficiaries' and deal[ing] with the local... authorities' (Cukur et al., 2005, p. 40). This was identified as having a positive outcome as it 'strengthened social trust, collective powers and self-esteem' (ibid). The implementing agency or government, or a community committee then compiled the beneficiary list. See Figure 7.3 for further details. 
Finally, five of the studies (Aysan et al., 2007; CARE International UK, 2015; CRS, 2010; Cukur et al., 2005; DiPretoro, 2010) identify the importance of 'transparency' in the beneficiary selection process, which can be supported by 'simple' criteria (Aysan et al., 2007) and verification by the wider community - either in meetings or through public display - helped project implementation by providing 'a transparent way for the community to learn about and have input into the program while mitigating the chances for exclusion and related complaints' (DiPretoro, 2010, p. 8). Challenges related to a 'non- transparent' process are reported by Samuel Hall for example in instances where, there was a 'single focus on community leaders' to identify beneficiaries, with limited broader community involvement (2012, p. 69). This hindered programme implementation due to the 'potential interference of nepotism and/or corruption' (ibid) and reduced the effectiveness of reaching vulnerable members in a community. This is echoed by Aysan et al. who note that 'disputes, tensions and sometimes abuses of power' arose from the beneficiary selection process, specifically in this instance in assessment of the level of damage to the existing house $(2007$, p. 18). For further information, see factor 13 (corruption).

Figure 7.3: Summary of included documents: Beneficiary selection (listed alphabetically)

\begin{tabular}{|c|c|c|c|}
\hline Document & $\begin{array}{l}\text { What was the basis of } \\
\text { eligibility? }\end{array}$ & $\begin{array}{l}\text { Was there a damage } \\
\text { assessment? }\end{array}$ & $\begin{array}{l}\text { Who compiled beneficiary } \\
\text { list? }\end{array}$ \\
\hline Aysan, 2008 & $\begin{array}{l}\text { Damage to home } \\
\text { (secure land) }\end{array}$ & Yes & Implementing agencies \\
\hline Barakat and Zyck, 2011 & $\begin{array}{l}\text { Damage to home } \\
\text { (secure land) }\end{array}$ & Yes & Unclear \\
\hline $\begin{array}{l}\text { CARE International UK, } \\
2015\end{array}$ & Level of vulnerability & No & $\begin{array}{l}\text { Community 'beneficiary } \\
\text { selection committee'; verified } \\
\text { by community (meeting) }\end{array}$ \\
\hline $\begin{array}{l}\text { Catholic Relief } \\
\text { Services, } 2010\end{array}$ & Damage to home & Yes & $\begin{array}{l}\text { Implementing agency } \\
\text { (supported by community } \\
\text { committee); verified by } \\
\text { community (publically } \\
\text { displayed) }\end{array}$ \\
\hline $\begin{array}{l}\text { Corsellis and } \\
\text { Sweetnam, } 2014\end{array}$ & $\begin{array}{l}\text { Damage to home and } \\
\text { level of vulnerability }\end{array}$ & Not clear & Not clear \\
\hline Cukur et al., 2005 & Varied & Varied & $\begin{array}{l}\text { Varied e.g. in Grapska the } \\
\text { 'Village Committee'; verified } \\
\text { by community }\end{array}$ \\
\hline DiPretoro, 2010 & Not clear & Yes & $\begin{array}{l}\text { Not clear; }{ }^{59} \text { verified by } \\
\text { community (meeting) }\end{array}$ \\
\hline Samuel Hall, 2012 & $\begin{array}{l}\text { Level of vulnerability } \\
\text { (secure land) }\end{array}$ & No (not rapid on-set) & Not clear \\
\hline Skat, 2009 & $\begin{array}{l}\text { Damage to home } \\
\text { (secure land) }\end{array}$ & Yes & Government \\
\hline van Dijk, 2012 & Not clear & No (not rapid on-set) & Not clear \\
\hline $\begin{array}{l}\text { van Leersum and } \\
\text { Arora, } 2011\end{array}$ & $\begin{array}{l}\text { Damage to home } \\
\text { (secure land?) }\end{array}$ & Yes & Implementing agency \\
\hline
\end{tabular}

6. Supporting coordinated community involvement and ensuring adequate two-way communication between the implementing agency and the households or community can help programme implementation.

Certainty in the evidence: Seven documents identify this as a factor that helped or hindered programme implementation. The documents describe interventions in several countries in response to both natural disasters and complex emergencies (see Figure 7.5 for further detail).

\footnotetext{
${ }^{59}$ The document notes that 'The program used community based targeting; working through village chairpersons', but does not explicitly state who compiled the beneficiary list (DiPretoro, 2010).
} 
Supporting coordinated community involvement is discussed in six of the studies, and includes building on existing community structures (Aspin, 2010), delivering training (Skat, 2009; van Dijk, 2012) and forming community groups - named 'pondok' committees (CRS, 2010), community development committees (Skat, 2009), village committees (Cukur et al., 2005) or new village reconstruction committees (van Leersum and Arora, 2011). In particular the committees helped support 'coordination and communication' with the wider community (CRS, 2010, p. 12), speeded up the process (ibid), supported resolution of issues (Corsellis and Sweetnam, 2014), presented an opportunity for 'harnessing local knowledge' (van Leersum and Arora, 2011) and essentially represented a strong community 'partner' to increase the effectiveness of programme delivery (Skat, 2009). Engaging with traditional community cooperation mechanisms (e.g. bayanihan, Philippines; ashar, Afghanistan) is reported to help project delivery, especially supporting the most vulnerable (CARE International UK, 2015; Corsellis and Sweetnam, 2014; Samuel Hall, 2012); however, the sources note it was not accepted in all communities.

Various two-way communication mechanisms between the implementing agency and households are noted in the documents:

- helplines and community facilitators in the field (Aspin, 2010)

- 24-hour hotline with a phone number, posted in a central location, which community members could call to provide feedback or submit complaints (CRS, 2010)

- business cards, posters and a toll-free phone number (Corsellis and Sweetnam, 2014)

- suggestion boxes (CARE International UK, 2015)

- discussions with community committees or implementing agency staff during site visits (CARE International UK, 2015; Corsellis and Sweetnam, 2014; CRS, 2010).

Despite the different communication options, a number of studies note that households typically 'defaulted' to face-to-face discussions (CARE International UK, 2015; Corsellis and Sweetnam, 2014; CRS, 2010). Furthermore as part of their lessons learned Barakat et al. note that low-tech methods of communication such as 'information boards would have been beneficial' (2008, p. 42) and this is mirrored by Aysan et al. who identifies as a lesson learned the value of communicating using 'pamphlets and notices, large exhibits and boards explaining the project and its progress' (Aysan et al., 2007, p. 21).

When two-way communication was not adequate, two documents note that this hindered programme implementation by leading to beneficiary confusion (Barakat et al., 2008; van Leersum and Arora, 2011) and 'inflated perceptions of corruption' (Barakat et al., 2008, p. 44).

\section{Delivering adequate financial, technical and/or material assistance that meets the needs of households and is suited to the context helps programme implementation.}

Certainty in the evidence: Nine documents identify this as a factor that helped or hindered programme implementation. The documents describe interventions in several countries and in response to both natural disasters and complex emergencies (see Figure 7.5 for further detail).

Interventions delivered one or a combination of material, technical and/or financial assistance (see 5.1 and Figure 5.2 in Section 5).

Financial assistance: Six of the interventions distributed financial assistance in instalments; this represents all five of the programmes that provided financial and technical assistance (Aysan, 2008; Corsellis and Sweetnam, 2014; CRS, 2010; Skat, 2009; van Leersum and Arora, 2011) and one of the interventions that provided financial assistance only (Barakat et al., 2008). ${ }^{60}$ For all the interventions that provided financial and technical assistance, payment of the next instalment was linked to inspection of progress and completion of the individual household and/or all the shelters in a community up to a certain level. CRS (2010), van Leersum (2011), Aysan et al. (2007) and Corsellis and Sweetnam (2014) all note that this helped programme implementation; for example by 'ensur[ing] that people spent the money provided on the rebuilding process' (Aysan et al., 2007, p. 23) and 'realizing high-

${ }^{60}$ The study reports that the majority of donors/implementing agencies providing financial assistance delivered it in instalments, this is with the notable exception of Jihad al Bina'a, who delivered it as a one-off payment. 
quality housing' (van Leersum, 2009, p. 78). However, the studies also report on challenges associated with these inspections associated with capacity of staff (see factor 11) and corruption (see factor 10).

Three studies report challenges related to inadequate levels of funding that resulted in incomplete shelters (Aysan, 2008), 'inappropriate' modification and lower-quality construction' (van Leersum and Arora, 2011) or necessitating households contributing additional funds to make up the shortfall (CRS, 2010) - see also factor 7. Conversely, Corsellis and Sweetnam note 'the size of the grant was set at a correct level for the majority of beneficiaries to be able to construct a shelter' (2014, p. 52).

Technical assistance: Three programmes that delivered technical assistance alongside material and/or financial assistance report that it helped contribute to improved construction quality (CARE International UK, 2015; CRS, 2010; Skat, 2009). In particular it is noted that site visits and practical hands-on/on-the-job training was 'effective' or the most 'liked' (Corsellis and Sweetnam, 2014, p. 43; van Leersum and Arora, 2011, p. 260). Conversely, both of the interventions that provided only financial assistance identified a need for complementary technical support. For example, Barakat and Zyck highlight that 'the lack of technical assistance meant that homes were built without regard to technical standards and without due caution to threats posed by earthquakes and renewed conflict' (2011, p. 150); equally DiPretero reports that from his research ' 72 percent of families could have used more information and/or training about ways to make their home more hurricane resistant... [highlighting] the need to provide appropriate technical assistance in cash for shelter programs' (2010, p. 6).

The level of technical assistance required by each household varied significantly and is noted as being dependant on or linked to:

- the degree of household dependence on skilled labour to construct their shelters; for example 'those who hired all skilled labour were generally disinterested in technical assistance' (CRS, 2010, p. 15)

- exposure to hazards (Aysan, 2008; Barakat et al., 2008; DiPretoro, 2010); for example where 'disasters risk is high and frequent... [there is greater need for] stronger technical support and closer monitoring to ensure safer reconstruction' (Aysan, 2008, p. 9)

- The level of existing knowledge; for example where women were traditionally less involved in construction it was noted that 'they'd have liked to be able to attend more training, and it would have enabled them to take a more active role in decision making and construction (CARE International UK, 2015, p. 47)

In particular Aysan et al. note that when delivering financial and technical assistance together, 'direct inspection of the progress, with construction and technical advice to beneficiaries... [and with payment] linked to the four instalments also had a positive impact on the quality of construction (2007, p. 23).$^{61}$ This is supported by CRS (2010) and Corsellis and Sweetnam (2014), who identify that it was necessary for the whole community to have completed construction to a defined level in order to be eligible for the next payment instalment. This approach is reported to help programme implementation as it supported vulnerable households to complete their shelters and 'kept beneficiary accountability high and led to high rates of success' (CRS, 2010, p. 4).

Material assistance: Four programmes provided materials and/or tools alongside technical assistance (Cukur et al., 2005; van Dijk, 2012) or technical and financial assistance (CARE International UK, 2015; Samuel Hall, 2012).

Key to the success of programmes providing material assistance was the quantity, quality and appropriateness of the materials provided. Households interviewed in the Philippines rated the quality and usefulness of the materials they received highly. Consequently, none of the materials had been sold or exchanged while just one family had given the materials away (CARE International UK, 2015). While satisfied with the materials they received in

\footnotetext{
${ }^{61}$ Technical assistance was delivered in later stages of the programme: 'The recognition of this shortcoming led to the establishment of regional technical offices by the UN Human Settlements Programme (UN-Habitat). Covering only 8 percent of southern Lebanon's communities from late 2007 onwards, at which point the vast majority of the population in southern Lebanon had begun if not yet completed housing rehabilitation, their impact was limited (Barakat and Zyck, 2011, p. 144).
} 
general, households in Afghanistan were less satisfied with the iron doors and window frames. "Both are inadaptable to the weather conditions (heat or cold) and subject to rust and deformation. [Thus] whenever their economic situation allowed it, beneficiaries removed iron frames to replace them with wooden ones' (Samuel Hall, 2012, p. 34).

In the programmes providing both material and financial assistance, the implementing agency provided specific items that were not available or affordable to beneficiaries in local markets. In Afghanistan these were I-beams, T-beams and ceiling bricks (Samuel Hall, 2012) while in the Philippines the "high quality CGI [corrugated galvanised iron] sheets were extremely popular' (CARE International UK, 2015, p. 38). The combination of material and financial assistance was noted to be 'both popular and effective, allowing stronger reconstruction and giving people a high degree of control over their own recovery' (CARE International UK, 2015, p. 64).

When providing a combination of assistance (for example construction materials, tools and cash) the sequencing of distribution was an important factor in successful implementation. CARE International UK report that lack of access to tools delayed construction progress as 'people had to wait and borrow tools when they became available' from other community members (CARE International UK, 2015, pp. 44-45). Similarly, in communities where cash assistance was distributed later than the materials, beneficiaries reported that they had to wait before they could use the materials (CARE International UK, 2015).

\section{What issues did the studies raise about vulnerability and gender?}

Vulnerable households are at a greater disadvantage than non-vulnerable households when involved in shelter-self recovery programmes; the standard 'package of assistance' may not meet their needs. This is a cross-cutting issue with links to factor 3 , factor 4 and factor 13.

Five of the studies identify that vulnerable households were at a greater disadvantage than others when involved in shelter self-recovery programmes - these include single elderly people, households with family members with disabilities, female-headed households and those on low incomes. Examples of disadvantages for vulnerable households provided include:

- access to skilled and unskilled labour: Vulnerable households had more problems in all areas 'except for the timely delivery of materials... [in particular] problems with [accessing] unskilled and skilled labour' (Samuel Hall, 2012, p. 42; also Barakat and Zyck, 2011).

- greater vulnerability to inflation: Vulnerable households 'given their inability to purchase materials prior to starting reconstruction, were the most likely to have been affected by inflation in the price of construction materials' (Barakat and Zyck, 2011, p. 150).

- challenges managing funds: Poorer households noted they had experienced difficulties in managing the money they received from the financial grant. They were not used to handling a large amount of money and they were 'overwhelmed by the huge task to handle funds and organize house construction' (Skat, 2009, p. 6).

Specific gender disadvantages reported for female-headed households include:

- access to tools based on prior ownership: 'it was noted by some women that not having tools meant they were not able to do construction for themselves, and were dependent on carpenters' (CARE International UK, 2015, p. 46).

- increased costs associated with paying for additional labour: Some female-headed households found 'that they had to hire greater amounts of casual labour to build their house because they had less of their own labour to provide and this was an additional cost' (Aysan et al., 2007, p. 18).

- poor quality materials and construction: Skat noted that women flagged that 'they were cheated by material suppliers with bad quality material and too high prices... [because] In most cases, female beneficiaries did not have the skills and capacities to supervise the construction site and to check quality (2009, p. 24).

- training not inclusive of women: 'many women expressed a desire to receive technical training, but the programme concentrated the training on carpenters and roving team members, which excluded many of the women' (CARE International UK, 2015, p. 59).

A number of the studies discuss wider community support (CARE International UK, 2015; Corsellis and Sweetnam, 2014; CRS, 2010) or support from (typically male) relatives or friends (Aysan et al., 2007; Skat, 2009) and flag this as a valuable support for vulnerable households to overcome the disadvantages identified. However, when targeted support for more vulnerable households is not built into the programme - for example paying instalments on 'community completion' - Aysan et al. highlight that support to vulnerable households 'was not universal and depended on the social networks of people' (2007, p. 18). Provision of additional assistance to vulnerable households during the construction process may be necessary if the standard approach does not meet their need (CARE International UK, 2015; Samuel Hall, 2012). 


\section{Contextual factors}

\section{Low levels of household and market economic recovery and high rates of inflation can hinder programme implementation.}

Certainty in the evidence: Five documents identify this as a factor that helped or hindered programme implementation. The documents describe interventions in several countries and in response to both natural disasters and complex emergencies (see Figure 7.5 for further detail).

High rates of inflation and high demand for materials are highlighted in four studies as hindering programme implementation because they resulted in increasing prices for transport, building materials and skilled labour, leading to incomplete houses or lower quality construction as the original level of financial assistance provided by the agency was insufficient (Aysan, 2008, p. 12; Barakat and Zyck, 2011; Corsellis and Sweetnam, 2014; van Leersum and Arora, 2011). The studies report significant increased costs of construction, for example where construction costs have 'almost doubled since the start of reconstruction' (Aysan et al., 2007, p. 5). Such an extreme price hike was also noted by Barakat and Zyck, the 'price of steel, for example, rose from US $\$ 605$ per tonne immediately prior to the conflict to US $\$ 1,166$ ' approximately two years later $(2011$, p. 151).

Conversely, a well-functioning market with the ability for supply to meet demand can help programme implementation because, as Aspin reports, construction materials and labour are available at 'relatively stable prices' (2010, p. 11).

Finally, the level of economic recovery of the individual household is identified as a factor in three documents: households without adequate income may spend funding provided for shelter on more urgent priorities such as food, medicine or household items thus hindering the programme by affecting the quality and the number of 'complete' shelters (CARE International UK, 2015; Samuel Hall, 2012; Skat, 2009).

\section{High levels of instability and armed conflict can hinder programme implementation.}

Certainty in the evidence: Four documents identify this as a factor that helped or hindered programme implementation. The documents describe interventions in Bosnia and Herzegovina, Afghanistan and Sri Lanka in response to complex emergencies (see Figure 7.5 for further detail).

Armed conflict or instability hindered programme delivery in the two projects implemented in the north-eastern provinces of Sri Lanka (Aysan, 2008; Skat, 2009), as well as in Afghanistan (Samuel Hall, 2012). Aysan reported that the conflict both interrupted the programme in some locations, and slowed down progress in others (2008). Specific challenges hindering programme implementation included material and labour shortages (Aysan, 2008; Skat, 2009) difficulty getting to banks (Aysan, 2008), increased material costs (Skat, 2009), shortage of available (qualified) staff (ibid), staff needing to be evacuated (Aysan, 2008) and restrictions on 'proper monitoring' and therefore the 'visibility over the programme' (Samuel Hall, 2012, p. 139).

Equally Cukur et al. note the value of a secure environment, in particular the role of the stabilization force in Bosnia and Herzegovina (SFOR) and its 24-hour surveillance during the initial stages of reconstruction; because 'without SFOR Grapska would not have been rebuilt, it would have been too dangerous' (2005, p. 24).

\section{Low levels of certainty over government policies can hinder programme implementation.}

Certainty in the evidence: Only one document identifies this as a factor that helped or hindered programme implementation. The document describes an intervention in Sri Lanka in response to a complex emergency (see Figure 7.5 for further detail).

Aysan (2008) reports that limited certainty in government policy - specifically related to coastal land that is considered higher risk for flooding or future tsunamis and may result in 
restrictions in construction ('buffer-zones') and additional funding provided to households ('top-ups') - can hinder programme implementation because:

- it can cause 'delays in the delivery of support for housing' as implementing agencies wait for government bodies to confirm policies (Aysan, 2008, p. 12)

- some households receive multiple forms of assistance, thus duplicating efforts and inefficiently allocating resources (Aysan et al., 2007).

\section{Inadequate numbers of staff with appropriate levels of skills and experience hinders programme implementation.}

Certainty in the evidence: Five documents identify this as a factor that helped or hindered programme implementation. The studies describe interventions in Bosnia and Herzegovina, the Philippines, Pakistan and Sri Lanka and in response to natural disasters and complex emergencies (see Figure 7.5 for further detail).

Inadequate numbers of staff (technical support, community mobilization or coordination, programme management, specialist procurement) is reported across four of the interventions (Aysan et al., 2007; CARE International UK, 2015; Skat, 2009; van Leersum, 2009). The studies note two key reasons why programme implementation was hindered, firstly as a result of delayed inspections of construction quality when funds are distributed in instalments (Aysan et al., 2007; van Leersum and Arora, 2011); which when coupled with rapid inflation and labour shortages 'created difficulties for beneficiaries who were unable to keep skilled labourers, and were grappling with rising prices for materials therefore sometimes having to take out loans in order to keep work moving' (Aysan et al., 2007, p. 22). Secondly, delayed delivery of training and other forms of technical assistance meant that assistance was not 'in line with the pace of reconstruction' leading to 'ambiguity about seismic-resistance compliance of built houses', and ultimately impacting on construction quality (van Leersum and Arora, 2011, pp. 261-263).

12. Positive pre-existing in-country relationships with government agencies, implementing partners and building materials suppliers can help programme delivery.

Certainty in the evidence: Four documents identify this as a factor that helped or hindered programme implementation. The studies describe interventions in Indonesia, Belize, the Philippines and Sri Lanka, in response to natural disasters and a complex emergency (see Figure 7.5 for further detail).

The documents note that pre-existing relationships between the implementing agency and the government (Skat, 2009), with local implementing partners (CARE International UK, 2015) or building supplies and hardware stores (DiPretoro, 2010) were valuable in supporting programme delivery. Specifically, the pre-existing relationship with the government helped positively to 'well anchor [the programme] in the country and the local context' (Skat, 2009, p. 22) and with the building supply store 'led to a more rapid delivery of assistance to the beneficiaries'(DiPretoro, 2010, p. 9).

CRS reports challenges in programme implementation as it had no previous relationship with the communities and as a result of the word 'Catholic' in its name, in predominantly Muslim communities, there were 'many isolated incidents of potential beneficiaries refusing, or initially refusing then later changing their minds, assistance for fear of religious pressures' (2010, p. 17). This is reported to hinder programme implementation as it 'significantly slow[ed] progress' while CRS undertook additional coordination activities to clarify the misunderstanding.

13. High levels of abuse of power for private gain (corruption) can hinder programme implementation.

Certainty in the evidence: Five documents identify this as a factor that hindered programme implementation. The documents describe interventions in several countries and in response to both natural disasters and complex emergencies (see Figure 7.5 for further detail). 
Instances of corruption or fraud - the abuse of power for private gain - is reported in seven studies (Aysan et al., 2007; Barakat and Zyck, 2011; Corsellis and Sweetnam, 2014; Cukur et al., 2005; Samuel Hall, 2012; Skat, 2009; van Leersum and Arora, 2011).

The opportunities for corruption are reported at three key stages of the programme, during the:

- beneficiary selection process (including the damage assessment where applicable)

- review of construction quality (when payment is made in instalments based on quality assessment by technical staff or others)

- purchasing of the materials.

However, only five documents explicitly note that this hindered programme implementation. The documents note that the programme was hindered because it led to misallocation of funds (Barakat and Zyck, 2011; Samuel Hall, 2012) and a key recommendation from Barakat et al. is that damage assessments should be undertaken by a 'fully independent [engineering] firm and complemented by community involvement' (2008, p. 42). Equally, during the review of construction quality for payment in instalments, Van Leersum reports that 'households' inability to satisfy demands for bribes slowed down their inspection and the disbursement of the next instalment, despite their house being fully compliant with ERRA's standards' (van Leersum and Arora, 2011, p. 259). Further, during the purchasing of materials Corsellis and Sweetnam note that 'procurement had been done by the landlord... [raising] concerns about the purchase of poor quality materials and the pocketing of funds (2014, p. 41).

\section{Limited availability of skilled and unskilled labour can hinder programme implementation.}

Certainty in the evidence: Three documents identify this as a factor that helped or hindered programme implementation. The documents describe interventions in Indonesia and Sri Lanka and in response to both natural disasters and complex emergencies (see Figure 7.5 for further detail).

Nine of the studies mention that households hired skilled or unskilled 'labourers' to build their shelters (Figure 7.4). Samuel Hall highlight that the employment of many 'labourers' had 'positive repercussion on the local economy' (2012, p. 48), thus emphasizing the relationship with factor 8. However, three studies note that the limited availability of the skilled and unskilled 'labourers' hindered the project by 'slow[ing] down progress' (Aysan, 2008, p. 15; CRS, 2010) and increasing costs (Skat, 2009). See Figure 7.4 for further detail.

\section{Figure 7.4: Summary of included documents: hiring skilled or unskilled labour} (listed alphabetically)

\begin{tabular}{|c|c|c|}
\hline Document & $\begin{array}{l}\text { Do the studies report } \\
\text { (some) households } \\
\text { hiring 'labourers'? }\end{array}$ & How is the hired labour described? \\
\hline Aysan, 2008 & Yes & Unskilled and skilled labour such as masonry \\
\hline Barakat and Zyck, 2011 & Yes & $\begin{array}{l}\text { Skilled labourers and engineers... technical } \\
\text { expertise and skilled builders }\end{array}$ \\
\hline CARE International UK, 2015 & Yes & Not detailed. \\
\hline Catholic Relief Services, 2010 & Yes & Skilled labourers \\
\hline Corsellis and Sweetnam, 2014 & Yes & Labour \\
\hline Cukur et al., 2005 & Yes & $\begin{array}{l}\text { Fully-qualified craftsmen... for roof constructions and } \\
\text { for plumbing and electrical work; hired labour }\end{array}$ \\
\hline DiPretoro, 2010 & Not clear & Not clear \\
\hline Samuel Hall, 2012 & Yes & Unskilled and skilled labour \\
\hline Skat, 2009 & Yes & Skilled masons and carpenters \\
\hline van Dijk, 2012 & Not clear & Not detailed. \\
\hline van Leersum and Arora, 2011 & Yes & Local artisans; migrant workers \\
\hline
\end{tabular}


15. Inaccurate records of land ownership and/or limited availability of land with adequate transport links, infrastructure, services and economic opportunities hinders programme implementation.

Certainty in the evidence: Five documents identify this as a factor that helped or hindered programme implementation. The documents describe interventions in several countries and in response to complex emergencies (see Figure 7.5 for further detail).

Availability and access to land with secure land tenure is a key eligibility criterion for five of the interventions (see Figure 7.3). Barakat et al. note the challenges arose because there were no accurate records of 'land tenure and the structures which existed upon each plot', thus assessing the loss of each household's asset (land and/or house) was at risk of corruption by being 'based on the interests and perceptions of municipal officials and governmental personnel' (2008, p. 42).

The availability of suitable land is also identified as a factor that hindered delivery of programme outcomes. This was more common for interventions where households were relocated to a different location following rapid-onset crises or a period of displacement caused by conflict. For example, Skat note that 'generally, families who remained at [their] existing plot are better off... Beneficiaries who were relocated to locations in-land tend to be poorer than the others. Main challenges are that they lost their social network by being resettled, spend more money on transport to working places and have difficulties to work in their old professions (e.g. fishermen) because they are far away from the sea... An estimated 20 to 60 percent of beneficiaries of the relocation projects appears to be worse-off from an economic point of view' (2009, p. 45). Finally Samuel Hall identifies that 'the main factors determining the sustainability of reintegration (location, access to basic services and access to livelihood)... the poor selection of locations for the shelter programme prevented, from the start, a sustainable return and reintegration process' (2012, pp. 138-139).

\section{The accessibility or remoteness of households hinders programme implementation.}

Certainty in the evidence: Three documents identify this as a factor that either helped or hindered programme implementation. The documents describe interventions in Pakistan, Sri Lanka and Afghanistan and in response to natural disasters and complex emergencies.

Aysan et al. (2007), van Leersum (2009) and Samuel Hall (2012) highlight the challenges involved in accessing remote households or those connected with poor roads or transport. For example there were additional transport costs for building materials (Aysan et al., 2007), reduced technical support and visits from programme staff (van Leersum, 2009) and higher costs of labour and building materials (Samuel Hall, 2012). 
Figure 7.5: Summary of factors reported in the studies (listed alphabetically)

\begin{tabular}{|c|c|c|c|c|c|c|c|c|c|c|c|c|c|c|c|c|}
\hline & 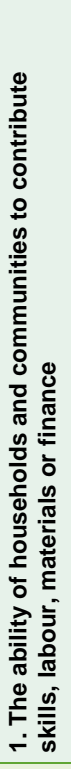 & 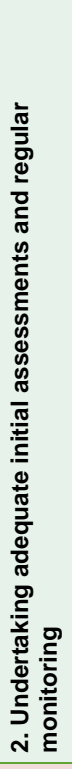 & 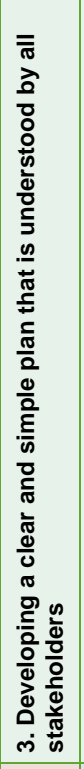 & 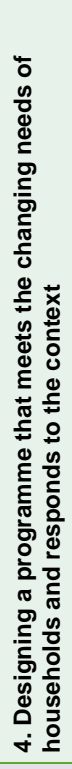 & 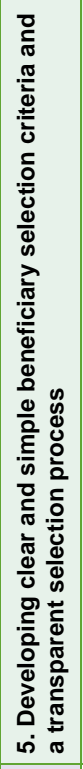 & 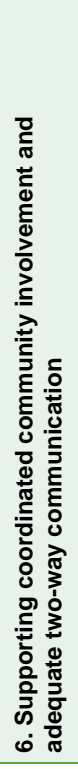 & 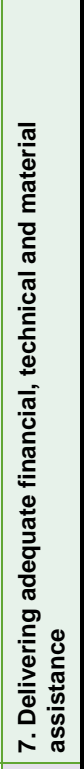 & 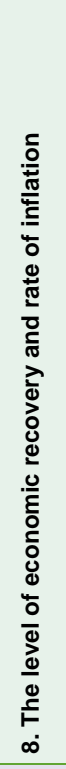 & 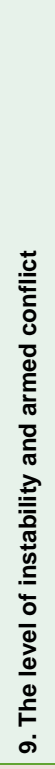 & 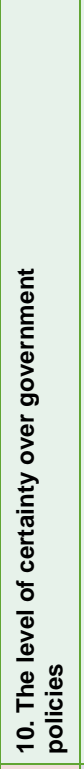 & 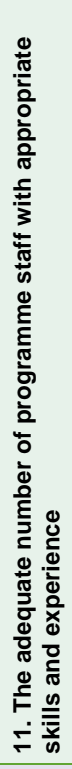 & 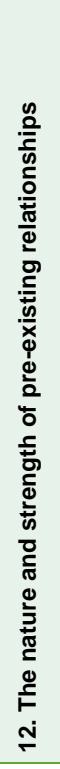 & 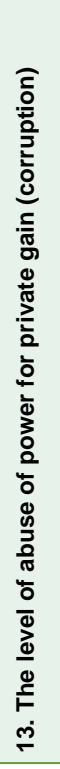 & 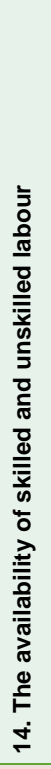 & 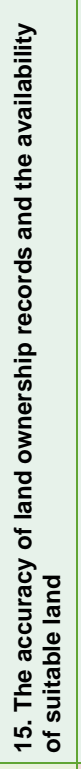 & 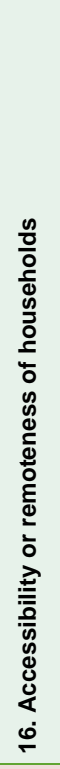 \\
\hline Aysan, 2008 & $P$ & $\mathrm{~N}$ & $\mathrm{~N}$ & $\mathrm{O}$ & $\mathrm{O}$ & & $\mathrm{O}$ & $\mathrm{O}$ & $\mathrm{N}$ & $\mathrm{N}$ & $\mathrm{O}$ & & & $\mathrm{N}$ & $P$ & $N\left({ }^{*}\right)$ \\
\hline Barakat and Zyck, 2011 & 0 & & & & $\mathrm{~N}$ & $\mathrm{~N}$ & $\mathrm{~N}$ & $\mathrm{~N}$ & & & & & $\mathrm{~N}$ & & $\mathrm{~N}$ & \\
\hline $\begin{array}{l}\text { CARE International UK, } \\
2015\end{array}$ & & $\mathrm{O}$ & $P$ & $\mathrm{O}$ & $\mathrm{O}$ & $P$ & $\mathrm{O}$ & $\mathrm{N}$ & & & $\mathrm{O}$ & $P$ & & & & \\
\hline $\begin{array}{l}\text { Catholic Relief Services, } \\
2010\end{array}$ & $P$ & $P$ & $P$ & $\mathrm{~N}$ & $P$ & $P$ & $P\left({ }^{*}\right)$ & $\mathrm{P}\left({ }^{*}\right)$ & & & & $\mathrm{N}$ & & $\mathrm{N}$ & & \\
\hline $\begin{array}{l}\text { Corsellis and Sweetnam, } \\
2014\end{array}$ & $P$ & $P$ & & $\mathrm{O}$ & & $P$ & $P$ & & & & & & $\mathrm{~N}$ & & & \\
\hline Cukur et al., 2005 & $P$ & & & $\mathrm{~N}$ & $P$ & $P$ & & & $P$ & & $P$ & & $\mathrm{~N}$ & & $P$ & \\
\hline DiPretoro, 2010 & $P$ & $P$ & & & $P$ & & $\mathrm{O}$ & & & & & $P$ & & & & \\
\hline Samuel Hall, 2012 & $\mathrm{~N}$ & $P$ & & & N & & $\mathrm{O}$ & & $\mathrm{N}$ & & & & $\mathrm{N}$ & & $\mathrm{N}$ & $\mathrm{N}$ \\
\hline Skat, 2009 & $P$ & $P$ & $\mathrm{O}$ & $\mathrm{N}$ & & $P$ & $P$ & $\mathrm{~N}$ & $\mathrm{~N}$ & & $\mathrm{~N}$ & $P$ & & $\mathrm{~N}$ & $\mathrm{O}$ & \\
\hline \multicolumn{17}{|l|}{ van Dijk, 2012} \\
\hline $\begin{array}{l}\text { van Leersum and Arora, } \\
2011\end{array}$ & $\mathrm{~N}$ & $P$ & & $P$ & & 0 & $\mathrm{O}$ & & & & $\mathrm{N}$ & & $\mathrm{N}$ & & & $\mathrm{N}$ \\
\hline
\end{tabular}

Note: The table identifies only those instances where authors explicitly noted that a factor helped or hindered programme implementation. For example, if a study noted that there was inflation, but did not provide detail of the effect the inflation had on the programme implementation this has not been marked on the table.

\section{Key for Figure 7.5}

\begin{tabular}{|l|l|}
\hline$\left(^{*}\right)$ & Noted in supporting document \\
\hline Programme factors (factors 1-6) \\
\hline N & Hindered (if not done) \\
\hline P & Helped (if done) \\
\hline O & Accounts of both: if done helped and if not done hindered \\
\hline Contextual factors (factors 7-15) \\
\hline N & Hindered \\
\hline P & Helped \\
\hline O & Accounts of both: helped and hindered \\
\hline
\end{tabular}


This section of the report summarises the key results of the research and their implications for future policy, practice and research. It concludes with reflections on the strengths and limitations of this research.

\section{HUMANITARIAN INTERVENTIONS SUPPORTING SHELTER SELF-RECOVERY}

\section{Results}

Topic: While funding for humanitarian response is at its highest level ever, the average level of funding per person has dropped as need has outstripped supply. The majority of shelter needs after humanitarian crises are met by affected households repairing, building or rebuilding their own shelters themselves or through using the local building industry. Humanitarian interventions supporting this process have been described as supporting shelter 'self-recovery'.

Definition: The phrase supporting shelter self-recovery has recently become popular in humanitarian practice, but the terms 'self-help', 'self-build', 'incremental' and 'owner-driven' have also been used to describe similar approaches. The research team proposed the following definition, based on analysis of existing programmes described as supporting shelter self-recovery:

Humanitarian interventions supporting shelter self-recovery: provide one or a combination of material, financial and technical assistance; during the relief and/or recovery phase; to enable affected households to repair, build or rebuild their own shelters themselves or through using the local building industry. Material assistance includes the provision of construction materials, tools and support for salvaging and reuse of debris. Financial assistance includes the provision of cash or vouchers. Technical assistance can include (but is not limited to) the provision of guidance on construction through training, guidelines or mass communications.

Theory of change: This review developed the following theory of change model for humanitarian interventions supporting shelter self-recovery. This highlighted that items typically reported as outputs from humanitarian shelter interventions - for example the number of households provided with training - are inputs into the shelter self-recovery process.

Figure 8.1: Theory of change. Source: The research team

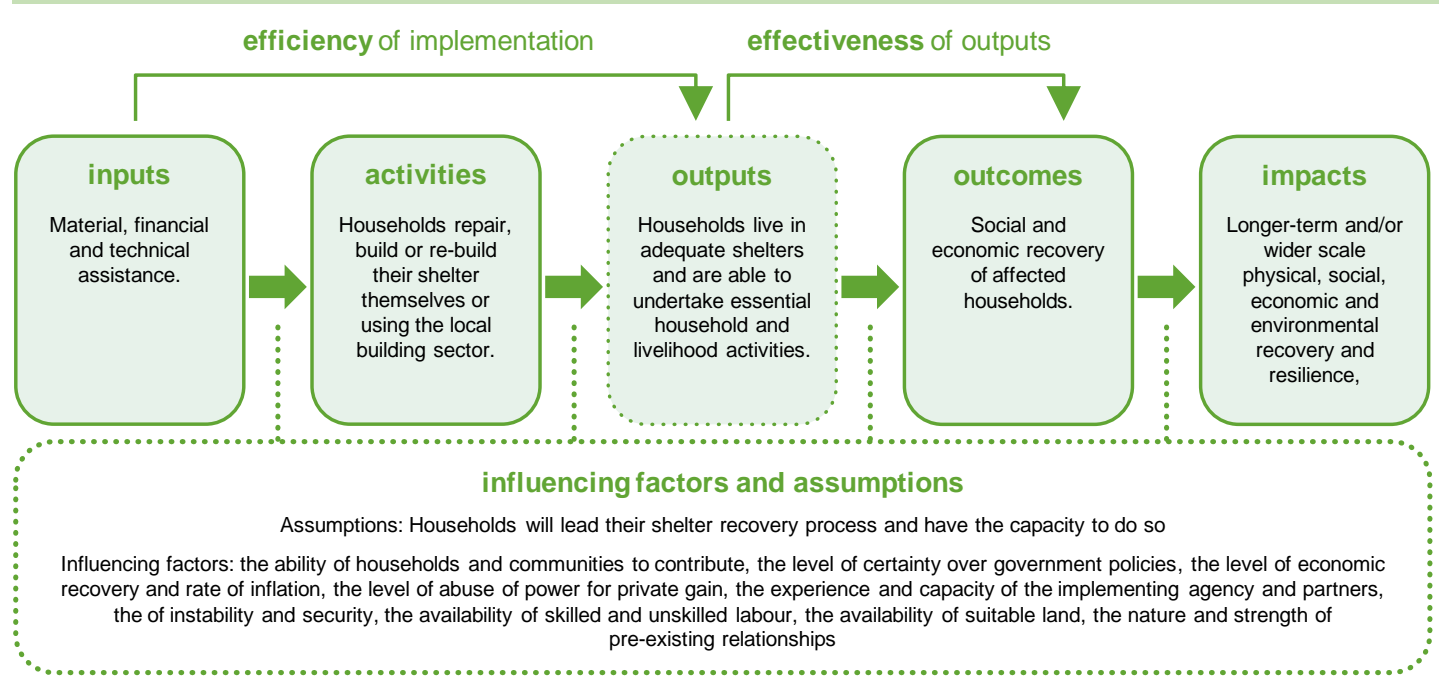


Effects identified: There is little commonality between the household-level outcomes measured in the studies. However, using a 'bottom-up' (or inductive) approach, the research team identified six household-level outcomes of interventions supporting shelter self-recovery. These are the level of household:

- dignity and self-reliance

- perception of safety and security

- income or livelihoods

- assets or debts

- physical and mental health

- knowledge about safer construction.

Effects - consistent results: The majority of the studies note that humanitarian interventions supporting shelter self-recovery had positive effects on households' 1) dignity and self-reliance and/or 2) their perception of safety and security. Increased dignity and self-reliance resulted from households both living in their own home and taking ownership of the construction process. Increased perception of safety and security resulted from reduced overcrowding, integration or reintegration into host communities, household awareness of the material and construction quality of their homes and the incorporation of safer construction techniques.

Effects - inconsistent results: There are unclear findings about the effects of humanitarian interventions on household incomes or livelihoods, assets or debts, physical and mental health, and knowledge of safer construction techniques.

Factors identified: The research team identified 16 factors that helped or hindered the implementation of interventions supporting shelter self-recovery. These are categorized as household, programme or contextual factors.

Household factors:

- the ability of households and communities to contribute skills, labour, materials or finance.

Programme factors:

- undertaking adequate assessments and regular monitoring

- developing a clear and simple plan

- designing a programme that meets the changing needs of households in different contexts

- developing clear and simple beneficiary selection criteria and transparent selection processes

- supporting coordinated community involvement and adequate two-way communication

- delivering adequate financial, technical and/or material assistance.

Contextual factors:

- the level of certainty over government policies

- the level of economic recovery and rate of inflation

- the level of abuse of power for private gain (corruption)

- the experience and capacity of the implementing agency and partners

- the level of instability and security

- the availability of skilled and unskilled labour

- the availability of suitable land

- the nature and strength of pre-existing relationships

- the accessibility or remoteness of the household.

Factors key finding: Almost all of the studies note the ability of households and communities to contribute skills, labour, materials or finance as a critical factor to the success of humanitarian interventions supporting shelter self-recovery. If programmes did not meet the specific and changing needs of households (for example because of inflation) then the households themselves had to make up the shortfall in order to 'complete' their houses. 
Programme and contextual factors: The majority of the studies also note that the programme factors helped implementation of the programme when they were completed adequately and hindered if this was not the case. Each of the contextual factors is identified by around one third of the studies. However, whether or not these factors are identified, and whether they helped or hindered programme implementation, varies depending on context so it is not possible to identify clear trends.

\section{Implications}

Topic: Understanding the process of shelter self-recovery and humanitarian interventions supporting this process is an important area of future research.

Definition: The use of different terms in different contexts and at different periods of time means that existing knowledge on this topic is difficult to find, synthesize and apply to current policy and practice. Greater clarity on what is meant by 'supporting shelter selfrecovery' can contribute to improved consensus and application of this term.

Theory of change: Greater clarity regarding the inputs, activities, outputs and outcomes of humanitarian interventions supporting shelter self-recovery would improve monitoring and evaluation of programmes and enable their efficiency and effectiveness to be compared with other types of shelter assistance.

Effects - consistent results: Existing guidance on humanitarian shelter and settlements highlights the importance of households taking ownership of the construction process. This evidence synthesis revealed that when this is the case it has positive effects on how households perceive their dignity, self-reliance and safety and security.

Effects - inconsistent results: Implementing agencies and the academic literature often suggest that interventions supporting shelter self-recovery - in addition to building shelters increase households' knowledge of safer construction techniques, improve their health, and contribute to an improvement in their economic situation. This synthesis finds little evidence to support these statements and this is a suggested topic for future research.

Factors - key finding: The ability of households and communities to contribute skills, labour, materials or finance is critical to the success of humanitarian interventions supporting shelter self-recovery. This should be assessed and inform programme design to avoid the shelter intervention placing an undue burden on households who are trying to recover all aspects of their lives.

Programme and contextual factors: The programme factors are core elements of humanitarian interventions supporting shelter self-recovery that support implementation in a range of contexts and settings. These should form the basis of future programme design. The importance of each of the contextual factors will vary depending on the specific situation. The potential effect of each of these factors on the shelter intervention should be assessed and incorporated into programme design. SHELTER AND SETTLEMENTS

\section{Results}

Evidence synthesis: This evidence synthesis investigates both the process of implementing humanitarian interventions supporting shelter self-recovery and the effects of the interventions. This study identified more than 4,500 documents but found only 11 studies eligible for inclusion following screening and quality appraisal, which is comparable with other systematic reviews. Scoping searches indicated that a similar number of documents (or less) would be eligible for inclusion in an evidence synthesis on the effectiveness of other humanitarian shelter and settlement interventions (e.g. transitional shelter or rental support). 
Scope: The research team synthesized evidence from humanitarian interventions supporting shelter self-recovery:

- targeting households who were either not displaced, or were returning or resettling in new locations

- to repair, build or rebuild their shelters

- through the provision of one or a combination of material, financial and technical assistance

- in predominantly rural areas ${ }^{62}$

- in nine (predominantly middle-income) countries $^{63}$

- in response to both natural disasters and complex emergencies.

Searches: The research team devoted the majority of its time to searching academic databases and grey literature websites (approximately 50:50). However, of the documents included in the evidence synthesis, only two were identified through searching academic databases. A further six studies were identified through searching grey literature websites and three through stakeholder engagement. While more than 35 grey literature websites were searched as part of the review only one document identified through the grey literature searches was not found on the ALNAP Humanitarian Evaluation and Learning Portal.

Risk of bias: All but one of the included studies are assessments, evaluations or studies completed by agency staff or external researchers commissioned by the implementing agency or donor. None of the documents explicitly note conflicts of interest, very few detail any ethical considerations, and just four describe the study limitations. This review found a significant absence of academic research into humanitarian shelter and settlement interventions. The studies identified were typically completed by Masters or $\mathrm{PhD}$ students rather than research teams. The studies also tend to investigate broader topics and trends rather than the effects of specific interventions.

Study design: Researching the effects of humanitarian shelter and settlement interventions requires expertise in topics ranging from construction and community engagement to economics and health. The use of quantitative methods of data collection and analysis are also an important aspect of investigating causality or identifying trends in programmes that assisted tens or hundreds of thousands of households. Eight of the studies eligible for inclusion in this evidence synthesis are of a mixed methods design while three are qualitative. Only two documents state their study design while the rest do not state whether they considered alternative research methods.

Research methods: There is little commonality within the studies in terms of the research methods or indicators used to identify effects, or even how effects were separated from activities and outputs. All of the studies collected qualitative data through interviews or focus groups with affected households and key informants. In the mixed methods studies, qualitative data was triangulated with quantitative data collected through household surveys.

\section{Implications}

Evidence synthesis: A number of documents were identified that would be suitable for inclusion in a broader 'lessons learned' or literature review focused more on the process of implementing humanitarian interventions supporting shelter self-recovery. These types of exploratory study are more appropriate to the humanitarian shelter and settlements sector given the level of evidence available - particularly regarding the limited information available on effects.

Scope: This review did not identify any eligible studies documenting humanitarian interventions supporting shelter self-recovery that targeted displaced populations while they are displaced or in Africa. Only one study described humanitarian interventions supporting shelter self-recovery in a low-income country, while just three commented on adaptation to urban or peri-urban contexts. These are potential topics for further research.

62 Just three studies commented on the differences in peri-urban and urban areas.

${ }^{63}$ Only one study describing an intervention in a low-income country (Afghanistan) was eligible for inclusion. 
Searches: Stakeholder engagement is critical to the identification of both documents and websites for inclusion in humanitarian shelter and settlements evidence reviews. Sufficient time and resources should be allocated to these activities in future research. The ALNAP Humanitarian Evaluation and Learning Portal is a key repository of evidence on the effects of humanitarian shelter and settlement interventions. Organizations producing or commissioning evaluations should systematically upload their evaluations to this website in order to build on the strength of the knowledge base.

Risk of bias: Implementing agencies and donors commissioning or producing evaluation reports are the key contributors to knowledge about the effects of humanitarian shelter and settlement interventions. This creates a significant risk of bias but also an opportunity for collaboration and sharing in order to improve the quantity and quality of evidence available in the sector. Partnerships between humanitarian agencies, donors and research institutions are also recommended to increase the relevance and applicability of academic research.

Study design, research methods, frameworks and indicators: Further research should focus on improving the quality of primary research and evaluations undertaken in the humanitarian shelter and settlement sector. This could include:

- investigating the factors that help or hinder the process of commissioning and learning from humanitarian evaluations

- providing guidance and/or training on applying appropriate study designs, research methods, evaluation frameworks and indicators.

\subsection{CONCLUDING REMARKS}

This evidence synthesis is the first application of the systematic review approach to humanitarian shelter and settlement interventions. It is therefore important to capture the challenges experienced in applying this methodology and highlight the strengths and limitations of this review. Further details on the limitations of the research are provided in Appendix G.

The initial research question posed by HEP was very broad.

- The research team completed a rigorous scoping assessment to ensure that the research focused on a topic that was both of interest to humanitarian policymakers and practitioners and had sufficient evidence available to make a synthesis worthwhile. The scoping assessment included a significant amount of stakeholder engagement and a comprehensive mapping of evidence available in the shelter and settlements sector. This process created a high level of stakeholder interest in both the process and the outputs of the research.

There is limited quantity and quality of evidence within the humanitarian shelter and settlements sector.

- The research team, in collaboration with HEP, decided that this research should take the form of an 'evidence synthesis' rather than a systematic review.

- The quality of the primary documents is a key limitation of this research. All documents state their research aims, objectives and/or research questions, provide some contextual background and outline the data collection methods. However, very few documents set out how data has been recorded or analysed, and only two state their study design. Critically for the research into effectiveness, there is very limited discussion or analysis linking the intervention to its effects (i.e. demonstrating causality). This is despite nine of the documents explicitly aiming to report on 'impacts'.

Knowledge in the humanitarian shelter and settlements sector is fragmented and different terminology is used in different contexts and at different periods of time.

- The research team decided to synthesize evidence from both natural disasters and complex emergencies in order to maximize the opportunity for learning in this review. 
- The research team needed to define humanitarian interventions 'supporting shelter selfrecovery' based on analysis of existing programmes. The definition developed ('providing one or a combination of material, financial and technical support') is arguably too broad for a systematic review. ${ }^{64}$ However, given the lack of existing research on this topic, focusing on just one method of assistance would have created an artificial distinction, when in reality one of the first decisions when designing a 'support for shelter selfrecovery' intervention is what type of assistance to provide.

- The research team needed to apply a 'bottom up' (or inductive) approach to data extraction and synthesis as there is little commonality in terms of the evaluation frameworks or indicators applied, the household-level outcomes identified, or the reporting of inputs, activities and outputs. Generalizations based on a relatively small sample of studies require testing through further research.

The majority of evidence on the effects of humanitarian shelter and settlement interventions is captured in evaluations rather than academic publications. Consequently:

- Searching humanitarian websites and libraries for grey literature was a key component of the search strategy. However, this was more time consuming than searching academic databases as well as less transparent (searches cannot be exported) and replicable (because these websites and search engines are subject to change).

- There is a significant risk of bias in the included studies as the majority were funded or even implemented by humanitarian agencies or donors. Very few of the studies can be considered truly independent. Similarly, evaluations with positive findings are more likely to be published and published evaluations are easier to find.

\section{The majority of evidence regarding humanitarian shelter and settlements is qualitative or mixed methods.}

- The research team had to develop a bespoke 'quality appraisal template' as there is limited guidance on the quality appraisal of mixed methods research. ${ }^{65}$

- The research team adopted a 'narrative synthesis' approach. However, the synthesis of qualitative and mixed methods studies is complex and time consuming. Extracting, synthesizing and verifying findings on these types of studies posed a significant challenge within the resources available for this research.

To conclude, the aim of this research was to synthesize the existing evidence on the effectiveness and efficiency of interventions that support affected populations' own shelter self-recovery processes following humanitarian crises. The synthesis revealed significant gaps in existing evidence within the shelter and settlements sector, it also highlighted disagreement and diversity among the literature and identified opportunities for further research. However, given the limitations noted above, the results should be viewed as exploratory and in need of verification through further research.

\footnotetext{
${ }^{64}$ Systematic reviews should have a narrow focus in order to synthesize results from comparable interventions.

${ }^{65}$ Following completion of the data extraction and quality appraisal process the researchers were introduced to the "Bond Evidence Principles and Checklist'. The Principles were designed specifically for NGOs to use as a reference guide when commissioning, designing and reviewing evidence-based work. The Checklist covers many of the key areas that the 'quality appraisal template' in Appendix E covers, and would have been a useful tool in this evidence synthesis (as it would not have been necessary to develop a bespoke template). The research team suggest that future evidence synthesis adopt the 'Bond Evidence Principles and Checklist'. Further information can be found at: https://www.bond.org.uk/data/files/Effectiveness_Programme/120828Full_Bond_checklist_and_guide.pdf
} 


\section{REFERENCES}

\section{Included studies and supporting documents}

Aspin, M. (2010). Inter-Agency Impact Assessment of the Cash Transfer Programs in West Sumatra. Retrieved from http://www.syrialearning.org/resource/7536

Aysan, Y. (2008). External Evaluation of the Swiss Consortium's Cash for Repair and Reconstruction Project in Sri Lanka 2005-08. Retrieved from http://www.alnap.org/resource/12521

Aysan, Y., Aheeyar, M. et al. (2007). External Evaluation Report on the Cash for Repair and Reconstruction Project Sri Lanka.

Barakat, S. and Zyck, S.A. (2011). Housing reconstruction as socio-economic recovery and state building: Evidence from Southern Lebanon. Housing Studies, 26(1), 133-54. Retrieved from http://www.Scopus.com/inward/record.url?eid=2-s2.0-

78650121932andpartnerID=40andmd5=8cfa1a5eef00f6393e376cac62869f43

Barakat, S., Zyck, S.A. and Hunt, J.E. (2008). Housing Compensation and Disaster Preparedness in the Aftermath of the July 2006 War in South Lebanon. Retrieved from https://www.york.ac.uk/media/prdu/documents/publications/pub.NRC Housing Compensation and Emergency Preparedness_Dec2008.pdf

CARE International UK. (2015). CARE Philippines: Typhoon Haiyan shelter recovery project evaluation. Retrieved from http://reliefweb.int/report/philippines/care-philippines-typhoonhaiyan-shelter-recovery-project-evaluation

Catholic Relief Services. (2010). CRS Indonesia West Sumatra Transitional Shelter Evaluation Report. Catholic Relief Services. Retrieved from http://www.alnap.org/resource/5842

Corsellis, T. and Sweetnam, P. (2014). Evaluation of One Room Shelter Programme for the 2011 floods response in South Sindh, Pakistan. Retrieved from https://www.iom.int/sites/default/files/country/docs/pakistan/IOM-Pakistan-Evaluation-ofOne-Room-Shelter-Program-for-2011-Flood-Response.pdf

Cukur, M., Magnusson, K. et al. (2005). Returning Home - An Evaluation of Sida's Integrated Area Programmes in Bosnia and Herzegovina. Retrieved from http://www.alnap.org/resource/3387

DiPretoro, S. (2010). Cash for Shelter Program $\square$ : Hurricane Richard 2010. Retrieved from http://www.cashlearning.org/downloads/resources/evaluations/evaluation-belize-cashvoucher-for-shelter-program.pdf

Samuel Hall. (2012). Evaluation of the UNHCR Shelter Assistance Programme. Retrieved from http://www.alnap.org/pool/files/unhcr-shelter-assistance-programme-evaluation.pdf

Skat. (2009). IFRC Community Recovery and Reconstruction Partnership (CRRP): Evaluation Report. Retrieved from http://www.alnap.org/resource/12574

van Dijk, S. (2012). Impact assessment of a Participatory Community Development Program in Cucuta, Colombia.

van Leersum, A. and Arora, S. (2011). Implementing seismic-resistant technologies in postearthquake Pakistan: A process analysis of owner driven reconstruction. Habitat International, 35(2), 254-64. Retrieved from http://www.Scopus.com/inward/record.url?eid=2-s2.078651517513andpartnerID $=40$ andmd5=dcd78a650c4ac10af89c2975b2ae9b9a 
van Leersum, A. (2009). Implementing seismic resistant construction in post-disaster settings - Insights from Owner Driven Reconstruction in Pakistan. Eindhoven University of Technology.

\section{Other studies cited in this evidence synthesis}

Anonymous. (2011). End of Project Evaluation of the Emergency Shelter Relief and Recovery Project - Anonymous.

Ashmore, J. and Treherne, C. (eds.). (2010). IFRC Shelter Kit Guidelines. Retrieved from http://www.ifrc.org/PageFiles/95530/Sidebar/171800-IFRC shelter kit-LR-EN.pdf

Bagić, D. and Dedic, D. (2005). The Impact of Aid for Reconstruction of Homes in Bosnia and Herzegovina. Retrieved from

http://www.sida.se/contentassets/a4c762fd439649baa09ac0b32361e85b/20051 -the-impactof-aid-for-reconstruction-of-homes-in-bosnia-herzegovina_1887.pdf

Buchanan-Smith, M. and Cosgrave, J. (2013). Evaluating Humanitarian Action (Pilot Guide). Retrieved 8 December 2015, from http://www.alnap.org/what-we-do/evaluation/eha

CASP. (2013). 10 questions to help you make sense of qualitative research. CASP (Critical Appraisal Skills Programme) UK. Retrieved from https://hhs.hud.ac.uk/lqsu/Useful/critap/Qualitative Research Checklist/CASP-QualitativeResearch-Checklist-31.05.13.pdf

Centre for Reviews and Dissemination. (2008). Systematic Reviews: CRD's guidance for undertaking reviews in health care. Retrieved from https://www.york.ac.uk/media/crd/Systematic_Reviews.pdf

Corsellis, T. and Vitale, A. (2005). Transitional settlement: displaced populations. Oxfam. Retrieved from http://humanitarianlibrary.org/resource/transitional-settlement-displacedpopulations

Darcy, J., Stobaugh, H. et al. (2013). The Use of Evidence in Humanitarian Decision Making ACAPS Operational Learning Paper. Retrieved 8 December 2015, from http://fic.tufts.edu/publication-item/the-use-of-evidence-in-humanitarian-decision-making/

Davis, I. (1978). Shelter after disaster. Oxford: Oxford Polytechnic Press.

DFID. (2011). DFID's approach to value for money (VfM). Retrieved 8 December 2015, from http://www.gov.uk/government/publications/dfids-approach-to-value-for-money-vfm

DFID. (2015). Humanitarian Response Funding Guidelines for NGOs. Retrieved 10 January 2016, from http://www.gov.uk/government/uploads/system/uploads/attachment_data/file/404342/Human itarian-Response-Funding-Guidelines-2015.pdf

Dijkzeul, D., Hilhorst, D. and Walker, P. (2013). Introduction: evidence-based action in humanitarian crises. Disasters, 37, S1-S19. http://doi.org/10.1111/disa.12009

Emergency Shelter Cluster. (2008). Emergency Shelter Cluster, Cyclone Nargis - May 2008, Myanmar: Strategic Framework. Retrieved 8 December 2015, from http://www.sheltercluster.org

Eri, C. and Fogden, D. (2013). Nigeria Floods 2012: Early Recovery Shelter: Beneficiary Satisfaction Survey. Retrieved from http://www.ifrc.org/en/publications-andreports/evaluations/

Ferretti, S. and Ashmore, J. (2010). Shelter Evaluation Afghanistan: Final Report. 
Flinn, B. (2010). CARE International Indonesia post-earthquake Shelter Response, Pariaman, Padang, West Sumatra - Progress Evaluation.

Flores, M.C. and Meaney, M.C. (2013). Pathways to Permanence: A Strategy for Disaster Response and Beyond. In Disaster Response Shelter Catalogue. Habitat for Humanity. Retrieved from http://www.sheltercasestudies.org/files/ $\mathrm{H} 4 \mathrm{H}$ DR_Shelter_Catalogue_Full_Version.pdf

Foley, P. (2005). Shelter Programme Monitoring and Evaluation. Retrieved from http://www.unhcr.org/4333f18e2.pdf

Ganapati, N.E. and Mukherji, A. (2014). Out of sync: World Bank funding for housing recovery, post disaster planning, and participation. Natural Hazards Review, 15(1), 58-73. Retrieved from http://www.Scopus.com/inward/record.url?eid=2-s2.084892699825andpartnerID=40andmd5=91d6102e86386d8b84e419f228f954c8

García, O. (2015). Evaluation of the Norwegian Refugee Council's Lebanon Host Community Shelter Programmes. Retrieved from

https://www.nrc.no/globalassets/pdf/evaluations/lebanon---shelter-evaluation---2014.pdf

Glenton, C., Colvin, C. et al. (2013). Barriers and facilitators to the implementation of lay health worker programmes to improve access to maternal and child health: qualitative evidence synthesis. Cochrane Database of Systematic Reviews (10).

Global Shelter Cluster. (2013). Strategic Operational Framework: Typhoon Yolanda, Philippines, 2013. Retrieved 8 December 2015, from http://www.sheltercluster.org

Government of Vanuatu. (2015). Tropical Cyclone Pam: Humanitarian Action Plan. Retrieved 8 December 2015, from http://www.sheltercluster.org

Hamdi, N. (1995). Housing without houses: participation, flexibility, enablement. London: Intermediate Technology.

Hanley, T., Binas, R. et al. (2014). IASC Inter-agency Humanitarian Evaluation of the Typhoon Haiyan Response. Retrieved from http://www.interaction.org/sites/default/files/9. Final report.pdf

Higgins, J. and Green, S. (eds.). (2011). Cochrane Handbook for Systematic Reviews of Interventions. Retrieved 8 December 2015, from http://handbook.cochrane.org/

Humanitarian Coalition. (2015). What is a humanitarian emergency? Retrieved 8 December 2015, from http://humanitariancoalition.ca/info-portal/factsheets/what-is-a-humanitarianemergency

Humanitarian Evidence Programme. (2015). Guidance Note: Evidence Synthesis in the Humanitarian Evidence Programme. Retrieved 8 December 2015, from http://www.oxfam.org.uk/hep

IFRC. (2010). Owner-Driven Housing Reconstruction Guidelines. Retrieved 8 December 2015, from

http://www.ifrc.org/PageFiles/95526/publications/E.02.06.\%200DHR\%20Guidelines.pdf

IFRC. (2013). Post-disaster shelter: Ten designs. Retrieved 8 December 2015, from http://www.sheltercasestudies.org

IFRC, UN-Habitat and UNHCR. (2013). Shelter Projects 2011-2012. Retrieved 8 December 2015, from http://www.sheltercasestudies.org

IFRC and UN OCHA. (2015). Shelter after Disaster. Retrieved 8 December 2015, from http://www.ifrc.org/Global/Documents/Secretariat/201506/Shelter_After_Disaster_2nd_Editio n.pdf 
IFRC, UNHCR and UN-Habitat. (2014). Shelter Projects 2013-2014. Retrieved 8 December 2015, from http://www.sheltercasestudies.org

Jha, A.K. and Duyne Barenstein, J.E. (2010). Safer Homes, stronger communities: A handbook for reconstructing after natural disasters. World Bank Publications. Retrieved from http://www.gfdrr.org/housingreconstruction

Kabir, R. (2009). Post-Cyclone Sidr Family Shelter Construction in Bangladesh: Documentation of Plans and Processes. Retrieved 8 December 2015, from http://www.sheltercluster.org

Kennedy, J., Ashmore, J. et al. (2007, March). Post-tsunami transitional settlement and shelter field experience from Aceh and Sri Lanka. Humanitarian Exchange Magazine (37).

Kenya Shelter Cluster. (2012). Kenya Shelter/NFI Strategy 2012-2013. Retrieved from http://www.sheltercluster.org/sites/default/files/docs/Shelter Strategy 2012-13 Final4.pdf

Kuittinen, M. and Winter, S. (2015). Carbon Footprint of Transitional Shelters. International Journal of Disaster Risk Science, 6(3), 226-37.

Light, R. and Pillemer, D. (1984). Summing Up: The Science of Reviewing Research. Cambridge (MA): Harvard University Press.

Loschmann, C., Parsons, C.R. and Siegel, M. (2014). Does Shelter Assistance reduce Poverty in Afghanistan? (No. 97). Retrieved from https://www.imi.ox.ac.uk/publications/wp97-14

Lyons, M., Schilderman, T. and Boano, C. (2010). Building Back Better. Delivering peoplecentred housing reconstruction at scale. Engineering Insight.

Maynard, V., Parker, E. and Twigg, J. (2016). The effectiveness and efficiency of interventions supporting shelter self-recovery following humanitarian crises: An evidence synthesis protocol. Retrieved from http://policy-practice.oxfam.org.uk/publications/theeffectiveness-and-efficiency-of-interventions-supporting-shelter-self-recov-605179

Minervini, C. (2002). Housing reconstruction in Kosovo. Retrieved from http://www.sciencedirect.com/science/article/pii/S0197397502000267

Nepal Shelter Cluster. (2015). Draft 1: Nepal shelter strategic directions. Retrieved 8 December 2015, from http://www.sheltercluster.org

Norwegian Refugee Council. (2013). Overview of the Housing Situation in the Gaza Strip. Retrieved 8 December 2015, from http://www.sheltercluster.org

Oketch, M., McCowan, T. and Schendel, R. (2014). The impact of tertiary education on development: A rigorous literature review. Department for International Development.

Parrack, C., Flinn, B. and Passey, M. (2014). Getting the message across for safer selfrecovery in post-disaster shelter. Open House International, 39(3), 47-58.

Peacock, W.G., Dash, N. and Zhang, Y. (2007). Shelter and Housing Recovery Following Disaster. In H. Rodríguez, E.L. Quarantelli and R.R. Dynes (eds.), Handbook of Disaster Research (pp. 258-74). New York: Springer.

Pluye, P., Robert, E. et al. (2011). Proposal: A mixed methods appraisal tool for systematic mixed studies reviews. Retrieved 8 December 2015, from http://mixedmethodsappraisaltoolpublic.pbworks.com/

Popay, J., Roberts, H. et al. (2006). Guidance on the conduct of narrative synthesis in systematic reviews. A product from the Economic and Social Research Council methods programme. Version (Vol. 1). Retrieved from http://www.researchgate.net 
Posthumus, H., Martin, A. and Chancellor, T. (2013). A systematic review on the impacts of capacity strengthening of agricultural research systems for development and the conditions of success.

Proudlock, K., Ramalingam, B. and Sandison, P. (2009). Improving humanitarian impact assessment: bridging theory and practice. Retrieved 8 December 2015, from http://www.alnap.org/resource/5663

Puri, J., Aladysheva, A. et al. (2014). What methods may be used in impact evaluations of humanitarian assistance? (No. 22). Retrieved from

http://www.3ieimpact.org/media/filer_public/2014/12/08/wp_22_humanitarian_methods_work ing_paper-top.pdf

Rantanen, J. (2011). Shelter Cluster Review: 2009 Indonesia Earthquakes. Retrieved 8 December 2015, from http://www.sheltercluster.org

Rashidian, A., Shakibazadeh, E. et al. (2013). Barriers and facilitators to the implementation of doctor-nurse substitution strategies in primary care: qualitative evidence synthesis.

Cochrane Database of Systematic Reviews, 2.

Rhyner, K. (2014). Honduras: "La Betania”, resettlement of a flooded neighbourhood. In Still Standing? Retrieved from http://developmentbookshop.com/still-standing

Sanderson, D., Knox Clarke, P. and Campbell, L. (2012). Responding to Urban Disasters: Learning from previous relief and recovery operations. Retrieved from http://www.alnap.org/resource/7772

Satterthwaite, D. (2010). Avoiding the urbanisation of disasters. Retrieved 8 December 2015, from http://www.ifrc.org/en/publications-and-reports/world-disasters-report/wdr2010/

Shelter Centre. (2012). Transitional Shelter Guidelines. Retrieved 8 December 2015, from http://www.humanitarianlibrary.org

Shelter Centre, UN OCHA and DFID. (2010). Shelter after disaster: strategies for transitional settlement and reconstruction. Retrieved 8 December 2015, from http://www.humanitarianlibrary.org

Shelter Cluster Somalia. (2013). Concept Paper: Sustainable Shelter Solustions, Internally Displaced Persons in Somalia. Retrieved 8 December 2015, from http://www.sheltercluster.org

Shelter Cluster South Sudan. (2014). Shelter and Non-Food Items Cluster, Republic of South Sudan: Strategy and Guidance. Retrieved 8 December 2015, from http://www.sheltercluster.org

Stoddard, A., Harmer, A. et al. (2015). The State Of The Humanitarian System Report 2015. Retrieved 8 December 2015, from http://www.alnap.org/resource/21036.aspx

Tafti, M.T. and Tomlinson, R.T. (2015). Best practice post-disaster housing and livelihood recovery interventions: Winners and losers. Retrieved from http://www.alnap.org/resource/21318

Tariq, F. (2012). Facilitating community development with housing microfinance: appraising housing solutions for Pakistan after disasters. Retrieved from http://web.mit.edu/incrementalhousing/articlesPhotographs/pdfs/TARIQCOMMUNITY=PAKISTAN.pdf

The Sphere Project. (2011). Humanitarian Charter and Minimum Standards in Humanitarian Response. Retrieved 8 December 2015, from http://www.sphereproject.org/handbook/

Turner, J. (1976). Housing by People: Towards Autonomy in Building Environments. Marion Boyars. London. 
Turner, J. and Fichter, R. (1972). Housing as a verb. Freedom to Build, pp. 148-75.

Twigg, J. (2002). Technology, post-disaster housing reconstruction and livelihood security. Benfield Hazard Research Centre, London, Disaster Studies Working Paper (Vol. 15).

Twigg, J. (2015). Disaster Risk Reduction (No. 9). Retrieved from http://goodpracticereview.org/9/

UN-Habitat, UNHCR and IFRC. (2008). Shelter Projects 2008. Retrieved 8 December 2015, from http://www.sheltercasestudies.org

UNHCR. (2011). Shelter/NFI Sector Meeting. Retrieved 8 December 2015, from http://www.sheltercluster.org

USAID/OFDA. (2012). Guidelines for Proposals. Retrieved January 10, 2016, from http://www.usaid.gov/sites/default/files/documents/1866/guidelines_for_proposals_2012.pdf

Wakely, P. and Riley, E. (2011). The Case for Incremental Housing. Retrieved 8 December 2015, from http://web.mit.edu/incrementalhousing/articlesPhotographs/pdfs/Case-forIncremental-Housing.pdf

Walker, D., Bergh, G. et al. (2013). Adapting systematic reviews for social research in international development: a case study on child protection. ODI.

World Humanitarian Summit. (2015). About the World Humanitarian Summit. Retrieved 8 December 2015, from https://consultations.worldhumanitariansummit.org/whs_about

Yates, T., Vujcic, J. et al. (2016). Impact of WASH Interventions during Disease Outbreaks in Humanitarian Emergencies: A systematic review protocol. Humanitarian Evidence Programme.

Yin, R.K. (2014). Case study research: design and methods. (Fifth). Thousand Oaks, Calif.: Sage.

Zetter, R. (2012). Shelter and Settlement for Forcibly Displaced People. In S.J. Smith (ed.), (pp. 330-35). San Diego: Elsevier. 


\section{APPENDICES}

\section{APPENDIX A: SEARCH TERMS}

This appendix details the search terms used for the evidence synthesis.

Note: Search terms include both words (e.g. house) and phrases (e.g. internally displaced) of interest. A number of words are truncated using $\left(^{*}\right)$ in order to search for variations of the word (e.g. shelter ${ }^{*}$ identifies shelter and shelters and sheltering).

\begin{tabular}{|c|c|c|c|}
\hline Concept 1: Shelter & $\begin{array}{l}\text { Concept 2: Humanitarian } \\
\text { crises }\end{array}$ & $\begin{array}{l}\text { Concept 3: Support for } \\
\text { shelter self-recovery }\end{array}$ & Concept 4: Effects \\
\hline $\begin{array}{l}\text { Shelter* } \\
\text { House } \\
\text { Housing } \\
\text { Home } \\
\text { Homes } \\
\text { Dwelling* } \\
\text { Settlement* } \\
\text { Neighbourhood } \\
\text { Neighborhood* } \\
\text { Self-build } \\
\text { "self build" } \\
\text { Owner-driven } \\
\text { "owner driven" } \\
\text { NOT } \\
\text { "care home" } \\
\text { "care homes" } \\
\text { "medical home" } \\
\text { "medical homes" } \\
\text { "nursing home" } \\
\text { "nursing homes" } \\
\text { "home care" } \\
\text { "medical house" } \\
\text { "home-grown" } \\
\text { "home treatment" } \\
\text { "home-based" } \\
\text { "home-delivered" } \\
\text { "home-produced" } \\
\text { "take-home" } \\
\text { "at-home" }\end{array}$ & $\begin{array}{l}\text { Disaster" } \\
\text { Humanitarian } \\
\text { Crisis } \\
\text { Crises } \\
\text { "Complex emergenc*" } \\
\text { "Armed conflict" } \\
\text { "Conflict affected" } \\
\text { "Armed intervention"” } \\
\text { War } \\
\text { Wars } \\
\text { Refugee* } \\
\text { "Internally displaced" } \\
\text { IDP } \\
\text { Earthquake* } \\
\text { Flood* } \\
\text { Tsunami* } \\
\text { Cyclone* } \\
\text { Hurricane* } \\
\text { Typhoon* } \\
\text { "Tidal wave" } \\
\text { "Volcanic eruption*" } \\
\text { Drought* } \\
\text { Famine* } \\
\text { Starvation } \\
\text { "Food insecurity" } \\
\text { "Storm surge*" } \\
\text { "Tropical storm"" } \\
\text { Displacement } \\
\text { Migration } \\
\text { Conflict } \\
\text { Avalanche* } \\
\text { Landslide* } \\
\text { Catastroph* } \\
\text { "large-scale emergenc*" } \\
\text { "mass emergenc*" }\end{array}$ & $\begin{array}{l}\text { Self-recovery } \\
\text { "Self recovery" } \\
\text { Self-help } \\
\text { "Self help" } \\
\text { Self-build } \\
\text { "Self build" } \\
\text { Owner-driven } \\
\text { "owner driven" } \\
\text { "Material assistance" } \\
\text { "Financial assistance" } \\
\text { "Technical assistance" } \\
\text { Cash } \\
\text { Voucher* } \\
\text { "Construction material*" } \\
\text { Tool* } \\
\text { Training } \\
\text { Workshop* } \\
\text { Guideline* } \\
\text { Manual" } \\
\text { Poster* } \\
\text { Leaflet* }^{*} \\
\text { Flyer* } \\
\text { "Mass communication" } \\
\text { Phone } \\
\text { Radio } \\
\text { Television } \\
\text { TV } \\
\text { Internet } \\
\text { Newspaper } \\
\text { Advert } \\
\text { Broadcast }\end{array}$ & $\begin{array}{l}\text { Outcome } \\
\text { Impact } \\
\text { Effect } \\
\text { Consequence } \\
\text { Evaluation } \\
\text { Assessment } \\
\text { Lessons } \\
\text { Learn* } \\
\text { "After action }\end{array}$ \\
\hline \multicolumn{4}{|l|}{$\begin{array}{l}\text { Documents in Englis } \\
\text { Documents publishe }\end{array}$} \\
\hline
\end{tabular}




\section{APPENDIX B: OVERVIEW OF SEARCH RESULTS}

This appendix details the search results for each database/website. Please note: the search terms set out in Appendix A were used for all the academic searches. These search terms were then adapted as detailed in the table below for the grey literature searches, balancing the requirements of sensitivity and precision.

\section{Figure B.1: Search results for each database/website}

\begin{tabular}{|c|c|c|c|}
\hline Name & Website and date searched & Search terms & $\begin{array}{l}\text { Number of } \\
\text { documents } \\
\text { identified }\end{array}$ \\
\hline \multicolumn{4}{|c|}{ Academic literature sources } \\
\hline Scopus & $\begin{array}{l}\text { http://www.Scopus.com/ } \\
\text { 28/01/16 }\end{array}$ & See Appendix A. & 406 \\
\hline PubMed & $\begin{array}{l}\text { http://www.ncbi.nlm.nih.gov/pubmed } \\
\text { 28/01/16 }\end{array}$ & See Appendix A. & 42 \\
\hline Web of Science & $\begin{array}{l}\text { http://wokinfo.com/ } \\
\text { 28/01/16 }\end{array}$ & See Appendix A. & 492 \\
\hline $\begin{array}{l}\text { ProQuest } \\
\text { Dissertations \& } \\
\text { Theses Global }\end{array}$ & $28 / 01 / 16$ & See Appendix A. & 139 \\
\hline \multicolumn{4}{|c|}{ Grey literature sources } \\
\hline \multicolumn{4}{|c|}{ A) Search string: Concept 1 using websites own search functions, search whole document } \\
\hline $\begin{array}{l}\text { Eldis (Institute of } \\
\text { Development } \\
\text { Studies) }\end{array}$ & $\begin{array}{l}\text { http://explorer.okhub.org/ } \\
2 / 02 / 16\end{array}$ & $\begin{array}{l}\text { Search string: Concept } 1 \\
\text { Shelter OR Shelters OR House OR Houses OR Housing OR Home } \\
\text { OR Homes OR Dwelling OR Dwellings OR Settlement OR Settlements } \\
\text { OR Neighbourhood OR Neighbourhoods OR Neighborhood OR } \\
\text { Neighborhoods OR Resettlement OR Reconstruction } \\
\text { Language: English }\end{array}$ & 57 \\
\hline $\begin{array}{l}\text { Abdul Latif Jameel } \\
\text { Poverty Action Lab } \\
\text { (J-PAL) }\end{array}$ & $\begin{array}{l}\text { https://www.povertyactionlab.org/evalua } \\
\text { tions } \\
2 / 02 / 16\end{array}$ & $\begin{array}{l}\text { Search string: Concept } 1 \\
\text { Shelter Shelters House Houses Housing Home Homes Dwelling } \\
\text { Dwellings Settlement Neighbourhood Resettlement Reconstruction } \\
\text { Search: 'evaluations' }\end{array}$ & 100 \\
\hline \multicolumn{4}{|c|}{$\begin{array}{l}\text { B) Search string: Concept } 1 \text { OR Concept } 4 \text { using Google due to limited search function on website; search whole document or title only } \\
\text { depending on number of hits (title only if more than } 175 \text { hits) }\end{array}$} \\
\hline $\begin{array}{l}\text { NSET (National } \\
\text { Society for } \\
\text { Earthquake } \\
\text { Technology - } \\
\text { Nepal) }\end{array}$ & $\begin{array}{l}\text { http://www.nset.org.np/nset2012/ } \\
\text { 2/02/16 }\end{array}$ & $\begin{array}{l}\text { Limited search function on website, use Google to search. } \\
\text { Search string: Concept } 1 \\
\text { Shelter OR Shelters OR House OR Houses OR Housing OR Home } \\
\text { OR Homes OR Dwelling OR Dwellings OR Settlement OR Settlements } \\
\text { OR Neighbourhood OR Neighbourhoods OR Neighborhood OR } \\
\text { Neighborhoods OR Resettlement OR Reconstruction } \\
\text { site:http://www.nset.org.np/nset2012/ filetype:pdf }\end{array}$ & 66 \\
\hline $\begin{array}{l}\text { ProVention } \\
\text { Consortium }\end{array}$ & $\begin{array}{l}\text { http://www.preventionweb.net/english/pr } \\
\text { ofessional/ } \\
4 / 02 / 16\end{array}$ & $\begin{array}{l}\text { Search string: Concept } 1 \\
\text { allintitle: Shelter OR Shelters OR House OR Houses OR Housing OR } \\
\text { Home OR Homes OR Dwelling OR Dwellings OR Settlement OR } \\
\text { Settlements OR Neighbourhood OR Neighbourhoods OR } \\
\text { Neighborhood OR Neighborhoods OR Resettlement OR } \\
\text { Reconstruction site:http://www.preventionweb.net filetype:pdf }\end{array}$ & 109 \\
\hline Save the Children & $\begin{array}{l}\text { http://search.savethechildren.org.uk/ } \\
2 / 02 / 16\end{array}$ & $\begin{array}{l}\text { Search string: Concept } 1 \\
\text { allintitle: Shelter OR Shelters OR House OR Houses OR Housing OR } \\
\text { Home OR Homes OR Dwelling OR Dwellings OR Settlement OR } \\
\text { Settlements OR Neighbourhood OR Neighbourhoods OR } \\
\text { Neighborhood OR Neighborhoods OR Resettlement OR } \\
\text { Reconstruction site:http://www.savethechildren.org.uk/ filetype:pdf }\end{array}$ & 12 \\
\hline $\begin{array}{l}\text { Australian Aid } \\
\text { (Australian Agency } \\
\text { for International } \\
\text { Development) }\end{array}$ & $\begin{array}{l}\text { http://dfat.gov.au/aid/Pages/australias- } \\
\text { aid-program.aspx } \\
2 / 02 / 16\end{array}$ & $\begin{array}{l}\text { Limited search function on website, use Google to search. } \\
\text { Search string: Concept } 1 \\
\text { Shelter OR Shelters OR House OR Houses OR Housing OR Home } \\
\text { OR Homes OR Dwelling OR Dwellings OR Settlement OR Settlements } \\
\text { OR Neighbourhood OR Neighbourhoods OR Neighborhood OR } \\
\text { Neighborhoods OR Resettlement OR Reconstruction } \\
\text { site:http://dfat.gov.au/aid filetype:pdf }\end{array}$ & 66 \\
\hline Build Change & $\begin{array}{l}\text { http://www.buildchange.org } \\
\text { 2/02/16 }\end{array}$ & $\begin{array}{l}\text { Limited search function on website, use Google to search. } \\
\text { Search string: Concept } 4 \\
\text { Outcome OR Impact OR Effect OR Consequence OR Evaluation OR } \\
\text { Assessment OR Lessons OR Learn* OR “After OR action" } \\
\text { site:http://www.buildchange.org filetype:pdf }\end{array}$ & 66 \\
\hline
\end{tabular}




\begin{tabular}{|c|c|c|c|}
\hline Name & Website and date searched & Search terms & $\begin{array}{l}\text { Number of } \\
\text { documents } \\
\text { identified }\end{array}$ \\
\hline $\begin{array}{l}\text { The Overseas } \\
\text { Development } \\
\text { Institute (ODI) }\end{array}$ & $\begin{array}{l}\text { http://www.odi.org/publications } \\
3 / 02 / 16\end{array}$ & $\begin{array}{l}\text { Limited search function on website, use Google to search. } \\
\text { Search string: Concept } 1 \\
\text { Shelter OR Shelters OR Houses OR House OR Housing OR } \\
\text { Settlement OR Home OR Homes OR Dwelling OR Dwellings OR } \\
\text { Settlement OR Neighbourhood site:http://www.odi.org/publications } \\
\text { filetype:pdf }\end{array}$ & 16 \\
\hline $\begin{array}{l}\text { Incremental } \\
\text { Housing - MIT }\end{array}$ & $\begin{array}{l}\text { http://web.mit.edu/incrementalhousing/ } \\
3 / 02 / 16\end{array}$ & $\begin{array}{l}\text { Limited search function on website, use Google to search. } \\
\text { Search string: Concept } 4 \\
\text { Outcome OR Impact OR Effect OR Consequence OR Evaluation OR } \\
\text { Assessment OR Lessons OR Learn* OR "After OR action" } \\
\text { site:http://web.mit.edu/incrementalhousing/ filetype:pdf }\end{array}$ & 57 \\
\hline Oxfam & $\begin{array}{l}\text { http://www.oxfam.org.uk/ } \\
\text { 2/02/16 }\end{array}$ & $\begin{array}{l}\text { Limited search function on website, use Google to search. } \\
\text { Search string: Concept } 1 \\
\text { Shelter OR Shelters OR House OR Houses OR Housing OR Home } \\
\text { OR Homes OR Dwelling OR Dwellings OR Settlement OR Settlements } \\
\text { OR Neighbourhood OR Neighbourhoods OR Neighborhood OR } \\
\text { Neighborhoods OR Resettlement OR Reconstruction } \\
\text { site:http://www.oxfam.org.uk/ filetype:pdf }\end{array}$ & 8 \\
\hline Plan International & $\begin{array}{l}\text { https://plan-international.org/ } \\
2 / 02 / 16\end{array}$ & $\begin{array}{l}\text { Limited search function on website, use Google to search. } \\
\text { Search string: Concept } 1 \\
\text { Shelter OR Shelters OR House OR Houses OR Housing OR Home } \\
\text { OR Homes OR Dwelling OR Dwellings OR Settlement OR Settlements } \\
\text { OR Neighbourhood OR Neighbourhoods OR Neighborhood OR } \\
\text { Neighborhoods OR Resettlement OR Reconstruction site:https://plan- } \\
\text { international.org/ filetype:pdf }\end{array}$ & 23 \\
\hline Shelter Cluster & $\begin{array}{l}\text { http://www.sheltercluster.org/search- } \\
\text { documents } \\
3 / 02 / 16\end{array}$ & $\begin{array}{l}\text { Limited search function on website, use Google to search. } \\
\text { Search string: Concept } 4 \\
\text { allintitle: Outcome OR Impact OR Review OR Effect OR Consequence } \\
\text { OR Evaluation OR Assessment OR Lessons OR Learn* OR “After OR } \\
\text { action" site:http://www.sheltercluster.org filetype:pdf }\end{array}$ & 119 \\
\hline Practical Action & $\begin{array}{l}\text { http://practicalaction.org/ } \\
\text { 2/02/16 }\end{array}$ & $\begin{array}{l}\text { Limited search function on website, use Google to search. } \\
\text { Search string: Concept } 1 \\
\text { allintitle: Shelter OR Shelters OR House OR Houses OR Housing OR } \\
\text { Home OR Homes OR Dwelling OR Dwellings OR Settlement OR } \\
\text { Settlements OR Neighbourhood OR Neighbourhoods OR } \\
\text { Neighborhood OR Neighborhoods OR Resettlement OR } \\
\text { Reconstruction site:http://practicalaction.org/ filetype:pdf }\end{array}$ & 16 \\
\hline USAID/OFDA & $\begin{array}{l}\text { https://www.usaid.gov/ } \\
\text { 2/02/16 }\end{array}$ & $\begin{array}{l}\text { Limited search function on website, use Google to search. } \\
\text { Search string: Concept } 1 \\
\text { allintitle: Shelter OR Shelters OR House OR Houses OR Housing OR } \\
\text { Home OR Homes OR Dwelling OR Dwellings OR Settlement OR } \\
\text { Settlements OR Neighbourhood OR Neighbourhoods OR } \\
\text { Neighborhood OR Neighborhoods OR Resettlement OR } \\
\text { Reconstruction site:https://www.usaid.gov/ filetype:pdf }\end{array}$ & 23 \\
\hline $\begin{array}{l}\text { ERRA (Earthquake } \\
\text { Reconstruction and } \\
\text { Rehabilitation } \\
\text { Authority) }\end{array}$ & $\begin{array}{l}\text { http://erra.pk/ } \\
2 / 02 / 16\end{array}$ & $\begin{array}{l}\text { Limited search function on website, use Google to search. } \\
\text { Search string: Concept } 1 \\
\text { allintitle: Shelter OR Shelters OR House OR Houses OR Housing OR } \\
\text { Home OR Homes OR Dwelling OR Dwellings OR Settlement OR } \\
\text { Settlements OR Neighbourhood OR Neighbourhoods OR } \\
\text { Neighborhood OR Neighborhoods OR Resettlement OR } \\
\text { Reconstruction site:http://erra.pk/ filetype:pdf }\end{array}$ & 24 \\
\hline $\begin{array}{l}\text { European } \\
\text { Commission } \\
\text { Humanitarian Aid } \\
\text { and Civil Protection } \\
\text { Department } \\
\text { (ECHO) }\end{array}$ & $\begin{array}{l}\text { http://ec.europa.eu/echo/_en } \\
\text { 2/02/16 }\end{array}$ & $\begin{array}{l}\text { Limited search function on website, use Google to search. } \\
\text { Search string: Concept } 1 \\
\text { allintitle: Shelter OR Shelters OR House OR Houses OR Housing OR } \\
\text { Home OR Homes OR Dwelling OR Dwellings OR Settlement OR } \\
\text { Settlements OR Neighbourhood OR Neighbourhoods OR } \\
\text { Neighborhood OR Neighborhoods OR Resettlement OR } \\
\text { Reconstruction site:http://ec.europa.eu/echo filetype:pdf }\end{array}$ & 5 \\
\hline \multicolumn{4}{|c|}{ C) Search string: Adaptation of search terms to suit websites own search functions and type of documentation } \\
\hline DFID (R4D) & $\begin{array}{l}\text { http://r4d.dfid.gov.uk/ } \\
4 / 02 / 16\end{array}$ & $\begin{array}{l}\text { Use advanced search function on website. } \\
\text { Search String: Concept 1, } 3 \text { AND } 4 \text { (document summary); } \\
\text { Type: 'Document' } \\
\text { Concept 1: Shelter OR Shelters OR House OR Houses OR Housing } \\
\text { OR Home OR Homes OR Dwelling OR Dwellings OR Settlement OR } \\
\text { Settlements OR Neighbourhood OR Neighbourhoods OR } \\
\text { Neighborhood OR Neighborhoods OR Resettlement OR } \\
\text { Reconstruction } \\
\text { Concept 3:Self-recovery OR "Self recovery" OR Self-help OR "Self } \\
\text { help" OR Self-build OR "Self build" OR "Material assistance" OR } \\
\text { "Financial assistance" OR "Technical assistance" OR Cash Voucher* } \\
\text { OR "Construction material*" OR Tool* OR Training Workshop* } \\
\text { OR Guideline* OR Manual* OR Poster OR Leaflet* OR } \\
\text { Flyer* OR "Mass communication" OR Phone OR Radio OR } \\
\text { Television OR TV OR Internet OR Newspaper OR Advert OR } \\
\text { Broadcast } \\
\text { Concept 4: Outcome OR Impact OR Effect OR Consequence OR } \\
\text { Evaluation OR Assessment OR Lessons OR Learn* OR "After action" }\end{array}$ & 168 \\
\hline
\end{tabular}




\begin{tabular}{|c|c|c|c|}
\hline Name & Website and date searched & Search terms & $\begin{array}{l}\text { Number of } \\
\text { documents } \\
\text { identified }\end{array}$ \\
\hline $\begin{array}{l}\text { Jolis: Joint Bank- } \\
\text { Fund Library of the } \\
\text { World Bank and } \\
\text { IMF }\end{array}$ & $\begin{array}{l}\text { http://external.worldbankimflib.org/uhtbi } \\
\text { n/webcat/\#_ } \\
\text { 3/02/16 }\end{array}$ & $\begin{array}{l}\text { Concept } 1 \text { AND Concept } 4 \text { (title) } \\
\text { Title: ((Shelter OR Shelters OR Houses OR House OR Housing OR } \\
\text { Settlement OR Home OR Homes OR Dwelling OR Dwellings OR } \\
\text { Settlement OR Neighbourhood) AND (Outcome OR Impact OR Effect } \\
\text { OR Consequence OR Evaluation OR Assessment OR Lessons OR } \\
\text { Learn*)) } \\
\text { Format: BIBLIO - articles and research working papers } \\
\text { Location: INTERNET } \\
\text { Language: English }\end{array}$ & 75 \\
\hline $\begin{array}{l}\text { 3ie's database of } \\
\text { impact evaluations }\end{array}$ & $\begin{array}{l}\text { http://www.3ieimpact.org/en/evidence } \\
\text { 3/02/16 }\end{array}$ & $\begin{array}{l}\text { Search string: Concept } 1 \text { (all text) AND adapted version of } \\
\text { Concept } 2 \text { (all text) } \\
\text { ((Shelter OR House OR Housing OR Home OR Dwelling OR } \\
\text { Settlement OR Neighbourhood) AND (Catastrophe OR emergencies } \\
\text { OR emergency OR Disaster OR Crisis OR Crises OR "Armed conflict" } \\
\text { OR "Conflict affected" OR War)) } \\
\text { Document type: All (including systematic reviews and impact } \\
\text { evaluations) }\end{array}$ & 3 \\
\hline $\begin{array}{l}\text { British Library for } \\
\text { Development } \\
\text { Studies (BLDS) }\end{array}$ & $\begin{array}{l}\text { http://blds.ids.ac.uk/ } \\
3 / 02 / 16\end{array}$ & $\begin{array}{l}\text { Search string: Concept } 1 \text { (keyword) } \\
\text { 'kw,wrdl: shelter or kw,wrdl: house or kw,wrdl: housing or kw,wrdl: } \\
\text { home or kw,wrdl: dwelling or kw,wrdl: settlement or kw,wrdl: } \\
\text { neighbourhood or kw,wrdl: neighborhood or kw,wrdl: resettlement or } \\
\text { kw,wrdl: reconstruction' with limit(s): 'mc-itype,phr:EBK or mc- } \\
\text { itype,phr:EJNL or mc-itype,phr:ERS In,rtrn:eng' } \\
\text { Item type:E-book, E-journal, E-resource } \\
\text { Language: English }\end{array}$ & 58 \\
\hline $\begin{array}{l}\text { International } \\
\text { Recovery Platform }\end{array}$ & $\begin{array}{l}\text { http://www.recoveryplatform.org/resourc } \\
\text { es/publications } \\
3 / 02 / 16\end{array}$ & Filter through theme: 'Shelter' & 143 \\
\hline $\begin{array}{l}\text { International } \\
\text { Federation of Red } \\
\text { Cross and Red } \\
\text { Crescent Societies } \\
\text { (IRFC) }\end{array}$ & $\begin{array}{l}\text { http://www.ifrc.org/en/publications-and- } \\
\text { reports/evaluations/ } \\
\text { 23/02/16 }\end{array}$ & $\begin{array}{l}\text { Filter through: } \\
\text { a) 'Types of Disasters/Categories' : Shelter } \\
\text { b) (Evaluation) 'Type': All }\end{array}$ & 44 \\
\hline \multicolumn{4}{|c|}{ D) Limited search functions on website, not searchable by Google; website hand searched. } \\
\hline $\mathrm{i}-\mathrm{Rec}$ & $\begin{array}{l}\text { http://www.grif.umontreal.ca/i- } \\
\text { rec/publications.html } \\
4 / 02 / 16\end{array}$ & Hand searched & $\mathrm{N} / \mathrm{A}$ \\
\hline $\begin{array}{l}\text { British Library e- } \\
\text { theses online } \\
\text { service (EThOS) } \\
\text { Humanitarian } \\
\text { Exchange } \\
\text { Magazine }\end{array}$ & $\begin{array}{l}\text { http://ethos.bl.uk/Home.do } \\
4 / 02 / 16\end{array}$ & $\begin{array}{l}\text { Hand searched: } \\
\text { For example, terms used: } \\
\text { 1) Shelter OR house* OR home* OR settlement* OR reconstruction } \\
\text { AND humanitarian (all anyword) Etc. } \\
\text { Select: Limit search to items available for immediate download from } \\
\text { EThOS or the Institution }\end{array}$ & $\mathrm{N} / \mathrm{A}$ \\
\hline $\begin{array}{l}\text { Social Science } \\
\text { Research Network } \\
\text { (SSRN) }\end{array}$ & $\begin{array}{l}\text { http://www.ssrn.com/en/ } \\
4 / 02 / 16\end{array}$ & $\begin{array}{l}\text { Hand searched. } \\
\text { For example, terms used: } \\
\text { 1) shelter AND humanitarian }\end{array}$ & $\mathrm{N} / \mathrm{A}$ \\
\hline
\end{tabular}

Stakeholder engagement (round 2)

\begin{tabular}{l|l|} 
Various & Various
\end{tabular}

Citation tracking and 'snowballing'

\begin{tabular}{|l|l|l|l|}
\hline Citation tracking and 'snowballing' & \multicolumn{2}{|l|}{} \\
\hline Various & Various & \\
\hline
\end{tabular}




\section{APPENDIX C: SCOPING ASSESSMENT SEARCH RESULTS AND SCREENING GUIDE}

This appendix details the inclusion/exclusion criteria used in the screening guide and the search results for each database/website.

\section{Scoping assessment: Screening guide}

\section{Figure C.1: Screening guide}

\begin{tabular}{|c|c|c|}
\hline \multicolumn{2}{|r|}{ First round of screening: Scope and relevance } & \multirow{2}{*}{$\begin{array}{l}\text { Notes to researcher } \\
\text { If the answer is no, exclude. }\end{array}$} \\
\hline 1 & Is the document in English? & \\
\hline 2 & $\begin{array}{l}\text { Does the document identify the intervention as a shelter or settlement } \\
\text { response to humanitarian crisis/crises? }\end{array}$ & If the answer is no, exclude. \\
\hline 3 & $\begin{array}{l}\text { Does the document describe intervention(s) in low and middle-income } \\
\text { countries? }\end{array}$ & If the answer is no, exclude. \\
\hline 4 & $\begin{array}{l}\text { Does the document describe the activities and outputs of the intervention } \\
\text { supporting shelter self-recovery? }\end{array}$ & If the answer is no, exclude. \\
\hline
\end{tabular}

\begin{tabular}{|l|l|l|}
\hline \multicolumn{2}{|l|}{ Second round of screening: Quality } \\
\hline 5 & Does the document report on the data collection methodology? & If the answer is no, exclude. \\
\hline 6 & Does the document clearly describe the shelter or settlement intervention? & If the answer is no, exclude. \\
\hline 7 & $\begin{array}{l}\text { Does the document describe the results of qualitative, quantitative or } \\
\text { mixed methods evaluations primary research? }\end{array}$ & If the answer is no, exclude. \\
\hline \multicolumn{2}{|l|}{ Documents identified as: 'Include in screening for evidence synthesis' or 'Exclude' } \\
\hline
\end{tabular}

\section{Scoping assessment: Search results}

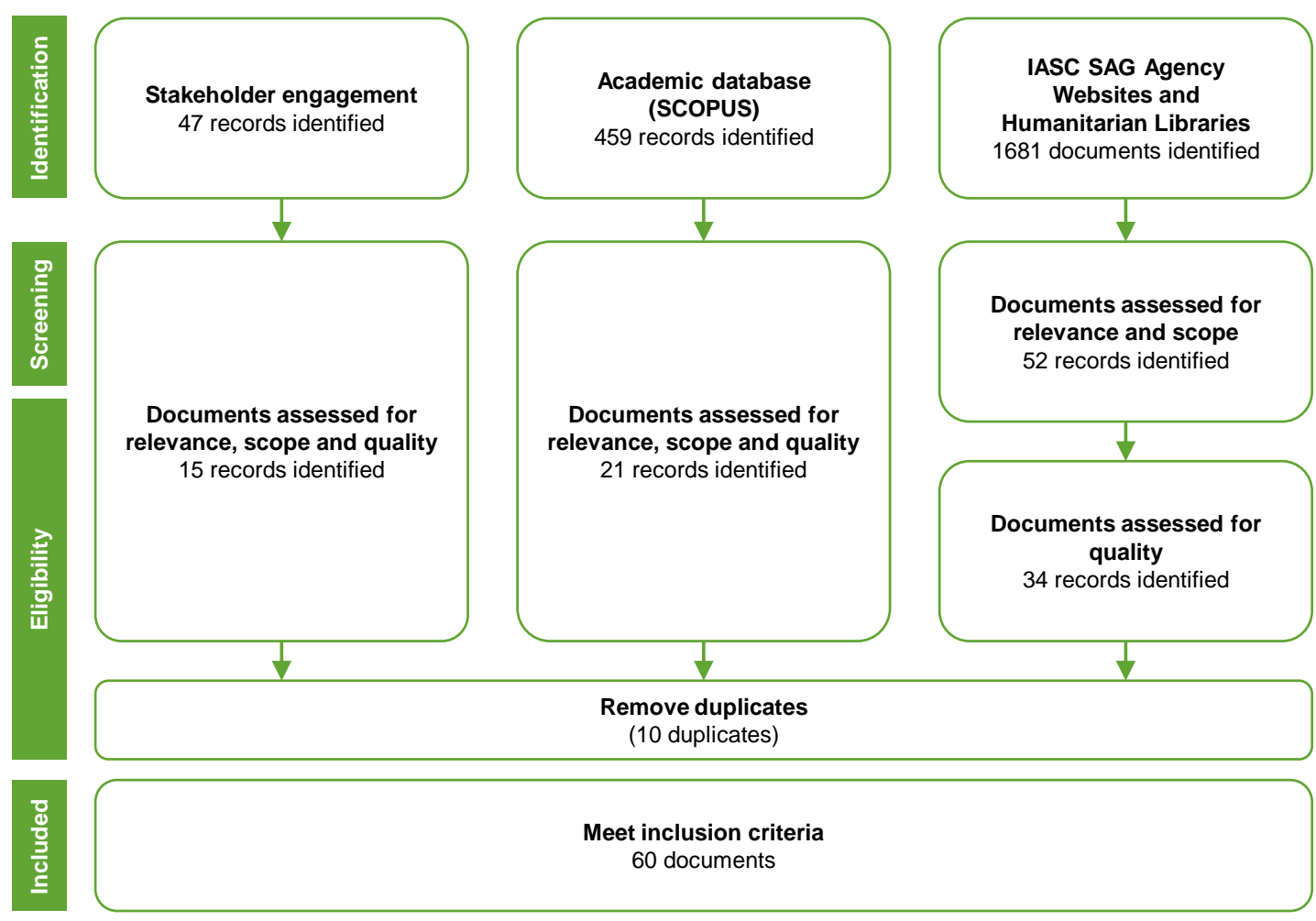




\section{APPENDIX D: LIST OF EXCLUDED DOCUMENTS}

This appendix details the documents that were excluded from the synthesis following the quality appraisal and round two of the screening process. Please also refer to the screening guide (Figure C.1) when reading this appendix.

\section{Documents excluded following quality appraisal}

As noted earlier, the principles of the 'quality appraisal template' were based on the following key factors underpinning quality (Posthumus et al. 2013; Centre for Reviews and

Dissemination 2008):

- appropriateness of study design to the research objective (e.g. the relevance)

- risk of bias (e.g. the systematic deviations from the true underlying effect brought about by poor study design or conduct in the collection, analysis, interpretation or publication).

Figure D.1: Four documents excluded following quality appraisal as using the 'quality appraisal template' (Appendix E)

\begin{tabular}{|c|c|c|c|c|}
\hline Author(s) & $\begin{array}{l}\text { Publication } \\
\text { date }\end{array}$ & Title & Web link & Reason for exclusion? \\
\hline $\begin{array}{l}\text { Kirkby, S.J., } \\
\text { Rose, J. }\end{array}$ & 2007 & $\begin{array}{l}\text { Going Home, Making a Life } \\
\text { after Conflict; Return and } \\
\text { Reintegration of IDPs and } \\
\text { Returnees in Bomi, Grand } \\
\text { Cape Mount and Gbarpolu } \\
\text { Counties, Liberia }\end{array}$ & $\begin{array}{l}\text { http://www.alnap.org/pool/files } \\
\text { /9261428.pdf }\end{array}$ & $\begin{array}{l}\text { Appropriateness (external validity) } \\
\text { External mid-term evaluation of multi-sectoral } \\
\text { programme. Research questions and framework } \\
\text { clearly described but not tailored specifically to } \\
\text { shelter. Research approach not justified. } \\
\text { Sources of data listed but unclear how } \\
\text { participants were selected and data collection } \\
\text { tools not included. Method of analysis and } \\
\text { ethical aspects not described. Limitations of the } \\
\text { study and the role of the researcher briefly } \\
\text { described. Findings lack depth and wider } \\
\text { implications of the study are not discussed. }\end{array}$ \\
\hline Anonymous & 2011 & $\begin{array}{l}\text { End of Project Evaluation of } \\
\text { the Emergency Shelter } \\
\text { Relief and Recovery Project } \\
\text {-Anonymous }\end{array}$ & Not available online & $\begin{array}{l}\text { Risk of bias } \\
\text { A subsequent field report/ assessment was } \\
\text { identified that presented alternative findings; } \\
\text { because it was not clear which source } \\
\text { accurately reflected the programme impacts, } \\
\text { both were excluded on the basis of quality. }\end{array}$ \\
\hline Rhyner, K. & 2014 & $\begin{array}{l}\text { Guatemala: Knowledge in } \\
\text { the hands of the people. In } \\
\text { Schilderman and Parker } \\
\text { (2014) Still Standing? }\end{array}$ & $\begin{array}{l}\text { http://developmentbookshop.c } \\
\text { om/still-standing }\end{array}$ & $\begin{array}{l}\text { Appropriateness (research objectives not } \\
\text { clearly stated) } \\
\text { Implementing agency revisit, } 36 \text { years following } \\
\text { completion of project, personal reflections. No } \\
\text { stated research questions or aims, very limited } \\
\text { or no detail on data collection, analysis and } \\
\text { research limitations. No discussion of research } \\
\text { limitations or researcher influence. Author } \\
\text { describes the application of lessons in other } \\
\text { contexts (which has already taken place) }\end{array}$ \\
\hline Sipus, M. E. & 2010 & $\begin{array}{l}\text { An Assessment of Sphere } \\
\text { Humanitarian Standards for } \\
\text { Shelter and Settlement } \\
\text { Planning in Kenya's Dadaab } \\
\text { Refugee Camps }\end{array}$ & $\begin{array}{l}\text { http://search.proquest.com/do } \\
\text { cview/867100717?accountid= } \\
14511\end{array}$ & $\begin{array}{l}\text { Appropriateness (research objectives not } \\
\text { clearly stated) } \\
\text { Masters Dissertation. Comparison of three cases } \\
\text { of housing assistance within the Dadaab refugee } \\
\text { camp. Unclear statement of research question } \\
\text { and research approach. No detail given on } \\
\text { selection of participants or data collection tools. } \\
\text { Method of analysis not described, findings } \\
\text { presented in a different structure from the } \\
\text { research framework, findings not referenced to } \\
\text { sources of data. Likely that more data collected } \\
\text { than reported. No discussion of limitations, } \\
\text { ethical issues or the role of the researcher. No } \\
\text { discussion of wider implication of findings. }\end{array}$ \\
\hline
\end{tabular}




\section{Documents excluded following round two screening}

Figure D.2: Documents excluded following round two screening

\begin{tabular}{|c|c|c|c|c|}
\hline Author(s) & $\begin{array}{l}\text { Publication } \\
\text { date }\end{array}$ & Title & Web link & Reasons for exclusion? \\
\hline Alam, K. & 2010 & $\begin{array}{l}\text { Bangladesh: Can large } \\
\text { actors overcome the } \\
\text { absence of state will? In } \\
\text { Lyons and Schilderman } \\
\text { (2010) Building Back Better, } \\
\text { Chapter } 10\end{array}$ & $\begin{array}{l}\text { http://practicalaction.org/building- } \\
\text { back-better-book }\end{array}$ & $\begin{array}{l}\text { Insufficient detail on intervention and } \\
\text { outcomes (screening questions } 11 \text { and 12). }\end{array}$ \\
\hline $\begin{array}{l}\text { All India } \\
\text { Disaster } \\
\text { Mitigation } \\
\text { Institute }\end{array}$ & 2005 & $\begin{array}{l}\text { Review of AIDMI's } \\
\text { Temporary Shelter } \\
\text { Programme in Tsunami- } \\
\text { Affected Southern India }\end{array}$ & $\begin{array}{l}\text { http://www.alnap.org/resource/332 } \\
2\end{array}$ & $\begin{array}{l}\text { Internal review. Insufficient detail on } \\
\text { intervention and outcomes (screening } \\
\text { questions } 11 \text { and 12). }\end{array}$ \\
\hline $\begin{array}{l}\text { Andrew, S.A. et } \\
\text { al. }\end{array}$ & 2013 & $\begin{array}{l}\text { The effect of housing } \\
\text { assistance arrangements } \\
\text { on household recovery: An } \\
\text { empirical test of donor- } \\
\text { assisted and owner-driven } \\
\text { approaches }\end{array}$ & $\begin{array}{l}\text { http://www.Scopus.com/inward/rec } \\
\text { ord.url?eid=2-s2.0- } \\
84875408726 \text { andpartnerlD=40and } \\
\text { md5=cdc5144ebc5077e7b8fc2479 } \\
9 \text { cc335a6 }\end{array}$ & $\begin{array}{l}\text { Document details two case studies, one of } \\
\text { which would be suitable for inclusion in the } \\
\text { review (in-situ owner driven). However } \\
\text { insufficient detail on the intervention and the } \\
\text { document indicates that those surveyed } \\
\text { may have received different interventions } \\
\text { (screening question 11). }\end{array}$ \\
\hline Atkinson, M. & 2001 & $\begin{array}{l}\text { Evaluation of ECHO's } \\
\text { Humanitarian Aid in favour } \\
\text { of the Timorese Population: } \\
\text { Rehabilitation, Repatriation, } \\
\text { Shelter and LRRD sectors }\end{array}$ & $\begin{array}{l}\text { http://www.alnap.org/pool/files/erd- } \\
\text { 2943-full.pdf }\end{array}$ & $\begin{array}{l}\text { Insufficient detail on source of data (if } \\
\text { primary data), methodology, intervention } \\
\text { and outcomes (screening questions } 8,9,11 \\
\text { and 12). }\end{array}$ \\
\hline $\begin{array}{l}\text { Bagić, D., } \\
\text { Dedic, D. }\end{array}$ & 2005 & $\begin{array}{l}\text { The Impact of Aid for } \\
\text { Reconstruction of Homes in } \\
\text { Bosnia and Herzegovina }\end{array}$ & $\begin{array}{l}\text { http://www.sida.se/contentassets/a } \\
\text { 4c762fd439649baa09ac0b32361e } \\
\text { 85b/20051-the-impact-of-aid-for- } \\
\text { reconstruction-of-homes-in-bosnia- } \\
\text { herzegovina_1887.pdf }\end{array}$ & $\begin{array}{l}\text { Insufficient detail on intervention (screening } \\
\text { question 11)- But included as a supporting } \\
\text { document for (Cukur et al., 2005). }\end{array}$ \\
\hline Blomquist, $\mathrm{H}$. & 2005 & $\begin{array}{l}\text { DRC Housing Project in } \\
\text { North Ossetia - Alanya - } \\
\text { Impact of housing on social } \\
\text { integration }\end{array}$ & $\begin{array}{l}\text { http://www.alnap.org/pool/files/erd- } \\
\text { 3351-full.pdf }\end{array}$ & $\begin{array}{l}\text { Insufficient detail on intervention (screening } \\
\text { question 11) }\end{array}$ \\
\hline $\begin{array}{l}\text { Bravo, P., } \\
\text { Ahmed, B.A., } \\
\text { Fogden, D. }\end{array}$ & 2013 & $\begin{array}{l}\text { An internal evaluation of the } \\
\text { shelter kit response }\end{array}$ & $\begin{array}{l}\text { http://www.ifrc.org/en/publications- } \\
\text { and-reports/evaluations/ }\end{array}$ & $\begin{array}{l}\text { Insufficient detail on outcomes (screening } \\
\text { question 12). }\end{array}$ \\
\hline $\begin{array}{l}\text { Bugnion, C. et } \\
\text { al. }\end{array}$ & 2000 & $\begin{array}{l}\text { External Evaluation of the } \\
\text { UNHCR Shelter Program in } \\
\text { Rwanda 1994-1999 }\end{array}$ & $\begin{array}{l}\text { http://www.alnap.org/pool/files/erd- } \\
\text { 2871-full.pdf }\end{array}$ & $\begin{array}{l}\text { Evaluation of multi-year programme with } \\
\text { multiple types of shelter assistance and } \\
\text { limited detail on specific interventions. } \\
\text { Excluded because of insufficient detail on } \\
\text { outcomes (screening question 12). }\end{array}$ \\
\hline $\begin{array}{l}\text { Catholic Relief } \\
\text { Services }\end{array}$ & In print & $\begin{array}{l}\text { Using Cash for Shelter: An } \\
\text { Overview of CRS Programs }\end{array}$ & & $\begin{array}{l}\text { Summary document, based on project } \\
\text { evaluations (?). Insufficient detail on } \\
\text { methodology (Screening question 9). }\end{array}$ \\
\hline $\begin{array}{l}\text { Catholic Relief } \\
\text { Services }\end{array}$ & 2016 & $\begin{array}{l}\text { Pintakasi. A review of } \\
\text { shelter/Wash delivery } \\
\text { methods in post-disaster or } \\
\text { recovery interventions }\end{array}$ & $\begin{array}{l}\text { http://www.cashlearning.org/downl } \\
\text { oads/pintakasi-review-of-shelter- } \\
\text { wash-post-disaster.pdf }\end{array}$ & $\begin{array}{l}\text { Insufficient detail on methodology and } \\
\text { outcomes (screening questions } 9 \text { and 12). }\end{array}$ \\
\hline $\begin{array}{l}\text { Causton, A., } \\
\text { Saunders, G. }\end{array}$ & 2006 & $\begin{array}{l}\text { Responding to shelter } \\
\text { needs in post-earthquake } \\
\text { Pakistan: A self-help } \\
\text { approach }\end{array}$ & $\begin{array}{l}\text { http://odihpn.org/magazine/respon } \\
\text { ding-to-shelter-needs-in-post- } \\
\text { earthquake-pakistan-a-self-help- } \\
\text { approach/ }\end{array}$ & $\begin{array}{l}\text { Summary paper of mid-term review. } \\
\text { Insufficient detail on the intervention (author } \\
\text { contacted for final evaluation) (screening } \\
\text { question 12). }\end{array}$ \\
\hline $\begin{array}{l}\text { Chamberlain, } \\
\text { P. }\end{array}$ & 2015 & $\begin{array}{l}\text { Mid-term review: BRC/PRC } \\
\text { Typhoon Haiyan - Iloilo } \\
\text { Recovery Programme }\end{array}$ & $\begin{array}{l}\text { http://www.ifrc.org/en/publications- } \\
\text { and-reports/evaluations/ }\end{array}$ & $\begin{array}{l}\text { Mid-term review. Insufficient detail on } \\
\text { outcome (author contacted for final } \\
\text { evaluation) (screening question 12). }\end{array}$ \\
\hline $\begin{array}{l}\text { Child, E., } \\
\text { Russo, C. }\end{array}$ & 2012 & $\begin{array}{l}\text { Reconstruction of Shelters, } \\
\text { Schools and Basic } \\
\text { Infrastructure" programme in } \\
\text { the cyclone affected district } \\
\text { of Labutta, Ayerwaddy } \\
\text { Division, Myanmar }\end{array}$ & & $\begin{array}{l}\text { The programme has two components } 1 \text { ) t- } \\
\text { shelters built to a standardized design with } \\
\text { some prefabricated components (excluded as } \\
\text { not shelter self-recovery) and 2) distribution of } \\
\text { materials and (DRR) training. However } \\
\text { insufficient detail on outcomes (screening } \\
\text { question 12). }\end{array}$ \\
\hline $\begin{array}{l}\text { Chr. Michelsen } \\
\text { Institute (Lead } \\
\text { Agency), } \\
\text { Copenhagen } \\
\text { Development } \\
\text { Consulting and } \\
\text { German } \\
\text { Association of } \\
\text { Development } \\
\text { Consultants }\end{array}$ & 2005 & $\begin{array}{l}\text { Humanitarian and } \\
\text { reconstruction assistance to } \\
\text { Afghanistan, 2001-2005, } \\
\text { from Denmark, Ireland, The } \\
\text { Netherlands, Sweden and } \\
\text { the United Kingdom: A joint } \\
\text { evaluation }\end{array}$ & $\begin{array}{l}\text { https://www.oecd.org/countries/afg } \\
\text { hanistan/35559322.pdf }\end{array}$ & $\begin{array}{l}\text { Evaluation of multi-year, multi-donor } \\
\text { programme with multiple types of } \\
\text { assistance (Health, Education etc). } \\
\text { However insufficient detail on shelter } \\
\text { intervention or outcomes noted (screening } \\
\text { questions } 11 \text { and 12). }\end{array}$ \\
\hline
\end{tabular}




\begin{tabular}{|c|c|c|c|c|}
\hline Author(s) & $\begin{array}{l}\text { Publication } \\
\text { date }\end{array}$ & Title & Web link & Reasons for exclusion? \\
\hline $\begin{array}{l}\text { Danish } \\
\text { Refugee } \\
\text { Council }\end{array}$ & 2011 & $\begin{array}{l}\text { Shelter Assessment Report: } \\
\text { Opinions from the host } \\
\text { community in Hilaweyn } \\
\text { refugee camp, Dollo Ado, } \\
\text { Ethiopia }\end{array}$ & $\begin{array}{l}\text { http://www.humanitarianlibrary.org/ } \\
\text { sites/default/files/2013/07/DRCShe } \\
\text { IterAssessmentreportHilaweynOct } \\
\text { 11.pdf }\end{array}$ & $\begin{array}{l}\text { Insufficient detail on intervention (screening } \\
\text { question 11). }\end{array}$ \\
\hline $\begin{array}{l}\text { Davidson, C.H. } \\
\text { et al. }\end{array}$ & 2007 & $\begin{array}{l}\text { Truths and myths about } \\
\text { community participation in } \\
\text { post-disaster housing } \\
\text { projects }\end{array}$ & $\begin{array}{l}\text { http://www.Scopus.com/inward/rec } \\
\text { ord.url?eid=2-s2.0- } \\
\text { 33846786684andpartnerID=40and } \\
\text { md5=62e1217aef2b2e396431c49a } \\
\text { 4b83d12d }\end{array}$ & $\begin{array}{l}\text { Insufficient detail on outcomes (screening } \\
\text { question 12). }\end{array}$ \\
\hline Desai, $\mathbf{R}$. & 2009 & $\begin{array}{l}\text { Orissa Flood Resilient } \\
\text { Shelter Program } \\
\text { Completion Evaluation }\end{array}$ & & $\begin{array}{l}\text { Insufficient detail on intervention (screening } \\
\text { question 11). }\end{array}$ \\
\hline Dikmen, N. & 2011 & $\begin{array}{l}\text { Comparative analysis of } \\
\text { permanent post-disaster } \\
\text { houses constructed in } \\
\text { Çankiki and Dinar }\end{array}$ & $\begin{array}{l}\text { http://www.Scopus.com/inward/rec } \\
\text { ord.url?eid=2-s2.0- } \\
\text { 79951648128andpartnerID=40and } \\
\text { md5=e5e22b1ee71 cd4b81ea2a39 } \\
\text { 32b235d23 }\end{array}$ & $\begin{array}{l}\text { Insufficient detail on intervention (screening } \\
\text { question 11). }\end{array}$ \\
\hline $\begin{array}{l}\text { Duyne } \\
\text { Barenstein, J. }\end{array}$ & 2008 & $\begin{array}{l}\text { From Gujarat to Tamil } \\
\text { Nadu: Owner-driven vs. } \\
\text { contractor-driven housing } \\
\text { reconstruction in India }\end{array}$ & $\begin{array}{l}\text { http://www.resorgs.org.nz/images/ } \\
\text { stories/pdfs/iRec_2008/postdFinal } \\
\text { 00087.pdf }\end{array}$ & $\begin{array}{l}\text { Summary paper based on a number of } \\
\text { related research projects. Insufficient detail } \\
\text { on any specific intervention (screening } \\
\text { questions } 11 \text { and 12). }\end{array}$ \\
\hline $\begin{array}{l}\text { Duyne } \\
\text { Barenstein, J. }\end{array}$ & 2006 & $\begin{array}{l}\text { Housing reconstruction in } \\
\text { post-earthquake Gujarat: A } \\
\text { comparative analysis }\end{array}$ & $\begin{array}{l}\text { http://www.alnap.org/pool/files/hou } \\
\text { sing-reconstruction-in- } \\
\text { postearthquake-gujarat-1.pdf }\end{array}$ & $\begin{array}{l}\text { Comparative analysis of several } \\
\text { interventions - only one of which is } \\
\text { supporting shelter self-recovery. Insufficient } \\
\text { detail on intervention or outcomes } \\
\text { (screening questions } 11 \text { and 12). }\end{array}$ \\
\hline El-Masri, S. D. & 1992 & $\begin{array}{l}\text { Reconstruction after } \\
\text { disaster : a study of war- } \\
\text { damaged villages in } \\
\text { Lebanon : the case of Al- } \\
\text { Burjain }\end{array}$ & $\begin{array}{l}\text { http://ethos.bl.uk/OrderDetails.do? } \\
\text { uin=uk.bl.ethos.238866 }\end{array}$ & $\begin{array}{l}\text { Does not review an intervention to assess } \\
\text { the outcomes, rather it analyses a conflict } \\
\text { affected community in order to gain insights } \\
\text { into the local conditions which could } \\
\text { influence and shape reconstruction of the } \\
\text { village (screening questions } 11 \text { and } 12 \text { ). }\end{array}$ \\
\hline Irvine, W. & 1998 & $\begin{array}{l}\text { Review of the UNHCR } \\
\text { housing programme in } \\
\text { Bosnia and Herzegovina }\end{array}$ & $\begin{array}{l}\text { http://www.alnap.org/resource/214 } \\
92\end{array}$ & $\begin{array}{l}\text { Insufficient detail on research methodology } \\
\text { (screening question 9), also limited detail on } \\
\text { intervention (screening question 11). }\end{array}$ \\
\hline $\begin{array}{l}\text { Elliot, P., } \\
\text { Serdaroglu, E. }\end{array}$ & 2014 & $\begin{array}{l}\text { Sri Lanka Red Cross Post- } \\
\text { Conflict Recovery } \\
\text { Programme: Indian Housing } \\
\text { Project - Internal Review }\end{array}$ & $\begin{array}{l}\text { http://www.ifrc.org/en/publications- } \\
\text { and-reports/evaluations/ }\end{array}$ & $\begin{array}{l}\text { Mid-term review. Insufficient detail on } \\
\text { outcome (screening question 12). }\end{array}$ \\
\hline $\begin{array}{l}\text { Eri, C., Fogden, } \\
\text { D. }\end{array}$ & 2013 & $\begin{array}{l}\text { Nigeria Floods 2012: Early } \\
\text { Recovery Shelter: } \\
\text { Beneficiary Satisfaction } \\
\text { Survey }\end{array}$ & $\begin{array}{l}\text { http://www.ifrc.org/en/publications- } \\
\text { and-reports/evaluations/ }\end{array}$ & $\begin{array}{l}\text { Intervention assessed as not supporting } \\
\text { shelter self-recovery because 'IFRC/NRCS } \\
\text { have constructed the structure of the house } \\
\text { (foundation/ Cement block wall (five } \\
\text { courses)/ Wooden structure / Concrete } \\
\text { columns / Fixing materials / Roof), before } \\
\text { passing it over to the recipient who is then } \\
\text { responsible for completing the remainder, } \\
\text { including the walls to roof height, and } \\
\text { positioning of doors and windows' (p. 25). } \\
\text { Therefore excluded on screening question } \\
11 .\end{array}$ \\
\hline $\begin{array}{l}\text { Fard, A. K., } \\
\text { Ahmad, M. H., } \\
\text { Ossen, D. R. }\end{array}$ & 2010 & $\begin{array}{l}\text { Cultural identity expressions } \\
\text { through visual analysis in } \\
\text { post-disaster housing }\end{array}$ & $\begin{array}{l}\text { http://www.Scopus.com/inward/rec } \\
\text { ord.url?eid=2-s2.0- } \\
\text { 79951784002andpartnerID=40and } \\
\text { md5 }=89500300951937 \mathrm{db} 5 \mathrm{c5ee} 0 \mathrm{a} \\
\text { c4979c7b5 }\end{array}$ & $\begin{array}{l}\text { Insufficient detail on the intervention } \\
\text { (screening question 11). }\end{array}$ \\
\hline Fayazi, M. & 2011 & $\begin{array}{l}\text { Reconstruction projects by } \\
\text { using core housing method } \\
\text { in Iran: Case study: Gilan } \\
\text { Province experience }\end{array}$ & $\begin{array}{l}\text { http://www.Scopus.com/inward/rec } \\
\text { ord.url?eid=2-s2.0- } \\
\text { 84858853535andpartnerlD=40and } \\
\text { md5=5b848be91 cae56a60691015 } \\
\text { 12acb2c49 }\end{array}$ & $\begin{array}{l}\text { Intervention not identified as a form of core- } \\
\text { house construction (rather than shelter-self } \\
\text { recovery), Therefore excluded on screening } \\
\text { question } 11 .\end{array}$ \\
\hline $\begin{array}{l}\text { Ferretti, S., } \\
\text { Ashmore, J., }\end{array}$ & 2010 & $\begin{array}{l}\text { Shelter Evaluation } \\
\text { Afghanistan: Final Report }\end{array}$ & $\begin{array}{l}\text { http://www.nrc.no/arch/_img/91802 } \\
\text { 93.pdf }\end{array}$ & $\begin{array}{l}\text { Insufficient detail on outcomes (screening } \\
\text { question 12). Included as supporting } \\
\text { document for (Samuel Hall, 2012). }\end{array}$ \\
\hline Flinn, B. & 2010 & $\begin{array}{l}\text { CARE International } \\
\text { Indonesia post-earthquake } \\
\text { Shelter Response, } \\
\text { Pariaman, Padang, West } \\
\text { Sumatra- Progress } \\
\text { Evaluation }\end{array}$ & & $\begin{array}{l}\text { Insufficient detail on methodology } \\
\text { (screening question 9). }\end{array}$ \\
\hline Foley, P. & 2005 & $\begin{array}{l}\text { Shelter Programme } \\
\text { Monitoring and Evaluation }\end{array}$ & $\begin{array}{l}\text { http://www.unhcr.org/4333f18e2.pd } \\
\text { f }\end{array}$ & $\begin{array}{l}\text { Insufficient detail on methodology } \\
\text { (screening question 9). Included as } \\
\text { supporting document for (Samuel Hall, } \\
\text { 2012). }\end{array}$ \\
\hline $\begin{array}{l}\text { Ganapati, N.E., } \\
\text { Mukherji, A. }\end{array}$ & 2014 & $\begin{array}{l}\text { Out of sync: World Bank } \\
\text { funding for housing } \\
\text { recovery, post disaster } \\
\text { planning, and participation }\end{array}$ & $\begin{array}{l}\text { http://www.Scopus.com/inward/rec } \\
\text { ord.url?eid=2-s2.0- } \\
\text { 84892699825andpartnerID=40and } \\
\text { md5=91d6102e86386d8b84e419f2 } \\
\text { 28f954c8 }\end{array}$ & $\begin{array}{l}\text { Insufficient detail on outcomes (screening } \\
\text { question 12). }\end{array}$ \\
\hline
\end{tabular}




\begin{tabular}{|c|c|c|c|c|}
\hline Author(s) & $\begin{array}{l}\text { Publication } \\
\text { date }\end{array}$ & Title & Web link & Reasons for exclusion? \\
\hline García, o & 2015 & $\begin{array}{l}\text { Evaluation of the Norwegian } \\
\text { Refugee Council's Lebanon } \\
\text { Host Community Shelter } \\
\text { Programmes }\end{array}$ & $\begin{array}{l}\text { http://www.nrc.no/arch/_img/91975 } \\
\text { 06.pdf }\end{array}$ & $\begin{array}{l}\text { Intervention provides indirect rental support- } \\
\text { funding provided to Landlords to } \\
\text { build/renovate properties and rent is } \\
\text { waivered for a year for beneficiary } \\
\text { households, therefore not shelter-self } \\
\text { recovery (screening question 11). }\end{array}$ \\
\hline $\begin{array}{l}\text { Government of } \\
\text { Uganda, } \\
\text { UNHCR, WFP }\end{array}$ & 2014 & $\begin{array}{l}\text { Uganda Joint Assessment } \\
\text { Mission }\end{array}$ & $\begin{array}{l}\text { http://www.unhcr.org/54d3762f0.pd } \\
f\end{array}$ & $\begin{array}{l}\text { Multi-sector, multi-agency study, insufficient } \\
\text { detail on outcomes and intervention } \\
\text { (screening questions } 11 \text { and 12). }\end{array}$ \\
\hline Hanif, M.W. & n.d. & $\begin{array}{l}\text { Principles, Themes and } \\
\text { Lessons Learnt: Design and } \\
\text { Implementation of ERRA's } \\
\text { Rural Housing Programme }\end{array}$ & $\begin{array}{l}\text { http://www.recoveryplatform.org/as } \\
\text { sets/publication/Pakistan\%20Earth } \\
\text { quake\%20Recovery/ERRA\%20Ru } \\
\text { ral\%20Housing.pdf }\end{array}$ & $\begin{array}{l}\text { Insufficient details on outcomes (screening } \\
\text { question 12). Also insufficient detail on } \\
\text { methodology (screening questions } 8 \text { and 9). }\end{array}$ \\
\hline Hanley, T. et al. & 2014 & $\begin{array}{l}\text { IASC Inter-agency } \\
\text { Humanitarian Evaluation of } \\
\text { the Typhoon Haiyan } \\
\text { Response }\end{array}$ & $\begin{array}{l}\text { http://www.interaction.org/sites/def } \\
\text { ault/files/9.\%20Final\%20report.pdf }\end{array}$ & $\begin{array}{l}\text { Multi-sector, multi-agency study, insufficient } \\
\text { detail on outcomes and intervention } \\
\text { (screening questions } 11 \text { and 12). }\end{array}$ \\
\hline $\begin{array}{l}\text { Hadafi, F; } \\
\text { Fallahi, A }\end{array}$ & 2010 & $\begin{array}{l}\text { Temporary housing respond } \\
\text { to disasters in developing } \\
\text { countries - Case study: } \\
\text { Iran- Ardabil and Lorestan } \\
\text { province earthquakes }\end{array}$ & $\begin{array}{l}\text { http://www.Scopus.com/inward/rec } \\
\text { ord.url?eid=2-s2.0- } \\
\text { 79951481222andpartnerID=40and } \\
\text { md5=15d0a0474fc9a527e66da318 } \\
\text { 08291d6a }\end{array}$ & $\begin{array}{l}\text { Insufficient detail on research methodology } \\
\text { (screening question 9). Insufficient detail on } \\
\text { the intervention (screening question 11). }\end{array}$ \\
\hline Hamid, Bauni & 2012 & $\begin{array}{l}\text { Reconstruction through } \\
\text { Collaboration Negotiation of } \\
\text { the Housing Process in } \\
\text { Disaster Recovery }\end{array}$ & $\begin{array}{l}\text { http://search.proquest.com/docvie } \\
\text { w/1082035936?accountid=14511 }\end{array}$ & $\begin{array}{l}\text { Insufficient detail on the intervention and } \\
\text { outcomes (screening question } 11 \text { and 12). }\end{array}$ \\
\hline Mukherji, A. & 2008 & $\begin{array}{l}\text { Negotiating housing } \\
\text { recovery: Why some } \\
\text { communities recovered } \\
\text { while others struggled to } \\
\text { rebuild in post-earthquake } \\
\text { urban Kutch, India }\end{array}$ & $\begin{array}{l}\text { http://www.anuradha.net/pdf/Mukh } \\
\text { erji_2008.pdf }\end{array}$ & $\begin{array}{l}\text { Insufficient detail on outcomes- research } \\
\text { focuses on impacts of policies in terms of } \\
\text { what recovery interventions were offered in } \\
\text { different communities (e.g. for homeowners, } \\
\text { for renters, for squatters)- rather than the } \\
\text { effects of the interventions on the } \\
\text { households (screening question 11). }\end{array}$ \\
\hline Hendy, A.O.A. & 2007 & $\begin{array}{l}\text { An approach to sustainable } \\
\text { construction in post-disaster } \\
\text { contexts: with specific } \\
\text { reference to the Marmara } \\
\text { region of Turkey }\end{array}$ & $\begin{array}{l}\text { http://ethos.bl.uk/OrderDetails.do? } \\
\text { uin=uk.bl.ethos. } 633631\end{array}$ & $\begin{array}{l}\text { zce State Hospital } \\
\text { (excluded, not shelter) and the World Bank's } \\
\text { Demetevlar Housing Project, also excluded } \\
\text { as insufficient detail, although does not } \\
\text { seem to be shelter- self recovery (screening } \\
\text { question 11). }\end{array}$ \\
\hline Hirano, S. & $2012 ?$ & $\begin{array}{l}\text { Learning From the Urban } \\
\text { Transitional Shelter } \\
\text { Response in Haiti }\end{array}$ & $\begin{array}{l}\text { http://www.crs.org/sites/default/file } \\
\text { s/tools-research/learning-urban- } \\
\text { transitional-shelter-response-haiti- } \\
\text { earthquake.pdf }\end{array}$ & $\begin{array}{l}\text { Insufficient detail on intervention, does not } \\
\text { seem to be shelter self-recovery (screening } \\
\text { question 11). }\end{array}$ \\
\hline $\begin{array}{l}\text { Jordan, E., } \\
\text { Javernick-Wil, } \\
\text { A., Amadei, B. }\end{array}$ & 2015 & $\begin{array}{l}\text { Post-disaster } \\
\text { reconstruction: lessons from } \\
\text { Nagapattinam district, India }\end{array}$ & $\begin{array}{l}\text { http://bldscat.ids.ac.uk/cgi- } \\
\text { bin/koha/opac- } \\
\text { detail.pl?biblionumber=236645 }\end{array}$ & $\begin{array}{l}\text { Insufficient linkages between intervention } \\
\text { and outcomes (analysis structured around } \\
\text { in situ and relocation). } \\
\text { Insufficient detail on intervention (s), (14 } \\
\text { different locations, supported by different } \\
\text { NGOs) does not seem to be shelter self- } \\
\text { recovery (screening question 11). }\end{array}$ \\
\hline Karunasena, G. & 2010 & $\begin{array}{l}\text { Post-disaster housing } \\
\text { reconstruction }\end{array}$ & $\begin{array}{l}\text { http://search.proquest.com/docvie } \\
\text { w/734462661?accountid=14511 }\end{array}$ & $\begin{array}{l}\text { Research addresses } 18 \text { (different donor } \\
\text { driven) projects and an unclear number of } \\
\text { 'owner-driven programmes'. Insufficient } \\
\text { detail on interventions (screening question } \\
\text { 11). }\end{array}$ \\
\hline $\begin{array}{l}\text { Kennedy, J., } \\
\text { Ashmore, J., } \\
\text { Babister, E., } \\
\text { Kelman, I. }\end{array}$ & 2008 & $\begin{array}{l}\text { The Meaning of Build Back } \\
\text { Better: Evidence from Post- } \\
\text { Tsunami Aceh and Sri } \\
\text { Lanka }\end{array}$ & $\begin{array}{l}\text { http://onlinelibrary.wiley.com/doi/10 } \\
.1111 / j .1468- \\
5973.2008 .00529 . x / \text { abstract }\end{array}$ & $\begin{array}{l}\text { Reflective research. Does not clearly } \\
\text { describe a specific intervention and then } \\
\text { directly attribute outcomes (screening } \\
\text { questions } 9,11 \text { and } 12 \text { ). }\end{array}$ \\
\hline King, K. G. & 2015 & $\begin{array}{l}\text { Resilience in the } \\
\text { humanitarian sphere : } \\
\text { stimulating resilience for } \\
\text { recovery in Haiti }\end{array}$ & $\begin{array}{l}\text { http://ethos.bl.uk/OrderDetails.do? } \\
\text { uin=uk.bl.ethos. } 647345\end{array}$ & $\begin{array}{l}\text { Document reports on whole post- } \\
\text { earthquake context. Does not clearly } \\
\text { describe a specific intervention and then } \\
\text { directly attribute outcomes (screening } \\
\text { questions } 11 \text { and 12). }\end{array}$ \\
\hline $\begin{array}{l}\text { Kuittinen, M., } \\
\text { Winter, S. }\end{array}$ & 2015 & $\begin{array}{l}\text { Carbon Footprint of } \\
\text { Transitional Shelters }\end{array}$ & $\begin{array}{l}\text { http://link.springer.com/article/10.1 } \\
007 / s 13753-015-0067-0\end{array}$ & $\begin{array}{l}\text { Impact evaluation of the carbon footprint of } \\
\text { shelters. Data used was secondary data } \\
\text { (IFRC publication 'Transitional Shelters -8 } \\
\text { Designs' (2008), therefore not primary data } \\
\text { (Screening question 8). }\end{array}$ \\
\hline $\begin{array}{l}\text { Lehmann, C., } \\
\text { Masterson, D. }\end{array}$ & 2014 & $\begin{array}{l}\text { Emergency Economies: } \\
\text { The Impact of Cash } \\
\text { Assistance in Lebanon }\end{array}$ & $\begin{array}{l}\text { https://data.unhcr.org/syrianrefuge } \\
\text { es/download.php?id=7112 }\end{array}$ & $\begin{array}{l}\text { Not a shelter-self recovery programme, } \\
\text { cash was transferred for heating. Document } \\
\text { does not report houses being constructed or } \\
\text { repaired with funding provided (screening } \\
\text { question 11). }\end{array}$ \\
\hline $\begin{array}{l}\text { Loschmann, C. } \\
\text { et al. }\end{array}$ & 2014 & $\begin{array}{l}\text { Does Shelter Assistance } \\
\text { reduce Poverty in } \\
\text { Afghanistan? }\end{array}$ & $\begin{array}{l}\text { http://www.imi.ox.ac.uk/pdfs/wp/wp } \\
-97-14 . p d f\end{array}$ & $\begin{array}{l}\text { Document does not report on primary data } \\
\text { collection- screening question } 8 \text {. Included } \\
\text { as supporting document for (Samuel Hall, } \\
\text { 2012). }\end{array}$ \\
\hline
\end{tabular}




\begin{tabular}{|c|c|c|c|c|}
\hline Author(s) & $\begin{array}{l}\text { Publication } \\
\text { date }\end{array}$ & Title & Web link & Reasons for exclusion? \\
\hline $\begin{array}{l}\text { Mahdi, F., Lee, } \\
\text { L. }\end{array}$ & $2012 ?$ & $\begin{array}{l}\text { Impact Evaluation: } \\
\text { Bangladesh Cyclone Aila } \\
\text { Recovery Programme }\end{array}$ & & $\begin{array}{l}\text { Good description of outcomes, but very } \\
\text { limited detail on intervention: p. } 33 \text {, notes } \\
\text { 'shelters were provided' indicating delivery } \\
\text { with no input from households, therefore not } \\
\text { shelter self-recovery (screening question } \\
\text { 11). }\end{array}$ \\
\hline Manyena, B. & 2009 & $\begin{array}{l}\text { Disaster resilience in } \\
\text { development and } \\
\text { humanitarian interventions }\end{array}$ & $\begin{array}{l}\text { http://ethos.bl.uk/OrderDetails.do? } \\
\text { uin=uk.bl.ethos. } 537361\end{array}$ & $\begin{array}{l}\text { Document reports on three different } \\
\text { interventions, none of which are supporting } \\
\text { shelter-self recovery (screening question } \\
\text { 11). }\end{array}$ \\
\hline $\begin{array}{l}\text { Marcillia, S.R., } \\
\text { Ohno, R. }\end{array}$ & 2012 & $\begin{array}{l}\text { Learning from Residents' } \\
\text { Adjustments in Self-built } \\
\text { and Donated Post Disaster } \\
\text { Housing after Java } \\
\text { Earthquake } 2006\end{array}$ & & $\begin{array}{l}\text { Document reports two case studies one is } \\
\text { self-built (e.g. without external support, } \\
\text { therefore no intervention) and the second } \\
\text { one reviews 'donated dome shelters'- } \\
\text { neither of which are shelter self-recovery } \\
\text { (screening question 11). }\end{array}$ \\
\hline Marshall, $\mathbf{R}$. & 2011 & $\begin{array}{l}\text { UNDP Core Family Shelter } \\
\text { Programme: Value for } \\
\text { Money Evaluation }\end{array}$ & & $\begin{array}{l}\text { Insufficient detail on the intervention, likely } \\
\text { not to be shelter self recovery (screening } \\
\text { question 11). }\end{array}$ \\
\hline $\begin{array}{l}\text { Meilani, A., } \\
\text { Hafidz, W., } \\
\text { King, A. }\end{array}$ & 2014 & $\begin{array}{l}\text { Integrated people-driven } \\
\text { reconstruction in Indonesia. } \\
\text { In Schilderman and Parker } \\
\text { (2014) Still Standing? }\end{array}$ & $\begin{array}{l}\text { http://developmentbookshop.com/s } \\
\text { till-standing }\end{array}$ & $\begin{array}{l}\text { Insufficient detail on intervention and } \\
\text { outcomes (screening questions } 11 \text { and 12). }\end{array}$ \\
\hline Minervini, C. & 2002 & $\begin{array}{l}\text { Housing reconstruction in } \\
\text { Kosovo }\end{array}$ & $\begin{array}{l}\text { http://www.Scopus.com/inward/rec } \\
\text { ord.url?eid=2-s2.0- } \\
\text { 0036891616andpartnerID=40andm } \\
\text { d5=a6f19edce7709a6046d74c648 } \\
\text { 77c81fd }\end{array}$ & $\begin{array}{l}\text { Insufficient detail on research methodology } \\
\text { (screening question 9), not clear if primary } \\
\text { data (screening question 8). }\end{array}$ \\
\hline $\begin{array}{l}\text { MMRD } \\
\text { Research } \\
\text { Services }\end{array}$ & 2008 & $\begin{array}{l}\text { Shelter Kit Survey: Final } \\
\text { Report - Myanmar } 2008\end{array}$ & $\begin{array}{l}\text { http://www.ifrc.org/en/publications- } \\
\text { and-reports/evaluations/ }\end{array}$ & $\begin{array}{l}\text { Insufficient detail on outcomes - but does } \\
\text { have information on the quality of the tools } \\
\text { distributed etc. (screening questions 12). }\end{array}$ \\
\hline $\begin{array}{l}\text { Monitoring and } \\
\text { Evaluation } \\
\text { Wing, } \\
\text { Earthquake } \\
\text { Reconstruction } \\
\text { and } \\
\text { Rehabilitation } \\
\text { Authority }\end{array}$ & 2008 & $\begin{array}{l}\text { Outcome level social } \\
\text { monitoring report (April- } \\
\text { June 2008) }\end{array}$ & & $\begin{array}{l}\text { Insufficient detail on outcomes - section } \\
\text { 1.3.6. is titled 'outcomes' but only reports on } \\
\text { outputs/inputs (screening questions 12). }\end{array}$ \\
\hline $\begin{array}{l}\text { Mutunga, T. et } \\
\text { al. }\end{array}$ & 2015 & $\begin{array}{l}\text { Evaluation of NRC's shelter } \\
\text { programme in Ethiopia }\end{array}$ & $\begin{array}{l}\text { http://www.nrc.no/arch/_img/92120 } \\
\text { 88.pdf }\end{array}$ & $\begin{array}{l}\text { Document reports on NRC programmes in } \\
\text { different camps over several years. Does } \\
\text { not clearly describe a specific intervention } \\
\text { and then directly attribute outcomes } \\
\text { (screening questions } 11 \text { and } 12 \text { ). }\end{array}$ \\
\hline $\begin{array}{l}\text { Norwegian } \\
\text { Refugee } \\
\text { Council }\end{array}$ & 2015 & $\begin{array}{l}\text { In search of a home Access } \\
\text { to adequate housing in } \\
\text { Jordan }\end{array}$ & $\begin{array}{l}\text { http://humanitarianlibrary.org/sites/ } \\
\text { default/files/2015/06/NRCJordan_I } \\
\text { nSearchofaHome_June2015\%20(c } \\
\text { ompressed).pdf }\end{array}$ & $\begin{array}{l}\text { Intervention provides indirect rental support- } \\
\text { funding provided to Landlords to } \\
\text { build/renovate properties and rent is } \\
\text { waivered for } 12-24 \text { months for beneficiary } \\
\text { households, therefore not shelter-self } \\
\text { recovery (screening question } 11 \text { ). }\end{array}$ \\
\hline $\begin{array}{l}\text { Norwegian } \\
\text { Refugee } \\
\text { Council? }\end{array}$ & $2014 ?$ & $\begin{array}{l}\text { NRC Sri Lanka; Shelter } \\
\text { programme, 2004-2013: } \\
\text { Overview and lessons } \\
\text { learnt }\end{array}$ & & $\begin{array}{l}\text { Insufficient detail on research methodology } \\
\text { (screening question 9). Also outcomes only } \\
\text { reported on individual households } \\
\text { (screening question 12). }\end{array}$ \\
\hline NSET-Nepal & n.d. & $\begin{array}{l}\text { Evaluation of Post- Flood } \\
\text { Shelter Restoration Project, } \\
\text { Barmer, Rajasthan, India }\end{array}$ & & $\begin{array}{l}\text { Project is participatory (e.g. communities } \\
\text { were involved in selection of beneficiaries), } \\
\text { but shelters were built to a standardized by } \\
\text { masons who received training as part of the } \\
\text { programme. Therefore material, financial or } \\
\text { technical training was not provided directly } \\
\text { to the households (screening question 11). }\end{array}$ \\
\hline $\begin{array}{l}\text { Pandya, Y., } \\
\text { Bista, P., } \\
\text { Chandel, A., } \\
\text { Mangwani, N. }\end{array}$ & 2014 & $\begin{array}{l}\text { India: Gandhi Nu Gam, an } \\
\text { example of holistic and } \\
\text { integrated reconstruction. In } \\
\text { Schilderman and Parker } \\
\text { (2014) Still Standing? }\end{array}$ & $\begin{array}{l}\text { http://developmentbookshop.com/s } \\
\text { till-standing }\end{array}$ & $\begin{array}{l}\text { Insufficient detail on research methodology } \\
\text { and intervention (screening questions } 9 \text { and } \\
\text { 11). }\end{array}$ \\
\hline $\begin{array}{l}\text { Parker, E., } \\
\text { Ajantha, A., } \\
\text { Pullenayegem, } \\
\text { V., Kamalaraj, } \\
\text { S. }\end{array}$ & 2014 & $\begin{array}{l}\text { Challenges for } \\
\text { sustainability: Introducing } \\
\text { new construction } \\
\text { technologies in post- } \\
\text { tsunami Sri Lanka. In } \\
\text { Schilderman and Parker } \\
\text { (2014) Still Standing? }\end{array}$ & $\begin{array}{l}\text { http://developmentbookshop.com/s } \\
\text { till-standing }\end{array}$ & $\begin{array}{l}\text { Limited detail on methodology (screening } \\
\text { question 9). Intervention describes training } \\
\text { being provided to masons/ professionals: } \\
\text { 'education programmes and on-site training } \\
\text { for skilled masons, carpenters, and } \\
\text { labourers and awareness programmes in } \\
\text { safe design principles and brick production, } \\
\text { and quality monitoring' (p. 105). Therefore } \\
\text { excluded on basis of screening question } 11 .\end{array}$ \\
\hline
\end{tabular}




\begin{tabular}{|c|c|c|c|c|}
\hline Author(s) & $\begin{array}{l}\text { Publication } \\
\text { date }\end{array}$ & Title & Web link & Reasons for exclusion? \\
\hline $\begin{array}{l}\text { Parrack, C., } \\
\text { Flinn, B., } \\
\text { Passey, M. }\end{array}$ & 2014 & $\begin{array}{l}\text { Getting the message across } \\
\text { for safer self recovery in } \\
\text { post-disaster shelter }\end{array}$ & $\begin{array}{l}\text { http://www.Scopus.com/inward/rec } \\
\text { ord.url?eid=2-s2.0- } \\
\text { 84929162938andpartnerID=40and } \\
\text { md5=5dd4afa5dc6debd6fda0d110 } \\
\text { 142cad10 }\end{array}$ & $\begin{array}{l}\text { Insufficient detail on research methodology } \\
\text { (screening question 9), not clear if primary } \\
\text { data (screening question 8). }\end{array}$ \\
\hline Plato, J. P. & 2011 & $\begin{array}{l}\text { Post-disaster } \\
\text { reconstruction: A current } \\
\text { analysis of Gujarat's } \\
\text { response after the } 2001 \\
\text { earthquake }\end{array}$ & & $\begin{array}{l}\text { Research describes both 'owner-driven } \\
\text { reconstruction' and 'donor-driven } \\
\text { reconstruction'. However limited detail on } \\
\text { intervention and questions are not } \\
\text { sufficiently clear in Figure } 2.5 \text { (were data is } \\
\text { disaggregated between the two intervention } \\
\text { types) and then there is insufficient } \\
\text { disaggregation of effects in Section } 5 \\
\text { 'Discussion' to link to the intervention } \\
\text { (screening questions } 11 \text { and } 12 \text { ). }\end{array}$ \\
\hline $\begin{array}{l}\text { Ratnayake, } \\
\text { R.M.G.D. }\end{array}$ & 2011 & $\begin{array}{l}\text { Post disaster Housing } \\
\text { Reconstruction: } \\
\text { Comparative Study of } \\
\text { Donor Driven vs. Owner } \\
\text { Driven Approach }\end{array}$ & $\begin{array}{l}\text { http://www.recoveryplatform.org/as } \\
\text { sets/publication/sri\%20lanka\%20c } \\
\text { omparision\%20of\%20owner\%20dri } \\
\text { ven\%20and\%20donor\%20driven\% } \\
\text { 20shelter.pdf }\end{array}$ & $\begin{array}{l}\text { Document reports on research undertaken } \\
\text { in multiple locations and programmes, } \\
\text { specific interventions are not described. } \\
\text { Does not clearly describe a specific } \\
\text { intervention and then directly attribute } \\
\text { outcomes (screening questions } 11 \text { and 12). }\end{array}$ \\
\hline Rhyner, K. & 2014 & $\begin{array}{l}\text { Honduras: 'La Betania', } \\
\text { resettlement of a flooded } \\
\text { neighbourhood. In } \\
\text { Schilderman and Parker } \\
\text { (2014) Still Standing? }\end{array}$ & $\begin{array}{l}\text { http://developmentbookshop.com/s } \\
\text { till-standing }\end{array}$ & $\begin{array}{l}\text { Insufficient detail of research methodology } \\
\text { (screening question 9) }\end{array}$ \\
\hline $\begin{array}{l}\text { Schilderman T., } \\
\text { Lyons M. }\end{array}$ & 2011 & $\begin{array}{l}\text { Resilient dwellings or } \\
\text { resilient people? Towards } \\
\text { people-centred } \\
\text { reconstruction }\end{array}$ & $\begin{array}{l}\text { http://www.Scopus.com/inward/rec } \\
\text { ord.url?eid=2-s2.0- } \\
\text { 80053637371andpartnerlD=40and } \\
\text { md5=d8366fd4273dda19809e9323 } \\
\text { 92db03f6 }\end{array}$ & $\begin{array}{l}\text { Insufficient detail on research methodology } \\
\text { (screening question 9), not clear if primary } \\
\text { data (screening question 8). }\end{array}$ \\
\hline $\begin{array}{l}\text { Schilderman, } \\
\text { T., Watanabe, } \\
\text { M. }\end{array}$ & 2014 & $\begin{array}{l}\text { Peru: Building on the } \\
\text { vernacular. In Schilderman } \\
\text { and Parker (2014) Still } \\
\text { Standing? }\end{array}$ & $\begin{array}{l}\text { http://developmentbookshop.com/s } \\
\text { till-standing }\end{array}$ & $\begin{array}{l}\text { Insufficient detail of research methodology } \\
\text { (screening question 9). }\end{array}$ \\
\hline $\begin{array}{l}\text { Sheppard, S., } \\
\text { Hill, R. }\end{array}$ & 2005 & $\begin{array}{l}\text { The Economic Impact of } \\
\text { Shelter Assistance in Post- } \\
\text { Disaster Settings }\end{array}$ & & $\begin{array}{l}\text { Insufficient detail on the intervention } \\
\text { (screening question 11). }\end{array}$ \\
\hline $\begin{array}{l}\text { Sida, L., } \\
\text { Caspersz, D., } \\
\text { Naqvi, A., } \\
\text { Vasseur, T. }\end{array}$ & 2012 & $\begin{array}{l}\text { Review of DFID response to } \\
\text { Pakistan floods } 2010\end{array}$ & & $\begin{array}{l}\text { Insufficient detail on the intervention and } \\
\text { outcomes (screening question } 11 \text { and 12). }\end{array}$ \\
\hline $\begin{array}{l}\text { Tafahomi, } \\
\text { Mahasti }\end{array}$ & 2013 & $\begin{array}{l}\text { Learning how to make } \\
\text { optimal decisions in design } \\
\text { and selection of post- } \\
\text { disaster shelters }\end{array}$ & & $\begin{array}{l}\text { Documents a classroom based case study } \\
\text { experiment, to test a decision making } \\
\text { framework (DSS); therefore not shelter-self } \\
\text { recovery (screening question 11). }\end{array}$ \\
\hline Tafti, M.T. & 2015 & $\begin{array}{l}\text { Housing assistance } \\
\text { distribution after disasters: } \\
\text { does it enable affected } \\
\text { households to recover? }\end{array}$ & $\begin{array}{l}\text { http://www.alnap.org/pool/files/tafti- } \\
\text { housing.pdf }\end{array}$ & $\begin{array}{l}\text { Insufficient detail on outcomes (screening } \\
\text { question 12). }\end{array}$ \\
\hline $\begin{array}{l}\text { Tafti M.T., } \\
\text { Tomlinson R. }\end{array}$ & 2015 & $\begin{array}{l}\text { Best practice post-disaster } \\
\text { housing and livelihood } \\
\text { recovery interventions: } \\
\text { Winners and losers }\end{array}$ & $\begin{array}{l}\text { http://www.alnap.org/resource/213 } \\
18\end{array}$ & $\begin{array}{l}\text { Sits outside of inclusion criteria timeframe: } \\
\text { 'The reconstruction of residential units } \\
\text { started two years after the earthquake' ( } p \text {. } \\
\text { 175) (screening question 10). Insufficient } \\
\text { detail on the intervention and outcomes } \\
\text { (screening question } 11 \text { and 12). }\end{array}$ \\
\hline Tariq, F & 2012 & $\begin{array}{l}\text { Facilitating community } \\
\text { development with housing } \\
\text { microfinance: appraising } \\
\text { housing solutions for } \\
\text { Pakistan after disasters }\end{array}$ & $\begin{array}{l}\text { http://web.mit.edu/incrementalhous } \\
\text { ing/articlesPhotographs/pdfs/TARI } \\
\text { Q-COMMUNITY=PAKISTAN.pdf }\end{array}$ & $\begin{array}{l}\text { Insufficient detail on research methodology } \\
\text { (screening question 9), not clear if primary } \\
\text { data (screening question 8). }\end{array}$ \\
\hline $\begin{array}{l}\text { Telyukov, A., } \\
\text { Paterson, M. }\end{array}$ & 2008 & $\begin{array}{l}\text { Impact Evaluation of PRM } \\
\text { Humanitarian Assistance to } \\
\text { the Repatriation and } \\
\text { Reintegration of Burundi } \\
\text { Refugees }\end{array}$ & $\begin{array}{l}\text { http://www.refworld.org/cgi- } \\
\text { bin/texis/vtx/rwmain?docid=49ed70 } \\
822\end{array}$ & $\begin{array}{l}\text { Summary report only covering multi-sector, } \\
\text { multi agency response (author contacted for } \\
\text { final evaluation). Insufficient detail on } \\
\text { shelter intervention in summary report } \\
\text { (screening question 11). }\end{array}$ \\
\hline TFM Consult & 2012 & $\begin{array}{l}\text { Mid Term Evaluation of } \\
\text { DFID CHASE Support for } \\
\text { NRC Programmes }\end{array}$ & $\begin{array}{l}\text { http://www.nrc.no/arch/_img/91801 } \\
\text { 55.pdf }\end{array}$ & $\begin{array}{l}\text { Multi-sector evaluation. Insufficient detail on } \\
\text { intervention and outcomes: does not clearly } \\
\text { describe a specific intervention and then } \\
\text { directly attribute outcomes (screening } \\
\text { questions } 11 \text { and 12). }\end{array}$ \\
\hline $\begin{array}{l}\text { Thiruppugazh, } \\
\text { V. }\end{array}$ & 2010 & $\begin{array}{l}\text { NGO Participation in } \\
\text { Reconstruction: Knowledge } \\
\text { Transfer and Capacity } \\
\text { Building for Sustainability; A } \\
\text { Case Study of Post- } \\
\text { Disaster Reconstruction in } \\
\text { Gujarat }\end{array}$ & $\begin{array}{l}\text { http://www.grif.umontreal.ca/obser } \\
\text { vatoire/contenu_pages/14_Thirupp } \\
\text { ugazh.pdf }\end{array}$ & $\begin{array}{l}\text { Insufficient detail on intervention. Report } \\
\text { does not clearly describe a specific } \\
\text { intervention and then directly attribute } \\
\text { outcomes (screening questions } 11 \text { and 12). }\end{array}$ \\
\hline
\end{tabular}




\begin{tabular}{|c|c|c|c|c|}
\hline Author(s) & $\begin{array}{l}\text { Publication } \\
\text { date }\end{array}$ & Title & Web link & Reasons for exclusion? \\
\hline Thomas, T. & 2009 & $\begin{array}{l}\text { Rehabilitation beyond } \\
\text { reconstruction: A study of } \\
\text { people's empowerment } \\
\text { through nongovernmental } \\
\text { organizations' interventions } \\
\text { in post earthquake Kutch, } \\
\text { India }\end{array}$ & $\begin{array}{l}\text { http://search.proquest.com/docvie } \\
\text { w/305006232?accountid=14511 }\end{array}$ & $\begin{array}{l}\text { Insufficient detail on the intervention } \\
\text { (screening question 11). }\end{array}$ \\
\hline Uehling, G. & 2004 & $\begin{array}{l}\text { Evaluation of UNHCR's } \\
\text { programme to prevent and } \\
\text { reduce statelessness in } \\
\text { Crimea, Ukraine }\end{array}$ & $\begin{array}{l}\text { http://www.unhcr.org/405ab4c74.p } \\
\text { df }\end{array}$ & $\begin{array}{l}\text { Multi-sector evaluation. Insufficient detail on } \\
\text { intervention and outcomes: does not clearly } \\
\text { describe a specific intervention and then } \\
\text { directly attribute outcomes (screening } \\
\text { questions } 11 \text { and } 12 \text { ). }\end{array}$ \\
\hline UN-Habitat & $2009 ?$ & $\begin{array}{l}\text { Post-Tsunami Aceh-Nias } \\
\text { Settlement and Housing } \\
\text { Recovery Review 2009- } \\
2010\end{array}$ & $\begin{array}{l}\text { https://spacesofaid.files.wordpress. } \\
\text { com/2014/03/unhabitat-review-to- } \\
\text { which-lisa-contributed.pdf }\end{array}$ & $\begin{array}{l}\text { Insufficient detail on research methodology } \\
\text { (screening question 9). Insufficient detail of } \\
\text { interventions, or clearly linking interventions } \\
\text { to outcomes (screening questions } 11 \text { and } \\
\text { 12). }\end{array}$ \\
\hline $\begin{array}{l}\text { UNISDR, UN- } \\
\text { Habitat }\end{array}$ & 2011 & $\begin{array}{l}\text { Lessons Learned and Way } \\
\text { Forward For Resilient } \\
\text { Shelter Interventions in } \\
\text { Rural Myanmar }\end{array}$ & $\begin{array}{l}\text { http://www.preventionweb.net/files/ } \\
\text { 19769_unhabitatpostnargisinterve } \\
\text { ntionless.pdf }\end{array}$ & $\begin{array}{l}\text { Insufficient detail of interventions, or clearly } \\
\text { linking interventions to outcomes (screening } \\
\text { questions } 11 \text { and 12). }\end{array}$ \\
\hline $\begin{array}{l}\text { Upadhyay, B., } \\
\text { Dixit, A. M., } \\
\text { Guragain, R. }\end{array}$ & 2002 & $\begin{array}{l}\text { Nepal- Gujarat Masons } \\
\text { Exchange and Training } \\
\text { Program: A community } \\
\text { based sub-regional } \\
\text { initiative. } \\
\text { pp. } 129-135\end{array}$ & $\begin{array}{l}\text { http://www.nset.org.np/nset2012/i } \\
\text { mages/publicationfile/2013072411 } \\
\text { 5429.pdf }\end{array}$ & $\begin{array}{l}\text { Insufficient detail on research methodology } \\
\text { (screening question 9). }\end{array}$ \\
\hline $\begin{array}{l}\text { Watt, J., Alam, } \\
\text { A. }\end{array}$ & 2013 & $\begin{array}{l}\text { Report of the Evaluation of } \\
\text { the FRESH project: South- } \\
\text { West Region, Bangladesh. } \\
\text { February-March } 2013\end{array}$ & $\begin{array}{l}\text { https://www.gov.uk/government/upl } \\
\text { oads/system/uploads/attachment_ } \\
\text { data/file/311949/FRESH-South- } \\
\text { West-Bangladesh.pdf }\end{array}$ & $\begin{array}{l}\text { Insufficient detail on the intervention and } \\
\text { outcomes (screening question } 11 \text { and 12). }\end{array}$ \\
\hline $\begin{array}{l}\text { Weerasinghe, } \\
\text { W.K., } \\
\text { Shigemura, T. }\end{array}$ & 2008 & $\begin{array}{l}\text { A study on transformation of } \\
\text { living environment and } \\
\text { domestic spatial } \\
\text { arrangements: Focused on } \\
\text { a western coastal housing } \\
\text { settlement of Sri Lanka after } \\
\text { Sumatra earthquake and } \\
\text { tsunami } 2004\end{array}$ & $\begin{array}{l}\text { http://www.Scopus.com/inward/rec } \\
\text { ord.url?eid=2-s2.0- } \\
\text { 77954929982andpartnerlD=40and } \\
\text { md5=a07450a894dec96cea6ab54 } \\
\text { 77da8f4b7 }\end{array}$ & $\begin{array}{l}\text { This study takes an area-based approach to } \\
\text { investigating recovery outcomes. Insufficient } \\
\text { detail of interventions, or clearly linking } \\
\text { interventions to outcomes (screening } \\
\text { questions } 11 \text { and } 12 \text { ). }\end{array}$ \\
\hline $\begin{array}{l}\text { Zea Escamilla, } \\
\text { E., Habert, G }\end{array}$ & 2015 & $\begin{array}{l}\text { Global or local construction } \\
\text { materials for post-disaster } \\
\text { reconstruction? } \\
\text { Sustainability assessment } \\
\text { of } 20 \text { post-disaster shelter } \\
\text { designs }\end{array}$ & $\begin{array}{l}\text { http://www.Scopus.com/inward/rec } \\
\text { ord.url?eid=2-s2.0- } \\
\text { 84934273564andpartnerlD=40and } \\
\text { md5=d8e1ed389a186e0097987c2 } \\
\text { 7b32848f7 }\end{array}$ & $\begin{array}{l}\text { Impact evaluation of the environmental, } \\
\text { economic and mechanical/technical } \\
\text { performances of approximately } 20 \\
\text { transitional shelters, based on existing } \\
\text { literature; therefore not primary data } \\
\text { (Screening question 8). }\end{array}$ \\
\hline
\end{tabular}




\section{APPENDIX E: QUALITY APPRAISAL TEMPLATE}

This 'quality appraisal template' has been developed by the authors from the following sources (listed alphabetically). For additional information see the research protocol (Maynard et al., 2016).

- (CASP, 2013)

- (Centre for Reviews and Dissemination, 2008)

- (Glenton et al., 2013)

- (Pluye et al., 2011)

- (Posthumus et al., 2013)

- (Rashidian et al., 2013)

- (Walker et al., 2013)

Use sections 1 and 2 for appraising all studies. Then for appraising a quantitative study, also use section $3 \mathrm{~A}$ or $3 \mathrm{~B}$ or $3 \mathrm{C}$ for randomized controlled, non-randomized and descriptive studies, respectively. For a qualitative study, also use section 3D. For a mixed methods study, use section $3 \mathrm{D}$ for appraising the qualitative component, and the appropriate section for appraising the quantitative component (3A or $3 \mathrm{~B}$ or $3 \mathrm{C}$ ).

The Mixed Methods Assessment Tool (MMAT) developed by Pluye and colleagues (2011) at McGill University provides further guidance when answering questions 3A-3D.

Figure E.1: Quality appraisal template

\begin{tabular}{|l|l|}
\hline Author & \\
\hline Publication date & \\
\hline Title & \\
\hline Research design (using definitions in Pluye et al. 2011) & \\
\hline Data collection methods & \\
\hline Quality comment & \\
\hline
\end{tabular}

\begin{tabular}{|c|c|c|c|c|c|c|c|}
\hline \multicolumn{2}{|c|}{ Question } & Notes to support appraisal & $\stackrel{\mathscr{\Xi}}{\boldsymbol{\nu}}$ & 은 & 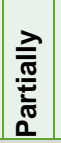 & $\begin{array}{l}\frac{\grave{d}}{0} \\
\frac{\mathrm{c}}{\mathrm{c}}\end{array}$ & $\begin{array}{l}\text { Researcher } \\
\text { comments }\end{array}$ \\
\hline \multicolumn{8}{|c|}{ Section 1: Appropriateness of study design to the research objective } \\
\hline 1.1 & $\begin{array}{l}\text { Are the research questions and/or } \\
\text { aims clearly stated? }\end{array}$ & $\begin{array}{l}\text { E.g. What was the goal of the research? } \\
\text { Why was it thought important? }\end{array}$ & & & & & \\
\hline 1.2 & $\begin{array}{l}\text { Is the approach (quantitative, } \\
\text { qualitative or mixed methods) } \\
\text { appropriate to address the research } \\
\text { question and/or research aims? }\end{array}$ & $\begin{array}{l}\text { E.g. For qualitative studies, if the } \\
\text { research seeks to interpret or illuminate } \\
\text { the actions and/or subjective } \\
\text { experiences of research participants }\end{array}$ & & & & & \\
\hline 1.3 & $\begin{array}{l}\text { Is the research approach (quantitative, } \\
\text { qualitative or mixed methods) } \\
\text { justified? }\end{array}$ & $\begin{array}{l}\text { E.g. If the researcher has justified the } \\
\text { research design Have they discussed } \\
\text { how they decided which method to use? }\end{array}$ & & & & & \\
\hline \multicolumn{8}{|c|}{ Section 2: Risk of bias: Data collection, reporting, ethics, publication, applicability } \\
\hline 2.1 & $\begin{array}{l}\text { Is the method of data collection clearly } \\
\text { described? }\end{array}$ & $\begin{array}{l}\text { E.g. If it is clear how data were collected } \\
\text { (e.g. focus group, semi-structured } \\
\text { interview, survey, questionnaire etc.); If } \\
\text { the researcher has made the methods } \\
\text { explicit (e.g. for interview method, is } \\
\text { there an indication of how interviews } \\
\text { were conducted, or did they use a topic } \\
\text { guide; or for surveys if they were paper } \\
\text { or online)? If methods were modified } \\
\text { during the study. If so, has the } \\
\text { researcher explained how and why? If } \\
\text { the form of data is clear (e.g. tape } \\
\text { recordings, video material, notes etc.) }\end{array}$ & & & & & \\
\hline
\end{tabular}




\begin{tabular}{|c|c|c|c|c|c|c|c|}
\hline \multicolumn{2}{|c|}{ Question } & \multirow{2}{*}{$\begin{array}{l}\text { Notes to support appraisal } \\
\text { E.g. Has the researcher justified the } \\
\text { methods chosen? }\end{array}$} & \multirow{2}{*}{ 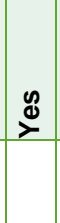 } & \multirow{2}{*}{ 은 } & \multirow{2}{*}{ 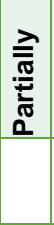 } & \multirow{2}{*}{ 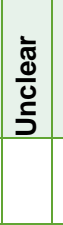 } & \multirow{2}{*}{$\begin{array}{l}\text { Researcher } \\
\text { comments }\end{array}$} \\
\hline 2.2 & Is the data collection method justified? & & & & & & \\
\hline 2.3 & $\begin{array}{l}\text { Is the data collection method } \\
\text { appropriate to the research question? }\end{array}$ & $\begin{array}{l}\text { E.g. Is it clear why they have chosen the } \\
\text { methods? Are the measures relevant } \\
\text { and meaningful to both the } \\
\text { intervention(s) and the study? }\end{array}$ & & & & & \\
\hline 2.4 & $\begin{array}{l}\text { Does it seem that all of the data } \\
\text { collected for the study is reported? }\end{array}$ & $\begin{array}{l}\text { E.g. Is there any evidence to suggest } \\
\text { that the authors measured more } \\
\text { outcomes than they reported? }\end{array}$ & & & & & \\
\hline 2.5 & $\begin{array}{l}\text { Is the method of analysis clearly } \\
\text { described? }\end{array}$ & $\begin{array}{l}\text { E.g. Is there is an in-depth description of } \\
\text { the analysis process? }\end{array}$ & & & & & \\
\hline 2.6 & $\begin{array}{l}\text { Was the data analysis sufficiently } \\
\text { rigorous? }\end{array}$ & $\begin{array}{l}\text { E.g. To what extent are contradictory } \\
\text { data taken into account? Are there any } \\
\text { data points excluded? If so, why? } \\
\text { Specifically for qualitative research, If } \\
\text { thematic analysis is used, is it clear how } \\
\text { the categories/themes were derived } \\
\text { from the data? }\end{array}$ & & & & & \\
\hline 2.7 & Is there a clear statement of findings? & $\begin{array}{l}\text { E.g. Are the findings supported by } \\
\text { sufficient data? I.e. did the data provide } \\
\text { sufficient depth, detail and richness? } \\
\text { Are the findings explicit? Are the } \\
\text { findings discussed in relation to the } \\
\text { original research question? Has the } \\
\text { researcher discussed the credibility of } \\
\text { their findings? }\end{array}$ & & & & & \\
\hline 2.8 & $\begin{array}{l}\text { Is appropriate consideration given to } \\
\text { the limitations of the study? }\end{array}$ & $\begin{array}{l}\text { E.g. Are the limitations identified? Are } \\
\text { the limitations associated with that } \\
\text { design type identified, and the manner } \\
\text { in which the research was undertaken } \\
\text { and the data analysed e.g. when } \\
\text { integrating findings or mixed methods } \\
\text { the possible divergence of qualitative } \\
\text { and quantitative data (or results }{ }^{\star} \text { ) in a } \\
\text { triangulation design? }\end{array}$ & & & & & \\
\hline 2.9 & $\begin{array}{l}\text { Have ethical issues been taken into } \\
\text { consideration? }\end{array}$ & $\begin{array}{l}\text { E.g. If there are sufficient details of how } \\
\text { the research was explained to } \\
\text { participants for the reader to assess } \\
\text { whether ethical standards were } \\
\text { maintained; If the researcher has } \\
\text { discussed issues raised by the study } \\
\text { (e.g. issues around informed consent or } \\
\text { confidentiality or how they have handled } \\
\text { the effects of the study on the } \\
\text { participants during and after the study) }\end{array}$ & & & & & \\
\hline 2.10 & $\begin{array}{l}\text { Do the researchers discuss if the } \\
\text { findings are transferable to other } \\
\text { contexts? (applicability or external } \\
\text { validity) }\end{array}$ & $\begin{array}{l}\text { E.g. Do the researchers discuss } \\
\text { whether or how the findings can be } \\
\text { transferred to other populations or } \\
\text { consider other ways the research may } \\
\text { be used }\end{array}$ & & & & & \\
\hline 2.11 & $\begin{array}{l}\text { Are the findings likely to be } \\
\text { transferable to other contexts? } \\
\text { (applicability or external validity) }\end{array}$ & $\begin{array}{l}\text { E.g. How closely does the study reflect } \\
\text { routine practice or the usual setting } \\
\text { where the intervention would be } \\
\text { implemented? }\end{array}$ & & & & & \\
\hline \multicolumn{8}{|c|}{ Section 3A: Quantitative randomized controlled } \\
\hline 3A.1 & $\begin{array}{l}\text { Is there a clear description of the } \\
\text { randomization (or an appropriate } \\
\text { sequence generation)? }\end{array}$ & $\begin{array}{l}\text { E.g. The allocation of a participant (or a } \\
\text { data collection unit, e.g., a school) into } \\
\text { the intervention or control group is } \\
\text { based solely } \\
\text { on chance, and researchers describe } \\
\text { how the randomization schedule is } \\
\text { generated }\end{array}$ & & & & & \\
\hline
\end{tabular}




\begin{tabular}{|c|c|c|c|c|c|c|c|}
\hline \multicolumn{2}{|c|}{ Question } & \multirow{2}{*}{$\begin{array}{l}\text { Notes to support appraisal } \\
\text { E.g., Researchers and participants are } \\
\text { unaware of the assignment sequence } \\
\text { up to the point of allocation (group } \\
\text { assignment is concealed in opaque } \\
\text { envelops until allocation) or researchers } \\
\text { and/or participants are unaware of the } \\
\text { group a participant is allocated to during } \\
\text { the course of the study. }\end{array}$} & \multirow{2}{*}{ 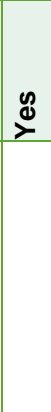 } & \multirow{2}{*}{ 운 } & \multirow{2}{*}{ 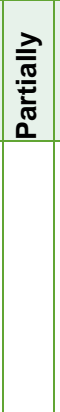 } & \multirow{2}{*}{$\begin{array}{l}\frac{\pi}{d} \\
\frac{0}{0} \\
5\end{array}$} & \multirow{2}{*}{$\begin{array}{l}\text { Researcher } \\
\text { comments }\end{array}$} \\
\hline 3A.2 & $\begin{array}{l}\text { Is there a clear description of the } \\
\text { allocation concealment (or blinding } \\
\text { when applicable)? }\end{array}$ & & & & & & \\
\hline 3A.3 & $\begin{array}{l}\text { Are there complete outcome data } \\
(80 \% \text { or above)? }\end{array}$ & $\begin{array}{l}\text { E.g., Almost all the participants } \\
\text { contributed to almost all measures. }\end{array}$ & & & & & \\
\hline 3A.4 & $\begin{array}{l}\text { Is there low withdrawal/drop-out } \\
\text { (below } 20 \% \text { )? }\end{array}$ & $\begin{array}{l}\text { E.g., Almost all the participants } \\
\text { completed the study. }\end{array}$ & & & & & \\
\hline \multicolumn{8}{|c|}{ Section 3B: Quantitative nonrandomized e.g. non-randomized control trials, cohort, case-control, cross-sectional analytic } \\
\hline 3B.1 & $\begin{array}{l}\text { Are participants (organizations) } \\
\text { recruited in a way that minimizes } \\
\text { selection bias? }\end{array}$ & $\begin{array}{l}\text { E.g. At recruitment stage: } \\
\text { For cohort studies, e.g., consider } \\
\text { whether the exposed (or with } \\
\text { intervention) and non-exposed (or } \\
\text { without intervention) groups are } \\
\text { recruited from the same population. } \\
\text { For case-control studies, e.g., consider } \\
\text { whether same inclusion and exclusion } \\
\text { criteria were applied to cases and } \\
\text { controls, and whether recruitment was } \\
\text { done independently of the intervention } \\
\text { or exposure status. } \\
\text { For cross-sectional analytic studies, } \\
\text { e.g., consider whether the sample is } \\
\text { representative of the population. }\end{array}$ & & & & & \\
\hline 3B.2 & $\begin{array}{l}\text { Are measurements appropriate (clear } \\
\text { origin, or validity known, or standard } \\
\text { instrument; and absence of } \\
\text { contamination between groups } \\
\text { when appropriate) regarding the } \\
\text { exposure/intervention and outcomes? }\end{array}$ & $\begin{array}{l}\text { E.g. At data collection stage: } \\
\text { Consider whether (a) the variables are } \\
\text { clearly defined and accurately } \\
\text { measured; (b) the measurements are } \\
\text { justified and appropriate for answering } \\
\text { the research question; and (c) the } \\
\text { measurements reflect what they are } \\
\text { supposed to measure. } \\
\text { For non-randomized controlled trials, } \\
\text { the intervention is assigned by } \\
\text { researchers, and so consider whether } \\
\text { there was absence/presence of a } \\
\text { contamination. E.g., the control group } \\
\text { may be indirectly exposed to the } \\
\text { intervention through family or } \\
\text { community relationships. }\end{array}$ & & & & & \\
\hline 3В.3 & $\begin{array}{l}\text { In the groups being compared } \\
\text { (exposed vs. non-exposed; with } \\
\text { intervention vs. without; cases vs. } \\
\text { controls), are the participants } \\
\text { comparable, or do researchers take } \\
\text { into account (control for) the difference } \\
\text { between these groups? }\end{array}$ & $\begin{array}{l}\text { At data analysis stage: } \\
\text { For cohort, case-control and cross- } \\
\text { sectional, e.g., consider whether (a) the } \\
\text { most important factors are taken into } \\
\text { account in the analysis; (b) a table lists } \\
\text { key demographic information comparing } \\
\text { both groups, and there are no obvious } \\
\text { dissimilarities between groups that may } \\
\text { account for any differences in } \\
\text { outcomes, or dissimilarities are taken } \\
\text { into account in the analysis. }\end{array}$ & & & & & \\
\hline 3B.4 & $\begin{array}{l}\text { Are there complete outcome data } \\
\text { ( } 80 \% \text { or above), and, when applicable, } \\
\text { an acceptable response rate ( } 60 \% \text { or } \\
\text { above), or an acceptable } \\
\text { follow-up rate for cohort studies } \\
\text { (depending on the duration of follow- } \\
\text { up)? }\end{array}$ & & & & & & \\
\hline
\end{tabular}




\begin{tabular}{|c|c|c|c|c|c|c|}
\hline \multicolumn{2}{|c|}{ Question } & Notes to support appraisal & $\stackrel{\mathscr{d}}{\boldsymbol{d}}$ & 은 & 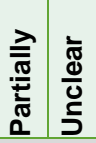 & $\begin{array}{l}\text { Researcher } \\
\text { comments }\end{array}$ \\
\hline \multicolumn{7}{|c|}{ Section 3C: Quantitative descriptive e.g. incidence or prevalence study without comparison group, case series, case report } \\
\hline 3C.1 & $\begin{array}{l}\text { Is the sampling strategy relevant to } \\
\text { address the quantitative research } \\
\text { question (quantitative aspect of the } \\
\text { mixed methods question)? }\end{array}$ & $\begin{array}{l}\text { E.g., consider whether (a) the source of } \\
\text { sample is relevant to the population } \\
\text { under study; (b) when appropriate, there } \\
\text { is a standard procedure for sampling, } \\
\text { and the sample size is justified (using } \\
\text { power calculation for instance). }\end{array}$ & & & & \\
\hline 3C.2 & $\begin{array}{l}\text { Is the sample representative of the } \\
\text { population understudy? }\end{array}$ & $\begin{array}{l}\text { E.g., consider whether (a) inclusion and } \\
\text { exclusion criteria are explained; and (b) } \\
\text { reasons why certain eligible individuals } \\
\text { chose not to participate are explained. }\end{array}$ & & & & \\
\hline 3C.3 & $\begin{array}{l}\text { Are measurements appropriate (clear } \\
\text { origin, or validity known, or standard } \\
\text { instrument)? }\end{array}$ & $\begin{array}{l}\text { E.g., consider whether (a) the variables } \\
\text { are clearly defined and accurately } \\
\text { measured; (b) measurements are } \\
\text { justified and appropriate for answering } \\
\text { the research question; and (c) the } \\
\text { measurements reflect what they are } \\
\text { supposed to measure. }\end{array}$ & & & & \\
\hline 3C.4 & $\begin{array}{l}\text { Is there an acceptable response rate } \\
(60 \% \text { or above)? }\end{array}$ & $\begin{array}{l}\text { The response rate is not pertinent for } \\
\text { case series and case report. E.g., there } \\
\text { is no expectation that a case series } \\
\text { would include all patients in a similar } \\
\text { situation. }\end{array}$ & & & & \\
\hline \multicolumn{7}{|c|}{ Section 3D: Qualitative e.g. ethnography, phenomenology, narrative, grounded theory, case-study, qualitative description } \\
\hline 3D.1 & $\begin{array}{l}\text { Does the researcher detail the sources } \\
\text { of qualitative data (informants, } \\
\text { observations)? }\end{array}$ & $\begin{array}{l}\text { E.g., Does the document describe how } \\
\text { the sources were identified, for example } \\
\text { how participants were selected? Does } \\
\text { the document detail any limitations to } \\
\text { participant involvement (e.g. if potential } \\
\text { participants chose not to participate } \\
\text { reasons are explained) }\end{array}$ & & & & \\
\hline 3D.2 & $\begin{array}{l}\text { Are the sources of qualitative data } \\
\text { (informants, observations) relevant to } \\
\text { address the research question } \\
\text { (objective)? }\end{array}$ & $\begin{array}{l}\text { E.g. Consider whether the selection of } \\
\text { the participants is clear, and appropriate } \\
\text { to collect relevant and rich data. }\end{array}$ & & & & \\
\hline 3D.3 & $\begin{array}{l}\text { Is appropriate consideration given to } \\
\text { how findings relate to the context, e.g., } \\
\text { the setting, in which the data were } \\
\text { collected? }\end{array}$ & $\begin{array}{l}\text { E.g., consider whether the study context } \\
\text { and how findings relate to the context or } \\
\text { characteristics of the context are } \\
\text { explained (how findings are influenced } \\
\text { by or influence the context). }\end{array}$ & & & & \\
\hline 3D.4 & $\begin{array}{l}\text { Is appropriate consideration given to } \\
\text { how findings relate to researchers' } \\
\text { influence, e.g., through their } \\
\text { interactions with participants? }\end{array}$ & $\begin{array}{l}\text { E.g. Is the role of the researcher clearly } \\
\text { described? Does the researcher } \\
\text { critically examine their own role, } \\
\text { potential bias and influence during (a) } \\
\text { Formulation of the research questions } \\
\text { (b) Data collection. How the researcher } \\
\text { responded to events during the study } \\
\text { and whether they considered the } \\
\text { implications of any changes in the } \\
\text { research design }\end{array}$ & & & & \\
\hline
\end{tabular}




\section{APPENDIX F: DEVIATIONS FROM PROTOCOL}

This appendix details the differences between the research method detailed in the protocol, and the method as implemented for research steps 2-5. Step 1 was 'Develop research protocol' and thus remains unchanged.

\section{Step 2: Run the search terms and initial screening of documents}

During the first round of screening of the academic documents it became clear that the terms 'owner-driven' and 'self-build' were used frequently in the documents 'potentially eligible' for inclusion. These terms were added to the search strings and any additional documents identified were screened for potential inclusion.

The following databases were identified in the protocol, but were not searched as part of the methodology implemented:

- International Union for Conservation of Nature (IUCN)

- Innovations for Poverty Action (IPA)

- Integrated Regional Information Networks (IRIN)

- DART-Europe E-theses Portal

They were replaced with the following websites, which were considered to present a higher priority:

- $\mathrm{IFRC}^{66}$

- International Recovery Platform

Finally, two of the questions in the screening guide detailed in the protocol were further broken down in order to more accurately assess the documents. See Figure F.1.

\section{Figure F.1: Differences between protocol screening questions and final screening} questions

\begin{tabular}{|c|c|c|}
\hline \multicolumn{2}{|c|}{ First round of screening } & Notes to researcher \\
\hline \multicolumn{2}{|r|}{$\begin{array}{l}\text { Question in protocol: } \\
\text { 1. Is the document about humanitarian interventions that support shelter } \\
\text { self-recovery by providing all or a combination of: } \\
\text { material assistance (including construction materials, tools, salvaging } \\
\text { and reuse of debris) } \\
\text { - financial assistance (cash or vouchers) for the purchase of construction } \\
\text { materials, tools or labour } \\
\text { technical assistance (including training and the provision guidance } \\
\text { through guidelines/mass communications). }\end{array}$} & $\begin{array}{l}\text { If clearly no, exclude (e.g. } \\
\text { editorials, newspaper } \\
\text { articles, different subject } \\
\text { matter). If yes or unclear, } \\
\text { include). }\end{array}$ \\
\hline \multicolumn{3}{|c|}{ Screening questions as implemented: } \\
\hline 1 & $\begin{array}{l}\text { Does the document describe intervention(s) responding to humanitarian } \\
\text { crisis/crises? }\end{array}$ & $\begin{array}{l}\text { If the answer is no, } \\
\text { exclude. }\end{array}$ \\
\hline 2 & Is the type of document likely to contain primary data? & $\begin{array}{l}\text { If the answer is no, } \\
\text { exclude. }\end{array}$ \\
\hline 3 & $\begin{array}{l}\text { Is the document about interventions that support shelter self-recovery by } \\
\text { providing a combination of material, financial and/or technical assistance? }\end{array}$ & $\begin{array}{l}\text { If the answer is no, } \\
\text { exclude. }\end{array}$ \\
\hline
\end{tabular}

\footnotetext{
${ }^{66}$ This website was also searched as part of the scoping assessment, but following additional stakeholder feedback a second review was considered vital to confirm all key documents had been identified.
} 


\begin{tabular}{|c|c|c|}
\hline \multicolumn{3}{|c|}{ Second round of screening } \\
\hline \multicolumn{2}{|r|}{$\begin{array}{l}\text { Question in protocol: } \\
\text { 9. Does the document clearly identify and describe the activities, outputs } \\
\text { and outcomes of the intervention? }\end{array}$} & $\begin{array}{l}\text { Note to researcher: If the } \\
\text { answer is no, exclude }\end{array}$ \\
\hline \multicolumn{2}{|c|}{ Screening questions as implemented: } & \\
\hline 11 & $\begin{array}{l}\text { Does the document clearly identify and describe the activities and outputs of } \\
\text { the intervention supporting shelter self-recovery? }\end{array}$ & $\begin{array}{l}\text { If the answer is no, } \\
\text { exclude. }\end{array}$ \\
\hline 12 & $\begin{array}{l}\text { Does the document clearly identify and describe the outcomes of the } \\
\text { intervention supporting shelter self-recovery? }\end{array}$ & $\begin{array}{l}\text { If the answer is no, } \\
\text { exclude. }\end{array}$ \\
\hline
\end{tabular}

\section{Step 3: Second screening of documents}

No differences - methodology as detailed in the protocol.

\section{Step 4: Critical appraisal of 'included studies'}

No differences - methodology as detailed in the protocol.

\section{Step 5: Data extraction and evidence synthesis}

Second round of data extraction: following a preliminary synthesis of the evidence, the qualitative data analysis software NVivo was used to systematically check each of the included studies for any data that may have been missed in the first round of data extraction. 


\section{APPENDIX G: STRENGTHS AND LIMITATIONS OF THE REVIEW}

The research methodology for this evidence synthesis is summarized in Figure 3.1, section 3.2. The research team identified the following strengths and limitations:

1) Search strategy: Systematic reviews typically search academic databases methodologically for documentation, and hand search grey literature websites (due to the limited search functions on many websites). These academic databases often have sophisticated search functions and generate exportable lists of document information (title, author, publication date, abstract etc.) that enable rapid screening and removal of duplicates.

However, in this synthesis, the scoping study identified that grey literature websites and databases were a key source of relevant documentation. Consequently the authors adapted the typical systematic review process - as detailed in (Higgins and Green, 2011; Humanitarian Evidence Programme, 2015) - to an approach that aimed to methodologically search the grey literature sources (see Appendix B). While appropriate to identify the necessary documentation, this had a number of limitations that may have impacted on the results.

- Searching was more time consuming because repositories did not generate exportable lists for rapid screening of titles/abstracts or remove duplicates (thus less repositories could be searched within the available project resources).

- In instances where grey literature websites did not have adequate search functions, Google was used to search targeted websites. However, this results in less replicable searches.

- Running the search terms through grey literature sources did not result in an exportable list, it was also not feasible to input the 2,500+ grey literature documents into an Excel spread sheet (or similar) in order to capture all the documents reviewed. Thus the process could be argued to be less transparent because there is not a record of the documents excluded from round 1 screening.

2) Narrative synthesis: The analysis followed the guidance provided by the Economic and Social Research Council Methods Programme for narrative synthesis in systematic reviews (Popay et al., 2006). The 11 documents that met the inclusion/exclusion criteria stated in the research protocol, and were subsequently included in the synthesis, were a combination of mixed methods and qualitative studies. Thus the narrative synthesis approach was crucial to the success of this research as it provided a mechanism to systematically compare findings from these divergent study types.

It should be noted, however, that synthesis of qualitative and mixed methods studies is complex and time consuming. The majority of the included studies were around 30 to 50 pages in length. However, two of the included studies exceeded 100 pages, while the two academic papers required reference to lengthy supporting documents in order to understand the complexity and context of the interventions being described. Studies of this length and complexity are not uncommon in qualitative and mixed methods research. However, extracting, synthesizing and verifying findings on studies of this length posed a significant challenge within the resources available for this research.

3) Publication bias: Following systematic review guidance, we used exhaustive methods to search for relevant documentation; however, we cannot be certain that we identified all relevant studies. The stakeholder engagement activities undertaken throughout this research were successful in identifying a number of unpublished studies. However, the authors recognize the high likelihood that the findings are affected by publication bias: this is anticipated to be greater than thought at the outset of the research ${ }^{67}$ - evaluations with positive findings are more likely to be published, while published evaluations are easier to find. We invite readers to contact us if they know of relevant published or unpublished studies we have missed.

\footnotetext{
${ }^{67}$ Noting the limited number of academic research documents that were 'included' in the synthesis, and that nine of the 'included' studies were in fact project or programme evaluations.
} 
4) Funding for research: 10 of the 11 included documents in the research were funded directly by the donor or implementing agency; in four of these instances staff employed by the implementing agency - or its umbrella organization - undertook the research. This represents a significant risk of bias, because staff or consultants employed by an agency or donor to undertake research may be exposed to conflicting pressures that could compromise the validity and integrity of the research finding, in terms of the data collection, data reported and the emphasis or level of detail of negative/positive findings. ${ }^{68}$

5) Differences in intervention: The research team made the decision to define the provision of one or a combination of material, financial and technical assistance as one intervention type ('supporting shelter self-recovery'). This was partly because one of the first decisions to be made when designing a 'support for shelter self-recovery' programme is whether to support households through the provision of material and/or financial and/or technical assistance. Thus, it is felt that there are lessons to be learned through comparing the different approaches. It is also because the scoping assessment indicated that there was unlikely to be sufficient documentation available on any one of these interventions.

It can be argued that these are in fact four different intervention types, ${ }^{69}$ and that analysis needed to be undertaken separately on the effects (question 1) and factors that helped or hindered (question 2) and independent conclusions drawn. For both research questions, the research team sought to identify patterns within the four different groupings of assistance that emerged. However, given the small sample of documents (11), and the wide diversity of activities, outputs and outcomes reported, no clear patterns were observed. This is a limitation of the synthesis and a key area for further research.

6) Quality of documentation: The documents included in this evidence synthesis varied significantly in quality. Nine of the 11 documents were assessments or evaluations; they were not academic research papers and were written with a different audience in mind. All documents stated their research aims, objectives and/or research questions, provided some contextual background and outlined the data collection methods. However, very few documents set out how data had been recorded or analysed, and only two stated their study design. Most documents did not report on ethical considerations, conflict of interests or the role of the researcher.

Critically for the findings for question 1 , there was limited discussion of causality in many of the documents (e.g. the effects of the intervention on the households). This is despite nine of the documents explicitly aiming to report on effects: one document was an 'impact assessment' (van Dijk, 2012), five used adapted versions of the OECD DAC structure of evaluation reporting and thus included sections on 'Impact' (Aysan, 2008; CARE International UK, 2015; CRS, 2010; Cukur et al., 2005; Skat, 2009), and three had bespoke structures with 'Impact' sections (Barakat and Zyck, 2011; Corsellis and Sweetnam, 2014; DiPretoro, 2010).

The quality of the primary documents is a key limitation to this research, and especially the findings for research question 1 (effects).

7) Measuring effects: Data collection on effects (outcomes) for 7 of the 11 interventions was undertaken during programme implementation or directly following completion (see Figure 5.5). Therefore this raises questions about the time lapse required in order to measure effects (outcomes). Can you measure outcomes while the project is underway? Should there be a standardized point following completion of an intervention at which outcomes are measured? Can you compare outcomes measures that are collected at different points in time following an intervention (e.g. three months, six months)? How do you accurately measure outcomes of multi-year programmes that are completed at different times for different households?

\footnotetext{
${ }^{68}$ For example, the research team noted that based on their prior knowledge or involvement with some of the programmes, a number of the 11 included reports were 'nicer' than they should have been, and that negative findings were often 'bookended' with positive ones, that resulted in more ambiguous findings.

${ }^{69}$ These are: 1) Material, financial and technical assistance; 2) Financial assistance; 3) Technical and financial assistance; 4) Material and technical assistance. See Section 5.2 for additional information.
} 
Within this research, positive/negative trends in outcomes have been mapped. With the limited data on effects available it has not been possible to explore this further; however, this is a valuable area of further research and exploration.

To conclude, the aim of this research is to synthesize the existing evidence on the effectiveness and efficiency of interventions that support affected populations' own shelter self-recovery processes following humanitarian crises. The chosen research approach has supported partial fulfilment of this aim, but due to the limited quantity and quality of evidence available on humanitarian shelter and settlements and the methodological limitations discussed in this section, its results should be viewed as exploratory and in need of verification through further research. 

Published by Oxfam GB under ISBN 978-0-85598-873-9 in January 2017.

Oxfam GB, Oxfam House, John Smith Drive, Cowley, Oxford, OX4 2JY, UK.

\section{OXFAM}

Oxfam is an international confederation of 20 organizations networked together in more than 90 countries, as part of a global movement for change, to build a future free from the injustice of poverty. Please write to any of the agencies for further information, or visit www.oxfam.org. 